\title{
Natural Product Studies on the
}

\section{Hamigerans}

\author{
By
}

Ethan Woolly

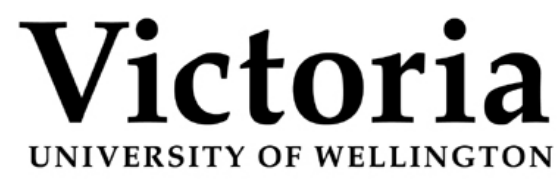

Te Whare Wānanga

o te Ūpoko o te Ika a Māui

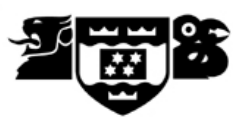

A thesis submitted to

Victoria University of Wellington

in partial fulfilment of the

requirements for the degree of

Master of Science in Chemistry

School of Chemical and Physical Sciences

Victoria University of Wellington 


\begin{abstract}
This study describes the NMR-directed isolation and structural elucidation of several new and semi-synthesised compounds. Carrying on from the previous examinations on the sponge Hamigera tarangaensis undertaken at VUW resulted in the isolation of an additional seven congeners to the hamigeran family. These included three debrominated analogues $(\mathbf{3 7}, \mathbf{6 0}, \mathbf{6 2})$, an alternative methyl ester analogue (63) and a 4-brominated analogue (64). Two structures with novel functionality were also isolated, which were found in fractions previously not investigated, the nitrile containing hamigeran $\mathrm{R}(\mathbf{6 1})$ and the dimer hamigeran $\mathrm{S}(\mathbf{6 5})$. The isolation of these novel compounds led to the proposal of a biosynthesis from a reaction with hamigeran $G(\mathbf{4 0})$ and ammonia, similar to the previous nitrogenous hamigerans biosynthesis with amino acids.
\end{abstract}

Semi-synthesis was undertaken to probe the biosynthesis of these and the other nitrogenous compounds. The results of this produced four new compounds: two imine intermediates, hamigeran $G$ imine (66) and hamigeran B imine (70), a glycine derived hamigeran (68) and the hamigeran D epimer (69).

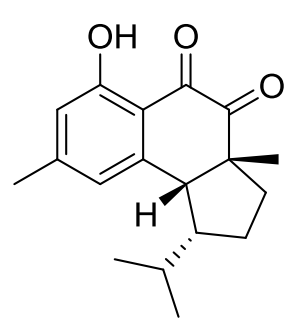

37

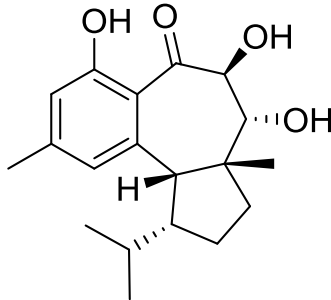

60<smiles>COC(=O)[C@]1(O)C(=O)[C@]2(C)CC[C@@H](C(C)C)[C@H]2c2c(O)cc(C)cc21</smiles>

62<smiles>CC[C@@]1(CC(=O)O)CC[C@@H](C(C)C)[C@@H]1c1cc(C)c(Br)c(O)c1C(=O)OC</smiles>

63 


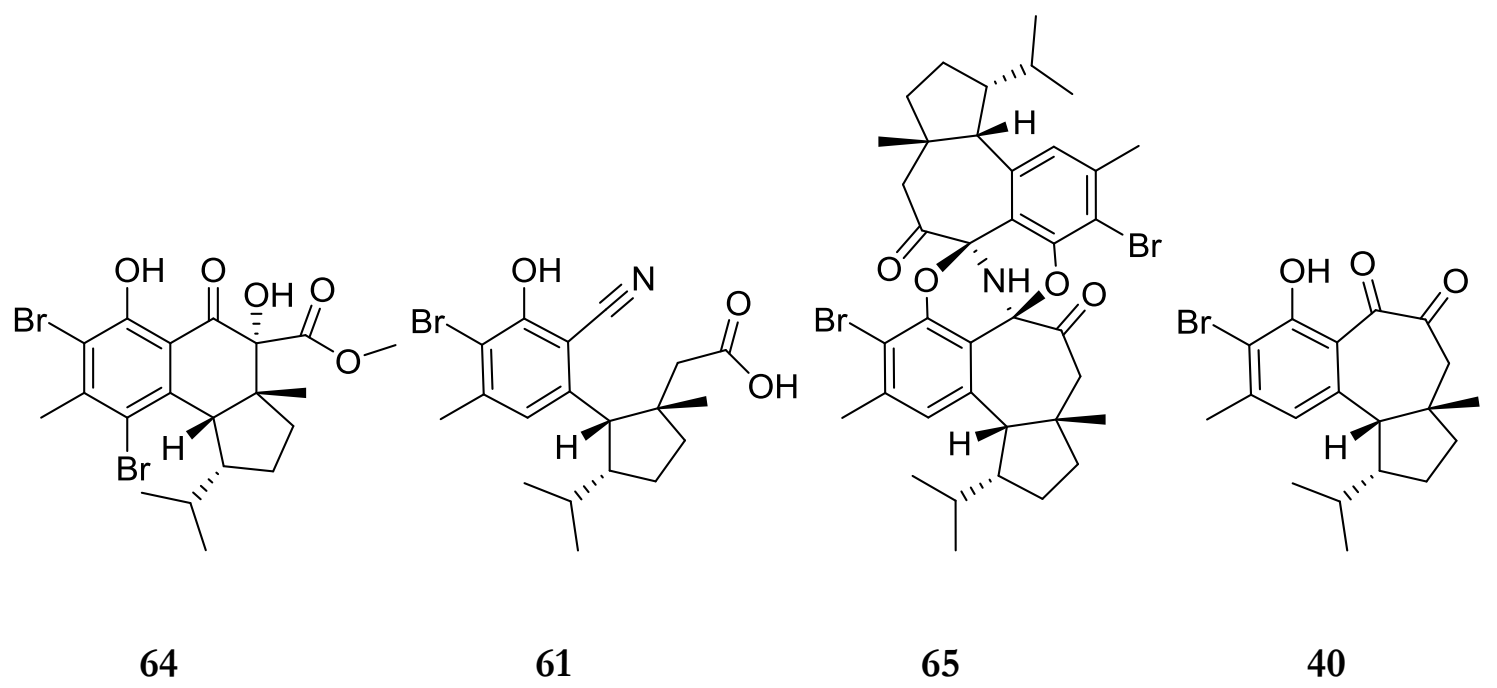

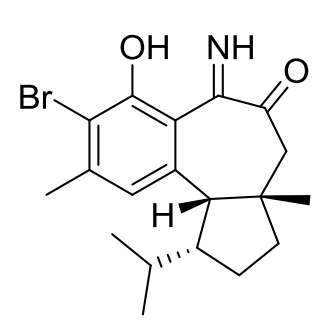

66

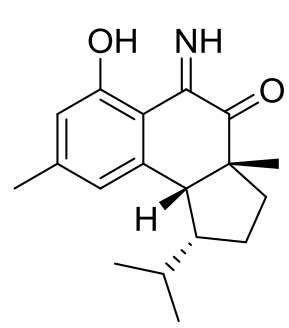

70

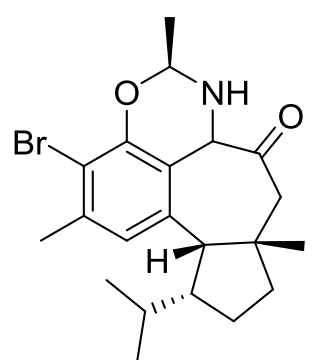

68

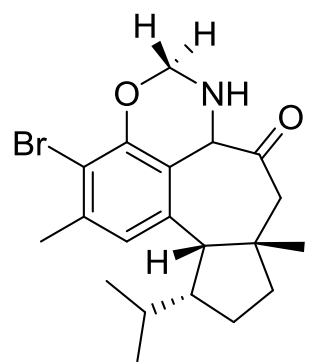

69 


\section{Acknowledgements}

I would like to thank my supervisor, Associate Professor Peter Northcote, for taking me on as a masters student. He has always been good at being a fountain of knowledge, super enthusiastic about research and for telling hilarious anecdotes. At the same time I would like to thank Dr Jonathan Singh, the original researcher of Hamigerans at VUW and a good friend. His attention for small details was the perfect complement to Peters big picture ideas. Their helpfulness and instruction guided me though in this research. Some of the greatest moments of these last two years were during the enthusiastic discussions involving the proposal of structures for new compounds with Peter and Jono, where ideas and theories would bounce around the room for sometimes hours at a time.

I would also like to thank my other lab mates, Helen Woolner, Taitusi Taufa and Sa Weon Hong, who have always been great to work with. A special thanks to Helen for running my MS samples. The Marine Natural Products group along with all the past and present members of the AquaVino group would have to be some of the most fun people to possibly work with, where there was always a lot of laughter shared.

The help from the various academics, staff and students around VUW has also been unreal, each one so willing to share their time and advice. I would like to thank Dr Rob Keyzers for helping me in editing, leading me to several relevant papers in my research and often pointing out things I had overlooked. A thanks to Dr Joanne Harvey, Dr Mattie Timmer and Dr Bridget Stocker for helping me work though some tricky mechanisms, give advice on several reactions and often provide reagents for those reactions. Ian Vorster for instruction of how to use the $600 \mathrm{MHz}$ NMR, along with the troubleshooting that it often needed. Teresa Gen for use of IR and the optical rotation and organisation of several Yum Cha lunch's that were always so good and filling. To Joe Gallaher for re-instructing on how to run UV. A special thanks to Sophie Crisp 
for helping proofread and edit. I would also like to say how grateful I am to have been awarded a Curtis-Gordon scholarship, which meant I did not have to go hungry for the past year.

The Biologists also deserve thanks for all there great work. Thanks to Euan Russel for performing the biological testing on the new hamigerans. Thanks also to Professor John Miller and Dr Paul Teesdale-Spittle for their help with biogenesis and providing amino acids for several reactions.

I could not have done this work without my friends. The ones from Te puke, Wellington and wherever else they are in New Zealand and around the world. The old ones which have always been great and the new ones which have been great getting to know, every one of you is wonderful.

Lastly I would like to thank my family. Their constant support has been a strong force that pulls me through any hard times and keeps me going. I love you all very much. 


\section{Table of Contents}

Abstract

Acknowledgements $\quad$ iv

Table of Contents $\quad$ vi

List of Figures $\quad$ ix

List of Schemes $\quad$ xi

List of Tables $\quad$ xii

Glossary $\quad$ xiii

Chapter 1: Marine Natural Products $\quad 1$

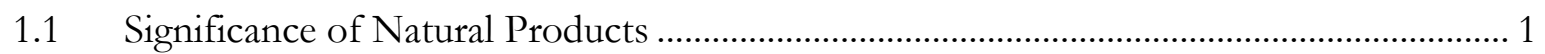

1.2: Isolation Techniques of Natural Products ......................................................................... 4

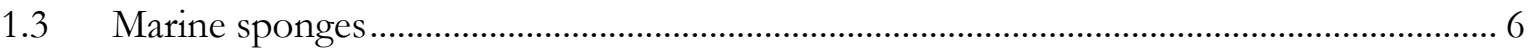

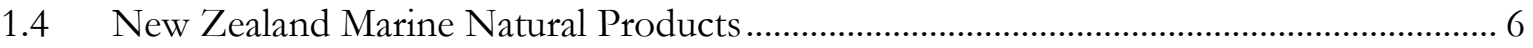

$\begin{array}{ll}\text { Chapter 2: The Hamigerans } & 10\end{array}$

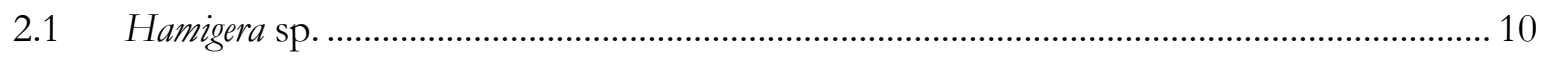

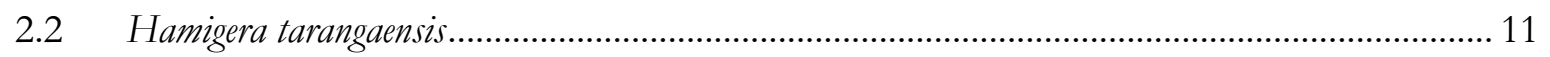

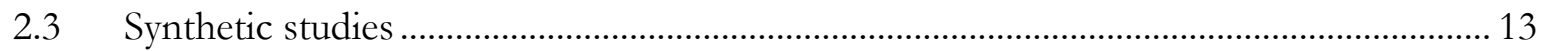

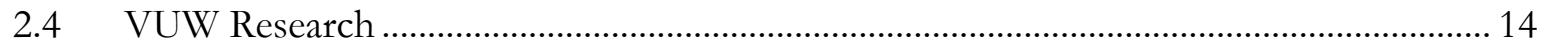

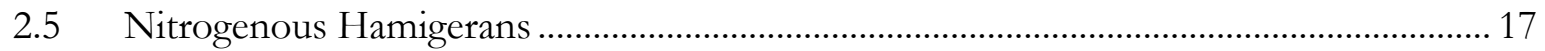

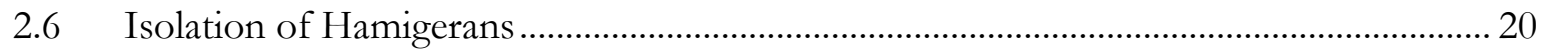




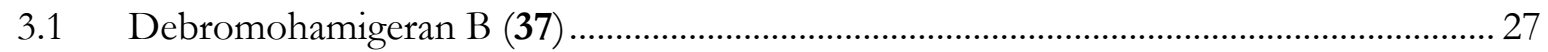

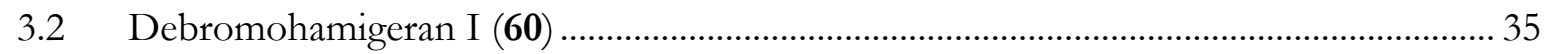

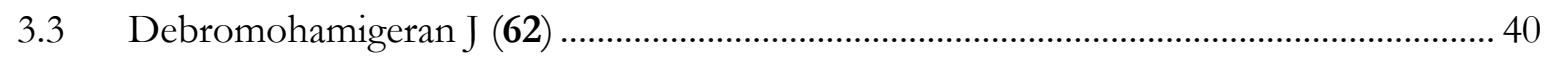

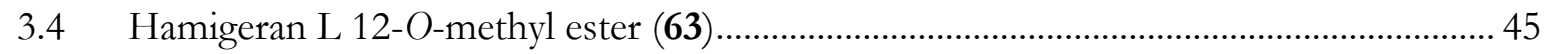

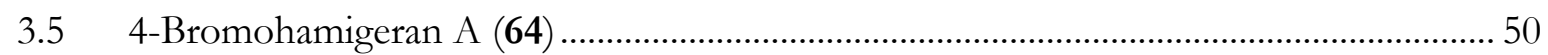

Chapter 4: Novel Hamigerans from Hamigera tarangaensis $\quad 55$

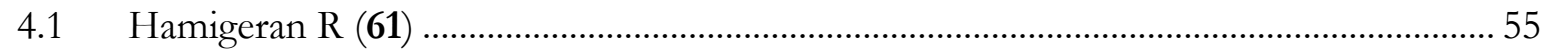

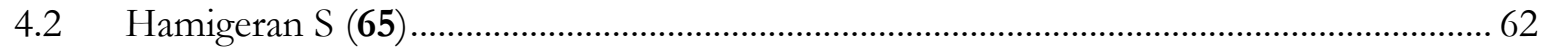

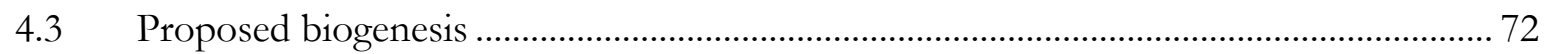

$\begin{array}{ll}\text { Chapter 5: Synthetic work on the Hamigerans } & 74\end{array}$

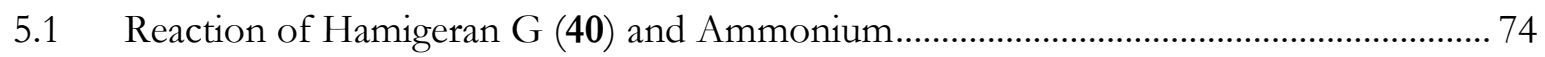

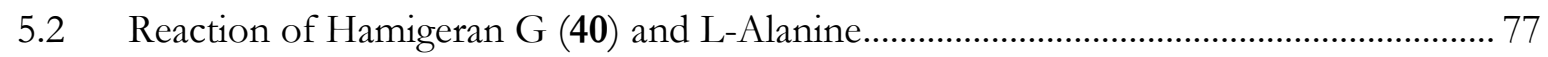

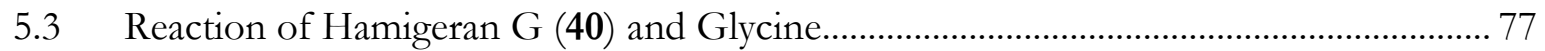

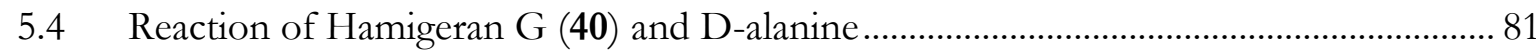

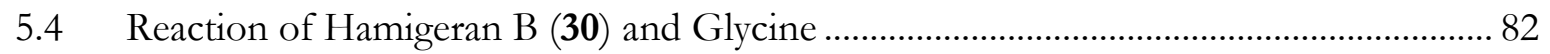

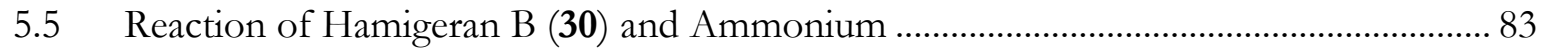

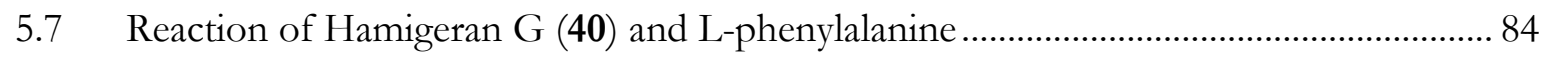

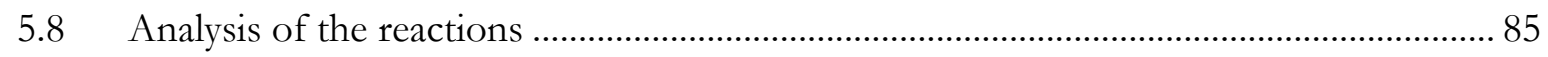

$\begin{array}{ll}\text { Chapter 6: Biological Activity of the Hamigerans } & 88\end{array}$

$\begin{array}{ll}\text { Chapter 7: Concluding remarks } & 90\end{array}$ 


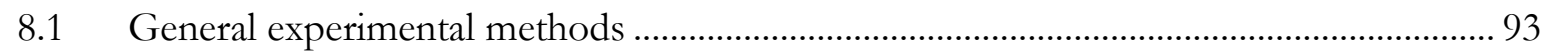

8.2 Isolation of Compounds from Hamigera tarangaensis ......................................................... 94

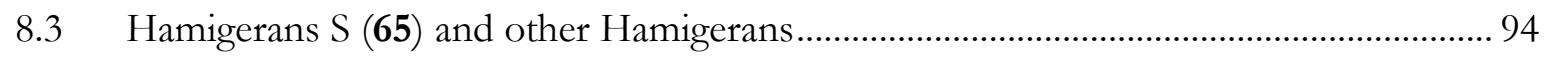

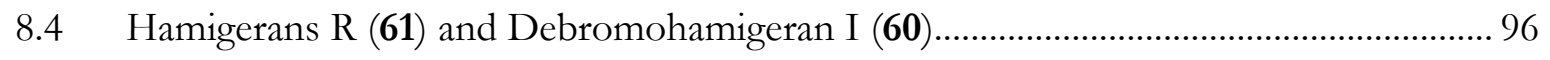

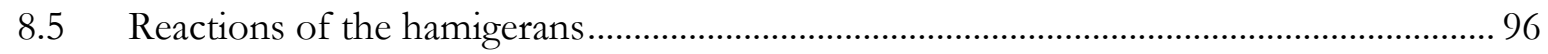

$\begin{array}{lll}\text { A Debromohamigeran B NMR Spectra } & 101\end{array}$

$\begin{array}{lll}\text { B Debromohamigeran I NMR Spectra } & 107\end{array}$

$\begin{array}{lll}\text { C Debromohamigeran J NMR Spectra } & 113\end{array}$

D Hamigeran L - O- methyl ester NMR Spectra 119

$\begin{array}{lll}\text { E } & \text { 4-Bromohamigeran A NMR Spectra } & 125\end{array}$

$\begin{array}{lll}\text { F Hamigeran R NMR Spectra } & 131\end{array}$

G Hamigeran S NMR Spectra $\quad 137$

H Imine from Hamigeran G reaction NMR Spectra 153

I Hamigeran D and Epimer from L-alanine Reaction NMR Spectra 158

J Hamigeran D and Epimer from D-alanine Reaction NMR Spectra 160

K Glycine Hamigeran NMR Spectra 162

L Imine from hamigeran B reaction NMR Spectra 168

M Hamigeran N and Epimer NMR Spectra 169

$\begin{array}{ll}\text { References } & 170\end{array}$ 


\section{List of Figures}

Figure 1.1. New Zealand Exclusive Economic Zone. Image courtesy of NIWA............................ 7

Figure 2.1. Hamigera tarangaensis, photographed by Peter Northcote. 12

Figure 3.1. Key HMBC and COSY correlations establishing the aromatic ring (substructure 1) of debromohamigeran B (37). 28

Figure 3.2. COSY correlations for the hydrocarbon sequence (substructure 2) and the isopropyl unit (substructure 3) spin systems of debromohamigeran B (37). 29

Figure 3.3. $\mathrm{HMBC}$ Correlations of $\mathrm{CH}_{3}-15$ connecting substructure 1 and 3 together and establishment of the cyclopentyl ring (ring C) of Debromohamigeran B (37).......... 30

Figure 3.4. Key HMBC correlations establishing substructure 3 to substructure 2 and connection of the ketones Debromohamigeran B (37) 31

Figure 3.5. Completed planar structure of debromohamigeran B (37). 31

Figure 3.6. Key NOE correlations establishing the relative configuration of debromohamigeran B (37).

Figure 3.7. Key HMBC and COSY correlations establishing substructures 1, 2 and 3 of Debromohamigeran I (60). 36

Figure 3.8. Key HMBC and COSY correlations connecting substructure 1, 2 and 3 together for debromohamigeran I (60). 36

Figure 3.9. Key $\mathrm{HMBC}$ correlations for $\mathrm{CH} 3-15$ and $\mathrm{HMBC}$ and $\mathrm{COSY}$ correlations $\mathrm{CH}-10$ and CH-11 of debromohamigeran I (60). 37

Figure 3.10. Completed planar structure of debromohamigeran I (60) 37

Figure 3.11. Key NOE correlations for debromohamigeran I (60). .38

Figure 3.12. Key HMBC and COSY correlations of substructures 1, 2 and 3 of debromohamigeran J (62) 41 
Figure 3.13. Key HMBC and COSY correlations connecting the three substructures and forming the cyclopentyl ring of debromohamigeran $\mathrm{J}(\mathbf{6 2})$. 41

Figure 3.14. Key HMBC correlations from $11-\mathrm{OH}$ and $\mathrm{CH}_{3}-18$ of debromohamigeran J (62).. 42

Figure 3.15. Completed planar structure of debromohamigeran J (62) 42

Figure 3.16. Key NOE correlations for debromohamigeran J (62). .43

Figure 3.17. Substructures 1, 2 and 3 of hamigeran L 12-O-methyl ester (63) 46

Figure 3.18. Key HMBC and COSY correlations connecting the three substructures and forming the cyclopentyl ring of hamigeran L 12-O-methyl ester (63) 46

Figure 3.19. Key HMBC correlations of $\mathrm{CH}_{2}-10$ and $\mathrm{CH}_{3}-18$ for hamigeran L 12-O-methyl ester (63). 47

Figure 3.20. Completed planar structure of hamigeran L 12-O-methyl ester (63). 47

Figure 3.21. Key NOE correlations for hamigeran L 12-O-methyl ester (63). .48

Figure 3.22. Key HMBC and COSY correlations establishing substructures 1, 2 and 3 of 4bromohamigeran A (64) 51

Figure 3.23. Key HMBC and COSY correlations connecting the substructures together and establishing the cyclopentyl ring of 4-bromohamigeran A (64).

Figure 3.24. Key HMBC correlations for C-10 and C-18 of establishing the methyl ester of 4bromohamigeran A (64) 52

Figure 3.25. Completed planar structure of 4-bromohamigeran A (64). 52

Figure 3.26. Key NOE correlations for 4-bromohamigeran A (64). 53

Figure 4.1. Key HMBC and COSY correlations establishing substructures 1, 2 and 3 of hamigeran $\mathrm{R}(\mathbf{6 1})$ 56

Figure 4.2. Key HMBC and COSY correlations connecting substructures 1, 2 and 3 together along with the junction methyl $\mathrm{CH}_{3}-16$ and $\mathrm{CH}_{2}-10$ of hamigeran $\mathrm{R}(\mathbf{6 1})$. 57

Figure 4.3. IR spectrum of hamigeran R (61). 59 
Figure 4.4. Completed planar structure of hamigeran R (61).

Figure 4.5. Key NOE correlations establishing the relative configuration of hamigeran R (61). 60

Figure 4.6. Key HMBC and COSY correlations establishing substructures 1, 2 and 3 of hamigeran S (65)

Figure 4.7. Key HMBC and COSY correlations connecting the substructures together, forming the cyclopentyl ring and B ring of hamigeran S (65) 64

Figure 4.8. IR spectrum of hamigeran $\mathrm{S}(\mathbf{6 5})$. .65

Figure 4.9. Key HMBC correlations for N-H of hamigeran S (65) 66

Figure 4.10. Possible planar structures for hamigeran S (65) 68

Figure 4.11. Completed planar structure of hamigeran S (65). 69

Figure 4.12. Key NOE correlations establishing the relative configuration of hamigeran S (65). 70

Figure 5.1. $\mathrm{CH}_{2}-18$ conformers for compound 68 . .79

Figure 5.2. ${ }^{1} \mathrm{H}$ NMR spectrum of $\mathrm{CH}_{2}-18$ conformers for glycine compound $\mathbf{6 8}$. .79

Figure 5.3. ${ }^{1} \mathrm{H}$ NMR spectrum of hamigeran D (33) and epimer (69) from L-alanine reaction.. 82 Figure 5.4. ${ }^{1} \mathrm{H}$ NMR spectrum of hamigeran D (33) and epimer (69) from D-alanine reaction. 82 Figure 5.5. ${ }^{1} \mathrm{H}$ NMR spectrum of $\mathrm{CH}-18$ proton of hamigeran $\mathrm{N}(\mathbf{5 2})$ and epi $\mathrm{Q}(\mathbf{5 3})$ .85

Figure 5. 6. ${ }^{1} \mathrm{H}$ NMR spectrum of $\mathrm{CH}-4$ proton of hamigeran $\mathrm{N}(\mathbf{5 2})$ and epi $\mathrm{Q}(\mathbf{5 3})$. 85

\section{List of Schemes}

Scheme 2.1. Biogenesis of the hamigerans proposed by Singh. ${ }^{48}$ 16

Scheme 2.2. Proposed formation of nitrogenous hamigerans by Singh. ${ }^{49}$

Scheme 3.1. Isolation of debromohamigeran I and the novel compound hamigeran R. 24

Scheme 3.2. Isolation of several new and novel hamigerans. 26 
Scheme 4.1. Proposed formation of new nitrogenous hamigerans. .73

Scheme 5.1. Revised proposed formation of nitrogenous hamigerans. 87

\section{List of Tables}

Table 2.1. Isolated hamigerans from previous research. .23

Table 2.2. Isolated nitrogen containing hamigerans from previous research.

Table 3.1. Chemical shifts of the aromatic carbons from hamigeran B (30) and its derivatives. 33

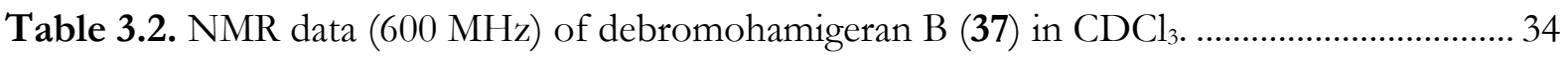

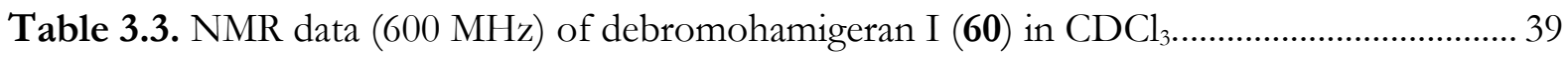

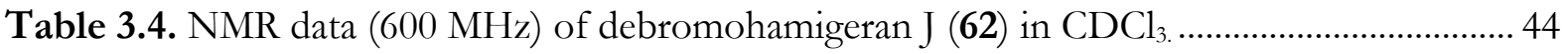

Table 3.5. NMR data $(600 \mathrm{MHz})$ of hamigeran L 12-O-methyl ester (63) in $\mathrm{CDCl}_{3}, \ldots \ldots \ldots \ldots \ldots \ldots . . . . . . . .49$

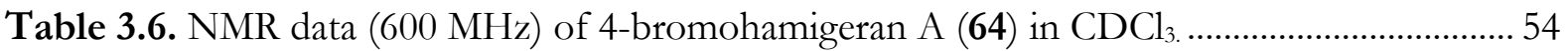

Table 4.1. $\mathrm{NMR}{ }^{13} \mathrm{C}$ shift comparison of aromatic nitriles and hamigeran $\mathrm{R}(\mathbf{6 1})$ in $\mathrm{CDCl}_{3} \ldots \ldots . . .58$

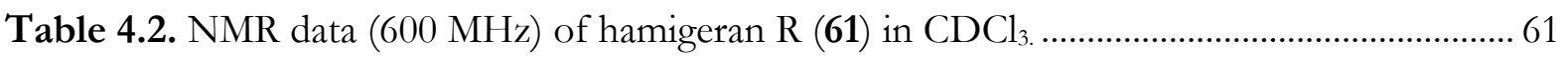

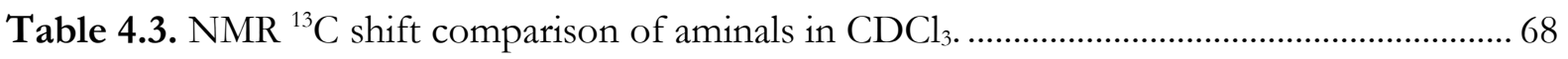

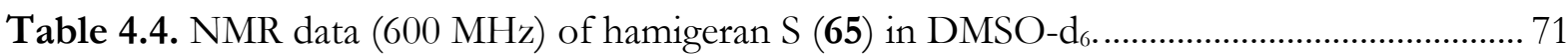

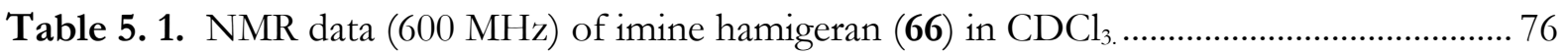

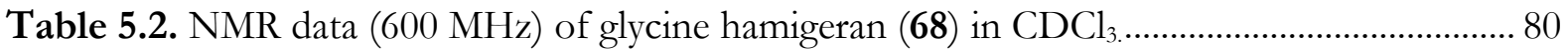

Table 6.1. Hamigeran IC $\mathrm{I}_{50}$ Values [HL-60, $n=3$ replicates, except for (40) and (64) $n=2$ ] ........ 89

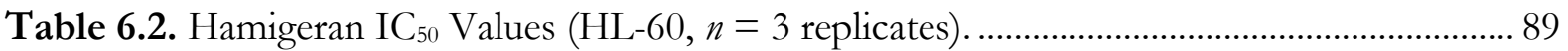




\section{Glossary}

$\delta$

${ }^{1}$ H NMR

${ }^{13}$ C NMR

$m / z$

J

$\Delta$

$[\alpha]_{\mathrm{D}}$

COSY

DIOL

DMSO

DMSO-D $_{6}$

DNA

HL-60

HMBC

HP-20/ HP-20ss

HRESIMS

HSQC

IHD -

IR

LH20

$\mathrm{IC}_{50}$

MS

NIWA
Chemical shift (ppm)

Proton nuclear magnetic resonance

Carbon-13 nuclear magnetic resonance

Mass-to-charge ratio

Scalar coupling constant

Resolution

Specific rotation

${ }^{1} \mathrm{H}-{ }^{1} \mathrm{H}$ correlation spectroscopy

2,3-Dihydroxy-1-propoxypropyl-derivatized silica gel

Dimethyl sulfoxide

Deuterated dimethyl sulfoxide

Deoxyribonucleic acid

Human promyelocytic leukaemia cell line

Heteronuclear multiple-bond correlations

PSDVB stationary support (Supelco)

High-resolution electrospray ionisation mass spectrometry

Heteronuclear single-quantum coherence

Index of hydrogen deficiency

InfraRed

Size exclusion stationary support (Sigma)

Inhibitory concentration in $50 \%$ of test subjects

Mass spectrometry

Nation Institute for water and atmospheric research 
NMR

NOE

NOESY

P388

ppm

PSDVB

ROESY

SCUBA

SEM

UV

VUW
Nuclear magnetic resonance

Nuclear Overhauser enhancement

Nuclear Overhauser enhancement spectroscopy

Murine leukaemia cell line

Parts per million

Poly(styrene-divinylbenzene)

Rotating-frame nuclear Overhauser enhancement spectroscopy

Self-contained underwater breathing apparatus

Standard error of mean

Ultraviolet

Victoria University of Wellington 


\section{Chapter 1: Marine Natural Products}

\subsection{Significance of Natural Products}

Primary metabolites are the building blocks of life, coming in the form of amino acids, fatty acids, carbohydrates and nucleobases. These are used to build up macromolecules such as proteins, phospholipids, polysaccharides and DNA. They are essential in cellular functions including nutrient assimilation, energy production, growth and development. Little variation occurs for primary metabolites throughout life to the level of phyla and even kingdom. ${ }^{1}$ Secondary metabolites, also called natural products, on the other hand tend to be species specific and are used by the organism in a variety of ways, including as pheromones, repellents, venoms, toxins; with many having unknown roles for the organism. ${ }^{2}$ It is thought that during the course of evolution if an organism produces a new compound/range of compounds which does not hinder the organism but instead gives it a competitive advantage, then this trait will be passed on. ${ }^{3}$ Organisms lacking physical defences or a way to evade predators are more likely to have evolved such a chemical defence. ${ }^{4}$ Secondary metabolites cost the organism energy to produce and are therefore often present in low quantities in comparison to primary metabolites. Due to the low abundance, secondary metabolites often have a high level of potency and are able to act on the desired target at a low concentration. Although there is no defining structure for a secondary metabolite, there is a tendency for them to have an amphiphilic nature, this allows them to be a least partially soluble in both hydrophobic (to pass though cell membranes) and hydrophilic (cytoplasm) media. ${ }^{5}$ Several large classes of natural products are the glycolipids, polyketides and terpenoids which are categorised by their biological origins; it is also common to have compounds from mixed biological origins. ${ }^{6}$

Since natural products can be exceptionally active in biological systems, they have the potential to be useful in the treatment of illness and disease. Unsurprisingly, humans have exploited this 
potential for thousands of years in the form of herbal medicines, but it has been only in the last two centuries that we have had the ability to identify these active compounds. ${ }^{7-9}$ The discovery of drugs such as morphine (1) from the poppy flower, and penicillin G (2) from Penicillium fungi illustrate the historical importance of natural products to medicine. Anticancer drugs have also been the target of natural products applications. Paclitaxel (3), isolated from the Pacific Yew tree in the early 1970's has been found to be a potent antitumor agent and has since been clinically used in the treatment of ovarian and breast cancers. ${ }^{10}$

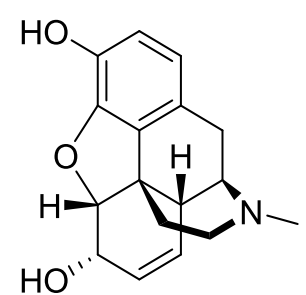

1<smiles>CC1(C)S[C@@H]2[C@H](NC(=O)Cc3ccccc3)C(=O)N2[C@H]1C(=O)O</smiles>

2

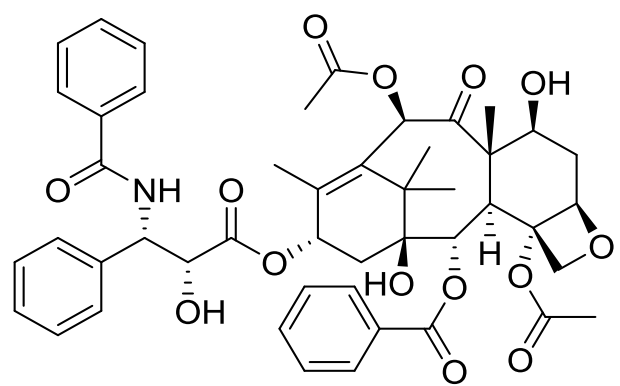

3

Traditionally, plants and other terrestrial organisms formed the basis behind natural product discovery. Marine organisms were more difficult to access, with early collections limited to the shore and intertidal zones. Only after World War Two did it become viable to collect in the marine environment following the invention of SCUBA by Jacques Cousteau. ${ }^{11}$ Consequently, marine exploration bloomed in the latter third of the $20^{\text {th }}$ century with scientists all over the world discovering new organisms and new compounds from their coastlines. ${ }^{12}$ With the ocean covering $70 \%$ of the Earth's surface, there is still plenty more left to be discovered both in terms of new organisms as well as new natural products.

The most studied groups of marine organisms are sponges, corals, molluscs and algae, with these contributing significantly to the over 25,000 marine natural products that have been reported in the literature. ${ }^{13}$ However, while many of these have been used in clinical trials, only a few have 
been developed into drugs. Eribulin (4), marketed under the name Halaven ${ }^{\circledR}$ is an approved drug for late stage cancer. This compound is a synthetic analogue of halichondrin B which was isolated from the sponge Halichondria okadai, collected around the Pacific coast of Japan. ${ }^{14}$ Ziconotide (5), is an $\omega$-conotoxin from the cone snail Conus magus licensed as a pharmaceutical for use in the treatment of chronic pain. ${ }^{15}$

The first report of marine natural products came from the sponge Tectitethya crypta in 1950, with the isolation of the compounds spongothymidine (6) and spongouridine (7), non-ribonucleosides containing the arabinose sugar. These compounds provided the inspiration of vidarabine (8), cytarabine (9), antiviral and anticancer agents as well as AZT (10), the first effective HIV drug. ${ }^{16}$

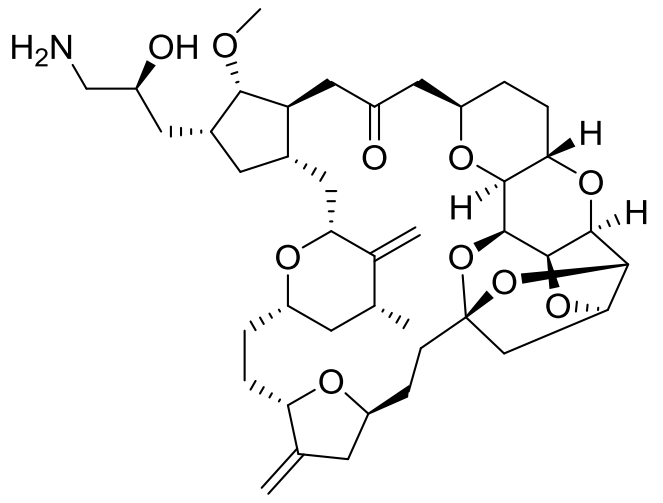

4

$\mathrm{H}_{2} \mathrm{~N}$-Cys-Lys-Gly-Lys-Gly-Ala-Lys-Cys-Ser-Arg-Leu-Met-Tyr-Asp-Cys-Cys-Thr-Gly-Ser-Cys-Arg-Ser-Gly-Lys-Cys-NH

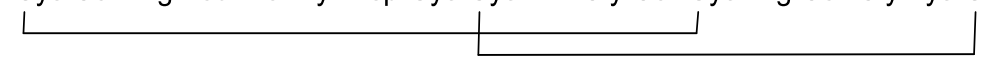<smiles>[R]c1cn([C@@H]2O[C@H](CO)[C@@H](O)[C@H]2O)c(=O)[nH]c1=O</smiles>

$6 \mathrm{R}=\mathrm{H}$

$7 \mathrm{R}=\mathrm{CH}_{3}$<smiles>Nc1ncnc2c1ncn2[C@@H]1O[C@H](CO)[C@@H](O)[C@H]1O</smiles>

8<smiles>Nc1ccn([C@@H]2O[C@H](CO)[C@@H](O)[C@H]2O)c(=O)n1</smiles>

9<smiles>Cc1cn([C@H]2CC(C#N)[C@@H](CO)O2)c(=O)nc1N</smiles>

10 


\section{2: Isolation Techniques of Natural Products}

Traditionally, organism screening and selection from terrestrial sources was aided with the history of traditional medicines, which gave an indication that potential interesting natural products would be present in these organisms. ${ }^{17}$ As no historic body of knowledge associated with marine organisms exists a different approach is undertaken for their collection. Gathering of organisms may focus on species that are related to already known producers of unique/bioactive molecules. As some organisms are difficult to identify in the field, in part due to a lack of distinguishing features, the preferred collection technique is to randomly sample organisms over several locations.

Screening with bioassay or structure guided techniques is often undertaken before a comprehensive isolation attempt is carried out to give an indication of the organism's potential. The choice of screening protocol often extends into the isolation process and guides the purification of compounds.

\subsubsection{Bioassay guided screening and isolation}

The most commonly used method of screening and tracking the isolation of natural products is though testing the crude or partially fractionated extracts by bioassay. Crude fractions that show a strong response for a chosen assay are elected for further purification. As the fractions go through these steps of purification, a particular high activity can be tracked, focusing on these fractions, the process repeated until pure compounds are isolated. This technique does have its drawbacks. Biological testing takes time, with each fraction generated requiring testing. Small amounts of highly active compounds can provide false leads when appearing in fractions with larger amounts of mildly active compounds, which may result in the sudden drop off in activity during fractionation. Differentiation between known and unknown compounds can also be a problem and many steps of purification may be undertaken before it is realised that the active compound is one with known biological activity. 


\subsubsection{Structure guided screening and isolation}

An alternative to the bioassay guided approach is structure guided screening and isolation, a technique utilised here at VUW by the Marine Natural Products group. Structure guided isolation was a traditional method used by natural product chemists before the culturing of cells and bioassays was readily available; it has, however, not lost its relevance. ${ }^{18}$ Due to the advances in spectroscopic techniques like high-resolution mass spectrometry and 1D and 2D NMR, interesting or unusual functionality can be quickly identified from crude extracts and can direct whether further purification could lead to the isolation of new compounds. NMR can be used to continually track interesting compounds through the subsequent stages of purification. An attitude in the VUW marine natural products group is that chemical novelty of a compound may also relate to interesting biological activity. Signals that are not typical of primary metabolites are considered unusual and are investigated further. Mass spectrometry can quickly determine if certain elements are present such as chlorine, bromine or sulfur.

${ }^{1} \mathrm{H}$ NMR signals that appear outside of the typical 0.50-5.50 ppm range are often associated with interesting structural motifs which can include alkenes, (hetero)aromatics, phenols and aldehydes. Knowing the functionality of compounds can help in designing better chromatography processes for purification of compounds. This approach is somewhat faster than traditional bioassay guided isolation. With the ability to determine known compounds early on in the isolation process efforts can be focused on the unknown compounds. It also allows selective exclusion of entire classes of compounds that are well known or not relevant to focus efforts elsewhere (dereplication). ${ }^{18}$

As the biological testing is only performed on pure compounds at the end of isolation process, there is the possibility that these compounds will not exhibit the selected bioactivity. This said, both structure guided isolation and bioassay guided isolation are powerful tools and not mutually exclusive in isolation and discovery of new natural products. 


\subsection{Marine sponges}

Sponges are considered to be the oldest multicellular animals, with fossil evidence dating back to the pre-Cambrian era. ${ }^{19}$ They are considered to be very primitive organisms as they lack many characteristics that are common to conventional animals such as developed nervous systems and a digestive tract. Classification of sponges can be very difficult as shape, size and colour can change depending on the location of the sponge, and often requiring taxonomic reclassification. The traditional means of classification to identify sponges is based on the shape of their skeletal structure (spicules) and its chemical composition (such as calcium carbonate or siliceous spicules). With advances in technology it is now possible to identify the sponge with DNA sequencing. ${ }^{20}$

The immobile nature of sponges and their lack of physical defences make them prone to predation and encroachment. To counter this, sponges often rely on chemical defences of secondary metabolites to ward off predators. As such, sponges have been a rich source of novel compounds for natural product chemists. Natural products have also been isolated from bacteria found in sponges, which often coexist in a symbiotic relationship. The bacteria provides natural products and nutrients for the sponge while gaining a host to live within. ${ }^{19}$

\subsection{New Zealand Marine Natural Products}

New Zealand has a unique marine environment due to its geographical isolation and extensive coastline. New Zealand islands and waters span 30 degrees in latitude, ranging from subtropical to sub-Antarctic environments (Figure 1.1). Around $80 \%$ of New Zealand's biodiversity is thought to be derived from the marine environment, which to date includes almost 800 identified sponges. $^{21}$ 


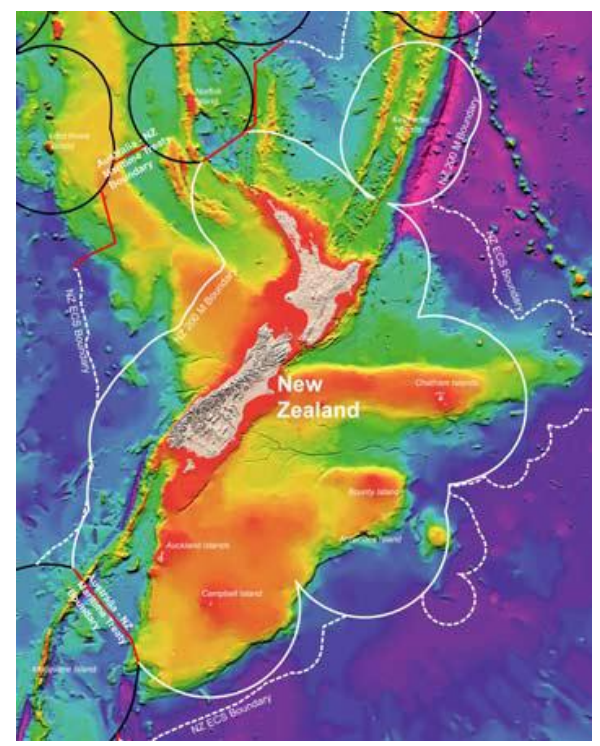

Figure 1.1. New Zealand Exclusive Economic Zone. Image courtesy of NIWA.

As stated before, marine natural product chemistry is relativity new in terms of chemistry, somewhat more so here in New Zealand. Three of the first and most prominent marine natural product chemists in New Zealand were Professors John Blunt, Murray Munro (both University of Canterbury) and Richard Cambie (University of Auckland). Blunt and Munro started marine natural product isolation with red algae, proceeding to sponge-based research later in their careers. $^{22,23}$ Some of their more prominent examples are as follows.

Discorhabdins B (11) and C (12) are two of several cytotoxic pigments that have been isolated from Latrunuclia sp. in New Zealand. ${ }^{24}$ This genus of sponge is known for its cytotoxic pigments, with many other species around the Pacific containing this class of compounds. New Zealand sponges also produce halichondrins, the compounds used in the development of $\operatorname{Halaven}^{\circledR}(\mathbf{4}) .^{25}$ The novel compound isohomohalichondrin B (13) was isolated from a Lissodendoryx sp. collected during dredging off the Kaikoura Peninsula. At the time of isolation of 13, the importance of halichondrin B was realised with it already being developed as an anticancer drug. The isolation of isohomohalichondrin B was useful in understanding the structure-activity relationship of these compounds and was central to the development of Halaven ${ }^{\circledR}$ (4). From the McMurdo Sound 
(New Zealand's territory of Antarctica), a collection of the sponge Kirkpatrickia varialosa yielded several related alkaloid compounds called the variolins. ${ }^{26}$ These compounds, such as variolin A (14) and D (16) were active against P-388 murine leukaemia cell lines, with variolin B also exhibiting antiviral activity.<smiles>O=C1C=C2S[C@H]3C[C@]2(C=C(Br)C1=O)C1=C3C2=[NH+]CCc3c[nH]c(c32)C1=O</smiles>

11<smiles></smiles>

12

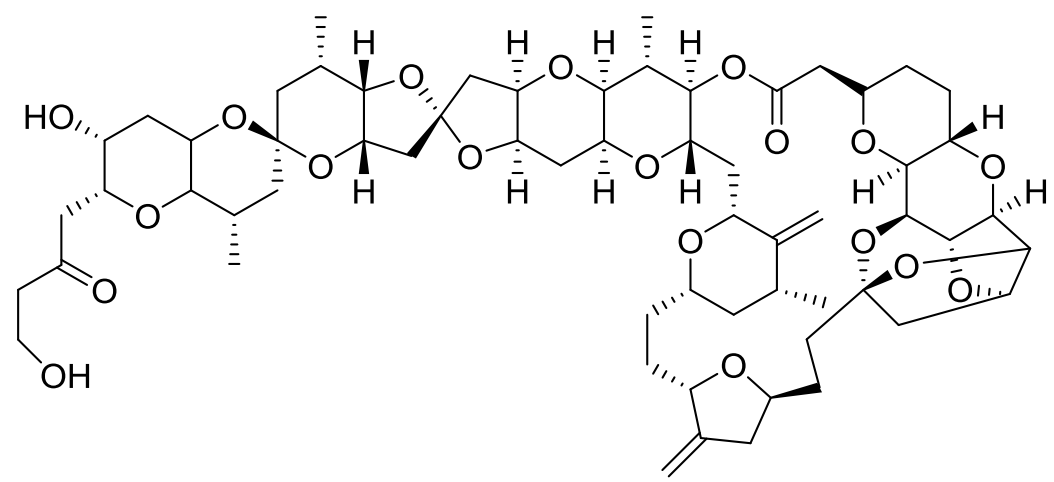

13<smiles></smiles>

14<smiles></smiles>

15

Of all the species of sponges studied in New Zealand, potentially the most interesting and valuable, is Mycale hentscheli. Several isolation studies have been performed from different collections around the South Island initially by both professors Blunt and Munro and later by 
Associate Professors Lyndon West and Peter Northcote. Mycalamide A (16) was first reported in 1988 from a sample collected from Otago Harbour using a bioassay directed isolation. ${ }^{27}$ Since then, mycalamides $\mathrm{B}, \mathrm{C}, \mathrm{D}$ and $\mathrm{E}$ have been isolated from subsequent collections. ${ }^{28-30} \mathrm{~A}$ collection of Mycale from Fiordland interestingly contained no mycalamide compounds and instead yielded the novel compound pateamine (17), a thiazole-containing macrolide. ${ }^{31}$ Pateamine exhibited immunosuppressive activity as well as potent cytotoxicity in the P-388 leukaemia cell line ( $\left.\mathrm{IC}_{50} 0.15 \mathrm{ng} / \mathrm{ml}\right)$. In another study, performed at VUW with Mycale from Pelorus Sound in the Marlborough Sounds, a new cytotoxic compound, peloruside A (18) was identified. ${ }^{32}$. The cytotoxicity of peloruside $\mathrm{A}$ is also on the nanomolar scale with a mode of action similar to the anticancer drug paclitaxel (3). Research on its potential use as a cancer treatment drug is ongoing. ${ }^{33-36}$

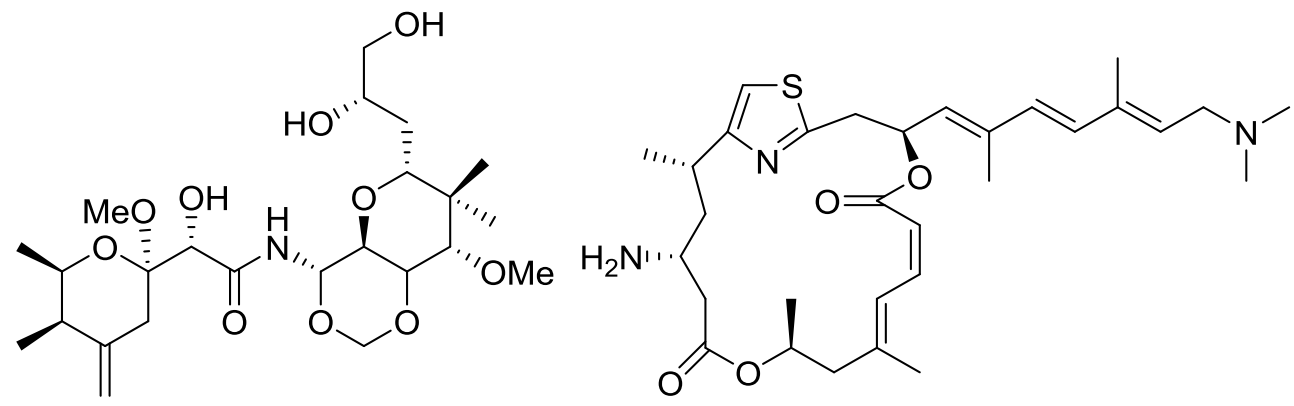

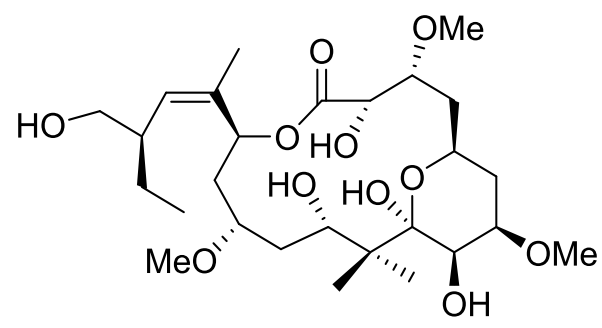




\section{Chapter 2: The Hamigerans}

\subsection{Hamigera sp.}

The genus Hamigera currently has five accepted species, one found in the Mediterranean Sea, two from the coast of Australia and Papua New Guinea and two endemic to New Zealand. Besides from the species Hamigera tarangaensis, only a handful of novel compounds have been reported from sponges in this genus. The species Hamigera hamigera, native to the Mediterranean, has yielded tyrosine and tryptophan amino acid derivatives (19-21), a sulfur containing nucleoside (22) and two dimeric steroids $(\mathbf{2 3}, \mathbf{2 4}) .^{37,38}$ Two sesterterpenoid spiroketals $(\mathbf{2 5}, \mathbf{2 6})$ have been isolated from Hamigera sp. collected in Papua New Guinea. ${ }^{39}$

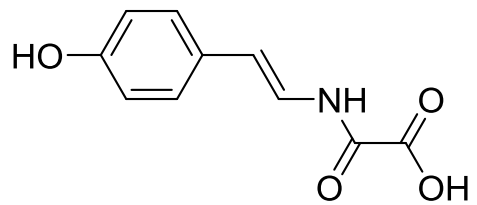

19<smiles>N=C(/C=C/c1c[nH]c2ccccc12)NC(=O)O</smiles>

21<smiles>N=C(N/C=C/c1ccc(O)cc1)C(=O)O</smiles>

20

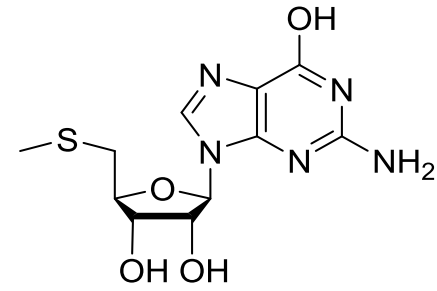

22 


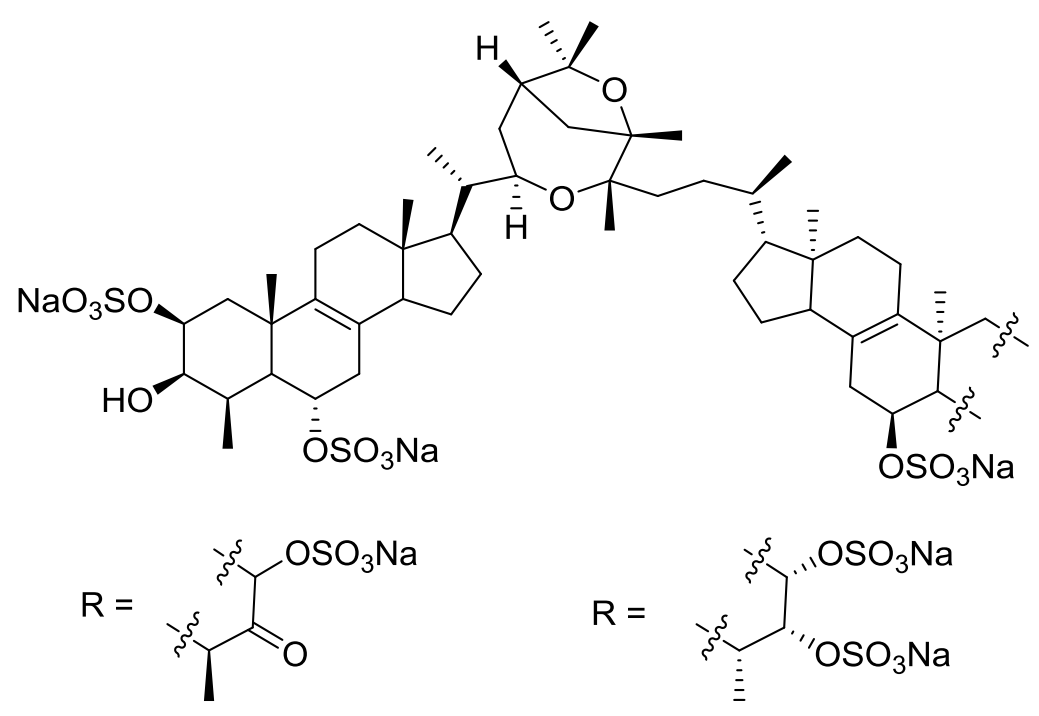

23

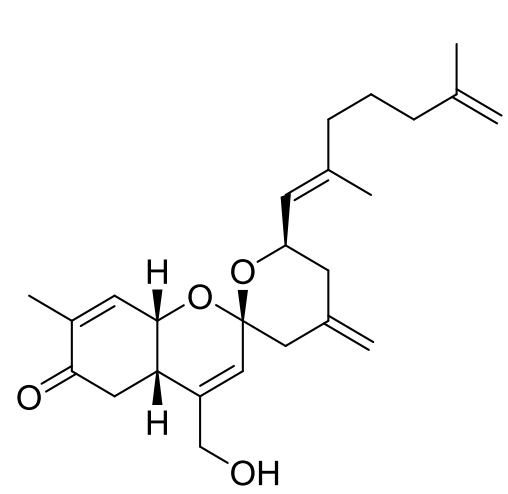

25<smiles>C=C(C)CCC/C(C)=C/[C@@H]1C[C@](C)(OC(=O)CC(C)C)C[C@]2(C=C(CO)[C@H]3CC(=O)C(C)=C[C@H]3O2)O1</smiles>

26

\subsection{Hamigera tarangaensis}

The source sponge of this study, Hamigera tarangaensis (Bergquist and Fromont, 1988) is bright yellow in colour (Figure 2.1). Native to the north-eastern waters of New Zealand coasts, the sponge is named after Taranga Island, the Maori name for the largest island of the Hen and Chicken Islands, from where it was first discovered. ${ }^{40}$ It has been a rich source of novel compounds in the last 20 years. 


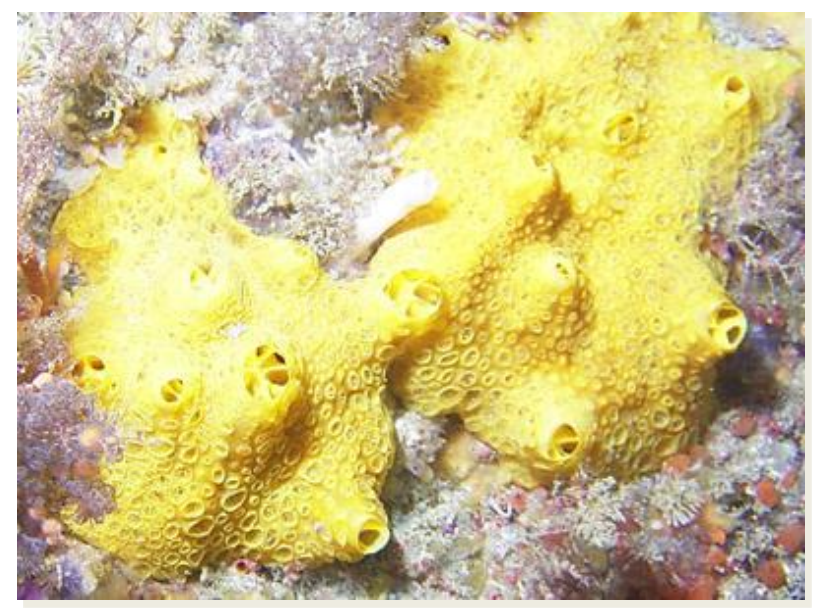

Figure 2.1. Hamigera tarangaensis, photographed by Peter Northcote.

Cambie's group were the first to investigate Hamigera tarangaensis. The first paper, published in 1995, detailed the isolation of a brominated benzocyclooctane compound (27). ${ }^{40}$ A second paper in 2000 revealed the isolation of several 6,6,5- and 6,7,5-tricarbocyclic structures, which Cambie dubbed the hamigerans (28-36). ${ }^{41}$ During the course of his second investigation it was realised that compound 27 was incorrectly identified and consequently was reassigned to the structure 35 . Hamigerans A (28) and B (30) were isolated in the most abundance followed by debromohamigeran A (29) and 4-bromohamigeran B (31). Hamigerans C (32) and D (33) both contain a seven-membered middle (B) ring, with hamigeran D the only congener containing nitrogen. Under mildly acidic conditions $\left(\mathrm{CDCl}_{3}\right)$ hamigeran $\mathrm{D}$ underwent oxidation to compound 34. Hamigeran E (35) and debromohamigeran E (36) are oxidised ring-opened versions of hamigeran B (30) and 2-debromohamigeran B respectively. The hamigerans were all found to have moderate (micromolar) cytotoxicity against the P-388 murine leukaemia cell line. Hamigeran B (30) was reported to exhibit a very strong antiviral response against herpes and polio viruses. 


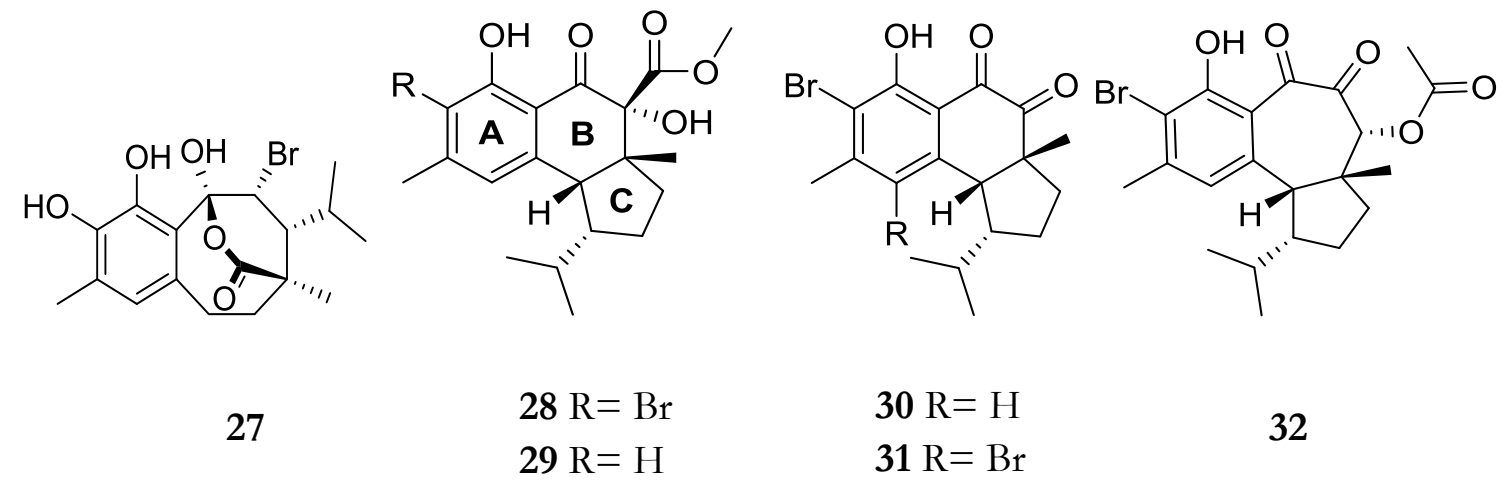

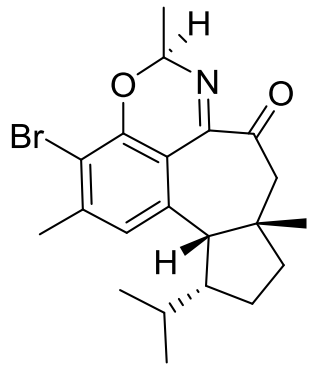

33<smiles>Cc1cc([C@]2(CC(=O)O)[C@H](C(C)C)CC[C@@]2(C)CC(=O)O)c2c(c1Br)OC(C)NC2=O</smiles>

34<smiles>[R]c1c(C)cc([C@@]2(C)[C@@H](C(=O)O)CC[C@H]2C(C)C)c(C(=O)O)c1O</smiles>

$35 \mathrm{R}=\mathrm{Br}$

$36 \mathrm{R}=\mathrm{H}$

\subsection{Synthetic studies}

The somewhat unusual structure of the hamigerans combined with their activity caught the attention of synthetic chemists with at least half a dozen syntheses now reported in the literature. ${ }^{42-47}$ Of these, the most extensive work came from the Nicolaou Laboratory with their total synthesis of hamigeran B and others using a Diels-Alder trapping method. ${ }^{42}$ Their work involved several attempts that led to non-natural analogues, with the trans-fusion of the B and C ring instead of natural cis-fusion, and the isopropyl tail sitting above the ring, before arriving at the right configuration. Debromohamigeran A (29) was the first to be fully synthesised with simple bromination and decarboxylation reactions able to produce hamigeran A (28), hamigeran B (30) and 4-bromohamigeran B (31). This extensive work also led to a new hamigeran analogue, 
debromohamigeran $\mathrm{B}$ (37) which was reacted with $\mathrm{H}_{2} \mathrm{O}_{2}$ causing an oxidative cleavage of the $\alpha$-diketone reaction to produce the naturally occurring debromohamigeran $\mathrm{E}(\mathbf{3 6}) .{ }^{42}$

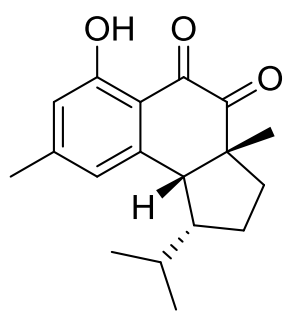

37

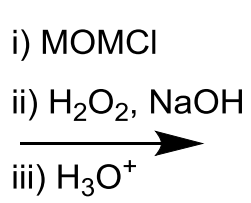

iii) $\mathrm{H}_{3} \mathrm{O}^{+}$

36

\subsection{VUW Research}

In 2003, the VUW Marine Natural Products group led by Northcote carried out a series of sponge collection dives around Northland, New Zealand. As part of his $\mathrm{PhD}$ research, $\mathrm{Dr}$ Jonathan Singh screened a selection of sponge samples from this collection using 1D and 2DNMR experiments. One of these, later identified as Hamigera tarangaensis, led to the isolation of several new hamigerans (38-44) along with many known variants. ${ }^{48}$ Some of these new compounds were very similar to Cambie's original hamigeran compounds. For example hamigeran G (40) contains a diketone like hamigeran B (30) but with a seven carbon B ring. Hamigeran G (40) also was isolated with a minor conformer and in enol form (41) which would readily interconvert during purification. With the addition of hamigerans $\mathrm{F}(\mathbf{3 8}), \mathrm{H}(\mathbf{4 2})$ and $\mathrm{J}$ (44), which had different carbon skeletons to the original hamigerans, Singh was able to propose a possible biogenesis for these compounds. This started with a diterpenoid origin which goes on to form either the hamigerane (six carbon $\mathrm{B}$ ring) or isobamigerane (seven carbon $\mathrm{B}$ ring) carbon skeleton, which then undergoes further derivation to form the observed hamigerans (Scheme 2.1). Hamigeran $\mathrm{F}$ (38) when left in $\mathrm{CDCl}_{3}$ rearranged to compound 39. This rearrangement, along with the degradation of hamigeran D (33) to 34 are the only hamigerans noted to undergo a rearrangement so far. Compound 45, a 13-epi-verrucosane congener, was isolated during separation but is unrelated to the hamigerans. 


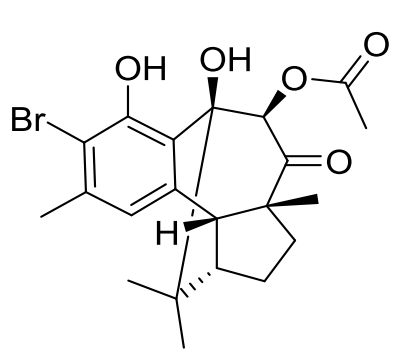

38

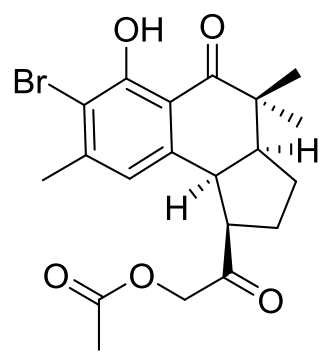

39

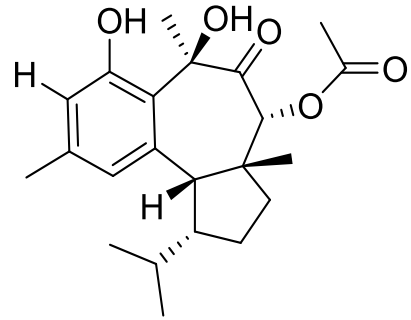

42

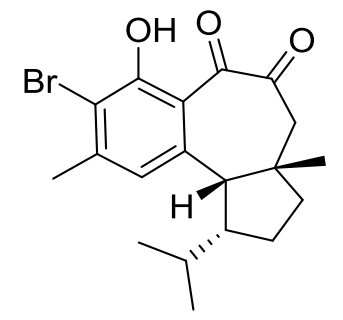

40

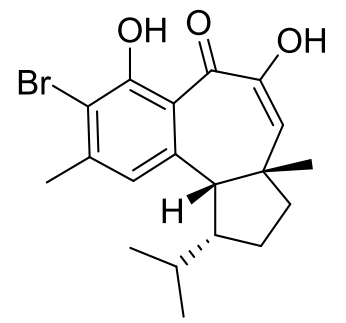

41

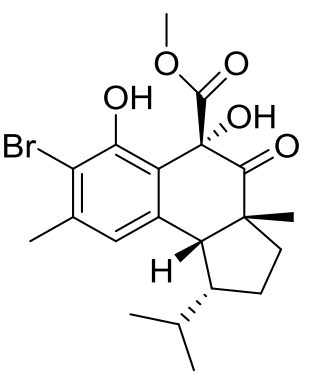

44

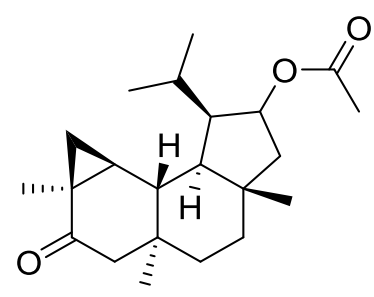

45 
Scheme 2.1. Biogenesis of the hamigerans proposed by Singh. ${ }^{48}$<smiles>CC(C)=CCCC(C)=CCCC(C)=CCC(C)CCOP</smiles>

gernylgernyl diphosphate
$[\mathrm{O}]$

$E / Z$ isomerization

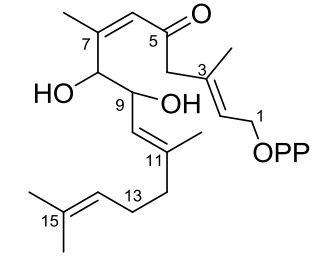

tautomerization
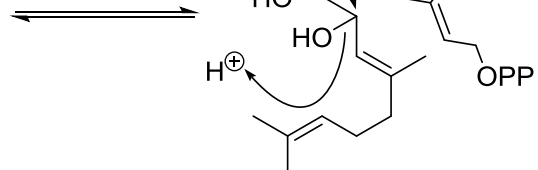

Enz-B:
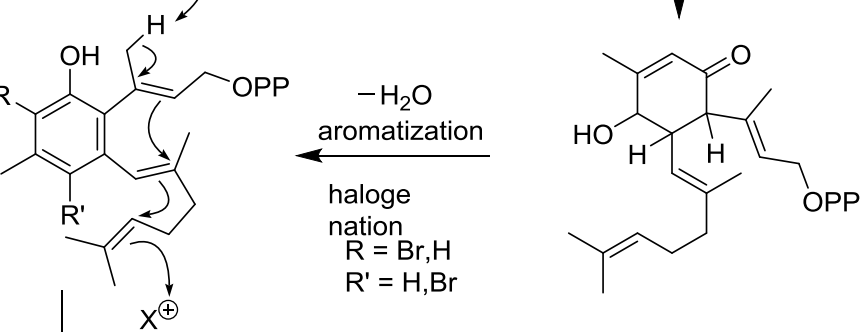
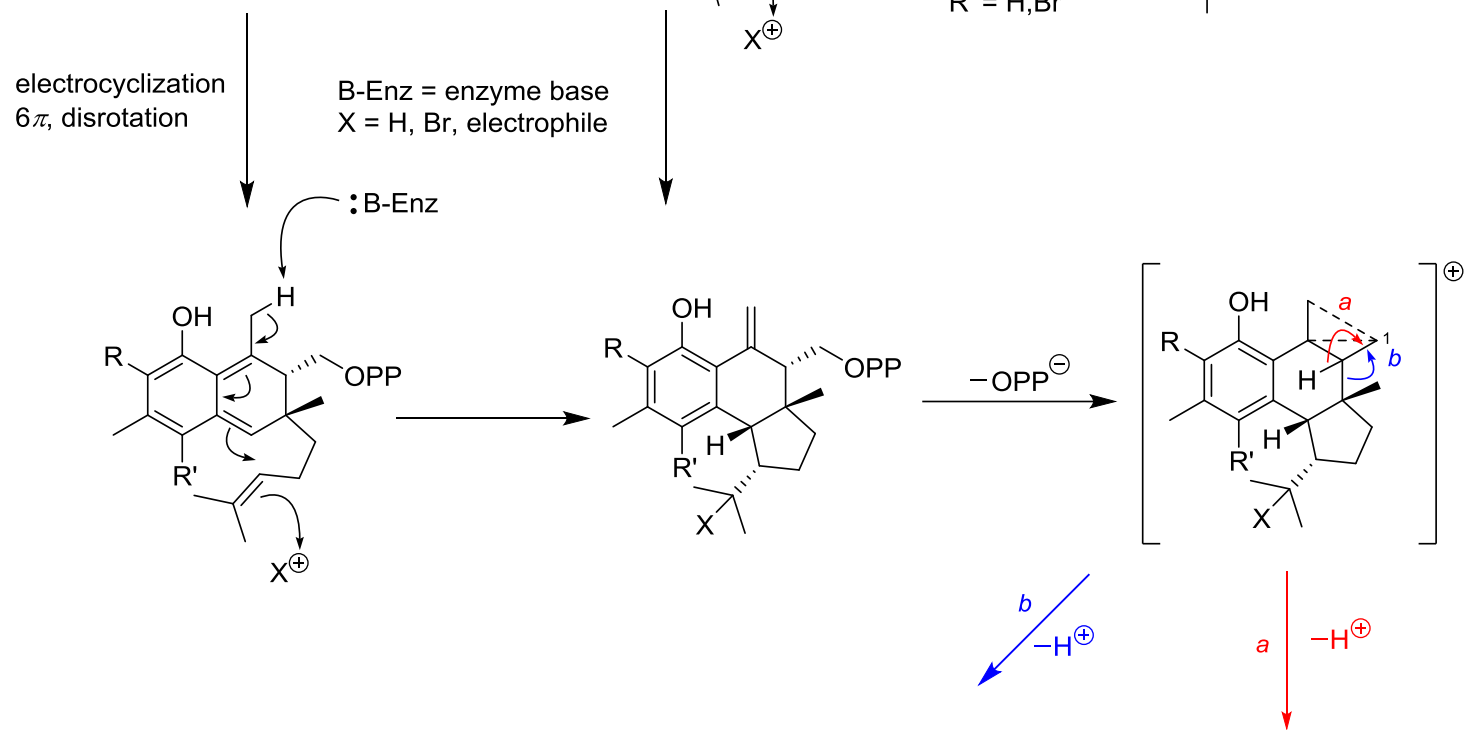

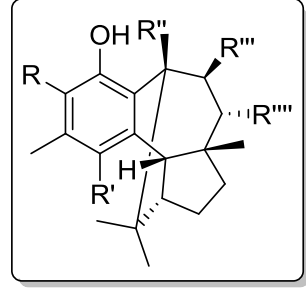

neohamigerane
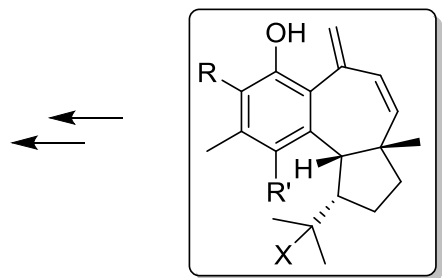

isohamigerane

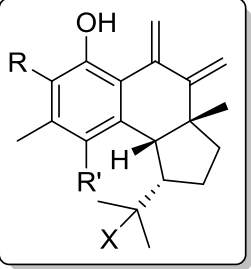

hamigerane 


\subsection{Nitrogenous Hamigerans}

After Singh's initial isolation of hamigerans 38-44, a visiting academic, Dr Jon Dattelbaum, worked on previously un-investigated fractions of the sponge. Several new hamigeran compounds were isolated (46-59). ${ }^{48,49}$ Hamigeran K (46), a partially reduced form of hamigeran B (30), was also isolated with a 4-bromo equivalent (47) and C-10 epimer (48). Hamigeran L (49), a ring-opened version of hamigeran $\mathrm{G}(\mathbf{4 0})$, and its $11-O$-methyl ester (50) were also isolated during this time. Dattelbaum and Singh isolated several new nitrogen-containing hamigerans, which appear to be derived from amino acid residues. Compounds derived from alanine (hamigeran D, 33), phenylalanine (hamigeran N, 52) valine (hamigeran O, 54), leucine (hamigeran P, 55) and isoleucine (hamigeran Q, 57) residues have been identified. The reisolation of hamigeran D (33) by Dattelbaum led to the reassignment of the configuration for C18, finding the original data had been misinterpreted. The C-18 epimers of hamigerans $\mathrm{N}, \mathrm{P}$ and $\mathrm{Q},(\mathbf{5 3}, \mathbf{5 6}, \mathbf{5 9})$ have also been isolated, along with the C-19 epimer of hamigeran Q, (58) respectively. A possible biosynthesis has been proposed by Singh (path A of Scheme 2.2) that suggests they are produced from a reaction of hamigeran $G$ (40) with an amino acid via decarboxylation. The oxazole containing compound hamigeran M (51) appears to be the only nitrogenous hamigeran that does not seem to be from a reaction with hamigeran $G$ (40). It has been proposed that it is a glycine hamigeran derivative that has undergone an alternative reaction (path B of Scheme 2.2). ${ }^{50}$

The isolation of three isoleucine-based compounds, hamigeran Q (57) and the two epimers (58) and (59) requires at least one must be derived from allo-isoleucine (D- or L-), a nonribosomal amino acid typical of prokaryotic secondary metabolism. However the hamigerans core is from terpene biosynthesis which is typical of eukaryotes such as sponges. This suggests a possible mixed-organism biogenesis for the nitrogenous hamigerans. ${ }^{50}$ 

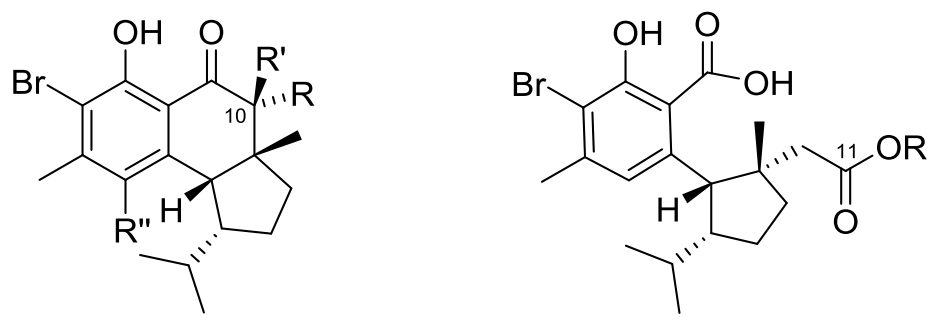

$$
\begin{aligned}
& 46 \mathrm{R}=\mathrm{R}^{\prime \prime}=\mathrm{H}, \mathrm{R}^{\prime}=\mathrm{OH} \\
& 47 \mathrm{R}=\mathrm{H}, \mathrm{R}^{\prime}=\mathrm{OH}, \mathrm{R}^{\prime \prime}=\mathrm{Br} \\
& 48 \mathrm{R}=\mathrm{OH}, \mathrm{R}^{\prime}=\mathrm{R}^{\prime \prime}=\mathrm{H}
\end{aligned}
$$

$$
\begin{aligned}
& 49 \mathrm{R}=\mathrm{H} \\
& 50 \mathrm{R}=\mathrm{CH}_{3}
\end{aligned}
$$

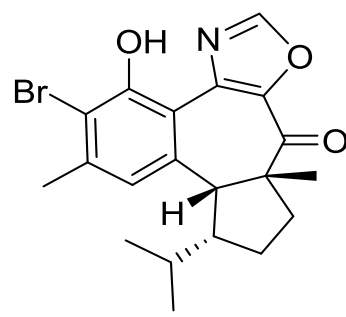

51

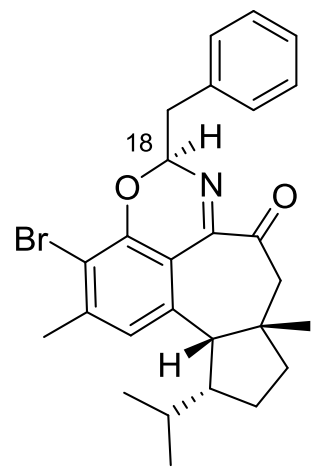

52

53 18-epi<smiles>Cc1cc2c3c(c1Br)O[C@H](C(C)C)N=C3C(=O)C[C@]1(C)CC[C@H](C(C)C)[C@H]21</smiles>

54

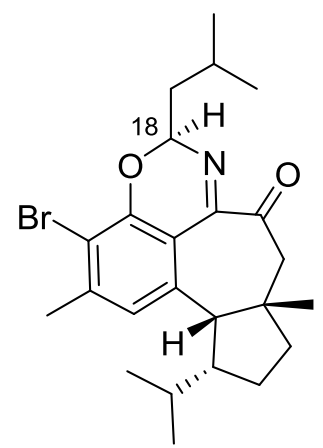

55

56 18-epi<smiles>CC[C@H](C)[C@H]1N=C2C(=O)C[C@]3(C)CC[C@H](C(C)C)[C@]34Cc3c2c(c(Br)c(C)c34)O[C@@H]1C(C)C</smiles>

57

58 19-ерi

59 18-epi 
Scheme 2.2. Proposed formation of nitrogenous hamigerans by Singh. ${ }^{49}$<smiles>CC(C)=CCCC(C)=CCCC(C)=CCCC(C)=CCOP</smiles><smiles>[R]C1C(=O)c2c(cc(C)c(Br)c2O)[C@]2(C(C)C)CC[C@H](C(C)C)[C@H]12</smiles><smiles>[R]C(N)C(=O)O</smiles><smiles>[R]C1C(=O)C(NC(C(=O)O)C(=O)O)=C2C(=O)C(Br)=C(C)C=C2[C@]2(CCC[C@@H]2C(C)C)[C@@H]1[R]</smiles>

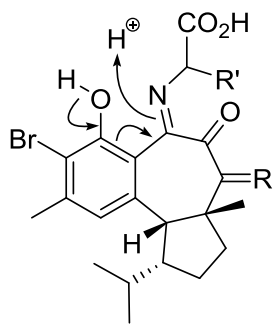

$-\mathrm{CO}_{2} \downarrow$ ox.

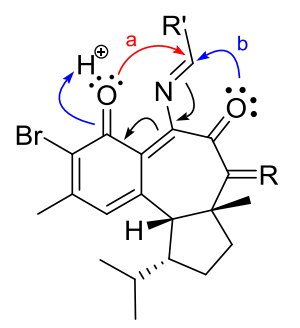

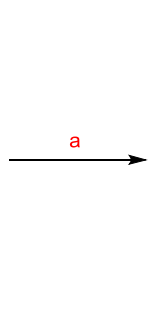<smiles>[R]C1N=C2C(=O)C(=O)C([R])[C@@]3(C)CC[C@H](C(C)C)[C@]3(C)c3cc(C)c(Br)c(c32)O1</smiles>

$\mathrm{R}=\mathrm{H}_{2}, \mathrm{R}^{\prime}=\mathrm{Me}$ $52 / 53 \quad \mathrm{R}=\mathrm{H}_{2}, \mathrm{R}^{\prime}=\mathrm{Bn}$ $54 \quad \mathrm{R}=\mathrm{H}_{2}, \mathrm{R}^{\prime}=i-\mathrm{Pr}$ $55 / 56 \quad \mathrm{R}=\mathrm{H}_{2}, \mathrm{R}^{\prime}=i-\mathrm{Bu}$ $57 / 58 / 59 R=H_{2}, R^{\prime}=s-B u$<smiles>CC(C)C</smiles>

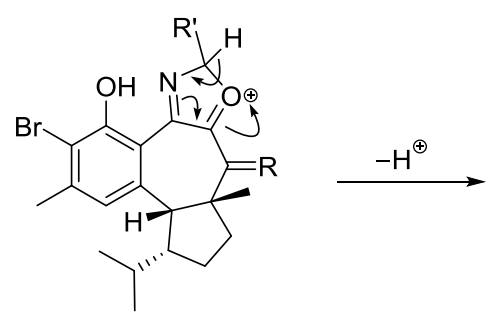

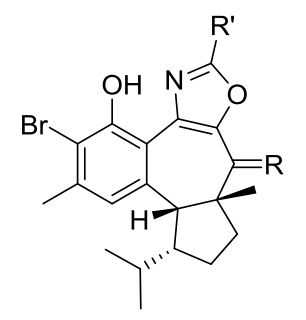
$51 \mathrm{R}=\mathrm{O}, \mathrm{R}^{\prime}=\mathrm{H}$ 


\subsection{Isolation of Hamigerans}

When Singh first examined this sponge its identity was unknown. The extract was unusually rich for a New Zealand sponge containing approximately ten times the mass of secondary metabolites for what is typical. HSQC screening revealed many unusual signals including those of highly substituted aromatic rings, deshielded methyl singlets and highly shielded methyl doublets. Digestion of the sponge material with $\mathrm{HNO}_{3}$ yielded unusually large microscleres (isochelas) siliceous spicules that quickly led to the sponge's identification as Hamigera tarangaensis. Literature revealed the earlier isolation attempts of the hamigeran compounds by Cambie, where he utilized the techniques of solvent partitioning and normal phase (silica gel) chromatography in extraction of the major constituents of the sponge. From the HSQC screen it was evident that some of the signals present in the VUW sample did not match the known hamigerans indicating that it was still worth pursuing. Normal phase (silica gel and DIOL) proved to be unusable due to loss of compounds and poor separation. A combination of reverse phase chromatography with PSDVB (polystyrene-divenyl benzene) resins and HPLC with an acidic buffer resulted in the isolation of several new hamigerans. This was further improved with the addition of size exclusion chromatography (LH20) with Dattlebaums work, the overall result adding 21 new compounds to the hamigeran family. However despite this impressive effort, only a fraction of this incredibly rich sponge has been investigated providing the opportunity for further research. 


\subsection{Proposed Research}

The aim of this body of work was to continue work started by Singh and Dattelbaum. The Hamigera tarangaensis samples were collected in 2003 from three sites in Northland (Cape Karikari, Matai Bay Pinnacle and Taheke Reef). All three had been extracted by Singh in methanol, and partitioned on PSDVB as $0 \%, 20 \%, 40 \%, 60 \%, 80 \%, 100 \% \mathrm{Me}_{2} \mathrm{CO} / \mathrm{H}_{2} \mathrm{O}$ fractions. Of these only the $80 \% \mathrm{Me}_{2} \mathrm{CO} / \mathrm{H}_{2} \mathrm{O}$ from Cape Karikari had been extensively examined in both Singh's and Dattelbaum's research. ${ }^{1} \mathrm{H}$ NMR analysis showed that the $60 \%, 80 \%$ and $100 \%$ $\mathrm{Me}_{2} \mathrm{CO} / \mathrm{H}_{2} \mathrm{O}$ fractions from each site all contained signals indicative of hamigerans. This left eight possible fractions from the three sponges meriting investigation. Initially the $100 \% \mathrm{Me}_{2} \mathrm{CO}$ fractions were considered not worth perusing due to the high primary metabolite: low hamigeran content, but with purification by size exclusion these fractions became easier to work with and hamigeran rich and therefore worth investigating.

The objectives of this research therefore became two-fold. First, to discover new hamigerans that complete the functionality series of the already discovered hamigerans, secondly, to discover hamigerans with new functionality. As shown by Tables 2.1 and 2.2, there are many missing debrominated and 4-brominated congeners which could be yet to be discovered hamigerans. The compounds with the hamigerane skeleton such as hamigeran A (28) and B (30), are the most abundant hamigerans; it is therefore not surprising that large amounts of debromohamigeran A (29) and 4-bromohamigeran B (31) have also been found. Less of the other hamigerans have been isolated which leaves the possibility that other debromohamigeran and 4-bromohamigeran compounds have not been discovered due to the smaller quantities in the sponge. This logic can also be applied to the isohamigeranes which besides hamigeran $G(\mathbf{4 0})$, are usually found in low abundance. In the case of hamigeran $\mathrm{H}(\mathbf{4 2})$, it is reasonable to assume a brominated equivalent should be biosynthetically produced. As for hamigeran L (49), which has also been isolated as an 11-O-methyl ester (50), there is the possibility that the 12-O-methyl ester or dimethyl ester 
compounds are possible to isolate. With the nitrogen containing hamigerans (Table 2.2) it is highly likely that the C-18 epimers of hamigeran D (33) and O (54) are present in the sponge. There is also the possibility that oxazole containing compound hamigeran $\mathrm{M}(\mathbf{5 1})$, is just one of many compounds with that heteroaromatic core, but substituted analogues would be difficult to detect due to the absence of the distinctive oxazole proton resonance. With size-exclusion chromatography able to remove most of the remaining primary metabolites from the $60 \%, 80 \%$ and $100 \% \mathrm{Me}_{2} \mathrm{CO} / \mathrm{H}_{2} \mathrm{O}$ fractions, the remaining mass would be hamigeran enriched, allowing a more productive throughput on HPLC, greatly increased the mass of fractions that were too small in quantity to previously pursue and therefore improving the chances of isolation of new congeners.

It would be safe to assume that there are hamigerans with functionalities that have yet to be isolated. This is especially so for compounds with the isobamigerane structure, the larger seven carbon B ring giving many more possible combinations of functionality and site of attachment. Isolation of hamigerans with these new structures was thought to be more likely in the $60 \%$ and $100 \% \mathrm{Me}_{2} \mathrm{CO} / \mathrm{H}_{2} \mathrm{O}$ fractions. These fractions would be thought to have a different range of compounds than the $80 \% \mathrm{Me}_{2} \mathrm{CO} / \mathrm{H}_{2} \mathrm{O}$ fraction, with the $60 \% \mathrm{Me}_{2} \mathrm{CO} / \mathrm{H}_{2} \mathrm{O}$ fraction containing more polar hamigerans and $100 \% \mathrm{Me}_{2} \mathrm{CO}$ fraction would more likely to have less polar analogues. 
Table 2.1. Isolated hamigerans from previous research.

\begin{tabular}{|c|c|c|c|}
\hline & Debromination & hamigerans & 4-Brominated \\
\hline 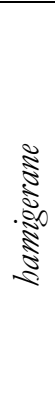 & $\begin{array}{l}\text { debromohamigeran A (29) } \\
\text { debromohamigeran E (36) }\end{array}$ & $\begin{array}{c}\text { hamigeran A (28) } \\
\text { hamigeran J (44) } \\
\text { hamigeran E (35) } \\
\text { hamigeran B (30) } \\
\text { hamigeran K (46) } \\
10 \text { epi-hamigeran K (48) }\end{array}$ & $\begin{array}{l}\text { 4-bromohamigeran B (31) } \\
\text { 4-bromohamigeran K (47) }\end{array}$ \\
\hline 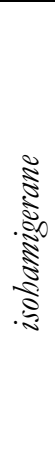 & hamigeran $\mathrm{H}(\mathbf{4 2})$ & $\begin{array}{c}\text { hamigeran F (38) } \\
\text { hamigeran C (32) } \\
\text { hamigeran I (43) } \\
\text { hamigeran G (40) } \\
\text { hamigeran L (49) } \\
\text { hamigeran L 11-O-methyl ester (50) }\end{array}$ & \\
\hline
\end{tabular}

Table 2.2. Isolated nitrogen containing hamigerans from previous research.

\begin{tabular}{c|c|c} 
oxazole amino hamigerans & Amino acid hamigerans & 18-epi-amino acid hamigerans \\
\hline hamigeran M (51) & hamigeran D (33) & \\
& hamigeran N (52) & 18-epi-hamigeran N (53) \\
hamigeran O (54) & \\
& hamigeran P (55) & 18-epi-hamigeran P (56) \\
& hamigeran Q (57) & 18-epi-hamigeran Q (58) \\
& 19-epi-hamigeran Q (59) &
\end{tabular}




\section{Chapter 3: New Hamigerans from Hamigera tarangaensis}

The two least worked on sponge samples were used for this research, the specimen from Matai Bay Pinnacle and the other from Taheke Reef. The $80 \% \mathrm{Me}_{2} \mathrm{CO} / \mathrm{H}_{2} \mathrm{O}$ fraction from Matai Bay Pinnacle had a high mass and revealed several signals in the ${ }^{1} \mathrm{H}$ NMR common to previously isolated hamigerans with traces of unidentified compounds. The $100 \% \mathrm{Me}_{2} \mathrm{CO}$ fraction from Matai Bay Pinnacle and $60 \% \mathrm{Me}_{2} \mathrm{CO} / \mathrm{H}_{2} \mathrm{O}$ fraction from Taheke Reef were also targeted due to the presence of several previously unobserved hamigeran-like signals in both samples. The $60 \%$ $\mathrm{Me}_{2} \mathrm{CO} / \mathrm{H}_{2} \mathrm{O}$ fraction (m) was subjected to size exclusion chromatography generating 95 fractions that were pooled into four groups; Fats, A, B and C the latter of which was separated with reversed-phase C18 HPLC generating nine fractions. Two of these fractions were pure, one containing debromohamigeran I (60) and the other hamigeran R (61) (Scheme 3.1).

Scheme 3.1. Isolation of debromohamigeran I and the novel compound hamigeran R.

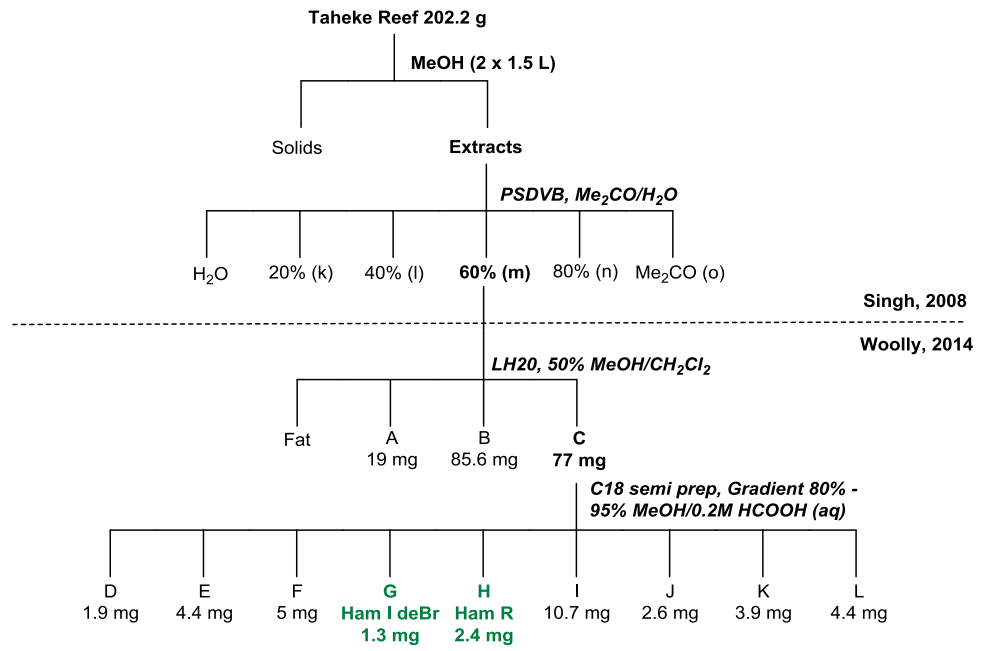


The Matai Bay Pinnacle $80 \% \quad \mathrm{Me}_{2} \mathrm{CO} / \mathrm{H}_{2} \mathrm{O}$ fraction (i) was subjected to size exclusion chromatography treatment though a series of columns generating around 70 fractions per column. These were pooled into four fractions as Fats, A, B and C. The largest fraction, B, was separated into 16 fractions using reversed-phase C18 HPLC $\left(\mathrm{MeOH} / \mathrm{H}_{2} \mathrm{O} 0.2 \mathrm{M} \mathrm{HCOOH}\right)$, many of which contained pure compounds including debromohamigeran A (29), hamigeran A (28), hamigeran B (30), 4-bromohamigeran B (31) and hamigeran G (40). Some of the fractions that looked promising by ${ }^{1} \mathrm{H}$ NMR and had significant mass were further purified using $\mathrm{C} 18$ HPLC. Fraction E was separated into an additional seven fractions, containing hamigeran F (38) and a new compound, debromohamigeran J (62). Fraction F was separated using a gradient of $60 \%-100 \% \mathrm{MeCN} / 0.2 \mathrm{M} \mathrm{HCOOH}_{(\mathrm{aq})}$ resulting in 12 fractions with two new compounds, hamigeran L 12-O-methyl ester (63) and debromohamigeran B (37). The new hamigeran 4bromohamigeran A (64) was isolated after two additional HPLC separations of fraction $\mathrm{N}$ (Scheme 3.2).

The $100 \% \mathrm{Me}_{2} \mathrm{CO}$ (j) fraction of the Matai Bay Pinnacle specimen was the last to be investigated. Pooled as five fractions after separation with size exclusion chromatography, Fats, AR, AS, AT and AU. Lipids and steroids were still in these fractions despite the majority being removed by LH20. Further investigation of the fraction AS led to the isolation of the new compound hamigeran S (65) after two HPLC separations (scheme 3.2). The HPLC running conditions required for the purification of hamigeran S (65) were much less polar compared to the isolation of the other hamigerans, not requiring the use of a buffer. 
Scheme 3.2. Isolation of several new and novel hamigerans.

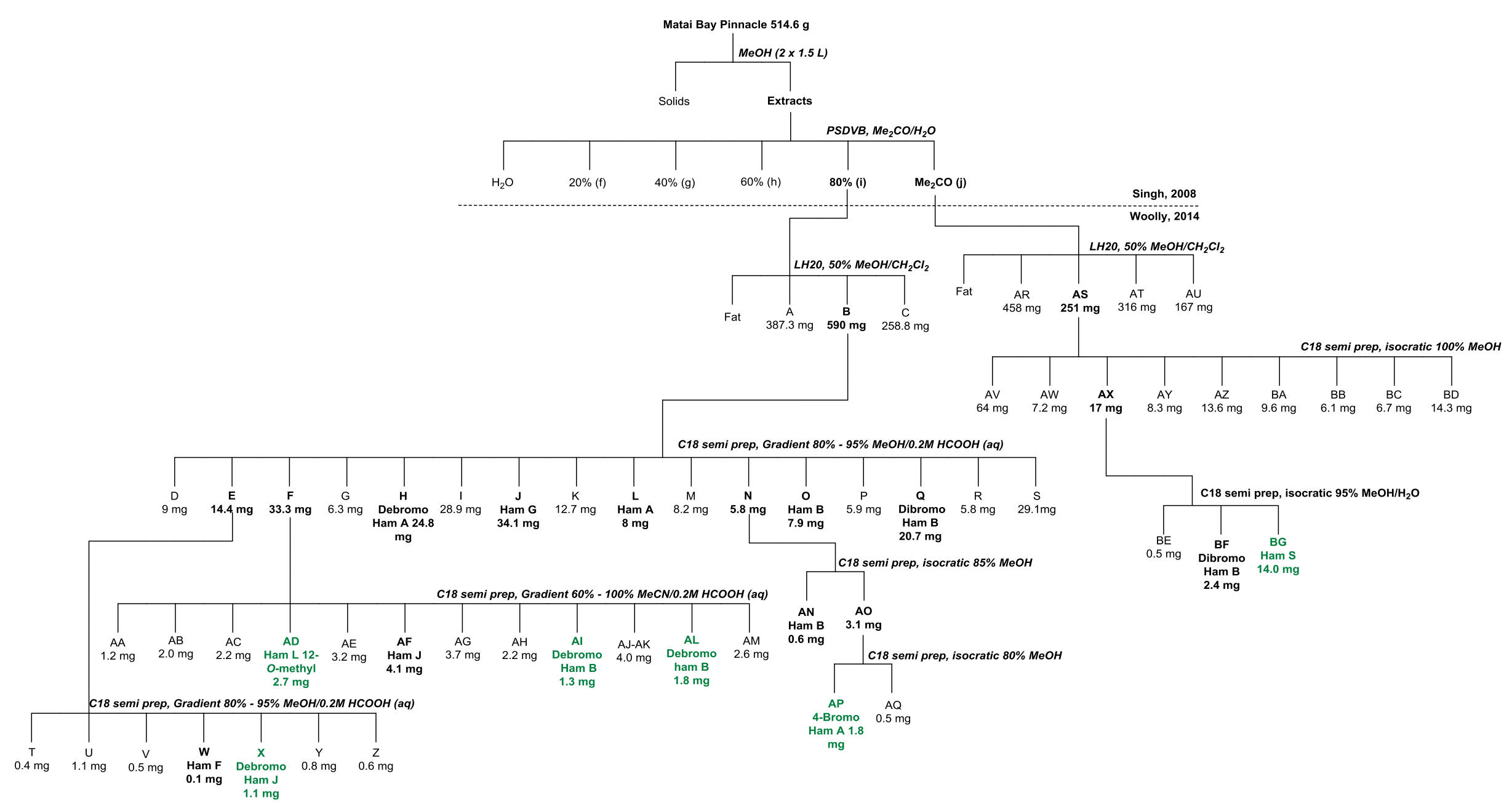




\subsection{Debromohamigeran B (37)}

Debromohamigeran B (37) was isolated as a bright yellow film. The molecular formula of $\mathrm{C}_{18} \mathrm{H}_{22} \mathrm{O}_{3}(\Delta=+1.08 \mathrm{ppm})$ was established from positive-ion mode HRESIMS analysis of the $[\mathrm{M}+\mathrm{H}]^{+}$adduct ion $m / z 287.1645$. Analysis of the ${ }^{13} \mathrm{C}$ and ${ }^{1} \mathrm{H}$ NMR spectra coupled with HSQC data provided evidence of 18 distinct carbon resonances coupling to 21 of the 22 protons of the molecular formula, indicating the presence of an exchangeable proton, $1-\mathrm{OH}\left(\delta_{\mathrm{H}} 11.93\right)$. The HSQC established the presence of four methyls $\left[\mathrm{CH}_{3}-15\left(\delta_{\mathrm{C}} 24.5, \delta_{\mathrm{H}} 1.30\right) ; \mathrm{CH}_{3}-14\left(\delta_{\mathrm{C}} 23.2, \delta_{\mathrm{H}}\right.\right.$ $\left.0.42) ; \mathrm{CH}_{3}-16\left(\delta_{\mathrm{C}} 22.6, \delta_{\mathrm{H}} 2.39\right) ; \mathrm{CH}_{3}-13\left(\delta_{\mathrm{C}} 19.8, \delta_{\mathrm{H}} 0.54\right)\right]$ two methylenes $\left[\mathrm{CH}_{2}-8\left(\delta_{\mathrm{C}} 33.2, \delta_{\mathrm{H}}\right.\right.$ 2.62, 1.56); $\left.\mathrm{CH}_{2}-7 \quad\left(\delta_{\mathrm{C}} \quad 26.9, \quad \delta_{\mathrm{H}} \quad 1.79,1.68\right)\right]$ and three alkyl methines $\left[\mathrm{CH}-5\left(\delta_{\mathrm{C}} 56.5, \delta_{\mathrm{H}} 3.4\right)\right.$; CH-6 ( $\left.\delta_{\mathrm{C}} 51.4, \delta_{\mathrm{H}} 2.29\right)$; $\left.\mathrm{CH}-12\left(\delta_{\mathrm{C}} 28.1, \delta_{\mathrm{H}} 1.2\right)\right]$. The remaining carbons were identified as two carbonyls [C-10 ( $\left.\delta_{C} 200.1\right)$; C-11 ( $\left.\left.\delta_{C} 184.3\right)\right]$, six olefinic sp ${ }^{2}$ carbons [C-1 $\left(\delta_{\mathrm{C}} 164.6\right) ; \mathrm{C}-3$ ( $\left.\delta_{\mathrm{C}} 150.8\right) ; \mathrm{C}-4 \mathrm{a}\left(\delta_{\mathrm{C}} 144.2\right) ; \mathrm{CH}-4\left(\delta_{\mathrm{C}} 123.4, \delta_{\mathrm{H}} 6.69\right) ; \mathrm{C}-11 \mathrm{a}\left(\delta_{\mathrm{C}} 116.7\right) ; \mathrm{CH}-2\left(\delta_{\mathrm{C}}\right.$ $\left.\left.116.2, \delta_{\mathrm{H}} 6.73\right)\right]$ and one quaternary $\mathrm{sp}^{3}$ carbon $\left[\mathrm{C}-9\left(\delta_{\mathrm{C}} 56.9\right)\right]$. The molecular formula required eight degrees of unsaturation, five of which could be explained as the two double bonds from the carbonyls and three from the six olefinic carbons, with the remaining three hydrogen deficiencies indicating that the structure is tricyclic.

On the basis of extensive 2D NMR data analysis three substructures could be assembled. The first was determined to be a tetra-substituted aromatic ring, accounting for all six of the olefinic carbons. It was assembled on the basis of HMBC correlations from three of the substituents as seen in Figure 4.1. The protons of the olefinic methyl $\mathrm{CH}_{3}-16$ showed HMBC correlations to the aromatic methine carbons, $\mathrm{CH}-2$ and $\mathrm{CH}-4$, along with a correlation to the non-protonated carbon C-3 that established the C-2 to $\mathrm{C} 3$ and $\mathrm{C}-3$ to $\mathrm{C}-4$ bonds along with the methyl attachment to $\mathrm{C}-3$. The phenol proton, 1-OH could be established to have a connection to $\mathrm{C}-1$ though an HMBC correlation, consistent with the downfield shift of C-1 ( $\delta_{C}$ 164.6). Further 
HMBC correlations from 1-OH established the connection between $\mathrm{CH}-2$ and $\mathrm{C}-1$, as well as the connection of C-1 to the carbonyl C-11a. The protons of an alkyl methine, $\mathrm{CH}-5$ showed HMBC correlations to the carbons of both $\mathrm{CH}-4$ and C-11a along with a weak correlation to a non-protonated carbon C-4a, providing the last position of the aromatic ring. These correlations finally established the C-11a to $4 \mathrm{a}, \mathrm{C}-4 \mathrm{a}$ to C-4 and C-5 to C-4a bonds clearly identifying an aromatic ring (substructure 1, Figure 3.1). A weak correlation observed in the HMBC between 1$\mathrm{OH}$ and the carbonyl C-11 established the connection of C-11a to C-11 identifying the last substituent on the aromatic ring. The assignments for the ring were further confirmed with ${ }^{1} \mathrm{H}$ ${ }^{1} \mathrm{H}$ couplings observed in the COSY experiment, with meta coupling detected between $\mathrm{CH}-2$ and CH-4 and three cases of extended allylic coupling from $\mathrm{CH}-2$ with $\mathrm{CH}_{3}-16, \mathrm{CH}_{3}-16$ with $\mathrm{CH}-4$ and $\mathrm{CH}-4$ with $\mathrm{CH}-5$.

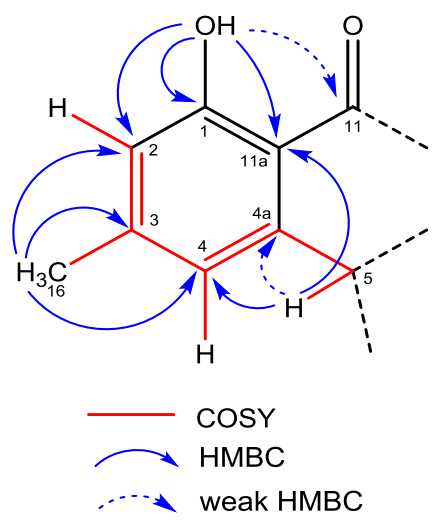

Figure 3.1. Key HMBC and COSY correlations establishing the aromatic ring (substructure 1) of debromohamigeran B (37).

The second substructure (substructure 2, Figure 3.2) identified was a three carbon unit, a linear sequence of a methine, CH-6 and two methylenes, $\mathrm{CH}_{2}-7$ and $\mathrm{CH}_{2}-8$ as evidenced from 
correlations in the COSY spectrum. The final substructure (substructure 3, Figure 3.2) was another three carbon sequence, identified as an isopropyl unit, established from COSY correlations of a methine, $\mathrm{CH}-12$ to two methyls, $\mathrm{CH}_{3}-13$ and $\mathrm{CH}_{3}-14$.
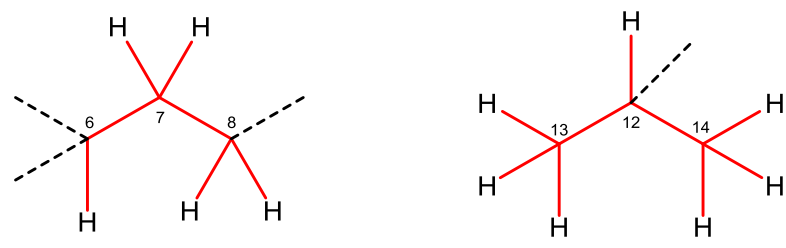

$\cos Y$

Figure 3.2. COSY correlations for the hydrocarbon sequence (substructure 2) and the isopropyl unit (substructure 3) spin systems of debromohamigeran B (37).

With these substructures identified, all the carbons of the molecular formula were accounted for except for a quaternary carbon C-9, a methyl singlet $\mathrm{CH}_{3}-15$ and a carbonyl C-10. The absence of coupling from the protons of $\mathrm{CH}_{3}-15$ to a non-protonated alkyl carbon C-9 was evident by $\mathrm{HMBC}$ and consistent with its lack of ${ }^{1} \mathrm{H}-{ }^{1} \mathrm{H}$ splitting. The other bonds to $\mathrm{C}-9$ were also identified by $\mathrm{HMBC}$ correlations from the protons of $\mathrm{CH}_{3}-15$ to the carbons of $\mathrm{CH}_{2}-8, \mathrm{CH}-5$ and the ketone C-10. These connections linked substructure 1 to substructure 2 (Figure 3.3). A cyclopentyl (C) ring was also established with the identification of the bond between C-5 and C-6 from a strong correlation observed with COSY, which again connected the substructures 1 and 2 together accounting for one of the two remaining degrees of unsaturation. 

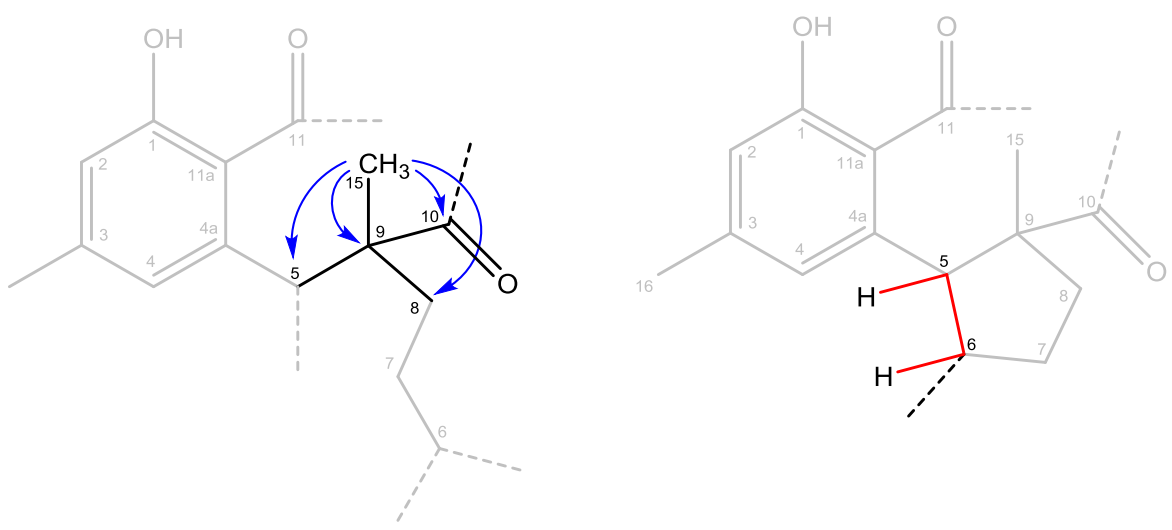

$\cos Y$

HMBC

Figure 3.3. $\mathrm{HMBC}$ Correlations of $\mathrm{CH}_{3}-15$ connecting substructure 1 and 3 together and establishment of the cyclopentyl ring (ring C) of Debromohamigeran B (37).

Substructures 2 and 3 were connected with the remaining unassigned bond of $\mathrm{CH}-6$ and $\mathrm{CH}-12$ with correlations seen in the HMBC from the methyl protons of the isopropyl unit to the carbon of $\mathrm{CH}-6$ and a correlation from the proton of $\mathrm{CH}-6$ to the carbon of $\mathrm{CH}-12$ (Figure 3.4). With all the atoms of the chemical formula now assigned, the remaining degree of unsaturation could be assigned to a linkage between the two carbonyls, C-10 and C-11, providing the final ring (ring B) of the tricyclic structure, completing the planar structure (Figure 3.5). Additional evidence of this bond comes from the chemical shifts of the carbonyls. A ketone carbonyl shift in ${ }^{13} \mathrm{C}$ NMR is normally around $220 \mathrm{ppm}$ but moves upfield when adjacent to other $\mathrm{sp}^{2}$ centres. C-10 ( $\delta_{\mathrm{C}}$ $200.1)$ is vicinal to one $\mathrm{sp}^{2}$ carbon, while $\mathrm{C}-11\left(\delta_{\mathrm{C}} 184.3\right)$ is next to two $\mathrm{sp}^{2}$ carbons. 


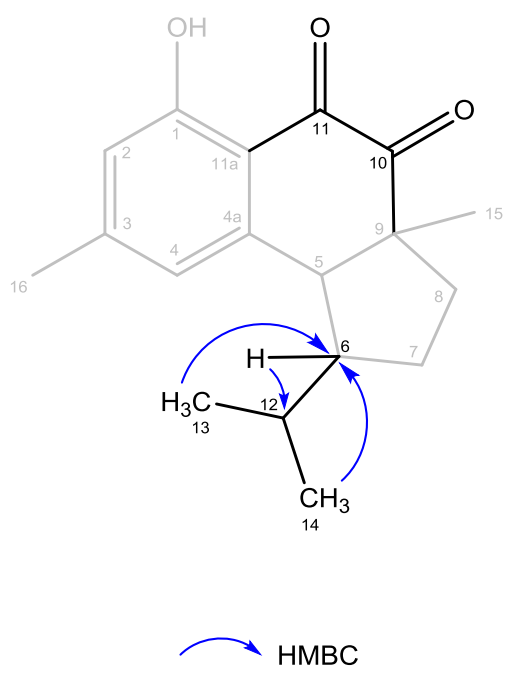

Figure 3.4. Key HMBC correlations establishing substructure 3 to substructure 2 and connection of the ketones Debromohamigeran B (37).

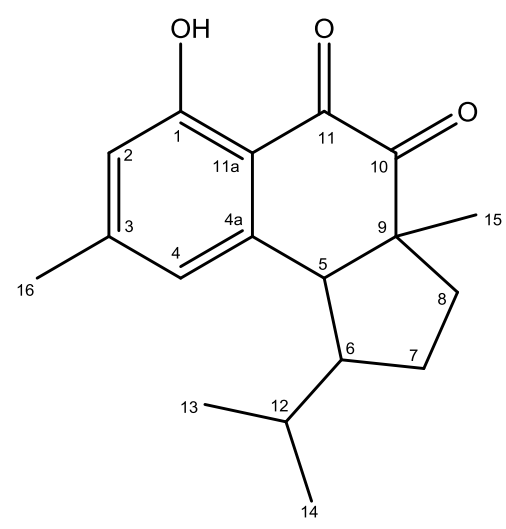

Figure 3.5. Completed planar structure of debromohamigeran B (37).

The relative configuration of debromohamigeran B (37) was established with NOESY correlations from the three stereogenic centres, $\mathrm{CH}-5, \mathrm{CH}-6$ and C-9. A NOE correlation between the methine $\mathrm{CH}-5$ and methyl $\mathrm{CH}_{3}-15$ established the cis-fusion of the $\mathrm{B}$ and $\mathrm{C}$ rings while NOE correlations from both $\mathrm{CH}-5$ and $\mathrm{CH}_{3}-15$ with the methine proton $\mathrm{CH}-6$ indicated they were on the same plane, placing the isopropyl tail below the $\mathrm{C}$ ring (Figure 3.6). Further evidence of this assignment of configuration comes from the shifts of the isopropyl tail protons 
being very similar to that of hamigeran B (30), where a change in configuration of the tail would significantly alter the chemical shifts of the protons. ${ }^{42}$ This is consistent with the stereogenic relationship of all other known hamigerans. Assuming the same absolute stereochemistry, this defines the absolute configuration of debromohamigeran $B(37)$ as $5 R, 6 R, 9 R$.

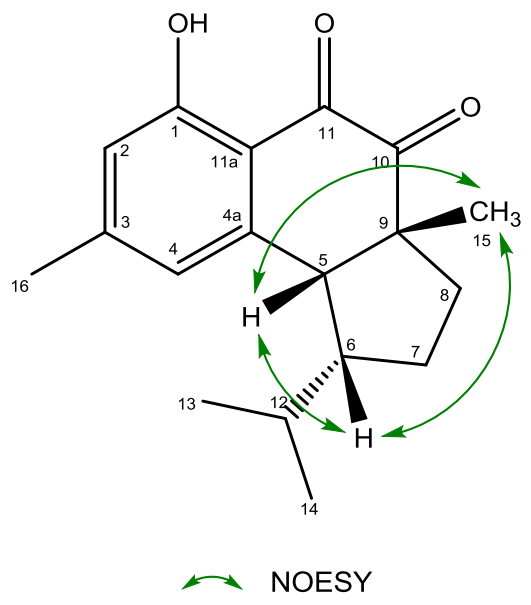

Figure 3.6. Key NOE correlations establishing the relative configuration of debromohamigeran B (37).

As is evident by the name, debromohamigeran B (37) is the 2-debromo analogue of hamigeran B (33), which was synthesised by Nicolaou. ${ }^{42}$ The spectral data matches that of the synthetic material. ${ }^{42}$ It has very similar chemical shifts to the previously isolated hamigerans, especially hamigeran B (30) and 4-bromohamigeran B (31). As expected the main differences are observed in the aromatic ring as summarised in Table 3.1. There is a noticeable downfield shift observed for C-2 and C-1 when a bromine is replaced with a proton on C-2 and an equivalent upfield shift for $\mathrm{C}-4$ if a bromine is attached to that position. The optical rotation data gave a rotation of the same sign and order as the hamigeran B (30) and 4-bromohamigeran B (31). ${ }^{41,48}$ 
Table 3.1. Chemical shifts of the aromatic carbons from hamigeran B (30) and its derivatives.

\begin{tabular}{|c|c|c|c|c|}
\hline $\mathrm{OH}$ & Position & Hamigeran B (30) & 4-Bromohamigeran B (31) & Debromohamigeran B (37) \\
\hline & $\overline{C C-1}$ & 160.8 & $\overline{160.1}$ & 165.7 \\
\hline & C-2 & 111.6 & 113.3 & 116.2 \\
\hline & $\mathrm{C}-3$ & 150.2 & 149.8 & 150.8 \\
\hline $30 \mathrm{R}=\mathrm{Br} \mathrm{R}_{1}=\mathrm{H}$ & $\mathrm{C}-4$ & 124.3 & 119.3 & 123.4 \\
\hline $31 \mathrm{R}=\mathrm{Br} \mathrm{R}_{1}=\mathrm{Br}$ & $\mathrm{C}-4 \mathrm{a}$ & 142.8 & 142.1 & 144.2 \\
\hline $37 \mathrm{R}=\mathrm{H} \quad \mathrm{R}_{1}=\mathrm{H}$ & C-11a & 117.3 & 117.6 & 116.7 \\
\hline
\end{tabular}

The sharp, down-field nature of the phenol $1-\mathrm{OH}$ in the ${ }^{1} \mathrm{H}$ NMR is also consistent with the phenol containing hamigerans with a ketone at C-11, with hydrogen bonding occurring between the phenol proton and the nearby ketone causing the deshielding effect observed. 
Table 3.2. NMR data $(600 \mathrm{MHz})$ of debromohamigeran $\mathrm{B}(37)$ in $\mathrm{CDCl}_{3}$.

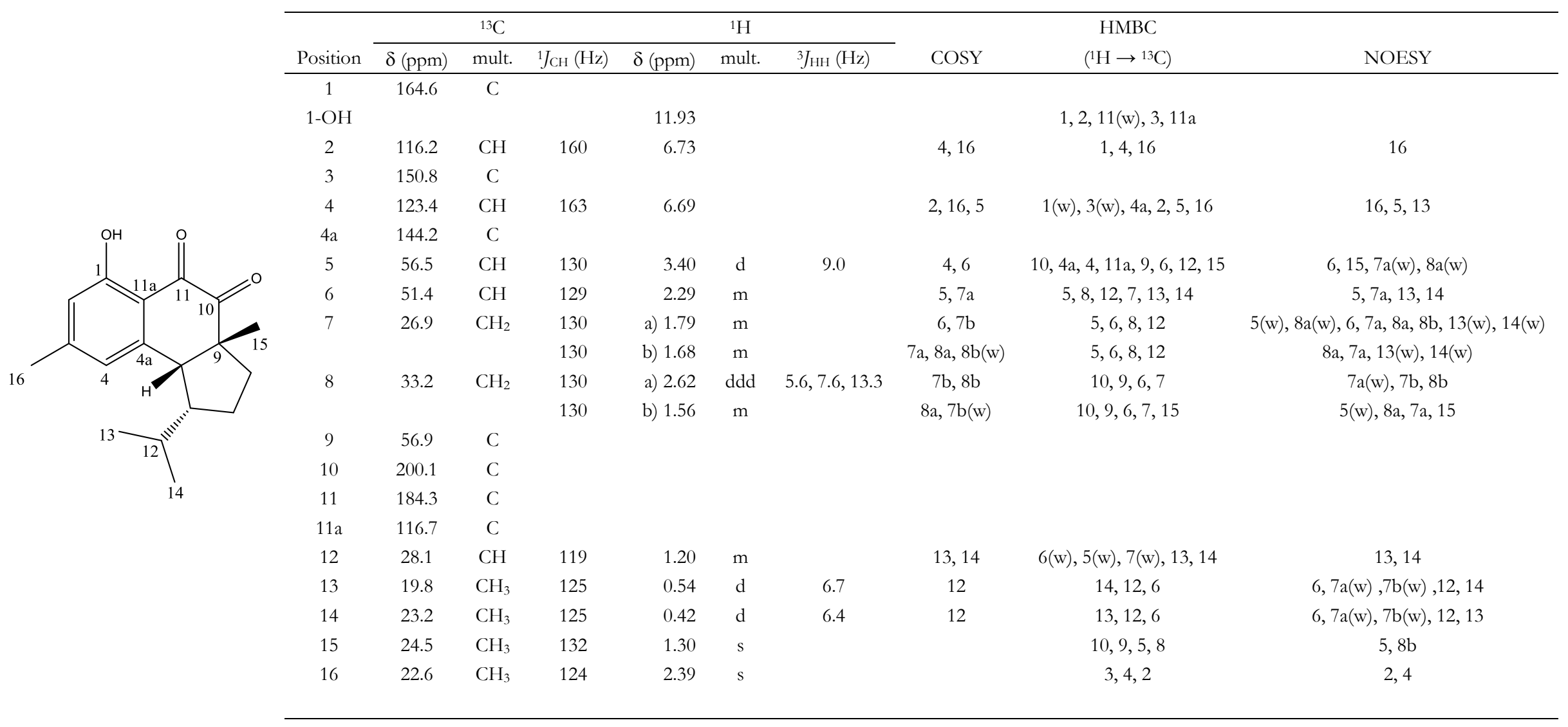




\subsection{Debromohamigeran I (60)}

Debromohamigeran I (60) was isolated as a pale yellow film. HRESIMS analysis revealed a $[\mathrm{M}+\mathrm{H}]^{+}$adduct ion at $m / ₹ 319.1902$, establishing a molecular formula of $\mathrm{C}_{19} \mathrm{H}_{26} \mathrm{O}_{4}(\Delta=-0.6$ ppm). Analysis of the ${ }^{13} \mathrm{C}$ and ${ }^{1} \mathrm{H}$ NMR spectra coupled with HSQC data indicated that 13 of the 19 carbons were attached to 23 of the 26 protons. Overall this was broken down as four methyls $\left[\mathrm{CH}_{3}-16\left(\delta_{\mathrm{C}} 30.0, \delta_{\mathrm{H}} 1.24\right) ; \mathrm{CH}_{3}-14\left(\delta_{\mathrm{C}} 23.2, \delta_{\mathrm{H}} 0.18\right) ; \mathrm{CH}_{3}-15\left(\delta_{\mathrm{C}} 22, \delta_{\mathrm{H}} 0.76\right) ; \mathrm{CH}_{3}-17\left(\delta_{\mathrm{C}} 21.8\right.\right.$, $\left.\left.\delta_{\mathrm{H}} 2.32\right)\right]$, two methylenes $\left[\mathrm{CH}_{2}-7\left(\delta_{\mathrm{C}} 32.3, \delta_{\mathrm{H}} 1.60,1.90\right) ; \mathrm{CH}_{2}-8\left(\delta_{\mathrm{C}} 34.4, \delta_{\mathrm{H}} 1.40,2.59\right)\right]$, five alkyl methines [CH-11 ( $\left.\delta_{\mathrm{C}} 74.4, \delta_{\mathrm{H}} 4.56\right)$; CH-10 ( $\left.\delta_{\mathrm{C}} 74.1, \delta_{\mathrm{H}} 3.33\right)$; $\mathrm{CH}-5\left(\delta_{\mathrm{C}} 61.3, \delta_{\mathrm{H}} 3.46\right)$; $\mathrm{CH}-6\left(\delta_{\mathrm{C}}\right.$ $\left.53.7, \delta_{\mathrm{H}} 2.21\right)$; $\mathrm{CH}-13\left(\delta_{\mathrm{C}} 29.5, \delta_{\mathrm{H}} 1.12\right)$ and two oxymethines [CHOH-11 $\left(\delta_{\mathrm{C}} 74.4\right)$ and $\mathrm{CHOH}-$ $\left.10\left(\delta_{\mathrm{C}} 74.1\right)\right]$. The other carbon signals included a ketone C-12 $\left(\delta_{\mathrm{C}} 204.2\right)$, six olefinic $\mathrm{sp}^{2}$ carbons [C-1 ( $\left.\delta_{\mathrm{C}} 164.8\right) ; \mathrm{C}-4 \mathrm{a}\left(\delta_{\mathrm{C}} 148.5\right) ; \mathrm{C}-3\left(\delta_{\mathrm{C}} 143.0\right) ; \mathrm{CH}-4\left(\delta_{\mathrm{C}} 127.8, \delta_{\mathrm{H}} 6.64\right) ; \mathrm{CH}-2\left(\delta_{\mathrm{C}} 117.9, \delta_{\mathrm{H}}\right.$ 6.77); C-12a $\left.\left(\delta_{C} 115.4\right)\right]$ and one quaternary $\mathrm{sp}^{3}$ carbon $\left[\mathrm{C}-9\left(\delta_{\mathrm{C}} 47.7\right)\right]$. The three exchanagble protons were identified as the phenol proton $1-\mathrm{OH}\left(\delta_{\mathrm{H}} 12.54\right)$ and the two on the oxymethines. The molecular formula requires seven degrees of unsaturation which could be attributed to one carbonyl and six olefinic carbons, the remaining three hydrogen deficiencies indicated a tricyclic structure.

The substructures 1, 2 and 3 identified in debromohamigeran B (37) were again present in debromohamigeran I (60) and elucidated in a similar fashion (Figure 3.7). HMBC correlations from three of the aromatic substituents pieced together substructure 1 with COSY correlations confirming their assignment. Substructures 2 and 3 were again assembled using COSY correlations. 


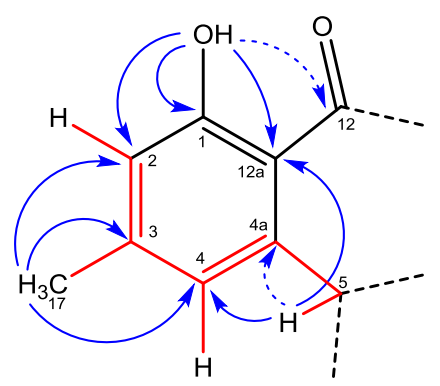

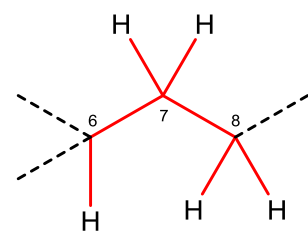<smiles>CC(C)C</smiles>

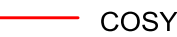

HMBC

weak HMBC

Figure 3.7. Key HMBC and COSY correlations establishing substructures 1,2 and 3 of Debromohamigeran I (60).

COSY correlations between $\mathrm{CH}-5$ and $\mathrm{CH}-6$ identified the connection between substructures 1 and 2 (Figure 3.8). COSY and HMBC correlations pieced together substructure 3 to 2 establishing the bond between C-13 and C-6. With these substructures identified and assembled together, all but the quaternary carbon $\mathrm{C}-9$, the methyl singlet $\mathrm{CH}_{3}-15$ and the two oxymethines $\mathrm{CHOH}-10$ and $\mathrm{CHOH}-11$ were accounted for.

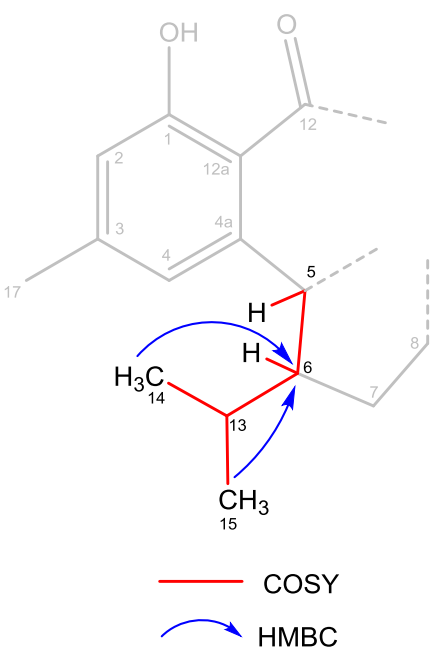

Figure 3.8. Key HMBC and COSY correlations connecting substructure 1, 2 and 3 together for debromohamigeran I (60). 
As for the previous compound, $\mathrm{HMBC}$ correlations showed $\mathrm{CH}_{3}-16$ was attached to $\mathrm{C}-9$, with further HMBC correlations establishing that carbons $\mathrm{CH}_{2}-8$ and $\mathrm{CH}-5$ connected to $\mathrm{C}-9$, again connecting substructure 1 and 2 together forming a cyclopentyl ring (Figure 3.9). The remaining bond to $\mathrm{C}-9$ was identified as $\mathrm{CHOH}-10$ though a $\mathrm{HMBC}$ correlation from $\mathrm{CH}_{3}-16$. Connection of $\mathrm{CHOH}-10$ and $\mathrm{CHOH}-11$ was evident from COSY correlations, HMBC correlations from both centres to the ketone $\mathrm{C}-12$ identified the bond between $\mathrm{CH}-11$ and $\mathrm{C}-12$ closing the seven membered B ring. This completed the planar structure of debromohamigeran I (60) (Figure 3.10), the debrominated analogue of hamigeran I (43).

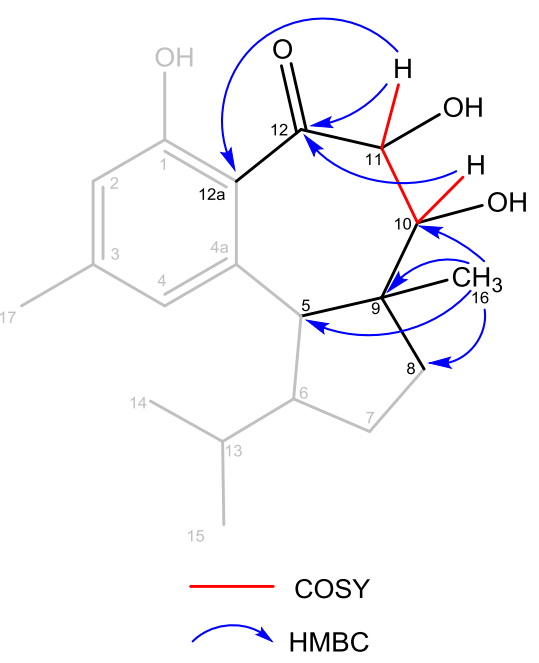

Figure 3.9. Key HMBC correlations for $\mathrm{CH} 3-15$ and $\mathrm{HMBC}$ and COSY correlations $\mathrm{CH}-10$ and CH-11 of debromohamigeran I (60).

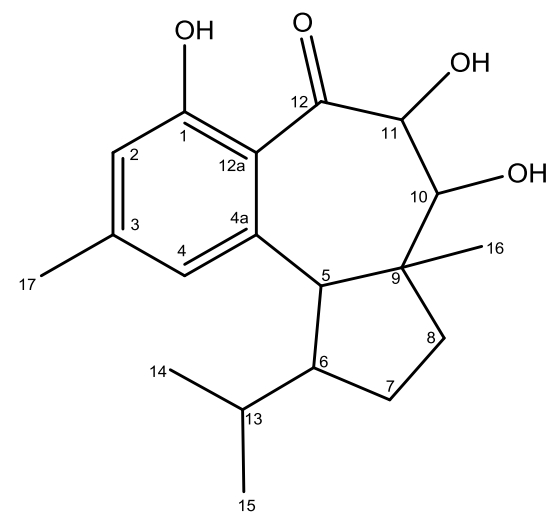

Figure 3.10. Completed planar structure of debromohamigeran I (60). 
Debromohamigeran I (60) includes five stereogenic centres (Figure 3.11). NOE correlations between $\mathrm{CH}-5, \mathrm{CH}-6$ and $\mathrm{CH}_{3}-16$ confirmed the usual cis-fused ring configuration and the isopropyl unit sitting below the ring. $\mathrm{CH}-5$ and $\mathrm{CH}_{3}-16$ both had NOE correlations to $\mathrm{CH}-10$ indicating the proton was on the same face, placing it above the ring while the hydroxyl sits below. A NOE correlation between $\mathrm{CH}-11$ and $\mathrm{CH}-13$ indicated both protons sit below the rings. This was evident from the large splitting between $\mathrm{H}-10$ and $\mathrm{H}-11$ in ${ }^{1} \mathrm{H}$ spectrum $\left({ }^{3} J_{\mathrm{HH}}=\right.$ 10.9 Hz) indicative of a trans relationship between the two protons. These assignments matched previous assignments of the brominated analogue hamigeran I (43) and assuming the same absolute stereochemistry, established the absolute configuration of debromohamigeran I (60) as 5R, 6R, 9R, 10R, 11S. The optical rotation data gave a rotation of the same sign and order as the hamigeran I (60). ${ }^{48}$

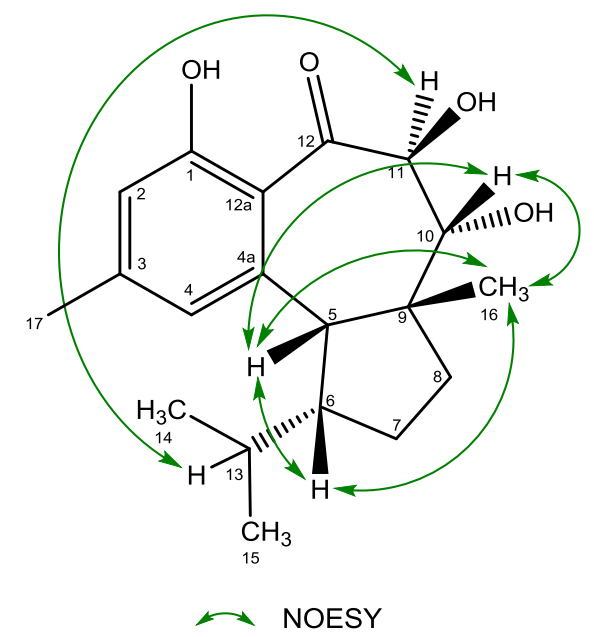

Figure 3.11. Key NOE correlations for debromohamigeran I (60). 
Table 3.3. NMR data $(600 \mathrm{MHz})$ of debromohamigeran $\mathrm{I}(\mathbf{6 0})$ in $\mathrm{CDCl}_{3}$.

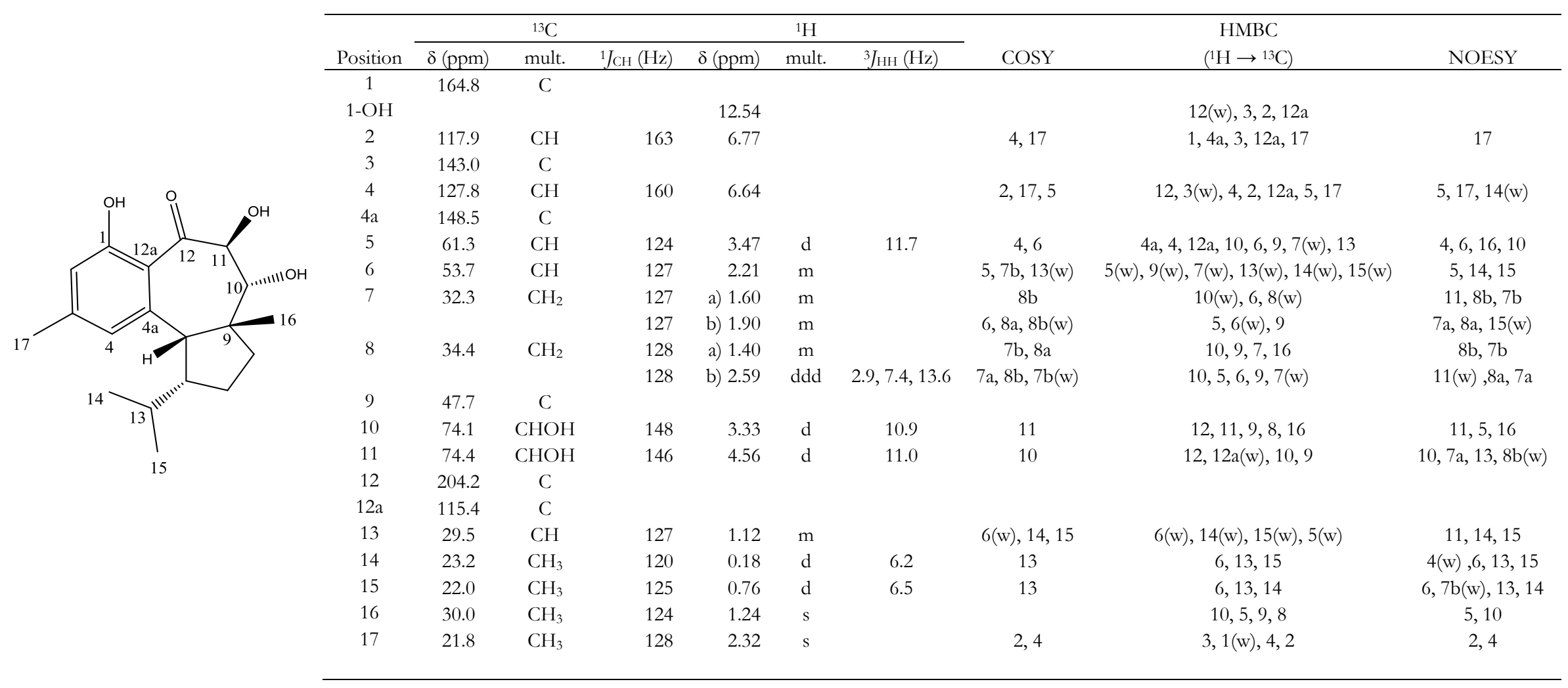




\subsection{Debromohamigeran J (62)}

Debromohamigeran J (62) was isolated as a colourless film. HRESIMS revealed a formula of $\mathrm{C}_{20} \mathrm{H}_{26} \mathrm{O}_{5}(\Delta=+2.8 \mathrm{ppm})$ from a $\left[\mathrm{M}+\mathrm{NH}_{4}\right]^{+}$adduct ion of $m / z 364.2118$. Analysis of ${ }^{13} \mathrm{C}$ and ${ }^{1} \mathrm{H}$ NMR spectra coupled with HSQC revealed 12 of the 20 carbons were attached to 24 of the 26 protons. This included three alkyl methines $\left[\mathrm{CH}-5\left(\delta_{\mathrm{C}} 57.8, \delta_{\mathrm{H}} 3.42\right)\right.$; $\mathrm{CH}-6\left(\delta_{\mathrm{C}} 51.0, \delta_{\mathrm{H}} 2.18\right)$; $\left.\mathrm{CH}-12\left(\delta_{\mathrm{C}} 27.1, \delta_{\mathrm{H}} 1.29\right)\right]$, two methylenes $\left[\mathrm{CH}_{2}-8\left(\delta_{\mathrm{C}} 35.1, \delta_{\mathrm{H}} 2.59,1.45\right) ; \mathrm{CH}_{2-7}\left(\delta_{\mathrm{C}} 26.3, \delta_{\mathrm{H}}\right.\right.$ $1.67,1.70)]$ and four methyls $\left[\mathrm{CH}_{3}-12\left(\delta_{\mathrm{C}} 27.1, \delta_{\mathrm{H}} 1.29\right) ; \mathrm{CH}_{3}-13\left(\delta_{\mathrm{C}} 23.2, \delta_{\mathrm{H}} 0.45\right) ; \mathrm{CH}_{3}-16\left(\delta_{\mathrm{C}}\right.\right.$ $\left.\left.21.4, \delta_{\mathrm{H}} 2.31\right) ; \mathrm{CH}_{3}-14\left(\delta_{\mathrm{C}} 19.3, \delta_{\mathrm{H}} 0.46\right)\right]$ and a methoxy $\left[\mathrm{CH}_{3}-18\left(\delta_{\mathrm{C}} 53.6, \delta_{\mathrm{H}} 3.72\right)\right]$. The remaining carbons were assigned as six olefinic sp ${ }^{2}$ carbons [C-1 ( $\left.\delta_{C} 156.0\right)$; C-3 ( $\left.\delta_{C} 140.4\right)$; C-4a $\left(\delta_{\mathrm{C}} 136.4\right) ; \mathrm{CH}-4\left(\delta_{\mathrm{C}} 123.6, \delta_{\mathrm{H}} 6.65\right)$; C-11a $\left.\left(\delta_{\mathrm{C}} 118.0\right) \mathrm{CH}-2\left(\delta_{\mathrm{C}} 116.3, \delta_{\mathrm{H}} 6.68\right)\right]$, two carbonyls [C-10 ( $\left.\delta_{C} 209.2\right) ;$ C-17 $\left.\left(\delta_{C} 169.9\right)\right]$ and two quaternary carbons [C-11 $\left(\delta_{C} 78.1\right)$; C-9 $\left.\left(\delta_{C} 54.7\right)\right]$. The remaining two protons were assigned to hydroxyls with broad singlets observed in the ${ }^{1} \mathrm{H}$ NMR spectrum $\left[1-\mathrm{OH}\left(\delta_{\mathrm{H}} 6.86\right) ; 11-\mathrm{OH}\left(\delta_{\mathrm{H}} 5.09\right)\right]$. The molecular formula indicated eight degrees of saturation which could be accounted for by two carbonyls, six olefinics and a tricyclic structure.

Like the previous compounds the structure of debromohamigeran J (62) was solved from COSY and HMBC correlations. Substructures 1, 2 and 3 were the same as the previous two compounds except that in substructure 1, no HMBC correlation was detected from the phenol to C-11 (Figure 3.12). Instead a weak HMBC correlation from $\mathrm{CH}-4$ was used to assign the position of the quaternary carbon $\mathrm{C}-11\left(\delta_{\mathrm{C}} 78.1\right)$, explaining the phenolic proton's more upfield shift compared to the previous described hamigerans due to a lack of hydrogen bonding. These substructures were assembled together using the same HMBC and COSY correlations as before (Figure 3.13), establishing the bonds from $\mathrm{CH}-5$ to $\mathrm{CH}-6$ and $\mathrm{CH}-6$ to $\mathrm{CH}-12$ along with cyclopentyl ring identified though $\mathrm{HMBC}$ correlations from the isolated methyl $\mathrm{CH}_{3}-15$ to $\mathrm{CH}-5$ 
and $\mathrm{CH}_{2}-8$. The methyls remaining $\mathrm{HMBC}$ correlation established a connection to the carbonyl C-10.
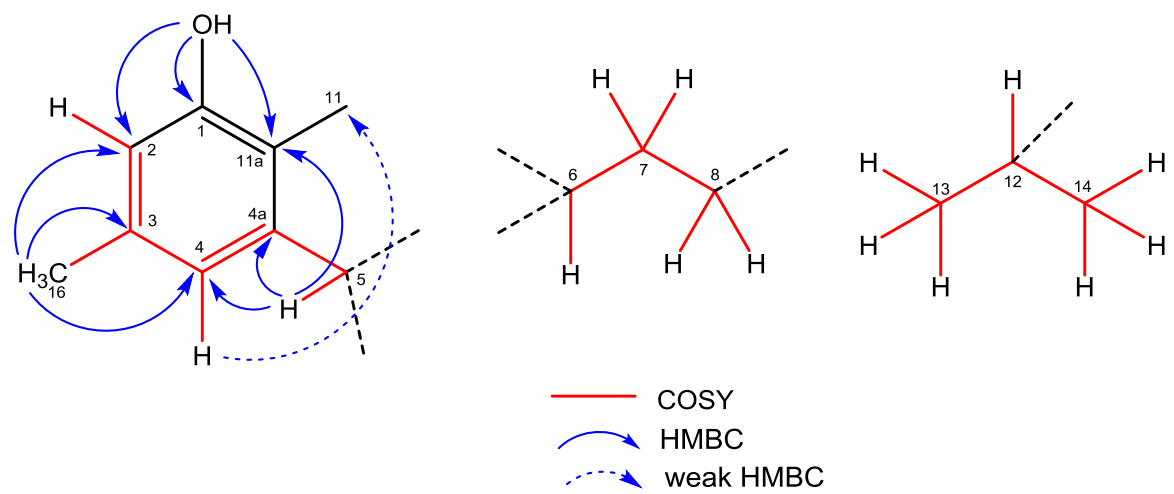

Figure 3.12. Key HMBC and COSY correlations of substructures 1, 2 and 3 of debromohamigeran J (62).

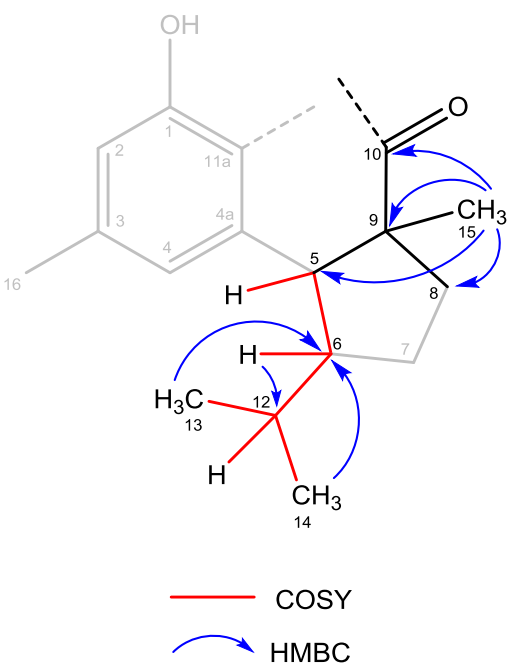

Figure 3.13. Key HMBC and COSY correlations connecting the three substructures and forming the cyclopentyl ring of debromohamigeran J (62).

The remaining atoms still to be assigned were carbonyl C-17, a hydroxyl and methoxy C-18. The hydroxyl 11-OH provided a weak HMBC correlation to its attachment point, the quaternary carbon C-11, along with weak HMBC correlations to C-10 and C-11a establishing the final ring of the tricyclic structure (Figure 3.14). $\mathrm{CH}_{3}-18$ was identified to be part of a methyl ester from a HMBC correlation to the carbonyl $\mathrm{C}-17$. The final bond of $\mathrm{C}-11$ was determined to be to the 
carbonyl C-17 based on both their carbon chemical shifts and in accordance with the molecular formula. This completed the planar structure (Figure 3.15) of debromohamigeran J (62), the third debrominated analogue of a known hamigeran.

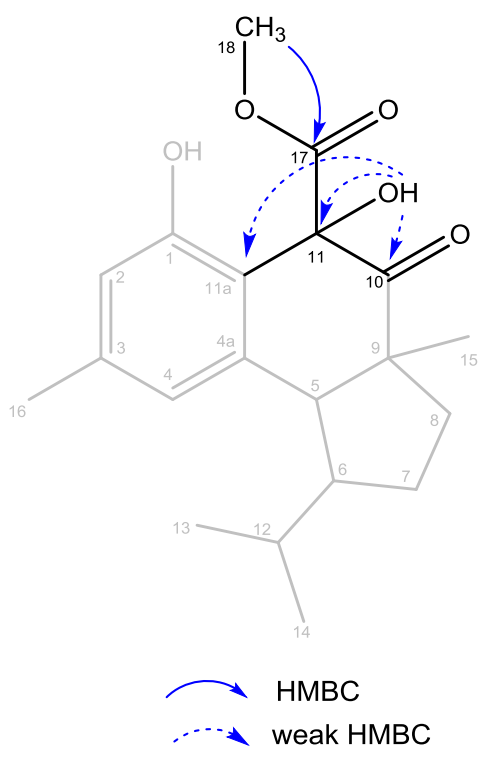

Figure 3.14. Key HMBC correlations from 11-OH and $\mathrm{CH}_{3}-18$ of debromohamigeran J (62).

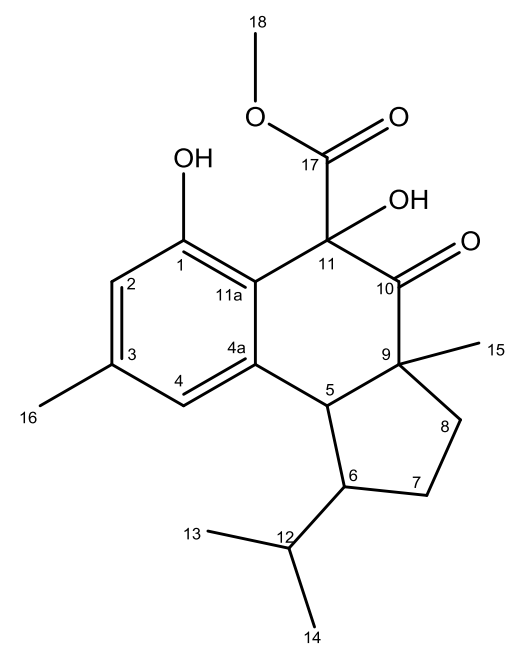

Figure 3.15. Completed planar structure of debromohamigeran J (62).

Debromohamigeran J (62) has four stereogenic centres (Figure 3.16). NOE correlations between CH-5, CH- 6 and $\mathrm{CH}_{3}-15$ established the typical cis-fusion between the $\mathrm{B}$ and $\mathrm{C}$ rings along with the isopropyl tail sitting below the $\mathrm{C}$ ring. A NOE correlation between $\mathrm{CH}_{3}-15$ and $\mathrm{CH}_{3}-18$ 
identified that the methyl ester was on the same side as the ring junction methyl $\mathrm{CH}_{3}-15$, therefore placing the hydroxyl of $\mathrm{C}-11$ below the $\mathrm{B}$ ring. This is in agreement with the NOE correlations seen for the brominated analogue, hamigeran J (44). Assuming the same absolute configuration, as the other hamigerans, the configuration of debromohamigeran $J(62)$ is $5 R, 6 R$, $9 \mathrm{R}, 11 \mathrm{~S}$. The optical rotation data gave a rotation of the same sign as the hamigeran $\mathrm{J}(\mathbf{4 4}) .^{48}$

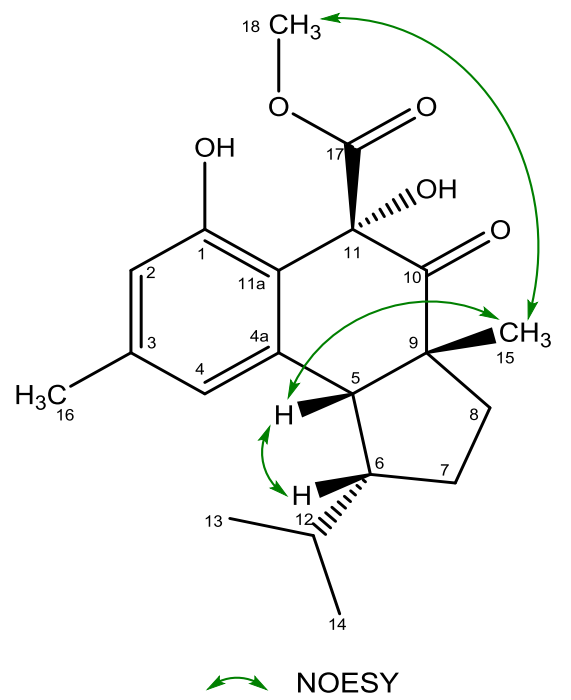

Figure 3.16. Key NOE correlations for debromohamigeran J (62). 
Table 3.4. NMR data $(600 \mathrm{MHz})$ of debromohamigeran $\mathrm{J}(\mathbf{6 2})$ in $\mathrm{CDCl}_{3}$.

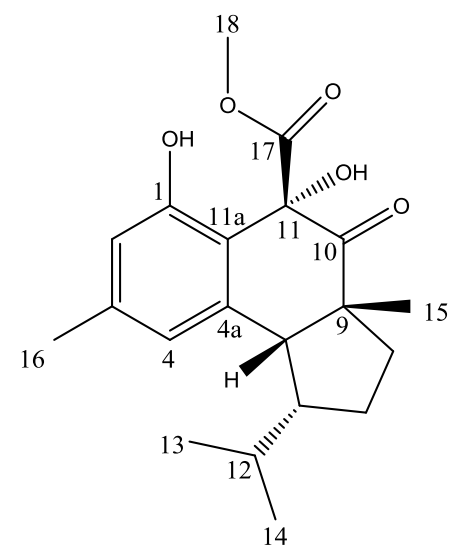

\begin{tabular}{|c|c|c|c|c|c|c|c|c|c|}
\hline \multirow[b]{2}{*}{ Position } & \multicolumn{3}{|c|}{${ }^{13} \mathrm{C}$} & \multicolumn{3}{|c|}{${ }^{1} \mathrm{H}$} & \multirow{2}{*}{\multicolumn{2}{|c|}{$\begin{array}{c}\mathrm{HMBC} \\
\left({ }^{1} \mathrm{H} \rightarrow{ }^{13} \mathrm{C}\right)\end{array}$}} & \multirow[b]{2}{*}{ NOESY } \\
\hline & $\delta(\mathrm{ppm})$ & mult. & ${ }^{1} J_{\mathrm{CH}}(\mathrm{Hz})$ & $\delta(\mathrm{ppm})$ & mult. & $3 J_{\mathrm{HH}}(\mathrm{Hz})$ & & & \\
\hline 1 & 156.0 & $\mathrm{C}$ & & & & & & & \\
\hline 1-OH & & & & 6.86 & brs & & & $1,2,11 \mathrm{a}$ & \\
\hline 2 & 116.3 & $\mathrm{CH}$ & 158 & 6.68 & $\mathrm{~s}$ & & 4,17 & $1,4,11 \mathrm{a}, 16$ & 16 \\
\hline 3 & 140.4 & $\mathrm{C}$ & & & & & & & \\
\hline 4 & 123.6 & $\mathrm{CH}$ & 159 & 6.65 & s & & $4,17,5(w)$ & $1,3,4 a, 11 a, 2,11(w), 5,16$ & $5,16,6(\mathrm{w}), 12$ \\
\hline $4 a$ & 136.4 & C & & & & & & & \\
\hline 5 & 57.8 & $\mathrm{CH}$ & 130 & 3.42 & $\mathrm{~d}$ & 9.1 & $4(w), 6$ & $10,4 a, 4,11 a, 9,6,12,7$ & $4,6,7,15$ \\
\hline 6 & 51.0 & $\mathrm{CH}$ & 132 & 2.18 & $\mathrm{~m}$ & & $5,12(\mathrm{w}), 7 \mathrm{a}$ & $5,9,8,12,7,13,14$ & $4(\mathrm{w}), 5,7,15,12,13,14$ \\
\hline \multirow[t]{2}{*}{7} & 26.3 & $\mathrm{CH}_{2}$ & 130 & a) 1.67 & $\mathrm{~m}$ & & $6,8 \mathrm{~b}, 7 \mathrm{~b}$ & $5,9,6,8,12$ & $5,8 \mathrm{a}, 6$ \\
\hline & & & & b) 1.70 & $\mathrm{~m}$ & & $8 \mathrm{a}, 8 \mathrm{~b}, 7 \mathrm{a}$ & $5,9,6,8,12$ & $5,6,8 \mathrm{~b}, 14$ \\
\hline \multirow[t]{2}{*}{8} & 35.1 & $\mathrm{CH}_{2}$ & 129 & a) 2.59 & $\mathrm{dt}$ & $7.2,13.1$ & $7 \mathrm{~b}, 8 \mathrm{~b}$ & $10,5,9,6,7$ & $7 \mathrm{a}, 8 \mathrm{a}, 15,14$ \\
\hline & & & & b) 1.45 & $\mathrm{~m}$ & & $7 \mathrm{a}, 7 \mathrm{~b}, 8 \mathrm{a}$ & $10,9,6$ & $8 b, 7 b$ \\
\hline 9 & 54.7 & $\mathrm{C}$ & & & & & & & \\
\hline 10 & 209.2 & C & & & & & & & \\
\hline 11 & 78.1 & $\mathrm{C}$ & & & & & & & \\
\hline $11-\mathrm{OH}$ & & & & 5.09 & brs & & & $10(\mathrm{w}), 11 \mathrm{a}(\mathrm{w}), 11(\mathrm{w})$ & \\
\hline $11 \mathrm{a}$ & 118.0 & $\mathrm{C}$ & & & & & & & \\
\hline 12 & 27.1 & $\mathrm{CH}$ & 125 & 1.29 & s & & $6(w), 13,14$ & $5,6,7,13,14$ & $4,6,13,14$ \\
\hline 13 & 23.2 & $\mathrm{CH}_{3}$ & 123 & 0.45 & $\mathrm{~m}$ & & 12 & $6,12,14$ & 6,14 \\
\hline 14 & 19.3 & $\mathrm{CH}_{3}$ & 124 & 0.46 & $\mathrm{~d}$ & 6.8 & 12 & $6,12,13$ & $8 a, 7 b, 13$ \\
\hline 15 & 26.1 & $\mathrm{CH}_{3}$ & 128 & 1.34 & $\mathrm{~d}$ & 6.8 & & $10,5,9,8$ & $18,5,8 \mathrm{a}, 6$ \\
\hline 16 & 21.4 & $\mathrm{CH}_{3}$ & 126 & 2.31 & s & & & $3,4,2$ & $2,4,18(w)$ \\
\hline 17 & 169.9 & $\mathrm{C}$ & & & & & & & \\
\hline 18 & 53.6 & $\mathrm{CH}_{3}$ & 149 & 3.72 & s & & & 17 & $16(w), 15$ \\
\hline
\end{tabular}




\subsection{Hamigeran L 12-O-methyl ester (63)}

Hamigeran L 12-O-methyl ester (63) was isolated as a colourless film. HRESIMS analysis established a molecular formula of $\mathrm{C}_{20} \mathrm{H}_{25} \mathrm{O}_{5} \mathrm{Br}(\Delta=-0.77 \mathrm{ppm})$ from a $[\mathrm{M}+\mathrm{H}]^{+}$adduct ion formula of $m / z 427.111$. Evidence of a bromine came from the equally intense $[\mathrm{M}+2+\mathrm{H}]^{+}$peak. Analysis of ${ }^{13} \mathrm{C}$ and ${ }^{1} \mathrm{H}$ NMR spectra coupled with HSQC showed that 12 of the 20 carbon resonances were attached to 23 of the 25 protons. Overall the carbons were identified as three methines $\left[\mathrm{CH}-5\left(\delta_{\mathrm{C}} 53.8, \delta_{\mathrm{H}} 3.64\right)\right.$; CH-6 $\left(\delta_{\mathrm{C}} 50.6, \delta_{\mathrm{H}} 2.2\right)$; CH-13 $\left.\left(\delta_{\mathrm{C}} 30.1, \delta_{\mathrm{H}} 1.36\right)\right]$, three methylenes $\left[\mathrm{CH}_{2}-10\left(\delta_{\mathrm{C}} 43.2, \delta_{\mathrm{H}} 2.15,1.84\right) ; \mathrm{CH}_{2}-8\left(\delta_{\mathrm{C}} 36.3, \delta_{\mathrm{H}} 1.95,1.81\right) ; \mathrm{CH}_{2}-7\left(\delta_{\mathrm{C}} 29.6, \delta_{\mathrm{H}}\right.\right.$ $2.18,1.68)]$, four alkyl methyls $\left[\mathrm{CH}_{3}-16\left(\delta_{\mathrm{C}} 27.6, \delta_{\mathrm{H}} 1.27\right) ; \mathrm{CH}_{3}-17\left(\delta_{\mathrm{C}} 24.2, \delta_{\mathrm{H}} 2.42\right) ; \mathrm{CH}_{3}-15\left(\delta_{\mathrm{C}}\right.\right.$ 22.3, $\delta_{\mathrm{H}}$ 0.58); $\left.\mathrm{CH}_{3}-14\left(\delta_{\mathrm{C}} 21.8, \delta_{\mathrm{H}} 0.87\right)\right]$ and a methoxy $\left[\mathrm{CH}_{3}-18\left(\delta_{\mathrm{C}} 52.6, \delta_{\mathrm{H}} 3.96\right)\right]$. Also included were two carbonyls [C-11 $\left(\delta_{\mathrm{C}} 177.5\right)$; C-12 $\left.\left(\delta_{\mathrm{C}} 170.5\right)\right]$, six olefinic sp ${ }^{2}$ carbons [C-1 $\left(\delta_{\mathrm{C}}\right.$ $155.5) ; \mathrm{C}-3\left(\delta_{\mathrm{C}} 142.5\right) ; \mathrm{C}-4 \mathrm{a}\left(\delta_{\mathrm{C}} 141.5\right) ; \mathrm{CH}-4$ ( $\left.\left.\delta_{\mathrm{C}} 123.0, \delta_{\mathrm{H}} 6.54\right) ; \mathrm{C}-12 \mathrm{a}\left(\delta_{\mathrm{C}} 115.9\right) ; \mathrm{C}-2\left(\delta_{\mathrm{C}} 111.5\right)\right]$ and a quaternary carbon C-9 $\left(\delta_{C}\right.$ 46.1). The remaining two protons were identified as exchangeables, one as the phenol proton 1-OH $\left(\delta_{\mathrm{H}} 9.9\right)$, with the other not observed in the ${ }^{1} \mathrm{H}$ NMR spectrum. The molecular formula indicated seven degrees of unsaturation, five of which were identified as the two carbonyls and the six olefinic carbons suggesting the structure is bicyclic, different from the previous three tricyclic compounds.

Substructures 1, 2 and 3 were identified in the same way as previously with minor changes noted for substructure 1 (Figure 3.17). The phenol showed only weak HMBC correlations to C-1, C-2 and $\mathrm{C}-12 \mathrm{a}$ with a weak HMBC correlation from $\mathrm{CH}-4$ to the carbonyl C-12 used to identify the substituent attached to C-12a. No COSY correlation was observed from $\mathrm{CH}-5$ to $\mathrm{CH}-4$ with assignments identified from $\mathrm{HMBC}$ correlations instead. The carbon C-2 did not have a proton unlike the last three described structures, instead it was bonded to bromine like the more commonly isolated hamigerans with this supported by the ${ }^{13} \mathrm{C}$ chemical shift of $\mathrm{C}-2$ and $\mathrm{C}-1$. 


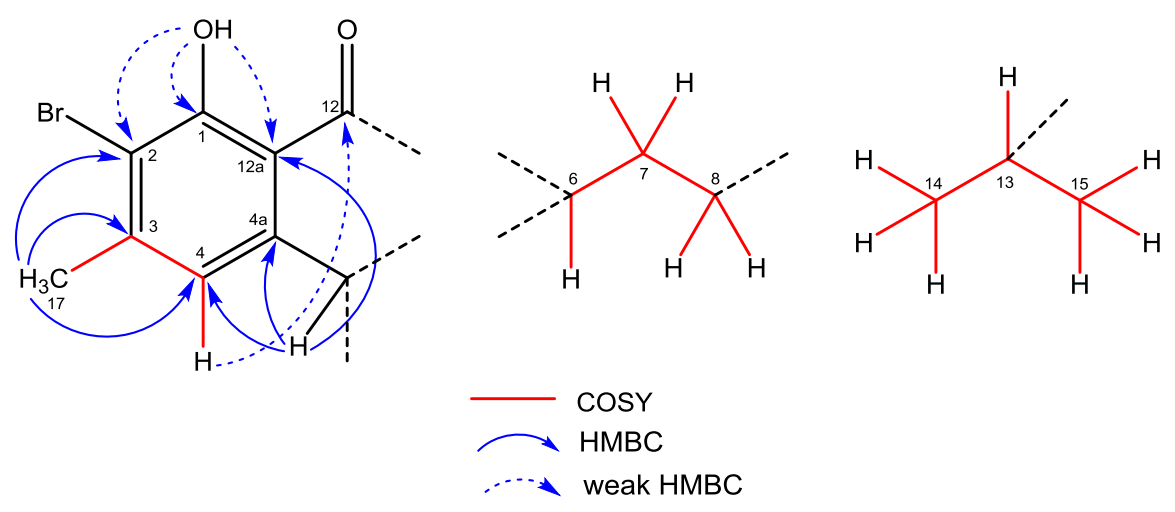

Figure 3.17. Substructures 1, 2 and 3 of hamigeran L 12- $O$-methyl ester (63).

The substructures along with the isolated methyl $\mathrm{CH}_{3}-16$ and the quaternary carbon C-9 were assembled together via the same bonds as before (Figure 3.18). HMBC and COSY correlations identified the bonds from $\mathrm{CH}-5$ to $\mathrm{CH}-6, \mathrm{CH}-6$ to $\mathrm{CH}-13$ and evidence of the cyclopentyl ring from the $\mathrm{CH}-5, \mathrm{C}-9$ and $\mathrm{CH}_{2}-8$ linkage. The remaining bond to $\mathrm{C}-9$ was identified as that to methylene $\mathrm{CH}_{2}-10$ by a $\mathrm{HMBC}$ correlation from $\mathrm{CH}_{3}-16$.

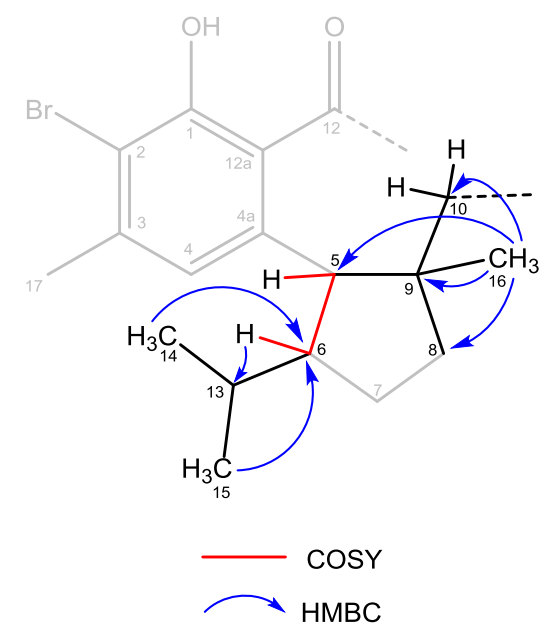

Figure 3.18. Key HMBC and COSY correlations connecting the three substructures and forming the cyclopentyl ring of hamigeran L 12-O-methyl ester (63).

The remaining atoms after these assignments were carbonyl C-11, methoxy $\mathrm{CH}_{3}-18$ and a hydroxyl. An $\mathrm{HMBC}$ correlation from $\mathrm{CH}_{3}-18$ to the carbonyl C-12 identified its connectivity as 
part of an ester. Evidence for the bond between the methylene $\mathrm{CH}_{2}-10$ and the carbonyl $\mathrm{C}-10$ was established by $\mathrm{HMBC}$ correlations from $\mathrm{CH}_{2}-10$ (Figure 3.19). Based on the ${ }^{13} \mathrm{C}$ chemical shift of carbonyl C-10 and the molecular formula it was determined the remaining hydroxyl was attached to C-11, as part of a carboxylic acid. With the molecular formula fully assigned and all bonds accounted for the planar structure was complete (Figure 3.20).

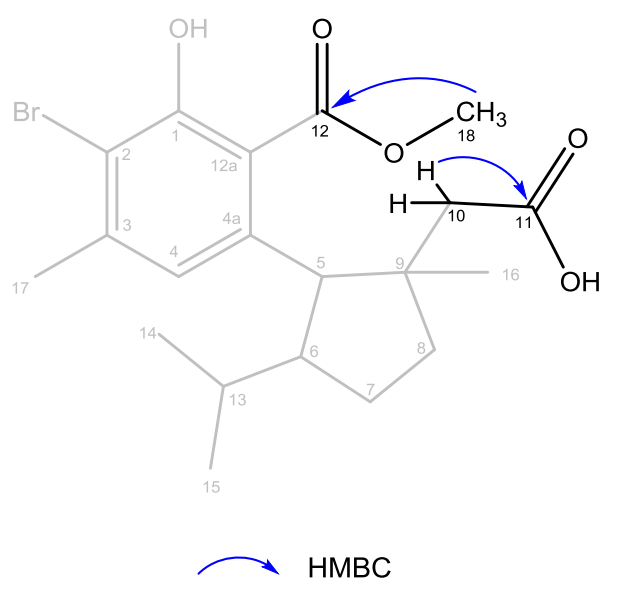

Figure 3.19. Key $\mathrm{HMBC}$ correlations of $\mathrm{CH}_{2}-10$ and $\mathrm{CH}_{3}-18$ for hamigeran L 12-O-methyl ester (63).

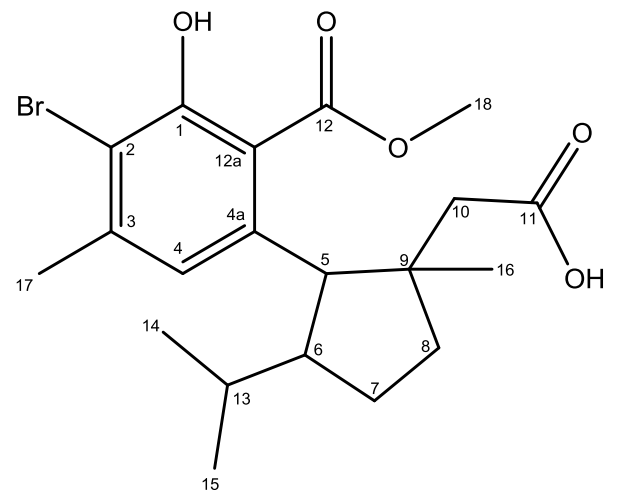

Figure 3.20. Completed planar structure of hamigeran L 12-O-methyl ester (63).

This new compound is a methyl ester analogue of the known hamigeran L (49) and is isomeric with hamigeran L 11-O-methyl ester (50). Only the standard three stereogenic centres were present in hamigeran L 12-O-methyl ester (63) with NOE correlations indicating the usual 
configurations for $\mathrm{CH}-5, \mathrm{CH}-6, \mathrm{CH}_{3}-16$ like the rest of the series, giving the absolute configuration of $5 R, 6 R, 9 R$ (Figure 3.21). The optical rotation data gave a rotation of the same sign and order as the hamigeran L (49) and hamigeran L 11-O-methyl ester (50). ${ }^{48}$

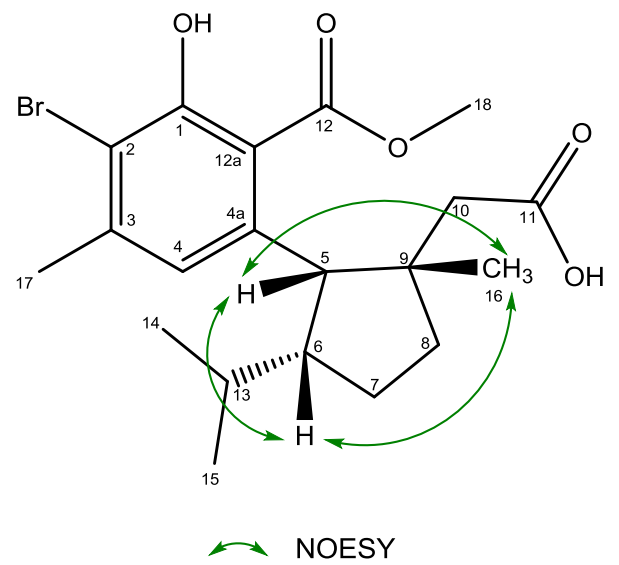

Figure 3.21. Key NOE correlations for hamigeran L 12-O-methyl ester (63). 
Table 3.5. NMR data $(600 \mathrm{MHz})$ of hamigeran L 12-O-methyl ester (63) in $\mathrm{CDCl}_{3}$.

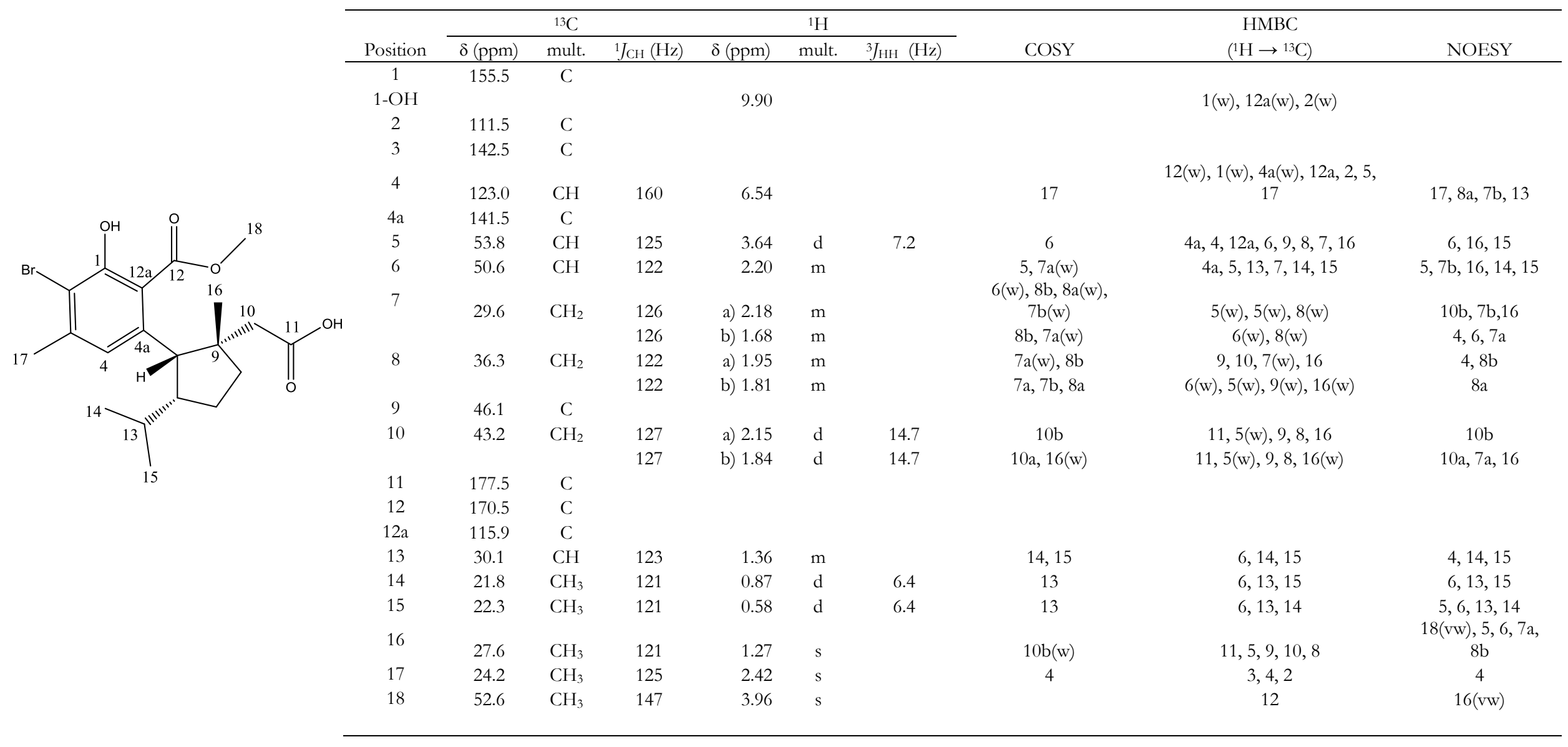




\subsection{4-Bromohamigeran A (64)}

4-bromohamigeran A (64) was isolated as a pale yellow film. HRESIMS analysis gave a $[\mathrm{M}+\mathrm{H}]^{+}$ adduct ion $m / ₹ 503.0063$ suitable for the formula $\mathrm{C}_{20} \mathrm{H}_{24} \mathrm{Br}_{2} \mathrm{O}_{4}(\Delta=-0.62 \mathrm{ppm})$. Evidence for a dibrominated compound came from a 1:2:1 ratio of the $[\mathrm{M}+\mathrm{H}]^{+},[\mathrm{M}+2+\mathrm{H}]^{+}$and $[\mathrm{M}+4+\mathrm{H}]^{+}$ peaks. Analysis of the ${ }^{1} \mathrm{H},{ }^{13} \mathrm{C}$ and HSQC NMR spectra revealed that 22 of the 24 protons were attached to ten of the 20 carbons. This included three methines [CH-5 ( $\left.\delta_{\mathrm{C}} 54.2, \delta_{\mathrm{H}} 3.82\right)$; $\mathrm{CH}-6$ $\left.\left(\delta_{\mathrm{C}} 47.6, \delta_{\mathrm{H}} 2.8\right) ; \mathrm{CH}-12\left(\delta_{\mathrm{C}} 27.7, \delta_{\mathrm{H}} 1.39\right)\right]$, two methlyenes $\left[\mathrm{CH}_{2}-8\left(\delta_{\mathrm{C}} 37.4, \delta_{\mathrm{H}} 1.69,1.49\right) ; \mathrm{CH}_{2^{-}}\right.$ $\left.7\left(\delta_{\mathrm{C}} 23.6, \delta_{\mathrm{H}} 1.81,1.57\right)\right]$ and four methyls $\left[\mathrm{CH}_{3}-16\left(\delta_{\mathrm{C}} 26.3, \delta_{\mathrm{H}} 2.75\right) ; \mathrm{CH}_{3}-14\left(\delta_{\mathrm{C}} 24.5, \delta_{\mathrm{H}} 0.78\right) ;\right.$ $\left.\mathrm{CH}_{3}-15\left(\delta_{\mathrm{C}} 23.6, \delta_{\mathrm{H}} 1.31\right) ; \mathrm{CH}_{3}-13\left(\delta_{\mathrm{C}} 16.7, \delta_{\mathrm{H}} 0.09\right)\right]$ and a methoxy $\left[\mathrm{CH}_{3}-18\left(\delta_{\mathrm{C}} 53.4, \delta_{\mathrm{H}} 3.59\right)\right]$. The other ten carbons were non-protonated centres, including two carbonyls [C-11 ( $\left.\delta_{\mathrm{C}} 197.9\right)$; C-17( $\left.\left.\delta_{C} 169.7\right)\right]$ six olefinic sp ${ }^{2}$ carbons [C-1 ( $\left.\delta_{C} 155.4\right)$; C-3 ( $\left.\delta_{C} 148.3\right)$; C-4a $\left(\delta_{C} 145.0\right)$; C-4 $\left.\left(\delta_{\mathrm{C}} 117.9\right) ; \mathrm{C}-11 \mathrm{a}\left(\delta_{\mathrm{C}} 114.9\right) ; \mathrm{C}-2\left(\delta_{\mathrm{C}} 111.0\right)\right]$ and two sp ${ }^{3}$ quaternary carbons [C-10 ( $\left.\delta_{\mathrm{C}} 85.3\right)$; C-9 $\left.\left.\delta_{\mathrm{C}} 47.6\right)\right]$. The other two protons were assigned as exchangeables $\left[1-\mathrm{OH}\left(\delta_{\mathrm{H}} 11.38\right) ; 10-\mathrm{OH}\left(\delta_{\mathrm{H}}\right.\right.$ 4.22)]. The molecular formular indicated eight degrees of unsaturation which could be accounted for from two carbonyls, six olefinics and a tricyclic structure.

The lack of aromatic proton resonances, two bromines and six non-protonated $\mathrm{sp}^{2}$ carbons suggested a fully substituted aromatic ring for substructure 1 with $\mathrm{H}-4$ replaced with a second bromine. This assignment was supported by the usual HMBC correlations from the three aromatic substituents, the proton from the phenol 1-OH, the aromatic methyl $\mathrm{CH}_{3}-16$ and the methine, CH-5. A weak HMBC correlation from 1-OH also identified C-11a was connected to the carbonyl C-11 (Figure 3.22). Substructures 2 and 3 remained unchanged and were connected together along with substructure 1 , the ring junction methyl $\mathrm{CH}_{3}-15$ and the quaternary carbon C-9 in the usual fashion (Figure 3.23). The remaining bond to C-9 was identified as the methylene carbon C-10 by an $\mathrm{HMBC}$ correlation from $\mathrm{CH}_{3}-15$. 


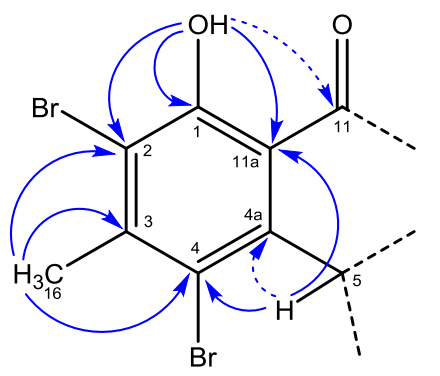<smiles>CCCC(C)C</smiles>

COSY

HMBC

.... weak HMBC<smiles>CCCC</smiles>

Figure 3.22. Key HMBC and COSY correlations establishing substructures 1, 2 and 3 of 4-bromohamigeran A (64).

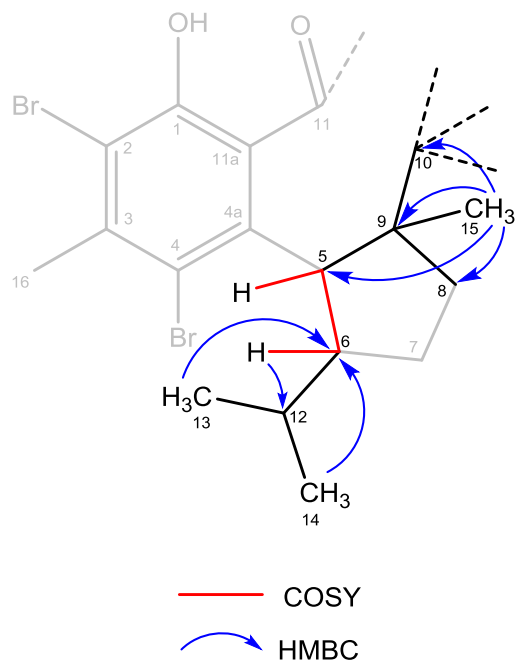

Figure 3.23. Key HMBC and COSY correlations connecting the substructures together and establishing the cyclopentyl ring of 4-bromohamigeran A (64).

The remaining atoms included a carbonyl, a methoxy and a hydroxyl. The hydroxyl had surprisingly strong $\mathrm{HMBC}$ correlations to its connection point $\mathrm{C}-10$, and to $\mathrm{C}-9$ and $\mathrm{C}-11$, establishing the final ring in the tricyclic structure (Figure 3.24). A weak HMBC correlation from 10-OH established the bond between C-10 and the carbonyl C-17 and an HMBC correlation from $\mathrm{CH}_{3}-18$ to $\mathrm{C}-17$ established it to be part of a methyl ester. With this, the planar structure was complete (Figure 3.25). 


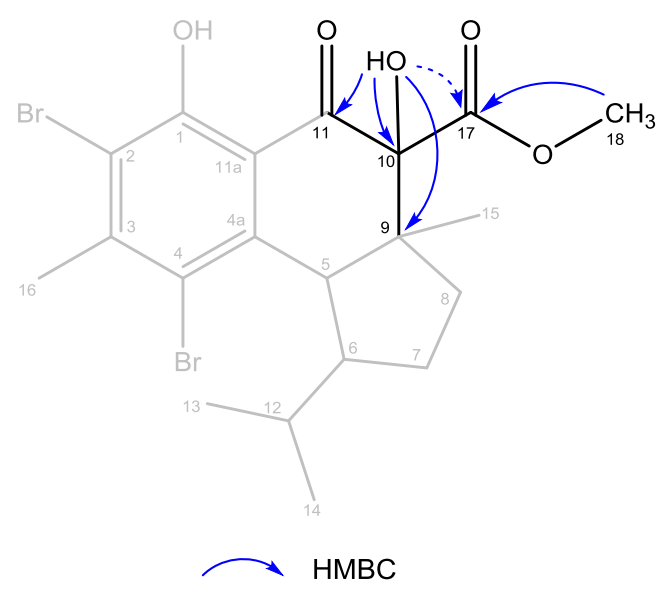

Figure 3.24. Key HMBC correlations for C-10 and C-18 of establishing the methyl ester of 4-bromohamigeran A (64).

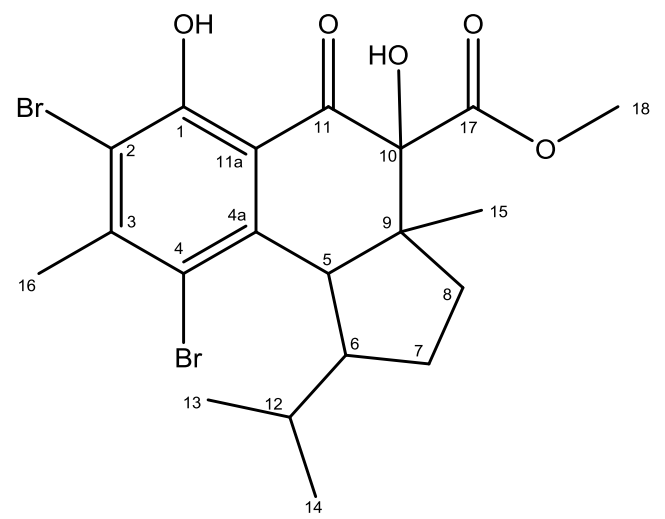

Figure 3.25. Completed planar structure of 4-bromohamigeran A (64).

NOE correlations between $\mathrm{CH}-5, \mathrm{CH}-6$ and $\mathrm{CH} 3-15$ confirmed the usual relative configuration of the stereogenic centres (Figure 3.26). A NOE correlation between $\mathrm{CH}_{3}-15$ and $\mathrm{CH}_{3}-18$ indicated the methyl ester was sitting above the ring with the hydroxyl below, consistent with the other 4-bromohamigerans (64), hamigeran A (28) and debromohamigeran A (29). This gives the absolute configuration as $5 S, 6 \mathrm{R}, 9 \mathrm{R}, 10 \mathrm{R}$. The optical rotation data gave a rotation of the same sign and order as the hamigeran A (28) and debromohamigeran A (29). 


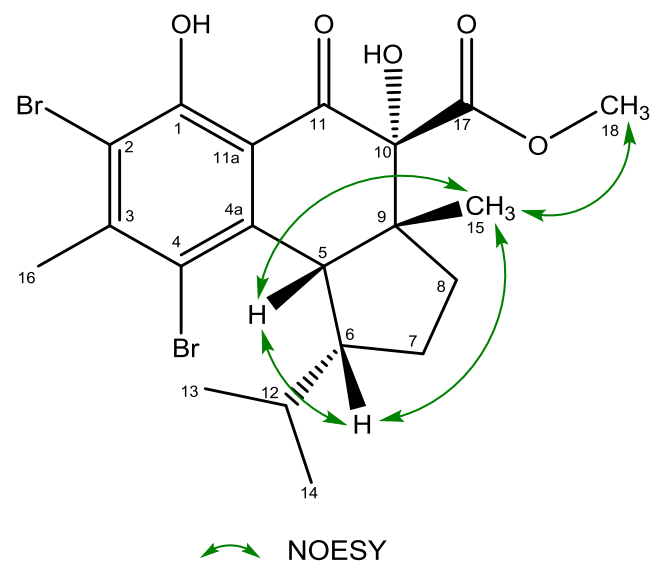

Figure 3.26. Key NOE correlations for 4-bromohamigeran A (64). 
Table 3.6. NMR data $(600 \mathrm{MHz})$ of 4-bromohamigeran $\mathrm{A}(64)$ in $\mathrm{CDCl}_{3}$.

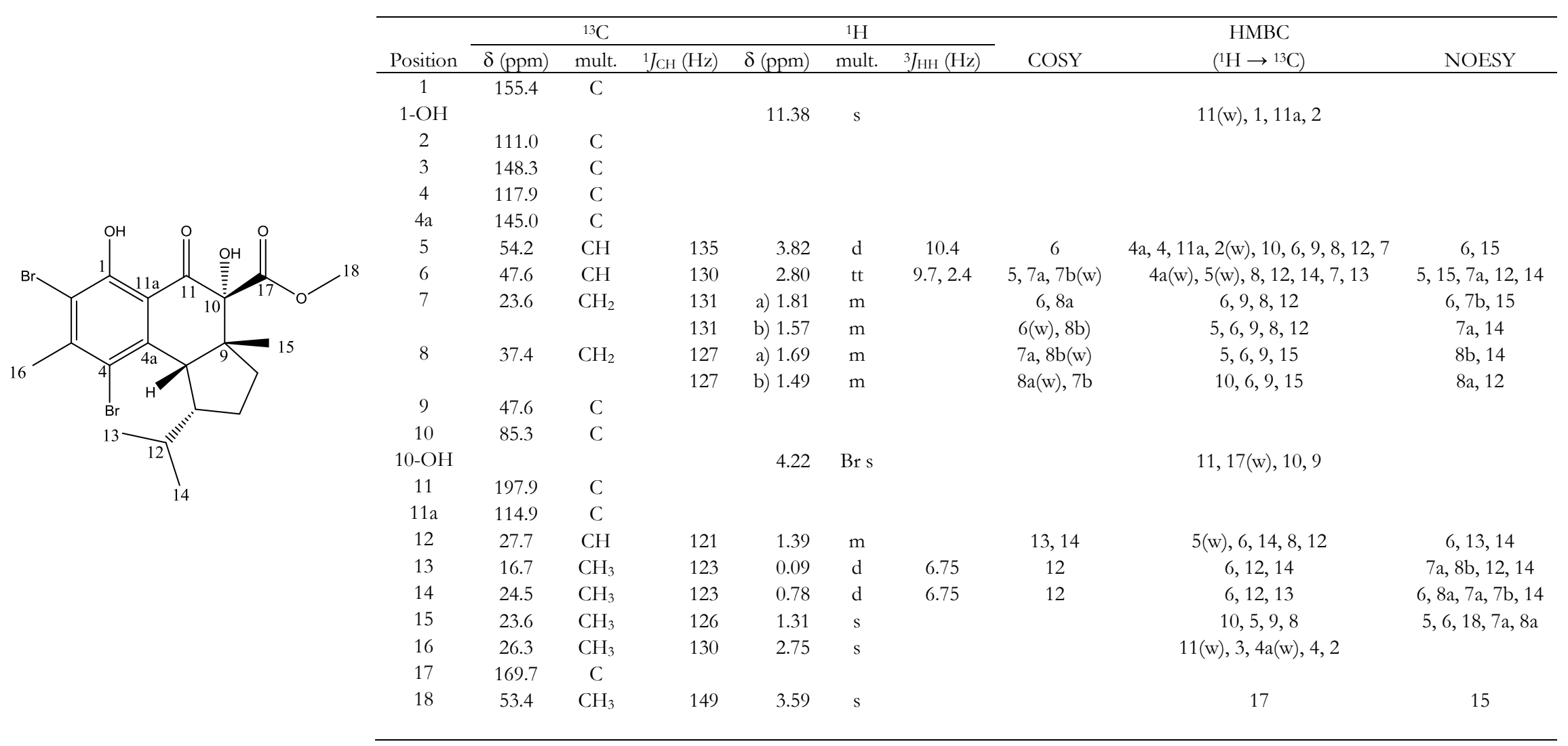




\section{Chapter 4: Novel Hamigerans from Hamigera tarangaensis}

\subsection{Hamigeran $\mathbf{R}(61)$}

Hamigeran R was isolated as a colourless film. Positive ion HRESIMS analysis of a $\left[\mathrm{M}+\mathrm{NH}_{4}\right]^{+}$ adduct ion at $m / z 411.1280$ indicated a molecular formula of $\mathrm{C}_{19} \mathrm{H}_{24} \mathrm{BrNO}_{3}(\Delta=+0.52)$. The presence of bromine was evident by a $\left[\mathrm{M}+2+\mathrm{NH}_{4}\right]^{+}$peak in a 1:1 ratio. At first it could not be determined if it was a $[\mathrm{M}+\mathrm{H}]^{+}$ion with a molecular formula of $\mathrm{C}_{19} \mathrm{H}_{27} \mathrm{BrN}_{2} \mathrm{O}_{3}$ or a $\left[\mathrm{M}+\mathrm{NH}_{4}\right]^{+}$ ion with a molecular formula of $\mathrm{C}_{19} \mathrm{H}_{24} \mathrm{BrNO}_{3}$ due to the same masses. To identify the correct molecular formula, negative ion HRESIMS analysis was required, which produced a $[\mathrm{M}-\mathrm{H}]^{-}$ adduct ion, $m / z 392.0874$ with a molecular formula $\mathrm{C}_{19} \mathrm{H}_{24} \mathrm{BrNO}_{3}(\Delta=-1.83 \mathrm{ppm})$ establishing that only one nitrogen was present in the compound. Analysis of ${ }^{13} \mathrm{C}$ and ${ }^{1} \mathrm{H}$ NMR with HSQC data identified 11 of the 19 carbon were attached to 22 of the 24 protons, the remaining two protons identified as exchangeable protons were not observed in the ${ }^{1} \mathrm{H}$ NMR spectrum. Overall these signals included four methyls $\left[\mathrm{CH}_{3}-16\left(\delta_{\mathrm{C}} 27.9, \delta_{\mathrm{H}} 1.34\right) ; \mathrm{CH}_{3}-17\left(\delta_{\mathrm{C}} 24.5, \delta_{\mathrm{H}} 2.45\right) ; \mathrm{CH}_{3}-14\right.$ $\left.\left(\delta_{\mathrm{C}} 22.2, \delta_{\mathrm{H}} 0.88\right) ; \mathrm{CH}_{3}-15\left(\delta_{\mathrm{C}} 22.1, \delta_{\mathrm{H}} 0.69\right)\right]$, three methylenes $\left[\mathrm{CH}_{2}-10\left(\delta_{\mathrm{C}} 43.3, \delta_{\mathrm{H}} 2.15,1.82\right) ;\right.$ $\left.\mathrm{CH}_{2}-8\left(\delta_{\mathrm{C}} 36.6, \delta_{\mathrm{H}} 1.81,1.87\right) ; \mathrm{CH}_{2}-7\left(\delta_{\mathrm{C}} 29.1, \delta_{\mathrm{H}} 1.67,1.84\right)\right]$, three methines [CH-5 $\left(\delta_{\mathrm{C}} 56.5, \delta_{\mathrm{H}}\right.$ 3.4); CH-6 ( $\left.\delta_{\mathrm{C}} 50.5, \delta_{\mathrm{H}} 2.31\right)$; $\mathrm{CH}-13\left(\delta_{\mathrm{C}} 30.4 \delta_{\mathrm{H}} 1.23\right)$ ], a carbonyl [C-11 ( $\left.\left.\delta_{\mathrm{C}} 176.9\right)\right]$, six sp ${ }^{2}$ olefinic carbons [C-1 ( $\left.\delta_{\mathrm{C}} 155.2\right)$; C-4a $\left(\delta_{\mathrm{C}} 145.2\right)$; C-3 $\left(\delta_{\mathrm{C}} 143.5\right)$; CH-4 $\left(\delta_{\mathrm{C}} 123.0, \delta_{\mathrm{H}} 6.62\right)$; C-2 ( $\delta_{\mathrm{C}}$ 111.1); $\left.\mathrm{C}-12 \mathrm{a}\left(\delta_{\mathrm{C}} 101.6\right)\right]$, an unusually shifted $\mathrm{C}-12\left(\delta_{\mathrm{C}} 115.3\right)$ and a quaternary sp ${ }^{3}$ carbon $[\mathrm{C}-9$ $\left.\left(\delta_{C} 46.5\right)\right]$. The molecular formula required eight degrees of unsaturation, four were identified as the carbonyl and the six olefinic carbons, with the remaining four unaccounted.

The aromatic ring of substructure 1 was monobrominated and identified in a similar fashion to the other monobrominated compound hamigeran L 12-O-methyl ester (63) with the exception of the phenol proton not being observed in the ${ }^{1} \mathrm{H}$ NMR spectrum (Figure 4.1). The sequence of 
C-2, C-1 and C-12a was instead identified by HMBC correlations from the aromatic methyl $\mathrm{CH}_{3}-$ 17 and $\mathrm{CH}-4$. The unusually shifted carbon $\mathrm{C}-12\left(\delta_{\mathrm{C}} 115.3\right)$ was established to be connected to C-12a by a weak HMBC from CH-4. Allylic COSY coupling was only observed between $\mathrm{CH}_{3}-17$ and $\mathrm{CH}-4$, not onto $\mathrm{CH}-5$ which is often suggestive of an open B ring hamigeran. Substructures 2 and 3 remained unchanged.
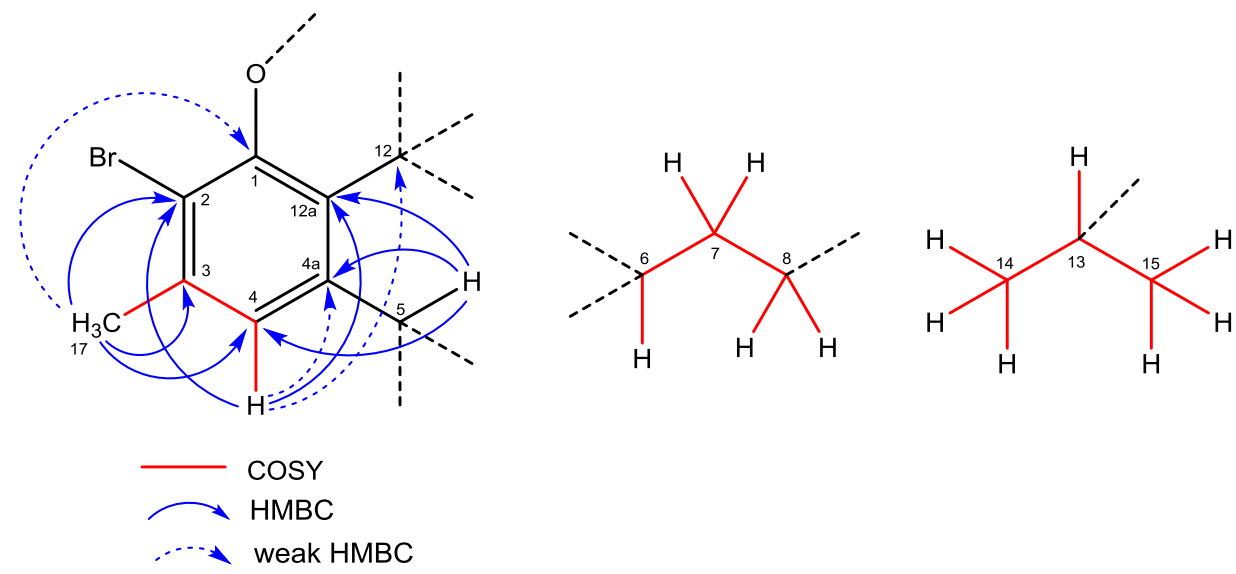

Figure 4.1. Key HMBC and COSY correlations establishing substructures 1, 2 and 3 of hamigeran R (61).

The three substructures were connected in the usual fashion with bonds of $\mathrm{CH}-5$ to $\mathrm{CH}-6$ and CH-6 to $\mathrm{CH}-13$ confirmed with COSY and HMBC correlations. The cyclopentyl ring was established though $\mathrm{HMBC}$ correlations from $\mathrm{CH}_{3}-16$ to $\mathrm{CH}-5, \mathrm{C}-9$ and $\mathrm{CH}_{2}-8$. The remaining HMBC correlation identified the methylene $\mathrm{CH}_{2}-10$ as the remaining carbon bonded to C-9. HMBC correlations from $\mathrm{CH}_{2}-10$ established its connectivity to carbonyl C-11 (Figure 4.2). 


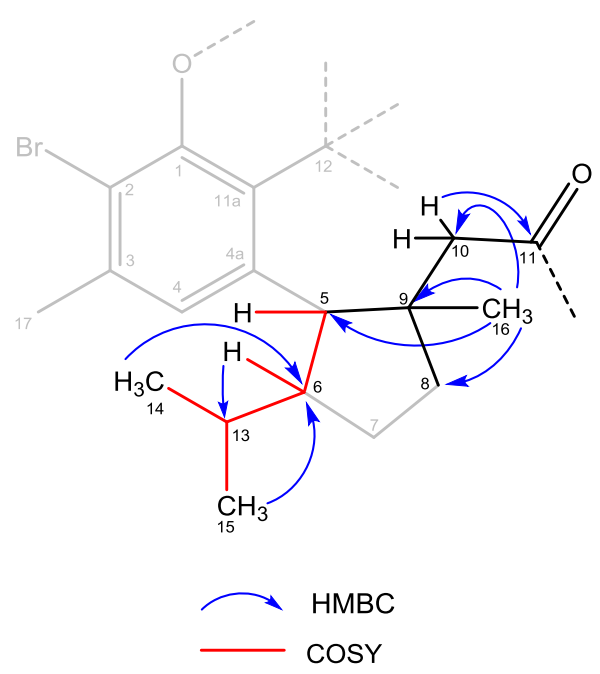

Figure 4.2. Key HMBC and COSY correlations connecting substructures 1, 2 and 3 together along with the junction methyl $\mathrm{CH}_{3}-16$ and $\mathrm{CH}_{2}-10$ of hamigeran $\mathrm{R}(\mathbf{6 1})$.

At this stage, all the atoms except for a nitrogen, an oxygen and two exchangeable protons were assigned. There were also two degrees of unsaturation unaccounted for. The ${ }^{13} \mathrm{C}$ chemical shift for C-12 ( $\left.\delta_{C} 115.3\right)$ suggested this compound was not like the other nitrogenous hamigerans $\left(\delta_{C} \sim 160.0\right)$ isolated previously. ${ }^{41,50}$ This shift and the remaining two degrees of freedom led to the possibility that this carbon and the nitrogen were a nitrile functionality. Comparing the ${ }^{13} \mathrm{C}$ aromatic shifts of hamigeran $\mathrm{R}(\mathbf{6 1})$ to benzonitrile and 2-hydroxybenzonitrile indicated that they have a high degree of similarity (Table 4.1). The presence of the nitrile able to explain the disruption to the electronic structure of the aromatic ring and the upfield shift of C-12a. 
Table 4.1. $\mathrm{NMR}{ }^{13} \mathrm{C}$ shift comparison of aromatic nitriles and hamigeran $\mathrm{R}(\mathbf{6 1})$ in $\mathrm{CDCl}_{3}$.

\begin{tabular}{|c|c|c|c|}
\hline position & hamigeran R (61) & 2-hydroxybenzonitrile & benzonitrile \\
\hline C-1 & 155.1 & 159.2 & 132.1 \\
\hline $\mathrm{C}-2$ & 111 & 116.7 & 129.2 \\
\hline C-3 & 143.4 & 134.9 & 132.8 \\
\hline C-4 & 123 & 120.8 & 129.2 \\
\hline C-4a & 145.3 & 133.1 & 132.1 \\
\hline C-12 & 115.3 & 116.7 & 118.8 \\
\hline C-12a & 101.5 & 99.3 & 112.4 \\
\hline & $\mathrm{Br}$ & & \\
\hline
\end{tabular}

Conclusive evidence of the nitrile came from of an IR spectrum. IR was first performed on several known compounds including hamigeran A (28) and hamigeran B (30) to gauge the spectrophotometers sensitivity, then on hamigeran L 11-O-methyl ester (50), as a close comparison to hamigeran $\mathrm{R}(\mathbf{6 1})$. The IR spectrum of hamigeran R (61) contained several peaks in common with the other hamigerans along with a small sharp peak at $2223 \mathrm{~cm}^{-1}$ (Figure 4.3 ). This peak is indicative of a carbon-nitrogen triple bond stretch, a very distinctive stretch not observed in any of the other hamigerans. The IR also revealed a broad peak at $3226 \mathrm{~cm}^{-1}$, typical of a hydroxyl stretch. This leads to the conclusion at least one hydroxyl is present in the compound.

The ${ }^{13} \mathrm{C}$ and ${ }^{1} \mathrm{H}$ shifts of $\mathrm{CH}_{2}-10$ and $\mathrm{C}-11$ of hamigeran $\mathrm{R}(\mathbf{6 1})$ are nearly identical to hamigeran L 12-O-methyl ester (63), which is part of a carboxylic acid at C-11. Alternatively hamigeran L 11-O-methyl ester (50) is part of an ester at C-11 and the chemical shifts are significantly different indicating that $\mathrm{C}-11$ for hamigeran $\mathrm{R}(\mathbf{6 1})$ is part of a carboxylic acid. The final proton could be assigned as part of the phenol 1-OH, its absence in the ${ }^{1} \mathrm{H}$ NMR due to lack of hydrogen bonding. With this finalised, the planar structure for hamigeran R (61) was complete (Figure 4.4). 


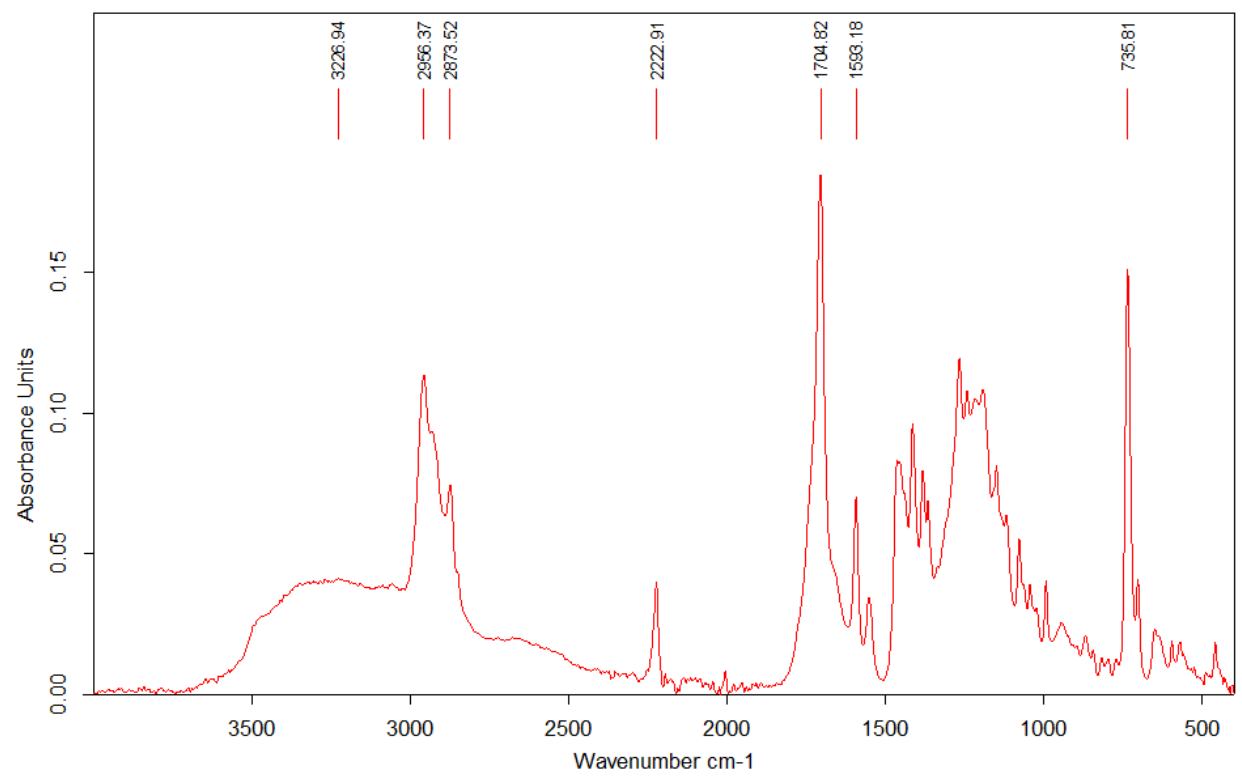

Figure 4.3. IR spectrum of hamigeran R (61).

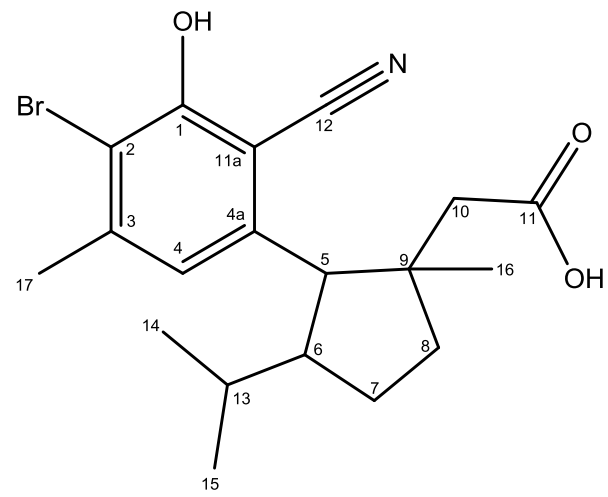

Figure 4.4. Completed planar structure of hamigeran R (61).

NOE correlations between $\mathrm{CH}-5, \mathrm{CH}-6$ and $\mathrm{CH}_{3}-16$ revealed the standard relative configuration in hamigeran $\mathrm{R}$ (61), like the rest of the hamigerans with the proposed absolute configuration being 5R, 6R, 9R (Figure 4.5) 


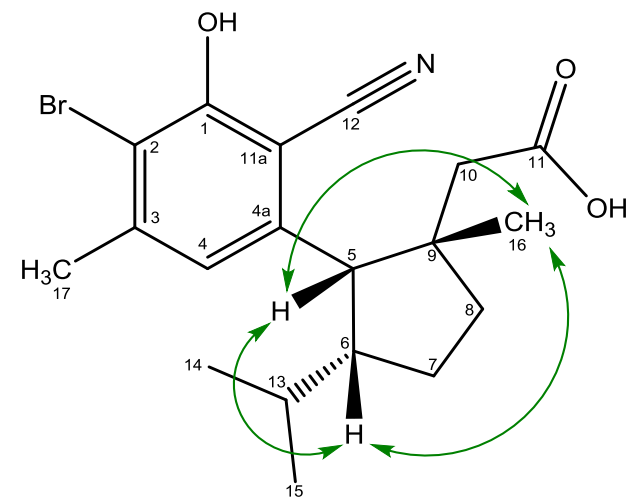

$\sim$ NOESY

Figure 4.5. Key NOE correlations establishing the relative configuration of hamigeran R (61). 
Table 4.2. NMR data (600 MHz) of hamigeran $\mathrm{R}(\mathbf{6 1})$ in $\mathrm{CDCl}_{3}$.

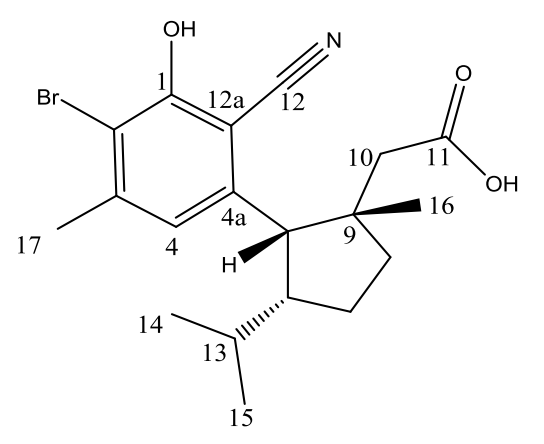

\begin{tabular}{|c|c|c|c|c|c|c|c|c|c|}
\hline \multirow[b]{2}{*}{ Position } & \multicolumn{3}{|c|}{${ }^{13} \mathrm{C}$} & \multicolumn{3}{|c|}{${ }^{1} \mathrm{H}$} & \multirow{2}{*}{\multicolumn{2}{|c|}{$\begin{array}{c}\text { HMBC } \\
\left({ }^{1} \mathrm{H} \rightarrow{ }^{13} \mathrm{C}\right)\end{array}$}} & \multirow[b]{2}{*}{ NOESY } \\
\hline & $\delta(\mathrm{ppm})$ & mult. & ${ }^{1} J_{\mathrm{CH}}(\mathrm{Hz})$ & $\delta(\mathrm{ppm})$ & mult. & $3 J_{\mathrm{HH}}(\mathrm{Hz})$ & & & \\
\hline 1 & 155.2 & $\mathrm{C}$ & & & & & & & \\
\hline 2 & 111.1 & $\mathrm{C}$ & & & & & & & \\
\hline 3 & 143.5 & $\mathrm{C}$ & & & & & & & \\
\hline 4 & 123.0 & $\mathrm{CH}$ & 161 & 6.62 & & & 17 & $1(\mathrm{w}), 4 \mathrm{a}(\mathrm{w}), 12(\mathrm{w}), 2,12 \mathrm{a}, 5,17$ & $17,8 \mathrm{~b}, 7 \mathrm{a}, 13$ \\
\hline $4 \mathrm{a}$ & 145.2 & $\mathrm{C}$ & & & & & & & \\
\hline 5 & 56.5 & $\mathrm{CH}$ & 131 & 3.40 & $\mathrm{~d}$ & 7 & 6 & $4 a, 4,12 a, 6,9,8,7,16$ & $6,10 \mathrm{a}(\mathrm{w}), 16,15$ \\
\hline 6 & 50.5 & $\mathrm{CH}$ & 125 & 2.31 & $\mathrm{~m}$ & & $5,7 \mathrm{a}(\mathrm{w}), 13(\mathrm{w})$ & $4 \mathrm{a}(\mathrm{w}), 5,13,7(\mathrm{w}), 14,15$ & $5,16,14,15$ \\
\hline \multirow[t]{2}{*}{7} & 29.1 & $\mathrm{CH}_{2}$ & 123 & a) 1.67 & $\mathrm{~m}$ & & $5(\mathrm{w}), 8 \mathrm{a}(\mathrm{w}), 7(\mathrm{~b})$ & $6,8,9,13$ & $4,10 \mathrm{a}, 14,8 \mathrm{~b}$ \\
\hline & & & 120 & b) 1.84 & $\mathrm{~m}$ & & $7 a)$ & $5,6,9,8,16$ & 16 \\
\hline \multirow[t]{2}{*}{8} & 36.6 & $\mathrm{CH}_{2}$ & 125 & a) 1.81 & $\mathrm{~m}$ & & $7 \mathrm{a}(\mathrm{w}), 8 \mathrm{~b}(\mathrm{w})$ & $5,6,9,7,16$ & $16,10 \mathrm{~b}, 8 \mathrm{~b}$ \\
\hline & & & 125 & b) 1.87 & $\mathrm{~m}$ & & $8 \mathrm{a}(\mathrm{w})$ & $6,9,7,16$ & $4,16,8 \mathrm{a}, 7 \mathrm{a}(\mathrm{w})$ \\
\hline 9 & 46.5 & $\mathrm{C}$ & & & & & & & \\
\hline \multirow[t]{2}{*}{10} & 43.3 & $\mathrm{CH}_{2}$ & 127 & a) 2.15 & $\mathrm{~d}$ & 14.4 & $10 \mathrm{a}$ & $11,5,9,8,16$ & $10 \mathrm{~b}, 7 \mathrm{a}, 16,14(\mathrm{w})$ \\
\hline & & & 127 & b) 1.82 & $\mathrm{~d}$ & 14.4 & $10 \mathrm{~b}$ & $11,5,6,9,8,16$ & $10 \mathrm{a}$ \\
\hline 11 & 176.9 & C & & & & & & & \\
\hline 12 & 115.3 & $\mathrm{C}$ & & & & & & & \\
\hline $12 \mathrm{a}$ & 101.6 & $\mathrm{C}$ & & & & & & & \\
\hline 13 & 30.4 & $\mathrm{CH}$ & 126 & 1.23 & $\mathrm{~m}$ & & $6(w), 14,15$ & $5,6,14,15,7$ & $4,7 \mathrm{a}(\mathrm{w}), 14,15$ \\
\hline 14 & 22.2 & $\mathrm{CH}_{3}$ & 124 & 0.88 & $\mathrm{~d}$ & 6.5 & 13 & $6,13,15$ & $6,10 a(w), 7 a, 13$ \\
\hline 15 & 22.1 & $\mathrm{CH}_{3}$ & 124 & 0.69 & $\mathrm{~d}$ & 6.5 & 13 & $6,13,14$ & $5,6,13$ \\
\hline 16 & 27.9 & $\mathrm{CH}_{3}$ & 127 & 1.34 & $\mathrm{~s}$ & & & $5,9,10,8$ & $5,6,8 \mathrm{~b}, 10 \mathrm{a}$ \\
\hline 17 & 24.5 & $\mathrm{CH}_{3}$ & 129 & 2.45 & s & & 4 & $1(\mathrm{w}), 3,4,2,12 \mathrm{a}(\mathrm{w})$ & 4 \\
\hline
\end{tabular}




\subsection{Hamigeran S (65)}

Hamigeran S (66) was isolated as a faintly yellow film. The positive ion HRESIMS analysis showed two ions, a $[\mathrm{M}+\mathrm{H}]^{+}$adduct ion at $m / z 738.1788$ and half as abundant, a $[\mathrm{M}+\mathrm{Na}]^{+}$ adduction at $m / z 798.1812$ indicating a molecular formula of either $\mathrm{C}_{38} \mathrm{H}_{45} \mathrm{Br}_{2} \mathrm{NO}_{4}(\Delta=-1.64$ ppm) or $\mathrm{C}_{38} \mathrm{H}_{49} \mathrm{Br}_{2} \mathrm{NO}_{6}(\Delta=-1.22 \mathrm{ppm})$. Two bromines were evident from the 1:2:1 ratio of both masses $[\mathrm{M}+\mathrm{H}]^{+},[\mathrm{M}+2+\mathrm{H}]^{+}$and $[\mathrm{M}+4+\mathrm{H}]^{+}$peaks (or $\mathrm{Na}^{+}$for the higher mass). Neither mass was observed in negative ion mode.

Analysis of the ${ }^{1} \mathrm{H}$ and ${ }^{13} \mathrm{C}$ NMR data with the use of multiplicity-edited HSQC NMR spectra revealed 19 carbon signals, with 11 of the carbons connected to 22 protons, far short of either of the molecular formula given by the HRESIMS. Overall three methines [CH-5 $\left(\delta_{\mathrm{C}} 49.7, \delta_{\mathrm{H}} 3.34\right)$; CH-6 ( $\left.\delta_{\mathrm{C}} 49.7, \delta_{\mathrm{H}} 2.14\right)$; CH-13 $\left.\left(\delta_{\mathrm{C}} 28.5, \delta_{\mathrm{H}} 2.01\right)\right]$, three methylenes $\left[\mathrm{CH}_{2}-10\left(\delta_{\mathrm{C}} 51.1, \delta_{\mathrm{H}} 2.13\right.\right.$, 2.38); $\left.\mathrm{CH}_{2}-8\left(\delta_{\mathrm{C}} 36.6, \delta_{\mathrm{H}} 1.48,1.58\right) ; \mathrm{CH}_{2}-7\left(\delta_{\mathrm{C}} 27.1, \delta_{\mathrm{H}} 1.84,2.02\right)\right]$ and four methyls $\left[\mathrm{CH}_{3}-16\left(\delta_{\mathrm{C}}\right.\right.$ $\left.\left.25.9, \delta_{\mathrm{C}} 1.14\right) ; \mathrm{CH}_{3}-17\left(\delta_{\mathrm{C}} 23.5, \delta_{\mathrm{H}} 2.31\right) ; \mathrm{CH}_{3}-14\left(\delta_{\mathrm{C}} 23.0, \delta_{\mathrm{H}} 0.49\right) ; \mathrm{CH}_{3}-15\left(\delta_{\mathrm{C}} 22.9, \delta_{\mathrm{H}} 0.91\right)\right]$, a carbonyl C-11 ( $\left.\delta_{\mathrm{C}} 199.9\right)$, six olefinic sp ${ }^{2}$ [C-1 ( $\left.\delta_{\mathrm{C}} 149.8\right)$; C-3 ( $\left.\delta_{\mathrm{C}} 139.9\right)$; C-4a $\left(\delta_{\mathrm{C}} 138.1\right)$; CH-4 $\left.\left(\delta_{\mathrm{C}} 122.5, \delta_{\mathrm{H}} 6.91\right) ; \mathrm{C}-12 \mathrm{a}\left(\delta_{\mathrm{C}} 118.6\right) ; \mathrm{C}-2\left(\delta_{\mathrm{C}} 110.8\right)\right]$ and two sp ${ }^{3}$ quaternary carbons [C-12 ( $\delta_{\mathrm{C}}$ 83.8); C-9 ( $\left.\left.\delta_{C} 44.5\right)\right]$ were detected. Four degrees of unsaturation were initially identified, three from the six olefinic carbons and one from the carbonyl. This mismatch between NMR spectra and the HRESIMS formula was perplexing. It is not unusual for compounds to form unusual adducts during HRESIMS including additional water molecules or dimerization. NMR analysis therefore became critical in confirming if hamigeran S (66) was truly a dimer or a species generated in situ in the HRESIMS. 
Like the previous compound, substructure 1 contained a monobrominated aromatic ring with no phenolic proton present in the ${ }^{1} \mathrm{H}$ NMR spectra (Figure 4.6). HMBC correlations from $\mathrm{CH}_{3}-17$, $\mathrm{CH}-4$ and $\mathrm{CH}-5$ were used to identify the aromatic ring and its substituents including the quaternary carbon $\mathrm{C}-12$. Substructures 2 and 3 remained the same and the three substructures were assembled together in the typical fashion seen in the previous six compounds (Figure 4.7). HMBC correlations from the methyl $\mathrm{CH}_{3}-16$ were used to identify the cyclopentyl ring and the bond between C-9 and the methylene $\mathrm{CH}_{2}-10$. Unusually there was $\mathrm{W}$ coupling detected between $\mathrm{CH}_{3}-16$ and one of the protons of $\mathrm{CH}_{2}-10(10 \mathrm{~b})$ in the COSY spectrum. This coupling is not usually observed because of the flexibility of the seven carbon B ring, suggesting there was some conformational restriction in this case. $\mathrm{HMBC}$ correlations from $\mathrm{CH}-10 \mathrm{~b}$ identified the connection to the carbonyl C-11 and the carbonyls connection to the quaternary carbon C-12, establishing the seven carbon B ring and completing a tricyclic structure.

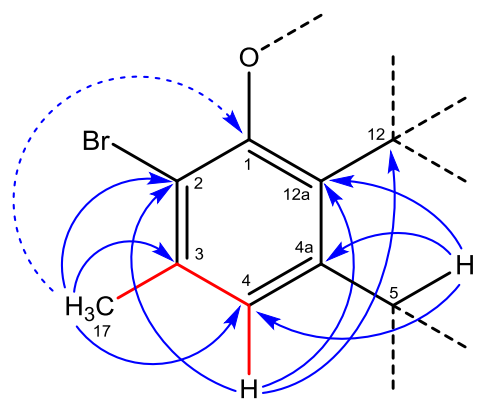

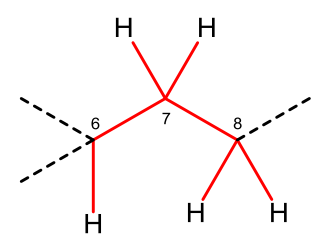

cosY

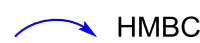

... weak HMBC

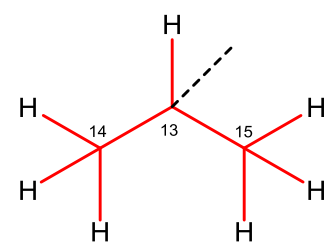

Figure 4.6. Key HMBC and COSY correlations establishing substructures 1, 2 and 3 of hamigeran S (65). 


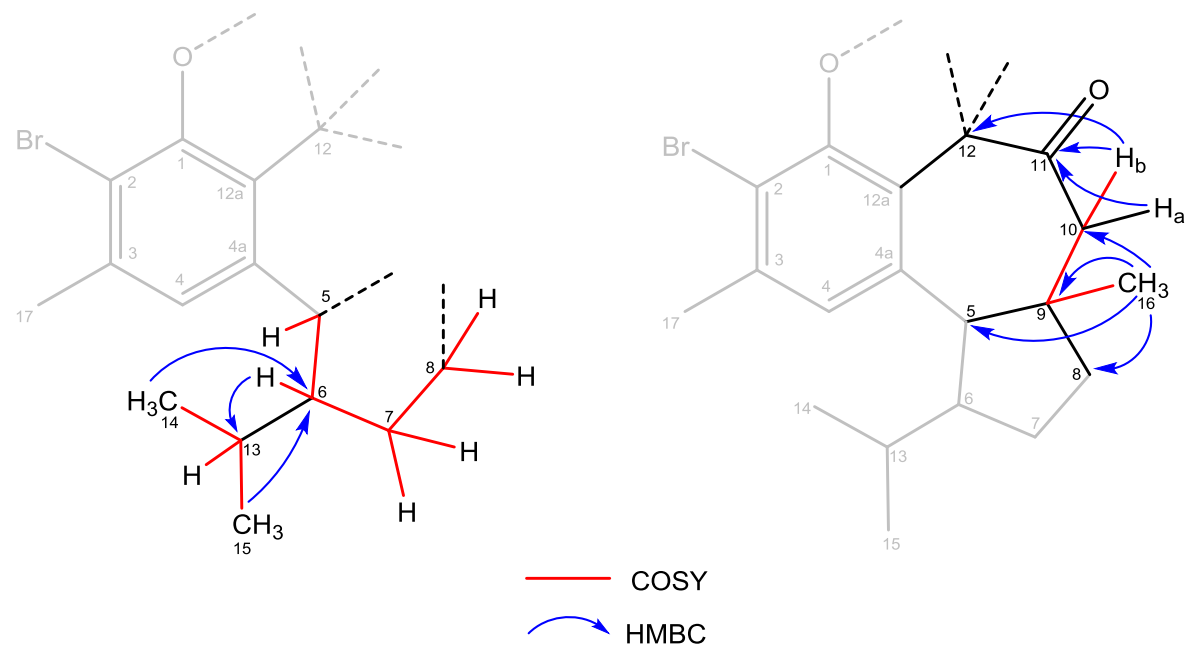

Figure 4.7. Key HMBC and COSY correlations connecting the substructures together, forming the cyclopentyl ring and B ring of hamigeran S (65).

The remaining two unassigned bond equivalents from carbon C-12 and one bond equivalent to the oxygen attached to $\mathrm{C}-1$ could not be identified from the standard NMR experiments in $\mathrm{CDCl}_{3}$. To identify whether either of these sites had exchangeable protons, a drop of a 1:1 $\mathrm{H}_{2} \mathrm{O} / \mathrm{D}_{2} \mathrm{O}$ was added to a NMR tube of hamigeran $\mathrm{S}(\mathbf{6 5})$ in $\mathrm{CDCl}_{3}$. This showed what appeared to be a splitting or broadening of carbons nearby exchangeable protons in the ${ }^{13} \mathrm{C}$ NMR spectrum. This splitting is due to the deuterium isotope effect on the chemical shift, with half of the exchangeable protons switched with deuterium, resulting in two peaks at half the height it was previously. It was expected that C-1 would show this splitting from the phenol 1-OH, with smaller splitting for C-2 and C-12a. However a splitting of C-12, with minor splitting for C-12a and C-11 was instead observed. This evidence suggested there was no exchangeable proton on the oxygen attached to C-1, but instead an exchangeable on a heteroatom attached to C-12.

The addition of the drop of $\mathrm{H}_{2} \mathrm{O} / \mathrm{D}_{2} \mathrm{O}$ also resulted in a new peak appearing in the ${ }^{1} \mathrm{H}$ NMR spectrum as a broad singlet $\left(\delta_{\mathrm{H}} 3.06\right)$. Integration of the peak showed it was a quarter the size of a proton from the remainder of hamigeran $\mathrm{S}(\mathbf{6 6})$. When this was repeated with a drop of $\mathrm{H}_{2} \mathrm{O}$ the peak integrated for half a relative proton. A rationale to this observed phenomenon would be that this exchangeable proton is in the centre of a $C_{2}$ symmetric dimer, with all the other protons 
doubled. To follow up this line of reasoning, an IR spectrum was obtained revealing a small single peak at $3300 \mathrm{~cm}^{-1}$, which matches the $\mathrm{N}-\mathrm{H}$ stretch of a secondary amine, typically of one band between $3350-3310 \mathrm{~cm}^{-1}$ (Figure 4.8). No broad OH stretching was present, supporting the results of the $\mathrm{H}_{2} \mathrm{O} / \mathrm{D}_{2} \mathrm{O}$ experiment which suggested the presence of only one exchangeable proton. The nitrogen, with its proton would be at the centre of the dimer, explaining why it can be singular in a $\mathrm{C}_{2}$ symmetric dimer.

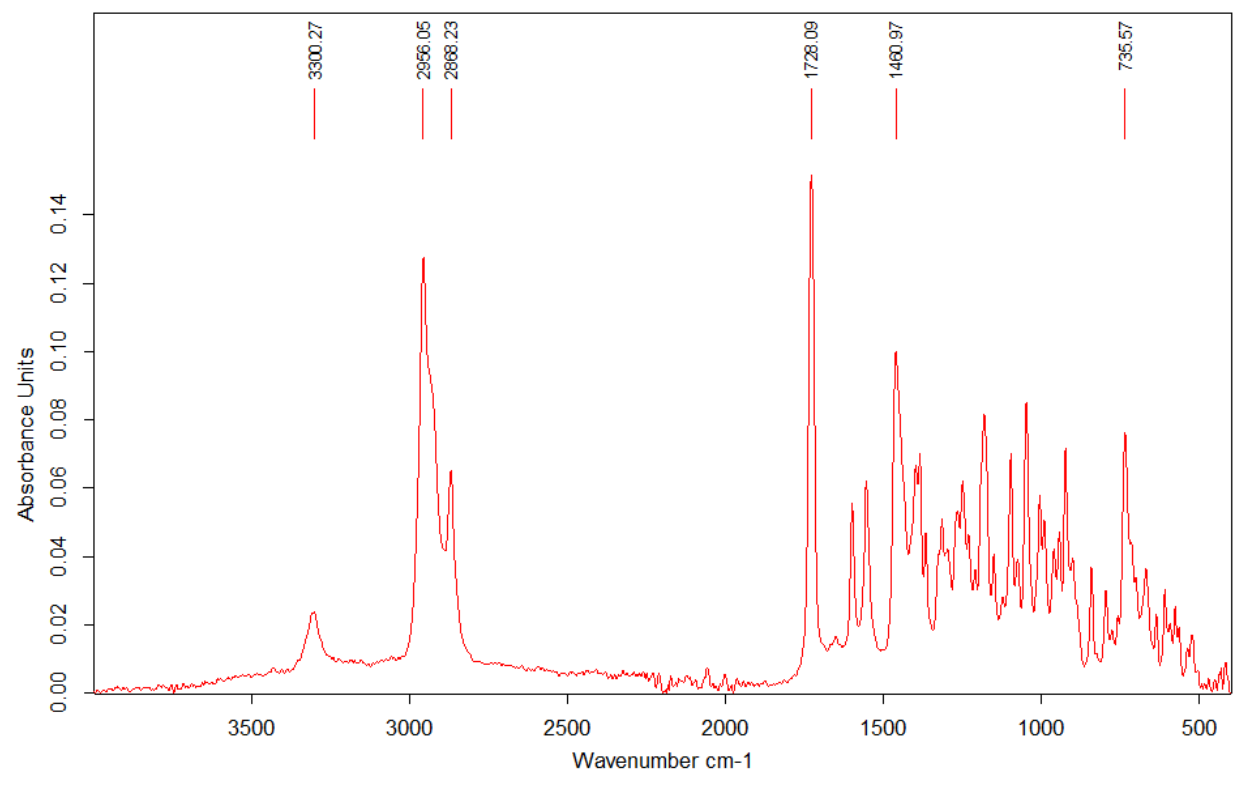

Figure 4.8. IR spectrum of hamigeran S (65).

As a final technique to prove the presence of an $\mathrm{N}-\mathrm{H}$ in hamigeran $\mathrm{S}$, the NMR spectra were rerun in DMSO-d6. This time, the $\mathrm{N}-\mathrm{H}$ proton was observable without added $\mathrm{H}_{2} \mathrm{O}$, integrating for half a relative proton as expected. ${ }^{15} \mathrm{~N}$ HSQC and HMBC data were also collected. A strong correlation with HSQC between the nitrogen and the exchangeable proton [12-NH $\left(\delta_{\mathrm{N}}-317.9\right.$, $\delta_{\mathrm{H}}$ 5.46)] confirmed their connectivity. HMBC correlations from exchangeable proton $11-\mathrm{NH}$ to C-11, C-12a and C-4a confirmed their connectivity to the rest of the carbon skeleton, placing them in the centre of the dimer (Figure 4.9). 


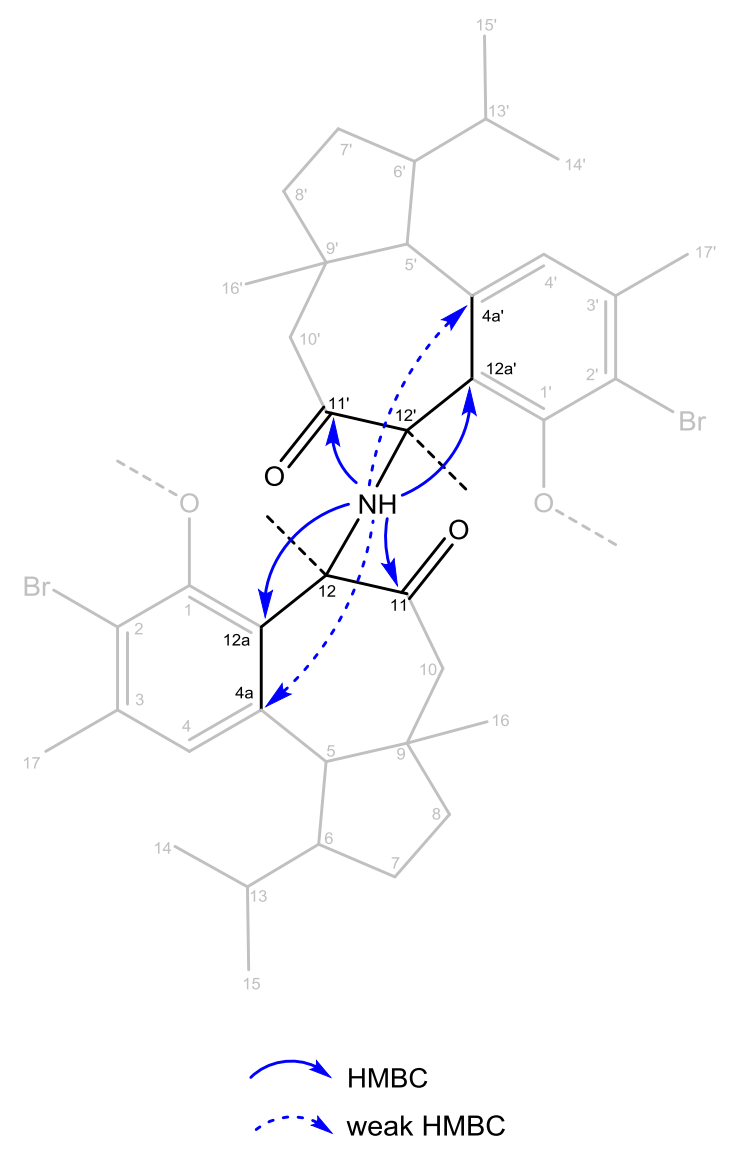

Figure 4.9. Key HMBC correlations for N-H of hamigeran S (65).

Only two bonds remained unaccounted for in each half of the dimer, from the oxygen attached to $\mathrm{C}-1$ and a bond at C-12. Three possible dimer structures could be proposed at this point for the connectivity of these bonds, but two could be eliminated from contradicting evidence leaving just one correct solution (Figure 4.10). The structure 65a matched the higher ion mass given by the HRESIMS, $[\mathrm{M}+\mathrm{Na}]^{+}$ion $m / ₹ 798.1812$ with the formula $\mathrm{C}_{38} \mathrm{H}_{49} \mathrm{Br}_{2} \mathrm{NO}_{6}$ but did not match the NMR data for the 1:1 $\mathrm{H}_{2} \mathrm{O} / \mathrm{D}_{2} \mathrm{O}$ experiment or the DMSO experiment which determined that there is only one exchangeable proton was present under NMR conditions. The IR also suggested that no hydroxyls are present under standard conditions. It is possible that this structure may exist under HRESIMS conditions.

The structure $65 \mathrm{~b}$ could also be eliminated, it has $\sigma_{\mathrm{h}}$ symmetry but this would require an inversion of configuration of the three stereogenic centres $\mathrm{CH}-5, \mathrm{CH}-6$ and $\mathrm{C}-9$ on one half of 
the molecule. This was thought of as extremely unlikely with all hamigerans found to date retaining the configuration of these centres. It also appears that it would contain $\mathrm{C}_{2}$ Symmetry but this is only when drawn planar. A 3D model would place the aminal ring perpendicular to the rest of the structure, destroying any rotation symmetry. Furthermore the four membered aminal ring, while not impossible, would also be quite strained and not favoured.

This left the structure $\mathbf{6 5} \mathbf{c}$ which matched the molecular formula of the lower mass given by the HRESIMS $[\mathrm{M}+\mathrm{H}]^{+}$ion at $m / z 738.1788, \mathrm{C}_{38} \mathrm{H}_{45} \mathrm{Br}_{2} \mathrm{NO}_{4}$, was consistent with the $1: 1 \mathrm{H}_{2} \mathrm{O} / \mathrm{D}_{2} \mathrm{O}$ experimental results, the IR and was $\mathrm{C}_{2}$ symmetric (though a $180^{\circ}$ rotation though the $\mathrm{N}-\mathrm{H}$ bond). A literature search revealed a synthesis of several dioxocin and dithiocin, aminal containing dimers including a dinaphthol compound with comparable carbon shifts to hamigeran S (65) (Table 4.3). ${ }^{51}$ The main difference in shifts results from the dioxocin having a tertiary carbon instead of quaternary bonded to the aminal. With the correct bonding identified, the planar structure of hamigeran S (65) was complete (Figure 4.11) and establishing the first hamigeran dimer ever found. 


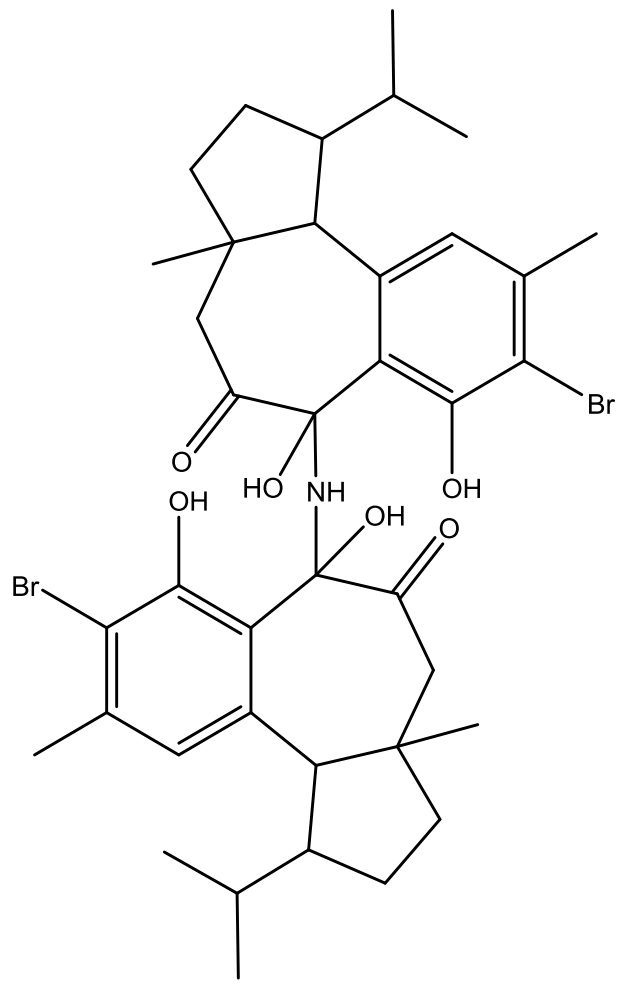

$65 a$
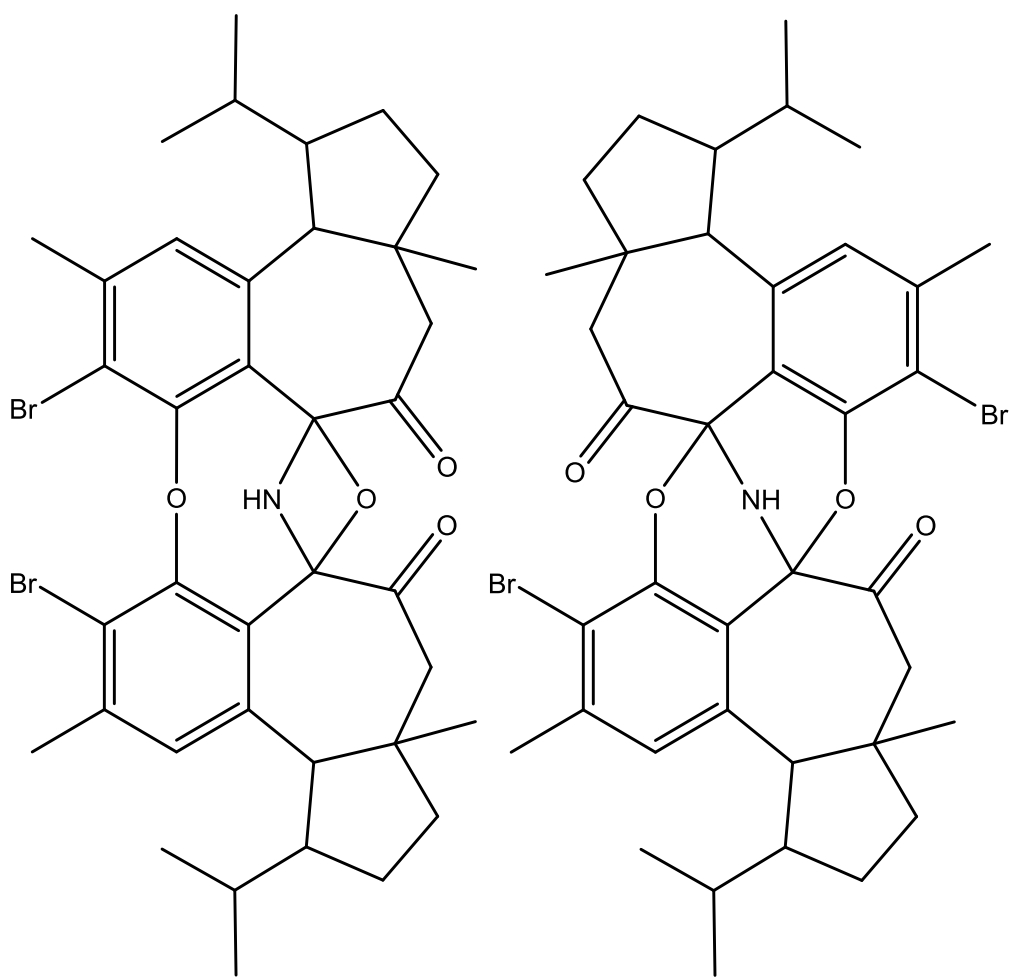

$65 b$

$65 c$

Figure 4.10. Possible planar structures for hamigeran S (65).

Table 4.3. $\mathrm{NMR}{ }^{13} \mathrm{C}$ shift comparison of aminals in $\mathrm{CDCl}_{3}$.

\begin{tabular}{c|c|c} 
position & hamigeran S (66) & 8,16-Imino-dinaphthol-1-5-dioxocin \\
\hline \hline $\mathbf{C}-1$ & 149.3 & 150.3 \\
\hline $\mathbf{C - 1 2}$ & 83.2 & \\
\hline C-12a & 117.4 &
\end{tabular}




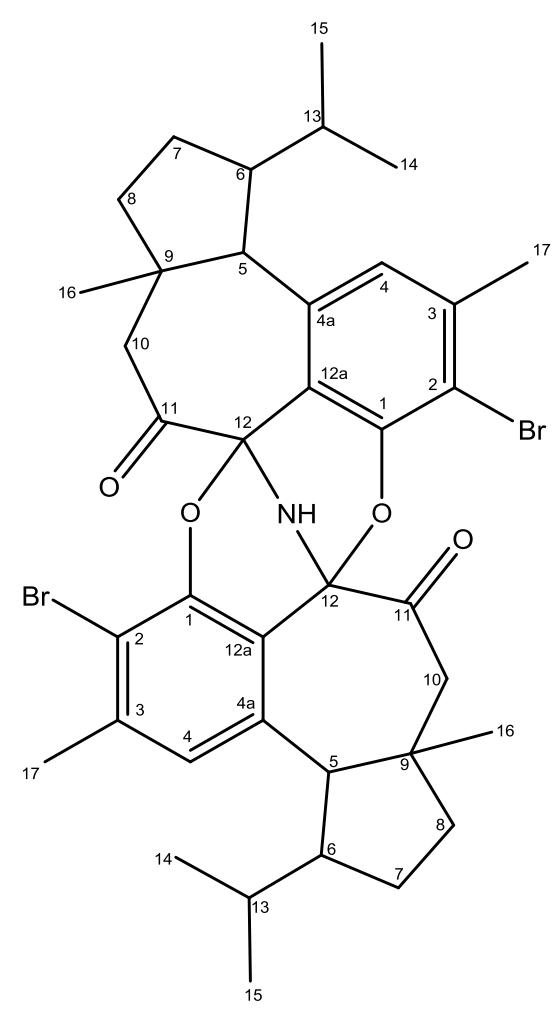

Figure 4.11. Completed planar structure of hamigeran S (65).

NOE correlations were used to determine the relative configuration of hamigeran $S$ as in all the previous hamigerans (Figure 4.12). NOE correlations showed the protons of $\mathrm{CH}-5, \mathrm{CH}-6$ and $\mathrm{CH}_{3}-16$ were all on the same side of the compound, giving the typical cis-fused $\mathrm{B}$ and $\mathrm{C}$ rings with the isopropyl tail sitting below the ring. Furthermore $\mathrm{CH}-5$ and $\mathrm{CH}_{3}-16$ showed NOE correlations to the proton $\mathrm{H}-10 \mathrm{a}$, placing it on the same side of the molecule as these centres. This assignment was confirmed COSY data mentioned before which placed H-10b on the opposite face to $\mathrm{H}_{3}-16$ from W coupling. $\mathrm{H}-10 \mathrm{~b}$ showed a weak NOE correlation to the N-H while H-10a did not. Peaks in the 1D ROESY supported these correlations indicating that the 12-NH sits below the ring. The absolute configuration of the eight stereogenic centres in hamigeran $S$ is therefore proposed to be $5 R, 6 R, 9 R, 12 R, 5^{\prime} R, 6{ }^{\prime} R, 9^{\prime} R, 12^{\prime} R$. 


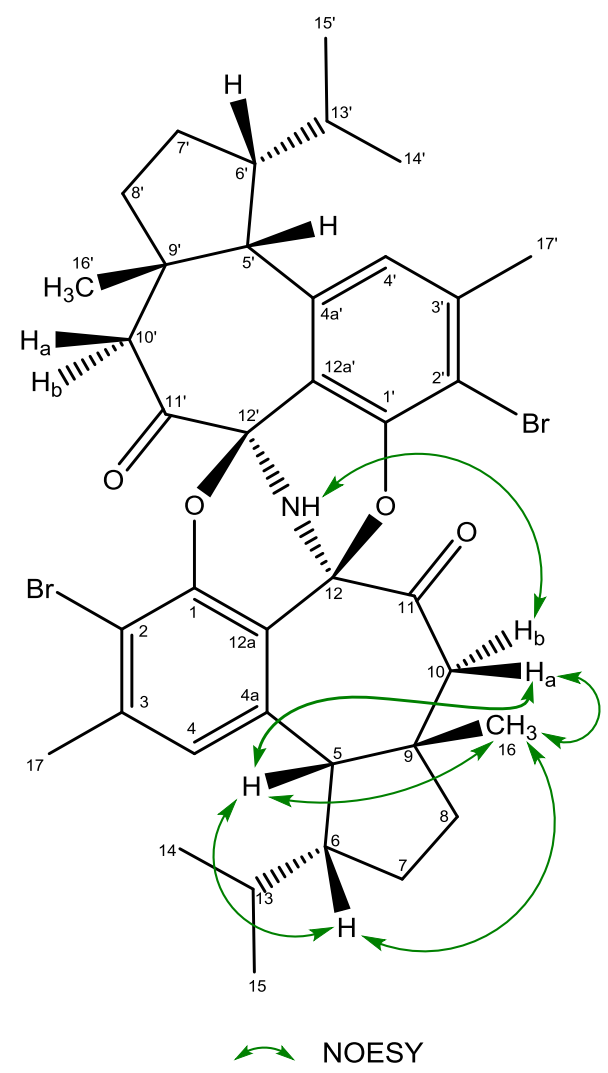

Figure 4.12. Key NOE correlations establishing the relative configuration of hamigeran S (65). 
Table 4.4. NMR data $(600 \mathrm{MHz})$ of hamigeran S (65) in DMSO-d 6 .

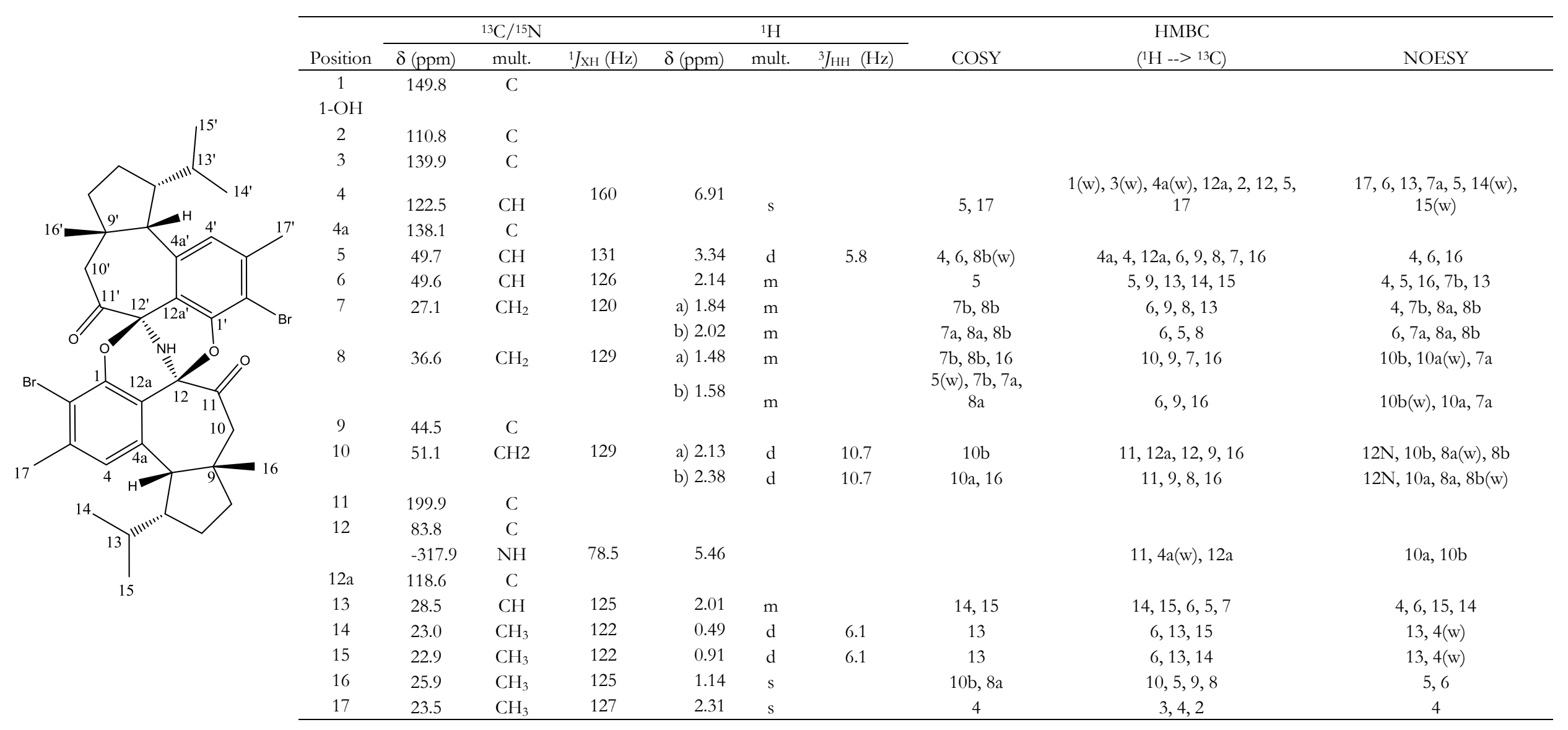




\subsection{Proposed biogenesis}

Hamigeran R (61) and hamigeran S (65) are believed to originate from a similar biogenesis. Like all other nitrogenous hamigerans isolated to date, except possibly hamigeran M (51), there seems to be a common precursor in hamigeran $G(\mathbf{4 0})$. The difference with hamigeran $\mathrm{R}(\mathbf{6 1})$ and hamigeran $S(\mathbf{6 5})$ is that instead of reacting with an amino acid, they react with ammonia. A proposed biogenesis is shown in Scheme 4.1.

To produce hamigeran $\mathrm{R}(\mathbf{6 1})$, first imine formation occurs at the ketone $\mathrm{C}-12$. This imine then undergoes a Baeyer-Villiger type reaction, inserting an oxygen in between the imine and the other ketone. This reaction also may occur in hamigeran B (30) in forming hamigeran E (35) and to hamigeran $G$ (40) in forming hamigeran L (49). Biological systems have been known to perform this reaction with Baeyer-Villiger monooxygenases. ${ }^{52}$ This intermediate, a carboximidate anhydride, could undergo an electrocyclic ring opening forming a nitrile and carboxylic acid. There is little to no evidence in the literature that Baeyer-Villiger reactions can occur to imines which may suggest the reaction first forms an anhydride then reacts with ammonia, but this too has little literature support. The formation of the nitrile is worth further investigation.

The mechanism for hamigeran S (65) starts with the formation of the imine. The enhanced electrophilicity of the imine makes it susceptible to attack from a phenol of a second equivalent of hamigeran $G(\mathbf{4 0})$, forming a hemiaminal. One the amine is reformed, it is then able to attack the ketone on the second hamigeran G (40) molecule. This results in the formation of a new ring and the second hemiaminal formation. The loss of water from the hemiaminal once again forms an imine. The new imine is trapped intramolecularly by the remaining phenol, forming a final hemiaminal, completing the structure of hamigeran S (65). A similar mechanism was proposed by Natividad for the synthesis of dithiocin imine and dioxocin imine compounds, for the aminal 
compound in Table 4.3. ${ }^{51}$ Natividad's mechanism is an improvement of a mechanism proposed by Biehl et al for the dimerization of 2-hydroxyl-1-naphthaldehyde with ammonium acetate. ${ }^{53}$

Scheme 4.1. Proposed formation of new nitrogenous hamigerans.
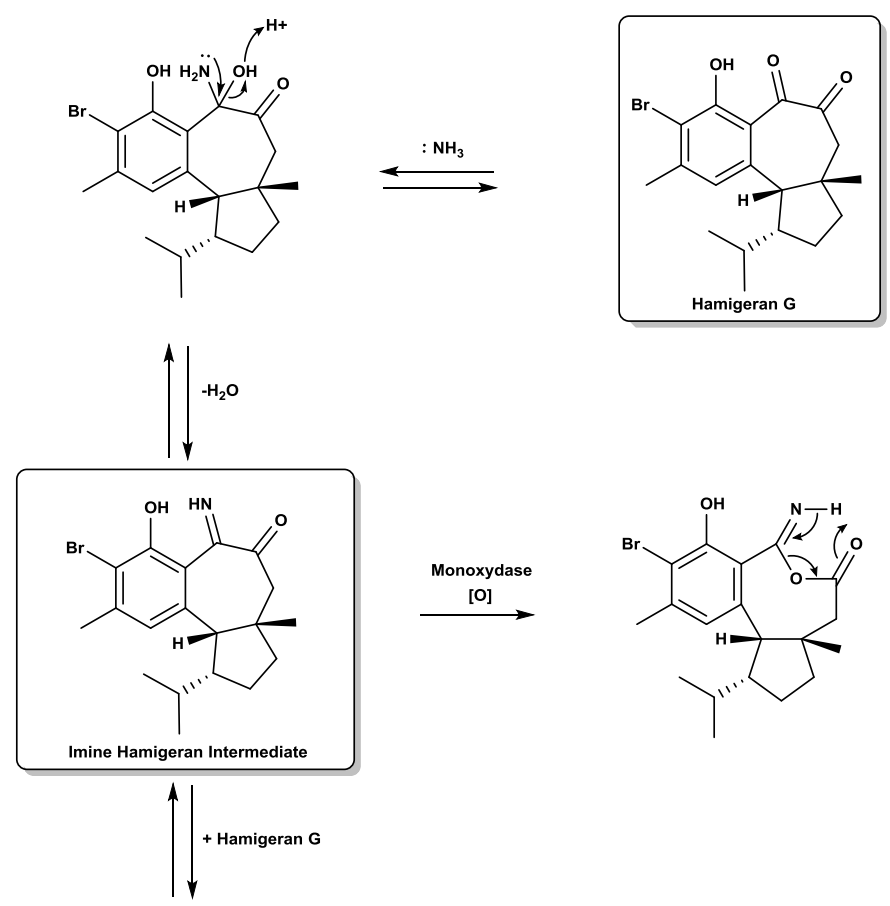

Electrocyclizatic Ring Opening
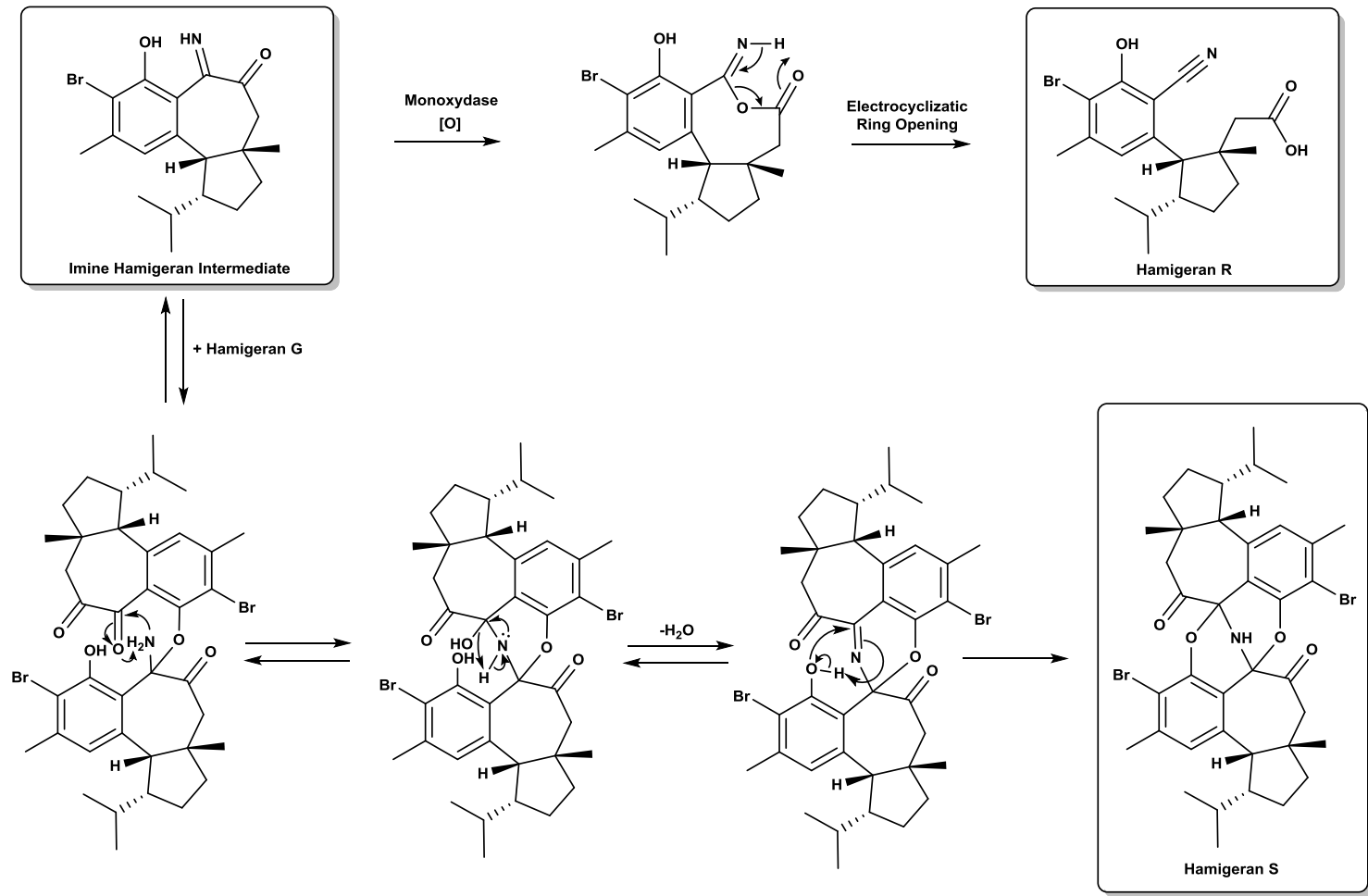


\section{Chapter 5: Synthetic work on the Hamigerans}

To test if the mechanism for the formation of hamigeran R (61) and hamigeran $\mathrm{S}$ (65) from hamigeran G (40) had any merit, some semi-synthesis was undertaken. During the isolation process, a workable amount $(34.1 \mathrm{mg})$ of hamigeran $\mathrm{G}(\mathbf{4 0})$ was isolated providing the means to perform such reactions. This also gave the opportunity to investigate the biogenesis of the other nitrogenous hamigerans.

\subsection{Reaction of Hamigeran G (40) and Ammonium}

The first experiment was to see if an imine would form from the reaction of hamigeran $G(40)$ with ammonia or with an ammonium source. The ketone closer to the aromatic ring (C-12) was thought to be more reactive with ammonia due its activation via hydrogen bonding with the phenol proton, making it more susceptible to nucleophilic attack. Formation of the imine could also lead to the spontaneous formation of hamigeran S (65), as based on the proposed mechanism of its biogenesis (scheme 4.1). An initial test was carried out by adding aqueous ammonia to a NMR tube containing hamigeran $G(40)$, where the colour rapidly changed from bright yellow to dark red. ${ }^{1} \mathrm{H}$ NMR analysis revealed a reaction had occurred, but the water resonance was obscuring several of the important signals with the reaction reverting before further NMR experiments could be acquired. A new ammonium source was used to counter this. The reaction of imine formation produces water but it was thought removal of any other water source would give significant conversion. Ammonium acetate in $\mathrm{EtOH}$ was initially chosen as it was the ammonium source used by Natividad in their synthesis of dithiocin imine and dioxocin imine compounds. However the acetate resonance obscured some of the hamigeran resonances in the ${ }^{1} \mathrm{H}$ NMR spectrum, it was replaced with ammonium formate, as any excess could easily be removed under reduced pressure. 
The reaction worked, with the ${ }^{1} \mathrm{H}$ and ${ }^{13} \mathrm{C}$ NMR spectra revealing the formation of the imine (66), with some hamigeran G (40), its minor configuration and hamigeran G enol (41) still present. The spectra were further complicated by other signals which appeared to be minor configuration and enol form of the imine (66). The reaction was repeated several times with increasing amounts of ammonium formate in an effort to favour the imine, with ten equivalents leading to the maximum amount converted. Without water the imine compound was relatively stable, taking several weeks to revert. Unfortunately, there was no sign of hamigeran S (65) present. The fact that the imine was able to be produced and was stable enough to acquire NMR data gave promise for further reactions.

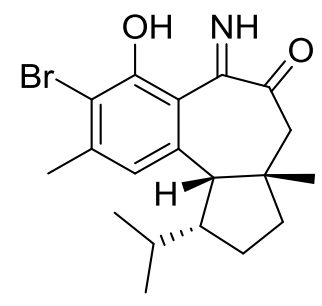


Table 5. 1. NMR data $(600 \mathrm{MHz})$ of imine hamigeran (66) in $\mathrm{CDCl}_{3}$,

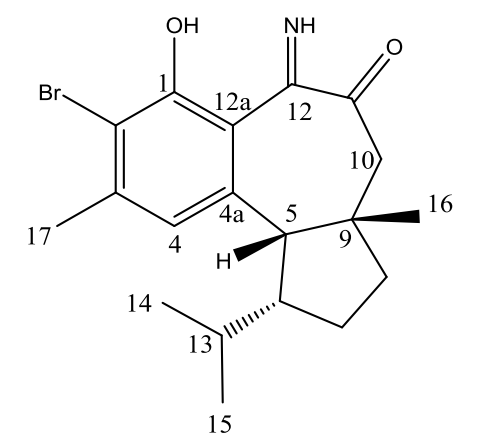

\begin{tabular}{|c|c|c|c|c|c|c|c|c|}
\hline \multirow[b]{2}{*}{ Position } & \multicolumn{3}{|c|}{${ }^{13} \mathrm{C}$} & \multicolumn{3}{|c|}{${ }^{1} \mathrm{H}$} & \multirow[b]{2}{*}{ COSY } & \multirow{2}{*}{$\begin{array}{c}\mathrm{HMBC} \\
\left({ }^{1} \mathrm{H} \rightarrow{ }^{13} \mathrm{C}\right)\end{array}$} \\
\hline & $\delta(\mathrm{ppm})$ & mult. & ${ }^{1} J_{\mathrm{CH}}(\mathrm{Hz})$ & $\delta(\mathrm{ppm})$ & mult. & ${ }^{3} J_{\mathrm{HH}}(\mathrm{Hz})$ & & \\
\hline 1 & 160.7 & $\mathrm{C}$ & & & & & & \\
\hline 1-OH & & & & 10.47 & & & & \\
\hline 2 & 113.9 & $\mathrm{C}$ & & & & & & \\
\hline 3 & 143.9 & $\mathrm{C}$ & & & & & & \\
\hline 4 & 126.9 & $\mathrm{CH}$ & & 6.64 & s & & 17,5 & $2,12 \mathrm{a}, 5,17,3(\mathrm{w}), 12(\mathrm{w}), 1(\mathrm{vw}), 4 \mathrm{a}(\mathrm{vw})$ \\
\hline $4 \mathrm{a}$ & 140.1 & $\mathrm{C}$ & & & & & & \\
\hline 5 & 60.1 & $\mathrm{CH}$ & & 3.30 & $\mathrm{~d}$ & 11 & 4,6 & $1(\mathrm{w}), 4 \mathrm{a}, 4,12 \mathrm{a}, 6,10,9,7,13(\mathrm{w})$ \\
\hline 6 & 54.0 & $\mathrm{CH}$ & & 1.91 & $\mathrm{~m}$ & & 5,13 & $7,13,14,15,5$ \\
\hline \multirow[t]{2}{*}{7} & 32.0 & $\mathrm{CH}_{2}$ & & a) 0.94 & $\mathrm{~m}$ & & $8 \mathrm{~b}, 7 \mathrm{~b}(\mathrm{w})$ & $8,6,13,14,15$ \\
\hline & & & & b) 1.70 & $\mathrm{~m}$ & & $8 \mathrm{~b}, 7 \mathrm{a}(\mathrm{w}), 8 \mathrm{a}$ & $5,6(\mathrm{w}), 9,8(\mathrm{w})$ \\
\hline \multirow[t]{2}{*}{8} & 39.9 & $\mathrm{CH}_{2}$ & & a) 1.62 & $\mathrm{~m}$ & & $8 \mathrm{~b}, 7 \mathrm{~b}(\mathrm{w})$ & $10,9,7$ \\
\hline & & & & b) 1.91 & $\mathrm{~m}$ & & $7 \mathrm{~b}, 7 \mathrm{a}, 8 \mathrm{a}$ & $9,5,10,7,6$ \\
\hline 9 & 46.2 & $\mathrm{C}$ & & & & & & \\
\hline \multirow[t]{2}{*}{10} & 52.8 & $\mathrm{CH}_{2}$ & & a) 2.44 & $\mathrm{~d}$ & 11 & $10 \mathrm{a}$ & $11,12,5,9,8(\mathrm{w}), 7(\mathrm{w})$ \\
\hline & & & & b) 2.68 & $\mathrm{~d}$ & 11 & $10 \mathrm{~b}$ & $11,9,8,7(\mathrm{w}), 5(\mathrm{w})$ \\
\hline 11 & 194.0 & $\mathrm{C}$ & & & & & & \\
\hline 12 & 167.9 & $\mathrm{C}$ & & & & & & \\
\hline $12 \mathrm{a}$ & 115.7 & $\mathrm{C}$ & & & & & & \\
\hline 13 & 29.1 & $\mathrm{CH}$ & & 0.91 & $\mathrm{~m}$ & & $6,14,15$ & $5,6,14,15$ \\
\hline 14 & 22.3 & $\mathrm{CH}_{3}$ & & 0.36 & $\mathrm{~d}$ & 5.8 & 13 & $6,13,15$ \\
\hline 15 & 22.2 & $\mathrm{CH}_{3}$ & & 0.66 & $\mathrm{~d}$ & 6.9 & 13 & $6,13,14$ \\
\hline 16 & 32.1 & $\mathrm{CH}_{3}$ & & 1.31 & s & & & $11(\mathrm{w}), 5,10,9,8$ \\
\hline 17 & 23.7 & $\mathrm{CH}_{3}$ & & 2.44 & s & & 4 & $2,3,4$ \\
\hline
\end{tabular}




\subsection{Reaction of Hamigeran G (40) and L-Alanine}

Since the imine compound was stable, it was proposed that it may also be possible to form an amino acid imine (67) under the same conditions. It was theorized that the carboxylic acid would remain as unlike in the sponge, there would be no enzyme catalysing the decarboxylation or the reduction necessary for it to cyclise and produce hamigeran D (33). L-Alanine and hamigeran G (40) were mixed in ethanol in a 10:1 ratio, partly for higher conversion and partly because Lalanine is not particularly soluble in ethanol. The reaction was refluxed for several hours with the colour noted changing from bright yellow to very pale yellow. It was then passed through an HP20 filter to remove any unreacted L-alanine and the crude reaction mixture analysed with NMR. Instead of compound 67 forming, hamigeran D (33) was observed, in what initially appeared to be an isomerically pure form (see below). This completely changed the understanding of the mechanism for the formation of the nitrogenous hamigerans. The reaction mixture was surprisingly pure. The only other compound being a small amount of hamigeran $G$ enol (41), with no hamigeran G (40) or its minor conformer present, indicating the amino acid may only react with the diketone and not the enol form.

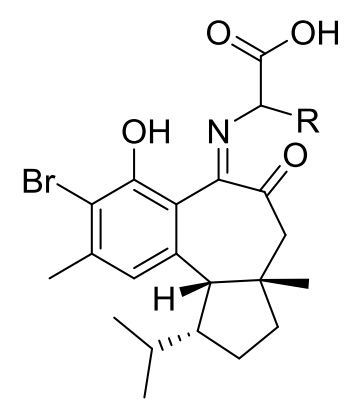

67<smiles>Cc1cc2c3c(c1Br)O[C@H](C)N=C3C(=O)C[C@@]1(C)CC[C@@H](C(C)C)[C@H]21</smiles>

33

\subsection{Reaction of Hamigeran G (40) and Glycine}

With the success of L-alanine it was decided that attempting a reaction between hamigeran $G$ (40) with glycine would be beneficial. The oxazole hamigeran (51) is thought to have been produced from a reaction with glycine and a hamigeran. What is unknown is whether it was a 
reaction with glycine and hamigeran $G(\mathbf{4 0})$ (where it formed the oxazole functionality and was later oxidized at the C-10 position), or if it was a reaction with glycine and an as yet unidentified hamigeran. A reaction between glycine and hamigeran $G(40)$ was carried out following the same procedure as before, the colour change from bright yellow to pale yellow was again observed and NMR used to identify the product (Table 5.2). The results indicated the formation of a new hamigeran (68), a synthetic nitrogenous hamigeran. It is plausible that compound $\mathbf{6 8}$ is produced by the sponge and is yet to be isolated. There was no indication of any oxazole containing compounds with the only minor compound present being hamigeran $G$ enol (41)

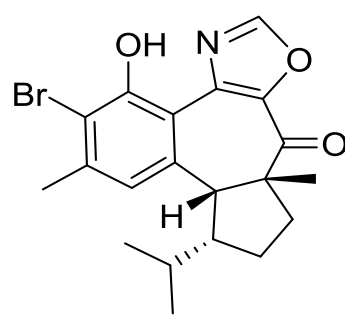

51

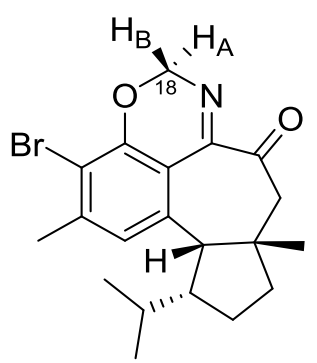

68

Compound 68 appeared in two conformations as is the case with many of the nitrogenous hamigerans. The heterocyclic ring can have either $\mathrm{CH}_{2}-18$ proton sitting pseudoaxial or psudoequatorial (Figure 5.1), which appears as two sets of doublets between 5 and 6 ppm (Figure 5.2). In cases with a carbon substituent such as a benzyl or isobutyl group as is the case with hamigerans (52) and (55), the conformer with the CH-18 proton pseudoaxial is predominantly observed in the ${ }^{1} \mathrm{H}$ NMR spectra. This can be further complicated by the presence of nitrogenous epimers. When the configuration of $\mathrm{CH}-18$ is reversed there is less preference in conformation with both conformers observed in almost equal amounts. In the case of compound $\mathbf{6 8}$ the preferred conformer cannot be confirmed. No NOE correlation between $\mathrm{CH}-13$ to $18-\mathrm{H}_{\mathrm{A}}$ was observed, which is what was used to assign the other conformers of the nitrogenous hamigeran compounds. 


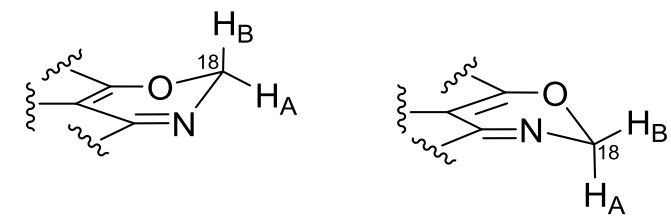

Figure 5.1. $\mathrm{CH}_{2}-18$ conformers for compound 68 .

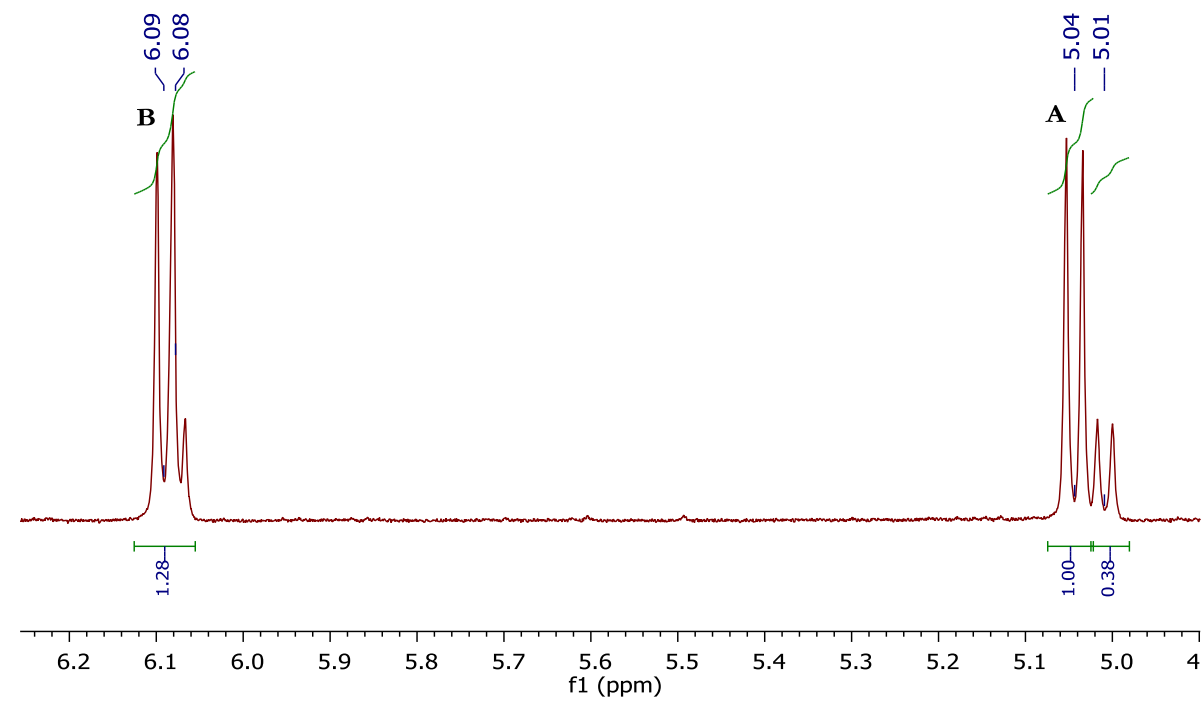

Figure 5.2. ${ }^{1} \mathrm{H}$ NMR spectrum of $\mathrm{CH}_{2}-18$ conformers for glycine compound 68 . 
Table 5.2. NMR data $(600 \mathrm{MHz})$ of glycine hamigeran (68) in $\mathrm{CDCl}_{3}$.

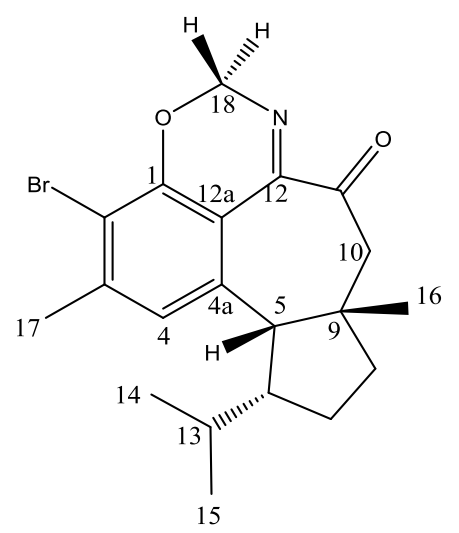

\begin{tabular}{|c|c|c|c|c|c|c|c|c|c|}
\hline \multirow[b]{2}{*}{ Position } & \multicolumn{3}{|c|}{${ }^{13} \mathrm{C}$} & \multicolumn{3}{|c|}{${ }^{1} \mathrm{H}$} & \multirow{2}{*}{\multicolumn{2}{|c|}{$\begin{array}{c}\mathrm{HMBC} \\
\left({ }^{1} \mathrm{H} \rightarrow{ }^{13} \mathrm{C}\right)\end{array}$}} & \multirow[b]{2}{*}{ NOESY } \\
\hline & $\delta(\mathrm{ppm})$ & mult. & ${ }^{1} J_{\mathrm{CH}}(\mathrm{Hz})$ & $\delta(\mathrm{ppm})$ & mult. & $3 J_{\mathrm{HH}}(\mathrm{Hz})$ & & & \\
\hline 1 & 154.7 & $\mathrm{C}$ & & & & & & & \\
\hline 2 & 110.6 & $\mathrm{C}$ & & & & & & & \\
\hline 3 & 144.4 & $\mathrm{C}$ & & & & & & & \\
\hline 4 & 129.4 & $\mathrm{CH}$ & 161 & 6.84 & $\mathrm{~s}$ & & 17,5 & $2,12 \mathrm{a}, 5,17,3(\mathrm{w}), 12(\mathrm{w}), 4 \mathrm{a}(\mathrm{w}), 1(\mathrm{w})$ & 17 \\
\hline $4 \mathrm{a}$ & 138.3 & $\mathrm{C}$ & & & & & & & \\
\hline 5 & 59.3 & $\mathrm{CH}$ & 130 & 3.28 & $\mathrm{~d}$ & 11 & 4,6 & $4 \mathrm{a}, 4,12 \mathrm{a}, 10,6,9,16,7,13(\mathrm{w}), 1(\mathrm{w})$ & 6,16 \\
\hline 6 & 53.9 & $\mathrm{CH}$ & 123 & 1.94 & $\mathrm{~m}$ & & $5,7 \mathrm{~b}, 7 \mathrm{a}, 13(\mathrm{w})$ & $4 a, 5,7,13,14,15$ & 5,16 \\
\hline \multirow[t]{2}{*}{7} & 31.8 & $\mathrm{CH}_{2}$ & 131 & a) 1.17 & $\mathrm{~m}$ & & $6,8 b, 7 a$ & $6,8,13$ & \\
\hline & & & 131 & b) 1.73 & $\mathrm{~m}$ & & $6,7 \mathrm{a}, 8 \mathrm{a}$ & $6,8(w), 9$ & \\
\hline \multirow[t]{2}{*}{8} & 39.9 & $\mathrm{CH}_{2}$ & 128 & a) 1.59 & $\mathrm{~m}$ & & $8 b, 7 a$ & $5(\mathrm{w}), 9,10(\mathrm{w})$ & \\
\hline & & & 128 & b) 2.03 & $\mathrm{~m}$ & & $7 \mathrm{a}, 8 \mathrm{a}$ & $5(\mathrm{w}), 10,9,8(\mathrm{w})$ & \\
\hline 9 & 46.8 & $\mathrm{C}$ & & & & & & & \\
\hline \multirow[t]{2}{*}{10} & 54.9 & $\mathrm{CH}_{2}$ & 100 & a) 2.66 & $\mathrm{~d}$ & 11.2 & $10 \mathrm{~b}$ & $11,5(\mathrm{w}), 8,9,16$ & \\
\hline & & & 105 & b) 2.49 & $\mathrm{~d}$ & 11.2 & $10 \mathrm{a}$ & $11,12,5,9,8,16$ & \\
\hline 11 & 196.1 & $\mathrm{C}$ & & & & & & & \\
\hline 12 & 160.6 & C & & & & & & & \\
\hline $12 \mathrm{a}$ & 117.8 & $\mathrm{C}$ & & & & & & & \\
\hline 13 & 29.6 & $\mathrm{CH}$ & 122 & 0.89 & $\mathrm{~m}$ & & $6(\mathrm{vw}), 14,15$ & $6,14,15,5(\mathrm{w})$ & $18 \mathrm{a}$ \\
\hline 14 & 22.4 & $\mathrm{CH}_{3}$ & 122 & 0.39 & $\mathrm{~d}$ & 6.8 & 13,15 & $13,15,6$ & \\
\hline 15 & 22.1 & $\mathrm{CH}_{3}$ & 122 & 0.68 & $\mathrm{~d}$ & 6.8 & 13,14 & $6,13,14$ & \\
\hline 16 & 32.3 & $\mathrm{CH}_{3}$ & 127 & 1.29 & $\mathrm{~s}$ & & & $5,10,9,8$ & 5,6 \\
\hline 17 & 23.3 & $\mathrm{CH}_{3}$ & 127 & 2.45 & $\mathrm{~s}$ & & 4 & $2,3,4$ & 4 \\
\hline \multirow[t]{2}{*}{18} & 79.6 & $\mathrm{CH}_{2}$ & 154 & a) 5.04 & $\mathrm{~d}$ & 11.2 & $18 \mathrm{~b}$ & $12,1,12 \mathrm{a}(\mathrm{w}), 11$ & \\
\hline & & & 180 & b) 6.09 & $\mathrm{~d}$ & 11.2 & $18 \mathrm{a}$ & $12,1,12 \mathrm{a}(\mathrm{w}), 11(\mathrm{w})$ & \\
\hline \multirow[t]{2}{*}{$18^{\prime}$} & & & & a) 5.01 & $\mathrm{~d}$ & 10.5 & & & \\
\hline & & & & b) 6.08 & $\mathrm{~d}$ & 10.5 & & & \\
\hline
\end{tabular}




\subsection{Reaction of Hamigeran G (40) and D-alanine}

One of the key steps in the mechanism for the formation of the nitrogenous hamigerans proposed by Singh (Scheme 3.2) involves the loss of configuration at C-18, meaning that the choice of $\mathrm{L}$ or $\mathrm{D}$ amino acid would not affect the outcome of the nitrogenous epimer produced. To test this, L-alanine was replaced with $\mathrm{D}$-alanine and the experiment was repeated. The resulting ${ }^{1} \mathrm{H}$ NMR spectra identified that both hamigeran D (33) and its C-18 epimer (70) were present. This is the first time this epimer has been observed as it yet to be isolated from a natural source. After purification of the L-alanine reaction mixture using HPLC, it became apparent there was a small amount of the epimer (69) present alongside hamigeran D (33). The ratios of hamigeran D (33) and its epimer (69) appear to be different based on whether L-alanine or Dalanine is used, with a higher amount of the epimer produced in the D-alanine reaction (Figures 5.3 and 5.4). Although this is not exactly surprising as chiral molecules such as hamigeran G (40) are known to influence the reaction by creating a prochiral surface in the intermediate resulting in a preferred configuration. What is unusual is that during isolation, the nitrogenous hamigerans and there epimers were isolated in near even amounts. This suggests a much more controlled reaction environment but further testing may be needed to confirm this relationship and to draw any strong conclusions.

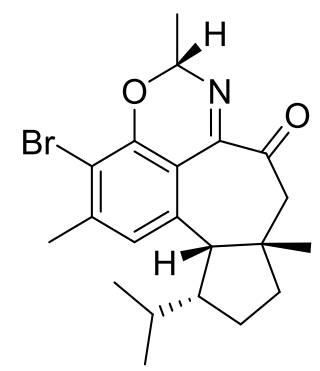

69 


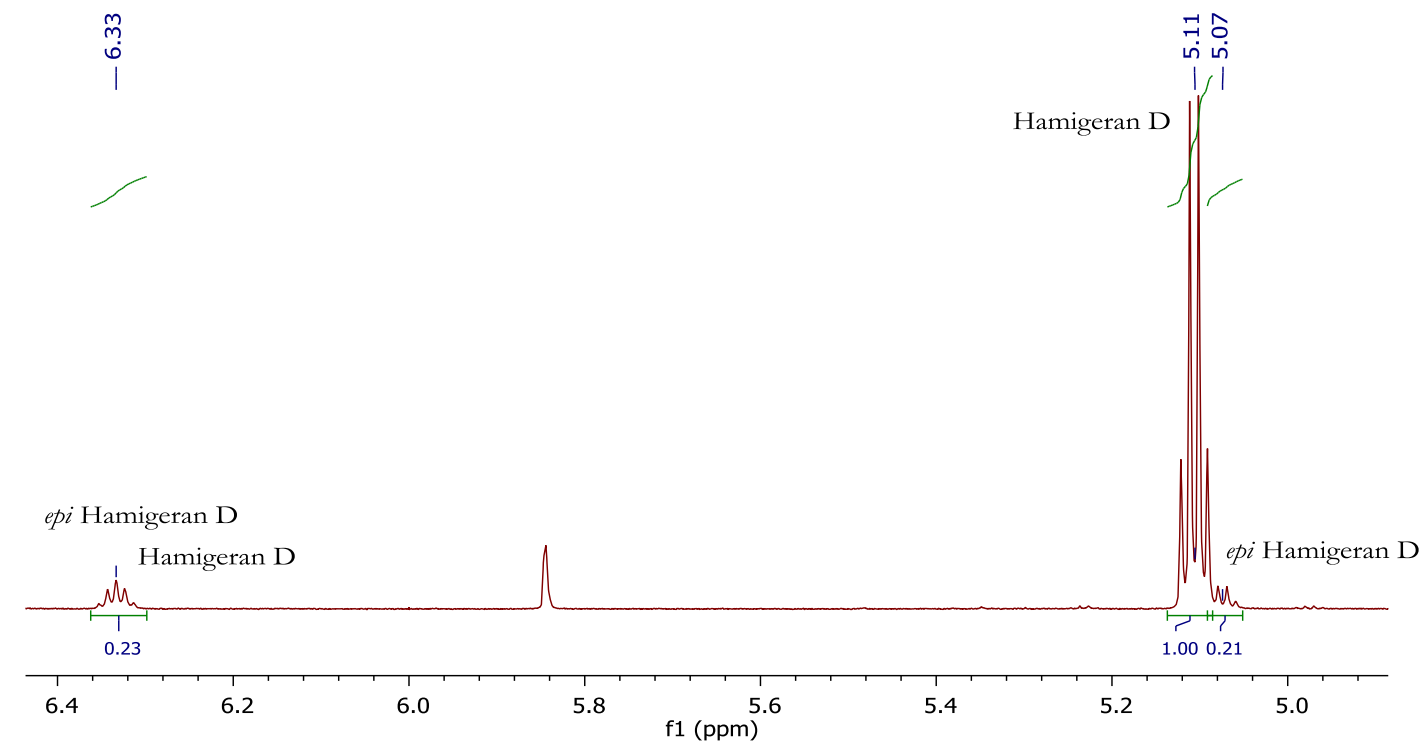

Figure 5.3. ${ }^{1} \mathrm{H}$ NMR spectrum of hamigeran D (33) and epimer (69) from L-alanine reaction.

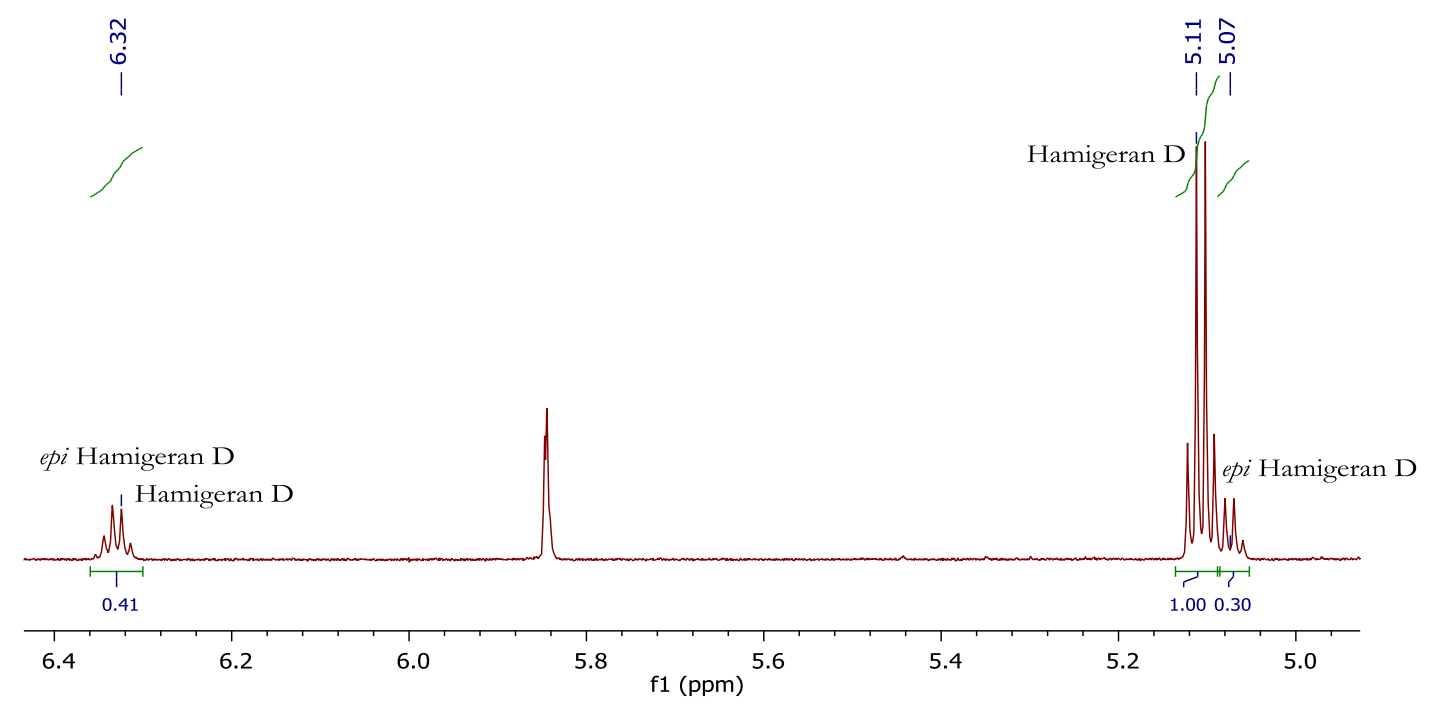

Figure 5.4. ${ }^{1} \mathrm{H}$ NMR spectrum of hamigeran D (33) and epimer (69) from D-alanine reaction.

\subsection{Reaction of Hamigeran B (30) and Glycine}

So far, no nitrogenous analogues based on hamigeran B (30) had been isolated, despite it being a diketone like hamigeran $G(\mathbf{4 0})$. This could possibly due to the isolation process excluding them either as they are only present in the sponge in very low abundances or that there is no reactivity between amino acids and hamigeran B (30). To test the latter reasoning, the glycine reaction was 
repeated replacing hamigeran G (40) with hamigeran B (30). No colour change was observed, even after extending the reaction overnight with analysis of the ${ }^{1} \mathrm{H}$ NMR spectra confirming that no reaction had taken place.

\subsection{Reaction of Hamigeran B (30) and Ammonium}

At this time a step back was needed to be taken. It was hypothesized that if hamigeran B (30) would not react with the amino acids, it potentially would not react with an ammonium source to form an imine either. A reaction of ammonium formate with hamigeran B (30) was undertaken. Unlike the reaction of ammonium formate and hamigeran $G(40)$, which had an instant colour change, no change was initially observed. However, after several hours the reaction mixture changed from bright yellow to a dull peach colour. Leaving it for 24 hours resulted in a final colour change leaving it as an orange solution. ${ }^{1} \mathrm{H}$ NMR data suggested a reaction had taken place, likely the formation of imine (70). The spectra was further complicated with the presence of hamigeran B (30) and an unidentified compound, possibly a diimine. Further analysis of this mixture was hindered by the reactivity of the imine compound (70) reverting back to hamigeran B (30). This reversion seemed to favour the ketone compared to the imine as for hamigeran $G$ (40). This could also explain the lack of reactivity seen between hamigeran B (30) and glycine. The difference in ring size of the B rings, hamigeran B (30) and G (40) seem to strongly affect their reactivity with ammonium and amino reactants. It may also provide the explanation as to why no nitrogenous hamigeran B analogues have been isolated.

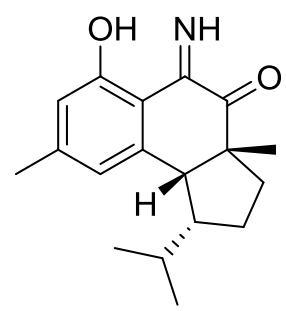




\subsection{Reaction of Hamigeran G (40) and L-phenylalanine}

With the reactions of L-alanine, glycine and D-alanine working so well, a reaction with a bulky amino acid was tested to see if it altered the reaction outcome. The reaction of L-phenylalanine with hamigeran $G(\mathbf{4 0})$ proceeded in the same manner as with the other amino acids with the loss of the bright yellow colour. ${ }^{1} \mathrm{H}$ NMR analysis revealed both hamigeran $\mathrm{N}(\mathbf{5 2})$ and its C-18 epimer (53) (Figure 5.5). The relative amounts of each compound could not be obtained from the $\mathrm{CH}-18$ resonance due to the overlap and was instead identified from the $\mathrm{CH}-4$ peak, with hamigeran $\mathrm{N}(\mathbf{5 2})$ present in a 5:1 ratio with the epimer (53) (Figure 5.6).

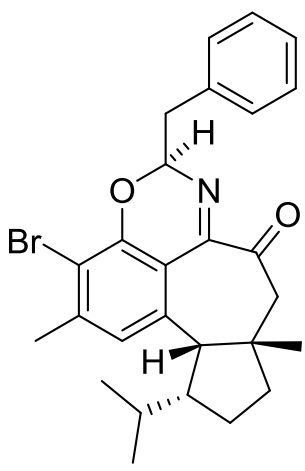

52<smiles>Cc1cc2c3c(c1Br)O[C@H](Cc1ccccc1)N=C3C(=O)C[C@@]1(C)CC[C@H](C(C)C)[C@@]21C</smiles>

53 


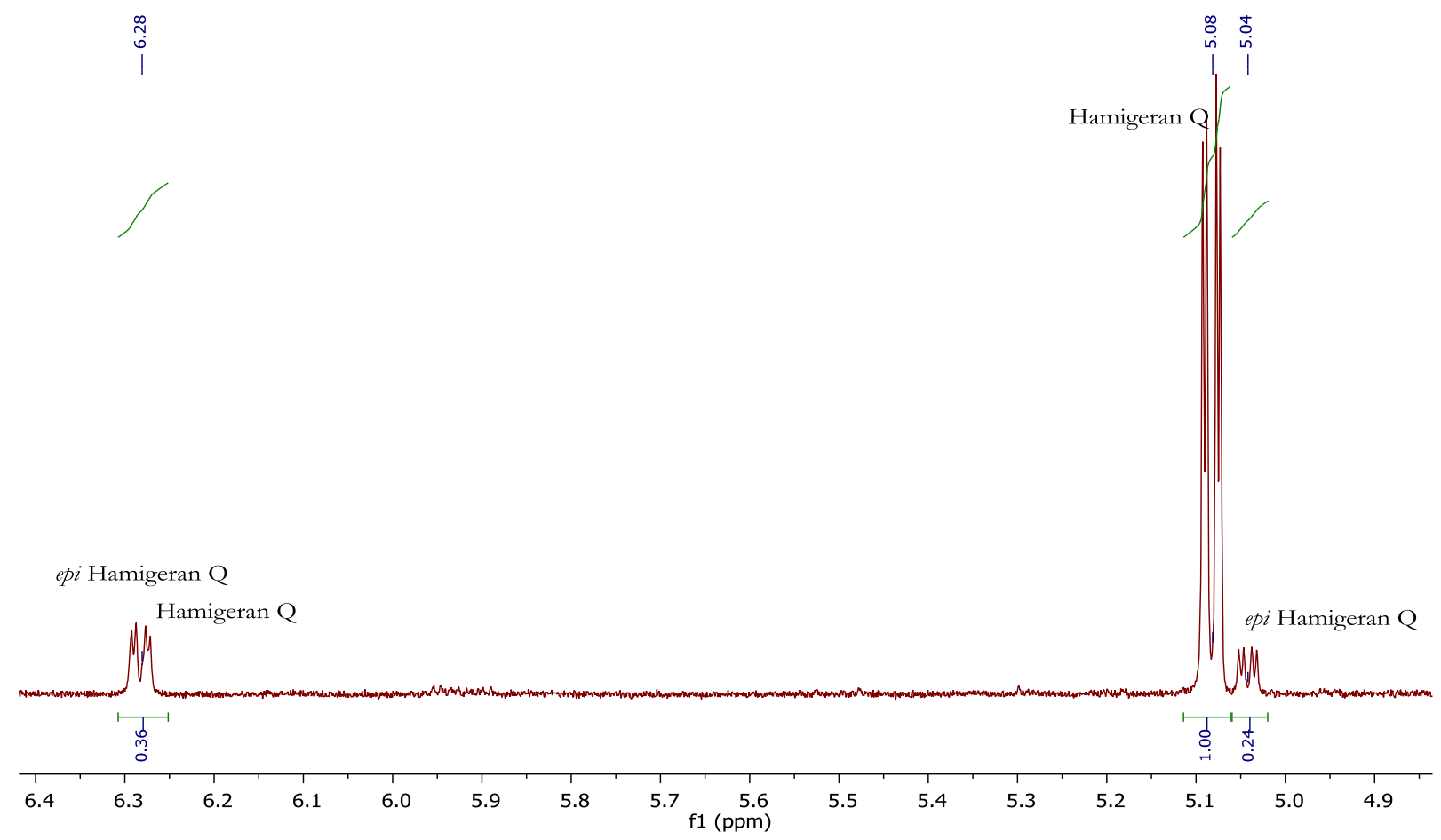

Figure 5.5. ${ }^{1} \mathrm{H}$ NMR spectrum of $\mathrm{CH}-18$ proton of hamigeran $\mathrm{N}(\mathbf{5 2})$ and epi $\mathrm{Q}(\mathbf{5 3})$.

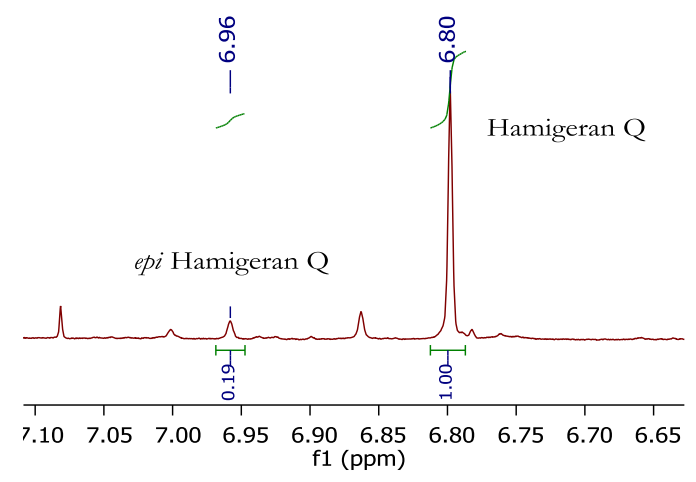

Figure 5. 6. ${ }^{1} \mathrm{H}$ NMR spectrum of $\mathrm{CH}-4$ proton of hamigeran $\mathrm{N}(\mathbf{5 2})$ and epi $\mathrm{Q}(\mathbf{5 3})$.

\subsection{Analysis of the reactions}

It was unfortunate that the imine (66) did not spontaneously form hamigeran S (65). The forming of the double hemiaminal structure should drive the reaction forward, presuming it would be able to get that far in the series of equilibria. One possible explanation is the phenol may require a form of activation for it to be able to attack the imine. Natividad's synthesis of the 
dithiocin imine and dioxocin imine compounds also performed reactions that produced trimers, including the trithiazine (71) and trioxazine (72) compounds. These were produced from reflux of

1-hydroxy-2-naphthaldehyde or thiosalicylaldehyde with ammonium acetate, acetic acid and toluene. The key differences in this reaction were acid and solvent. Ethanol, being a protic solvent, may possibly be having a strong solvating interaction with the phenol, reducing its ability to attack. ${ }^{51}$ Ethanol was selected as the solvent of choice as it provided excellence yields in the formation of the dithiocin imine and dioxocin imine compounds. The sterics of dimerization of hamigeran G (40) may have been a factor as without enzymatic control, the reaction kinetics would be slowed. The reaction should be repeated changing the conditions and solvent to find a possible route to dimerization, unfortunately this is beyond the scope of this master's research.<smiles></smiles>

71<smiles>c1ccc2c3c(ccc2c1)OC1c2c(ccc4ccccc24)OC2c4c(ccc5ccccc45)OC3N12</smiles>

72

The mechanism for the formation of the nitrogenous hamigerans from the reaction of amino acids and hamigeran $G(\mathbf{4 0})$ proposed by Singh required the use of a hydride acceptor during decarboxylation of the amino acid. This could be explained in a biological system with $\mathrm{NADH}^{+}$ but this does not make sense in a "test tube" reaction. Overall, the reaction loses $\mathrm{H}_{2} \mathrm{O}, \mathrm{CO}_{2}, 2 \mathrm{H}^{+}$ and $2 \mathrm{e}^{-}$through oxidation. An alternative to this is loss of $2 \mathrm{H}_{2} \mathrm{O}$ and $\mathrm{CO}$, with the oxidation occurring with the CO. A proposed mechanism for a loss of CO is shown in Scheme 5.1, where the amino acid attacks forming the initial imine. An electron cascade starting from the phenol results in the loss of the carboxylic acid as $\mathrm{CO}$ and $\mathrm{H}_{2} \mathrm{O}$. An electrocyclic ring closing could then 
occur to restore the aromaticity of the A ring resulting in the nitrogenous hamigeran product. Testing for presence of $\mathrm{CO}$ during this reaction could help in verification of this mechanism. Methylation of the carboxylic acid of the amino acid would also verify this mechanism, as this would not halt the reaction. Instead it would produce $\mathrm{MeOH}$ in exchange for one of the $\mathrm{H}_{2} \mathrm{O}$ molecules. If however the reaction mechanism is producing $\mathrm{CO}_{2}$ then the methylation of the amino acid will prevent the decarboxylation from occurring, potentially limiting the reaction to the imine product. This hypothesis would very interesting to test but due to time limits this will have to wait.

Scheme 5.1. Revised proposed formation of nitrogenous hamigerans.<smiles>Cc1cc2c(c(O)c1Br)C(=O)C(=O)C[C@]1(C)CC[C@@H](C(C)C)[C@]21C</smiles><smiles>[R]C(N)C(=O)O</smiles>

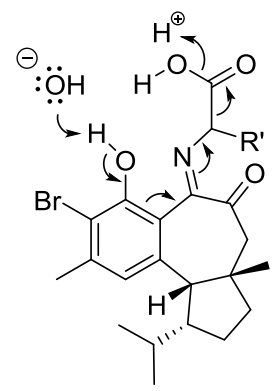<smiles>[R]C1N=C2C(=O)C[C@]3(C)CC[C@H](C(C)C)[C@]3(C)c3cc(C)c(Br)c(c32)O1</smiles><smiles>[CH]1CC1</smiles>

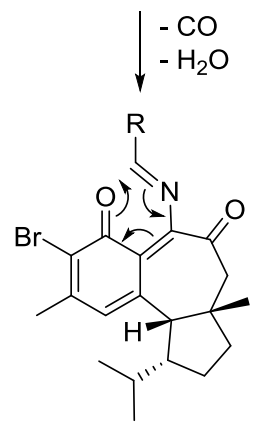




\section{Chapter 6: Biological Activity of the Hamigerans}

The preliminary results for testing against HL-60 cell lines of the seven new hamigerans are summarized in Table 6.1, provided by the School of Biological Science at VUW. Interestingly, hamigeran $G(40)$, which was retested to use as a comparison, did not exhibit the same levels of cytotoxicity as it normally features (Table 6.2). Regardless of this, all the analogs of the known hamigerans $(37,60,62,63,64)$ showed a comparable level of biological activity to their counterparts. This is consistent with previously tested hamigerans, with debromination, addition of bromine or methylation of an acid group not altering the $\mathrm{IC}_{50}$ significantly.

Hamigerans R (61) and S (65) were an anomaly being over an order of magnitude weaker than the other hamigerans. It is thought from the isolation of hamigeran Q (57) and the two epimers $(\mathbf{5 8}, \mathbf{5 9})$, that the nitrogenous hamigerans come from a mixed biogenesis with bacteria reacting an amino acid with hamigeran $G(\mathbf{4 0})$ to reduce its potency. This same logic could be applied to hamigeran $\mathrm{R}$ (61) and S (65), with the bacteria releasing an ammonium source instead of an amino acid, resulting in the formation of less cytotoxic products.

Retesting of biological activity is needed for all the new hamigerans before any more conclusions are drawn. 
Table 6.1. Hamigeran IC $\mathrm{I}_{50}$ Values [HL-60, $n=3$ replicates, except for (40) and (64) $n=2$ ].

\begin{tabular}{|c|c|}
\hline Compound & $\begin{array}{c}\text { Mean } \mathrm{IC}_{50} \pm \text { SEM } \\
(\mu \mathrm{M})\end{array}$ \\
\hline Hamigeran G (40) & $18.0 \pm 0.1$ \\
\hline Debromohamigeran B (37) & $43.0 \pm 5.7$ \\
\hline Debromohamigeran I (60) & $19.6 \pm 0.8$ \\
\hline Debromohamigeran J (62) & $19.4 \pm 1.5$ \\
\hline Hamigeran L 12-O-Methyl Ester (63) & $15.9 \pm 1.1$ \\
\hline 4-Bromohamigeran A (64) & $19.6 \pm 1.1$ \\
\hline Hamigeran R (61) & $>100$ \\
\hline Hamigeran S (65) & $>100$ \\
\hline
\end{tabular}

Table 6.2. Hamigeran $\mathrm{IC}_{50}$ Values (HL-60, $n=3$ replicates).

\begin{tabular}{|c|c|c|c|}
\hline Compound & $\begin{array}{c}\text { Mean } \mathrm{IC}_{50} \pm \mathrm{SEM} \\
(\mu \mathrm{M})\end{array}$ & Compound & $\begin{array}{c}\text { Mean } \mathrm{IC}_{50} \pm \mathrm{SEM} \\
(\mu \mathrm{M})\end{array}$ \\
\hline Hamigeran A (28) & $16.0 \pm 4.5$ & 4-Bromohamigeran K (47) & $5.6 \pm 0.4$ \\
\hline Debromohamigeran A (29) & $12.5 \pm 3.4$ & 10-epi-Hamigeran K (48) & $28.5 \pm 1.6$ \\
\hline Hamigeran B (30) & $3.4 \pm 0.4$ & Hamigeran L (49) & $78.3 \pm 0.5$ \\
\hline Hamigeran D (33) & $6.1 \pm 0.3$ & Hamigeran L 11-O-Methyl Ester (50) & $21.1 \pm 3$ \\
\hline Hamigeran F (38) & $4.9 \pm 1.2$ & Hamigeran M (51) & $6.9 \pm 0.4$ \\
\hline Hamigeran F Rearrangement (39) & $7.4 \pm 1.9$ & Hamigeran N (52) & $19.5 \pm 0.6$ \\
\hline Hamigeran G (40) & $2.5 \pm 0.2$ & 18-epi-Hamigeran N (53) & $14.1 \pm 0.4$ \\
\hline Hamigeran $\mathrm{H}(42)$ & $16.5 \pm 1.4$ & Hamigeran O (54) & $14.7 \pm 0.4$ \\
\hline Hamigeran I (43) & $37.2 \pm 1.4$ & Hamigeran P (55) & $21.3 \pm 0.7$ \\
\hline Hamigeran J (44) & $48.2 \pm 1.2$ & 18-epi-Hamigeran P (56) & $11.6 \pm 0.2$ \\
\hline Hamigeran K (46) & $13.7 \pm 0.6$ & Hamigeran Q (57) & $33.3 \pm 0.6$ \\
\hline
\end{tabular}




\section{Chapter 7: Concluding remarks}

Further studies on the Hamigera tarangaensis have continued to be rewarding with isolation of seven new hamigeran congeners. The semi-purified fractions first generated by Singh proved to be rich in new compounds. Separation of the $80 \% \mathrm{Me}_{2} \mathrm{CO} / \mathrm{H}_{2} \mathrm{O}$ fraction resulted in the isolation of four analogues to previously known hamigerans (37, 62, 63, 64). The $60 \%$ and $100 \%$ $\mathrm{Me}_{2} \mathrm{CO} / \mathrm{H}_{2} \mathrm{O}$ fractions, which had not been previously investigated, proved to a good source of novel compounds leading to the isolation of hamigeran R (61) and S (65) along with the isolation of another analogue of a known hamigeran (60).

There were over a dozen fractions that contained resonances in ${ }^{1} \mathrm{H}$ NMR indicative of a hamigeran which did not match any of the known compounds. Unfortunately it is not always possible to follow up each one. This was sometimes due to low mass or lack of purity after fractionation. Often the most promising fractions were focused in on, with time considerations restricting further investigation into others. From the $100 \% \mathrm{Me}_{2} \mathrm{CO}$ fractions in which hamigeran S (65) was isolated, there appeared to be indication of hamigerans that were even more non-polar than hamigeran S (65), which could suggest a trimer, along with fractions containing potentially interesting steroids and a compound that appeared to change colour depending on whether it was exposed to fluorescent or natural light. There is possibly dozens of other hamigerans compounds that the sponge produces that we are yet to isolate, though that in is self does not warrant reinvestigation. Replication would be more and more likely with any subsequent study and the biological activity of the hamigerans has indicated it to be not exceptional regardless of their wonderful structures.

The surprising success of the reactions resulted in the semi-synthesis of the two new congeners, the glycine hamigeran (68) and the epimer (69) to hamigeran D and two intermediates, 
hamigeran $G$ imine (66) and hamigeran B imine (70). The two congeners are both likely present in the sponge and are yet to be isolated. The two imines however, if generated in the sponge would not last long before $\mathrm{H}_{2} \mathrm{O}$ would displace the imine to reform the ketones or go on to form other compounds. Overall with the isolation efforts and the semi-synthesis the gaps in the table of hamigerans have started to be filled in, while also creating new ones (Table 7.4 and Table 7.5).

The sponge's key compounds, in terms of the biological activity that has been tested, are hamigeran B (30) and hamigeran G (40), two nearly identical compounds, differing by a methylene unit. Hamigeran G (40) itself appears to be the origin of most of the nitrogenous hamigerans. This may be the sponge's way to diversify its chemical defences as a way of lessening predation or possibly the response of bacteria living in the sponge in a way to deal with the toxicity of hamigeran $G(\mathbf{4 0})$, transforming it to a less potent analogue. If this is the case it would be unknown how the bacteria would combat hamigeran B (30). The addition of hamigeran R (61) and S (65) has only added to the oddity of this family of compounds.

It would be beneficial to repeat the hamigeran $G$ imine (66) reaction under different conditions such as changing the solvent to toluene or trying alteration to the $\mathrm{pH}$ to see if the synthesis of hamigeran S (65) can be achieved. Other beneficial reactions would be attempting to attach an amino acid to hamigeran $G(\mathbf{4 0})$ which has an acidic or basic functionality. Such functionality would likely hinder the reaction, or cause further reactions. This may be why no such nitrogenous hamigeran of this type has been isolated so far. The reaction by Nicolaou of debromohamigeran $\mathrm{B}(37)$ to debromohamigeran $\mathrm{E}$ (36) with $\mathrm{H}_{2} \mathrm{O}_{2}$ and $\mathrm{NaOH}$ could be tried on hamigeran $\mathrm{G}$ imine (66) which could result in the formation of hamigeran $\mathrm{R}(\mathbf{6 1})$ or hamigeran $\mathrm{L}$ (49) depending on whether the imine would react with $\mathrm{H}_{2} \mathrm{O}_{2}$ or not. More pressing is the reaction of a methylated amino acid with hamigeran $G(40)$, evidence of CO generation would be very intriguing. 
Table 7.4. Total isolated hamigerans (new in blue).

\begin{tabular}{|c|c|c|c|}
\hline & Debrominated & Hamigerans & 4-Brominated \\
\hline 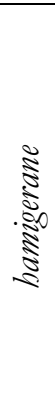 & $\begin{array}{l}\text { debromohamigeran A (29) } \\
\text { debromohamigeran J (62) } \\
\text { debromohamigeran E (36) } \\
\text { debromohamigeran B (37) }\end{array}$ & $\begin{array}{c}\text { hamigeran A (28) } \\
\text { hamigeran J (44) } \\
\text { hamigeran E (35) } \\
\text { hamigeran B (30) } \\
\text { hamigeran K (46) } \\
10 \text { epi-hamigeran K (48) }\end{array}$ & $\begin{array}{l}\text { 4-bromohamigeran (64) } \\
\text { 4-bromohamigeran B (31) } \\
\text { 4-bromohamigeran K (47) }\end{array}$ \\
\hline 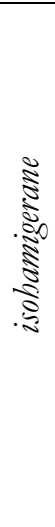 & $\begin{array}{c}\text { hamigeran } \mathrm{H}(\mathbf{4 2}) \\
\text { debromohamigeran I (60) }\end{array}$ & $\begin{array}{c}\text { hamigeran F (38) } \\
\text { hamigeran C (32) } \\
\text { hamigeran I (43) } \\
\text { hamigeran G (40) } \\
\text { hamigeran L (49) } \\
\text { hamigeran L 11-O-methyl ester (50) } \\
\text { hamigeran L 12-O-methyl ester (63) }\end{array}$ & \\
\hline
\end{tabular}

Table 7.4. Isolated and semi-synthesised nitrogen containing hamigerans

(new in blue, synthesised in red).

\begin{tabular}{|c|c|c|}
\hline oxazole amino hamigerans & Amino acid hamigerans & 18-epi-amino acid hamigerans \\
\hline hamigeran M (51) & $\begin{array}{c}\text { glycine hamigeran (68) } \\
\text { hamigeran D (33) } \\
\text { hamigeran N (52) } \\
\text { hamigeran O (54) } \\
\text { hamigeran P (55) } \\
\text { hamigeran Q (57) } \\
\text { 19-epi-hamigeran Q (59) }\end{array}$ & $\begin{array}{l}\text { 18-epi-Hamigeran D (69) } \\
\text { 18-epi-hamigeran N (53) } \\
\text { 18-epi-hamigeran P (56) } \\
\text { 18-epi-hamigeran Q (58) }\end{array}$ \\
\hline Debrominated & Ammonia hamigerans & 4-Brominated \\
\hline & $\begin{array}{c}\text { hamigeran R (61) } \\
\text { hamigeran S (65) } \\
\text { hamigeran G imine (66) } \\
\text { hamigeran B imine (70) }\end{array}$ & \\
\hline
\end{tabular}




\section{Chapter 8: Experimental}

\subsection{General experimental methods}

NMR spectra were obtained using a Varian DirectDrive spectrometer equipped with a triple resonance $\mathrm{HCN}$ cryogenic probe, operating at $25 \mathrm{~K}$ at frequencies of $600 \mathrm{MHz}, 150 \mathrm{MHz}$ and $60 \mathrm{MHz}$ for ${ }^{1} \mathrm{H},{ }^{13} \mathrm{C},{ }^{15} \mathrm{~N}$ nuclei respectively. Chemical shifts $\delta$ (ppm) were referenced to the residual solvent peak. ${ }^{54}$ All spectra were run in $\mathrm{CDCl}_{3}$ or DMSO- $\mathrm{d}_{6} \cdot{ }^{1} \mathrm{H}$ NMR quantifications of samples were performed with an internal $\mathrm{CH}_{3} \mathrm{NO}_{2}$ standard using acquisition parameters as described by West. ${ }^{55}$ HRESIMS results were obtained from an Agilent 6530 Q-TOF mass spectrometer equipped with an Agilent 1260 HPLC for solvent delivery utilising a JetStream ${ }^{\mathrm{TM}}$ electrospray ionisation source in positive and negative ion modes.

Optical rotations were measured using Rudolph Autopol II polarimeter in the solvent $\mathrm{CH}_{2} \mathrm{Cl}_{2}$. $\mathrm{UV} /$ vis spectra were recorded on the Agilent 8453 diode Array Spectrometer in $\mathrm{MeOH}$. IR spectra were recoreded using the Bruker Platinum ATR, deposited as a thin film by evaporation of a drop of $\mathrm{CH}_{2} \mathrm{Cl}_{2}$. TLC plates were developed in $5 \% \mathrm{MeOH} / \mathrm{CH}_{2} \mathrm{Cl}_{2}$ and visualised under a UV lamp source $(\lambda=254 \mathrm{~nm})$, then analysed by dipping in a solution of $5 \% \mathrm{KOH}$ (conc.)/MeOH followed up by heating. Reversed-phase column chromatography was achieved using Supelco Diaion HP20, HP20SS or Tosohass Amberchrom poly(styrene-divinylbenzene) (PSDVB) chromatographic resin.

Two separate HPLC systems were used for fine separation, firstly Agilent Technologies 1260 Infinity HPLC equipped with a quaternary pump, a thermostatted column compartment and diode array detector (DAD). Secondly using a Rainin Dynamax SD-200 solvent delivery system 
with $25 \mathrm{~mL}$ Pump heads. A C-18 semi-preparative column was used for all HPLC seperation. UV/vis detection for HPLC runs was obtained with a Varian Prostar 335 photodiode array detector. Solvents used for reversed-phase column chromatography are of HPLC or analytical grade quality. All other solvents were purified by distillation before use and filtered. Solvent mixtures are reported as $\% \mathrm{vol} / \mathrm{vol}$ unless otherwise stated.

Sponge material used was fractions generated by Singh. The sponges were originally collected from various locations around northland, New Zealand by the Marine Natural Products Group, VUW, and stored ar $-20{ }^{\circ} \mathrm{C}$ until required. Identification of the sponge used a subsample immersed in concentrated $\mathrm{HNO}_{3}$ until all organic matter had dissolved leaving the spicules which were analysed under optical and scanning electron microscopy (SEM). This was then compared to literature. Purified compounds were submitted to the school of Biological Sciences, VUW for biological testing.

\subsection{Isolation of Compounds from Hamigera tarangaensis}

The work by Singh during his thesis generated several fractions that did not get past the first stage of purification. Work up to the $\mathbf{f}-\mathbf{j}$ and $\mathbf{k}-\mathbf{o}$ fractionation of the samples of sponges was done by Singh. LH20 work and later was done as part of this thesis. Of the Fractions a-e, d was investigated extensively by Singh and later on by Dattelbaum leading to the isolation of hamigeran F (38) to 18-epi-hamigeran Q (59).

\subsection{Hamigerans S (65) and other Hamigerans}

Frozen Hamigera tarangaensis (PTN2_71J, 514.6 g), collected from Matai Bay Pinnacle, Cape Karikari, New Zealand, was cut into small pieces and extracted with $\mathrm{MeOH}(2 \times 1.7 \mathrm{~L})$. The second and first extracts were cyclic loaded (to $13.6 \mathrm{~L}$ of $\mathrm{H}_{2} \mathrm{O}$ and $\mathrm{MeOH}$ ) on a column packed with $1 \mathrm{~L} \mathrm{HP20}$, pre-equilibrated in $\mathrm{MeOH}$. The column was eluted with 3L portions of i) $\mathrm{H}_{2} \mathrm{O}$, ii $20 \% \mathrm{Me}_{2} \mathrm{CO} / \mathrm{H}_{2} \mathrm{O}$ (fraction f), iii) $40 \% \mathrm{Me}_{2} \mathrm{CO} / \mathrm{H}_{2} \mathrm{O}$ (fraction g) iv) $60 \% \mathrm{Me}_{2} \mathrm{CO} / \mathrm{H}_{2} \mathrm{O}$ (fraction 
h) v) $80 \% \mathrm{Me}_{2} \mathrm{CO} / \mathrm{H}_{2} \mathrm{O}$ (fraction $\mathbf{i}$ ) and vi) $\mathrm{Me}_{2} \mathrm{CO}$ (fraction $\mathbf{j}$ ). The fractions $\mathbf{f}-\mathbf{j}$ were diluted threefold with $\mathrm{H}_{2} \mathrm{O}$, backloaded on to $200 \mathrm{ml} \mathrm{HP} 20$ pre-equilibrated in $\mathrm{MeOH}$, and eluted with $600 \mathrm{ml} \mathrm{MeOH}$ or $\mathrm{Me}_{2} \mathrm{CO}$.

A portion of fraction $\mathbf{i}($ c. $2.5 \mathrm{~g})$ was loaded onto a LH20 column pre-equilibrated in 50\% $\mathrm{MeOH} / \mathrm{CH}_{2} \mathrm{Cl}_{2}$ over three columns, each column taking several hours to elute, often run over night with fractions automatically collected every fifteen minutes. All the fractions eluted from the column where combined four parts, fats (green), A (brown), B (orange), C (yellow). Portions of $\mathbf{B}$ were put though HPLC, (gradient, $40 \mathrm{~min} 80 \%$, ramp to $95 \%$ over five min, $\mathrm{MeOH} / 0.2 \mathrm{M}$ Formic $\left._{(\mathrm{aq})}\right)$ over a series of runs and recombined generating a total of 16 fractions, D-S. This lead to the isolation of several previously identified hamigerans including debromohamigeran A (29) (fraction $\mathbf{H}, t_{\mathrm{R}} 16.8 \mathrm{~min}, 24.8 \mathrm{mg}$ ), hamigeran $\mathrm{G}$ (40) (fraction $\mathbf{J}, t_{\mathrm{R}} 20.4 \mathrm{~min}, 34.1 \mathrm{mg}$ ) hamigeran A (28) (fraction $\mathbf{L}, t_{\mathrm{R}} 28.8 \mathrm{~min}, 8 \mathrm{mg}$ ) hamigeran $\mathrm{B}(\mathbf{3 0})$ (fraction $\mathbf{O}, t_{\mathrm{R}} 43.4 \mathrm{~min}, 7.9$ $\mathrm{mg}$ ) dibromohamigeran B (31) (fraction $\mathbf{Q}, t_{\mathrm{R}} 48.5 \mathrm{~min}, 20.7 \mathrm{mg}$ ). Further purification with the same conditions with the fraction $\mathbf{E}$ generated of seven fractions, $\mathbf{T}-\mathbf{Z}$ and lead to the isolation of hamigeran $\mathrm{F}$ (38) (6.8 $\mathrm{min}, 0.1 \mathrm{mg})$ in fraction $\mathbf{W}$ and the new compound, debromohamigeran $\mathrm{J}(\mathbf{6 1})\left(t_{\mathrm{R}} 7.3 \mathrm{~min}, 1.1 \mathrm{mg}\right)$ in fraction $\mathbf{X}$. Fraction $\mathbf{F}$ was also submitted to further HPLC, (gradient, $25 \mathrm{~min} 60 \%$ ramp to $100 \%$ over five min, MeCN/0.2M Formic (aq) generated 12 fractions, AA-AM from which fraction AD gave hamigeran L 12-O-methyl ester (63) ( $t_{\mathrm{R}} 12.4$ min, $2.7 \mathrm{mg}$ ) and fractions AI afforded debromohamigeran B (37) ( $\left.t_{\mathrm{R}} 21.4 \mathrm{~min}, 1.3 \mathrm{mg}\right)$. Work up fraction $\mathbf{N}$ with two isocratic HPLC $(85 \%, 80 \%, \mathrm{MeOH})$ runs lead to the isolation of 4 bromohamigeran A (64) ( $\left.t_{\mathrm{R}} 33.8 \mathrm{~min}, 1.8 \mathrm{mg}\right)$.

The fraction $\mathbf{j}(3.3 \mathrm{~g})$ was also subjected to a LH20 column, under the same conditions as the previous LH20 column. The eluted fractions were separated into 5 parts, fats (green), AR (brown), AS (red), AT (orange), AU (yellow). HPLC (isocratic, 100\% $\mathrm{MeOH}$ ) was used to separate $\mathbf{A S}$ into nine fractions, $\mathbf{A V}-\mathbf{B D}$, with $\mathbf{A X}$ taken up for further purification on HPLC 
(isocratic, $95 \% \mathrm{MeOH} / \mathrm{H}_{2} \mathrm{O}$ ). This lead to the isolation of Hamigeran S (65) from one of the three fractions, BG (t $12.8 \mathrm{~min}, 14.0 \mathrm{mg})$.

\subsection{Hamigerans R (61) and Debromohamigeran I (60)}

Frozen Hamigera tarangaensis (PTN2_79F, 202.2 g), collected from Taheke reef, Cavalli Island, New Zealand, was cut into small pieces and extracted with $\mathrm{MeOH}(2 \times 1 \mathrm{~L})$. The second and first extracts were cyclic loaded (to $8 \mathrm{~L}$ of $\mathrm{H}_{2} \mathrm{O}$ and $\mathrm{MeOH}$ ) on a column packed with $1 \mathrm{~L} \mathrm{HP20,}$ pre-equilibrated in $\mathrm{MeOH}$. The column was eluted with $3 \mathrm{~L}$ portions of i) $\mathrm{H}_{2} \mathrm{O}$, ii $20 \%$ $\mathrm{Me}_{2} \mathrm{CO} / \mathrm{H}_{2} \mathrm{O}$ (fraction k), iii) $40 \% \mathrm{Me}_{2} \mathrm{CO} / \mathrm{H}_{2} \mathrm{O}$ (fraction l) iv) $60 \% \mathrm{Me}_{2} \mathrm{CO} / \mathrm{H}_{2} \mathrm{O}$ (fraction m) v) $80 \% \mathrm{Me}_{2} \mathrm{CO} / \mathrm{H}_{2} \mathrm{O}$ (fraction $\mathbf{n}$ ) and vi) $\mathrm{Me}_{2} \mathrm{CO}$ (fraction o). The fractions k-o were diluted threefold with $\mathrm{H}_{2} \mathrm{O}$, backloaded on to $200 \mathrm{ml} \mathrm{HP} 20$ pre-equilibrated in $\mathrm{MeOH}$, and eluted with $600 \mathrm{ml} \mathrm{MeOH}$ or $\mathrm{Me}_{2} \mathrm{CO}$.

The entirety of fraction $\mathbf{m}(c .0 .55 \mathrm{~g})$ was loaded onto a LH20 column pre-equilibrated in $50 \%$ $\mathrm{MeOH} / \mathrm{CH}_{2} \mathrm{Cl}_{2}$. The column produced 95 fractions. Which were pooled into four parts, fats (green), A (brown), B (orange), C (yellow). Part C (77.0 mg) was subjected to HPLC, (gradient $80 \%-95 \% \mathrm{MeOH} / 0.2 \mathrm{M}$ Formic $\left.{ }_{(\mathrm{aq})}\right)$ resulting in nine fractions $\mathbf{D}-\mathbf{L}$ with the fractions $\mathbf{G}$ and $\mathbf{H}$ having debromohamigeran I (60) ( $t_{\mathrm{R}} 10.0 \mathrm{~min}, 1.3 \mathrm{mg}$ ) and hamigeran R (61) (t $10.9 \mathrm{~min}, 2.4$ $\mathrm{mg}$ ), respectively.

\subsection{Reactions of the hamigerans}

All reactions excluding the initial NMR tube reaction of hamigeran $G(40)$ and ammonia $(a q)$ were in absolute ethanol. All ammonium containing reactions performed in sample vials at room temperature. All amino acid containing reactions performed in round bottle flasks under reflux in a 10:1 ratio of amino acid to hamigeran. 


\section{Synthesis of hamigeran G imine (66)}

Hamigeran G (5 mg, $0.0132 \mathrm{mmol})$ was dissolved in EtOH $(10 \mathrm{ml})$. Ammonium formate (0.8 $\mathrm{mg}, 0.0132 \mathrm{mmol}$ ) was added, reacting instantly. The reaction was concentrated under reduced pressure to yield a bright red film which contained 66 . The reaction was repeated with $2 \mathrm{mg}$ (0.0264 mmol), $4 \mathrm{mg}(0.0528 \mathrm{mmol})$ and $8 \mathrm{mg}(0.1048 \mathrm{mmol})$ of ammonium formate till maximum conversion appeared to be obtained.

\section{Synthesis of hamigeran D (33) and epimer (69) from reaction with hamigeran G (40) and}

\section{L-alanine}

Hamigeran G (5 mg, $0.0132 \mathrm{mmol})$ was dissolved in EtOH (10 ml). L-Alanine (12 mg, 0.1322 mmol) was added and the reaction stirred under reflux for 2 hours. The reaction was filtered through HP20ss with $\mathrm{Me}_{2} \mathrm{CO}$ and the filtrate was concentrated under reduced pressure to yield a pale yellow film. This was purified with HPLC (isocratic, $85 \% \mathrm{MeOH} / \mathrm{H}_{2} \mathrm{O}$ ) resulting in 4 fractions, the third fraction containing both compounds 33 and $\mathbf{6 9}\left(t_{\mathrm{R}} 6.5 \mathrm{~min}, 2.3 \mathrm{mg}\right)$.

\section{Synthesis of glycine hamigeran (68) from reaction with Hamigeran G (40) and glycine}

Hamigeran G (2.5 mg, $0.0066 \mathrm{mmol})$ was dissolved in EtOH $(10 \mathrm{ml})$. Glycine $(5 \mathrm{mg}, 0.0662$ mmol) was added and the reaction stirred under reflux for 2 hours. The reaction was filtered through HP20ss with $\mathrm{Me}_{2} \mathrm{CO}$ and the filtrate was concentrated under reduced pressure to yield a pale yellow film. This was purified with HPLC (isocratic, $85 \% \mathrm{MeOH} / \mathrm{H}_{2} \mathrm{O}$ ) resulting in 6 fractions, the forth fraction containing both compounds $\mathbf{6 8}\left(t_{\mathrm{R}} 9.3 \mathrm{~min}\right)$.

\section{Synthesis of Hamigeran D (33) and epimer (69) from reaction with hamigeran G (40) and D-alanine}

Hamigeran G (3 mg, $0.0079 \mathrm{mmol})$ was dissolved in EtOH (10 ml). L-Alanine (7 mg, 0.0793 mmol) was added and the reaction stirred under reflux for 2 hours. The reaction was filtered through HP20ss with $\mathrm{Me}_{2} \mathrm{CO}$ and the filtrate was concentrated under reduced pressure to yield a 
pale yellow film. This was purified with HPLC (isocratic, $85 \% \mathrm{MeOH} / \mathrm{H}_{2} \mathrm{O}$ ) resulting in 4 fractions, the third fraction containing both compounds 33 and $\mathbf{6 9}\left(t_{\mathrm{R}} 6.6 \mathrm{~min}, 1.5 \mathrm{mg}\right)$.

\section{Attempted synthesis of hamigeran B glycine compound}

Hamigeran B (2.5 mg, $0.0069 \mathrm{mmol})$ was dissolved in EtOH (10 ml). Glycine (5 mg, 0.0687 mmol) was added and the reaction stirred under reflux for 2 hours. No colour change occurred, so reflux was extended 12 hours. The reaction was filtered through HP20ss with $\mathrm{Me}_{2} \mathrm{CO}$ and the filtrate was concentrated under reduced pressure to yield starting material hamigeran B (30).

\section{Synthesis of hamigeran B imine (70)}

Hamigeran B (5 mg, $0.0069 \mathrm{mmol})$ was dissolved in EtOH $(10 \mathrm{ml})$. Ammonium formate (4.4 mg, $0.0687 \mathrm{mmol}$ ) was added, slight colour change noted. Reaction stirred at room temperature for 5 hours, equilibrated another 24 hours. The reaction was concentrated under reduced pressure to yield a dull orange film which contained $\mathbf{7 0 .}$

\section{Synthesis of Hamigeran $N$ (52) and epimer (53) from hamigeran G (40) and L-phenylalanine}

Hamigeran G (1.5 mg, $0.0039 \mathrm{mmol})$ was dissolved in EtOH (10 ml). L-Alanine $(7 \mathrm{mg}, 0.0396$ mmol) was added and the reaction stirred under reflux for 2 hours. The reaction was filtered through HP20ss with $\mathrm{Me}_{2} \mathrm{CO}$ and the filtrate was concentrated under reduced pressure to yield a pale yellow film. This was purified with HPLC (isocratic, $85 \% \mathrm{MeOH} / \mathrm{H}_{2} \mathrm{O}$ ) resulting in 8 fractions, the eighth fraction containing both compounds $\mathbf{5 2}$ and $\mathbf{5 3}\left(t_{\mathrm{R}} 19.2 \mathrm{~min}\right)$. 
Hamigeran A (28). Yellow film; IR $v_{\max } 3500$ (O-H), 2956 (C-H aromatic), 2850 (C-H), 1738 $(\mathrm{C}=\mathrm{O}$ ester), 1634 ( $\mathrm{C}=\mathrm{O}$ ketone), 1173 (C-O); All other data previously described.

Debromohamigeran A (29). Pale yellow film; IR $\nu_{\max } 3500(\mathrm{O}-\mathrm{H}), 2956$ (C-H aromatic), 2870 (C-H), 1736 (C=O ester), 1637 (C=O ketone), 1231 (C-O); All other data previously described.

Hamigeran B (30). Bright yellow film; IR $\nu_{\max } 2957$ (C-H aromatic), 2871 (C-H), 1725 (C=O ketone), 1634 (C=O ketone); All other data previously described.

Debromohamigeran B (37). Bright yellow film; $[\alpha]_{D}^{25}-80.5^{\circ}\left(c 0.42, \mathrm{CH}_{2} \mathrm{Cl}_{2}\right)$; UV $(\mathrm{MeOH}) \lambda_{\max }$

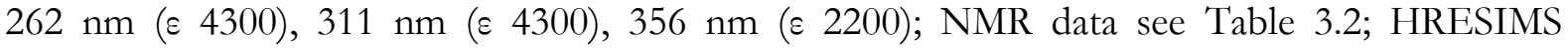
$[\mathrm{M}+\mathrm{H}]^{+}$, observed $m / z 287.1645$, calculated 286.1572 for $\mathrm{C}_{18} \mathrm{H}_{22} \mathrm{O}{ }_{3} \mathrm{H}, \Delta=+1.08$ ppm.

Debromohamigeran I (60). Pale yellow film; $[\alpha]_{D}^{25}-50.4^{\circ}\left(c 0.635, \mathrm{CH}_{2} \mathrm{Cl}_{2}\right)$; UV (MeOH) $\lambda_{\max }$ $216 \mathrm{~nm}(\varepsilon 28000), 278 \mathrm{~nm}\left(\varepsilon\right.$ 6900); NMR data see Table 3.3; HRESIMS $[\mathrm{M}+\mathrm{H}]^{+}$, observed $m /$ z 319.1902, calculated 318.1829 for $\mathrm{C}_{19} \mathrm{H}_{26} \mathrm{O}_{4} \mathrm{H}, \Delta=-0.6 \mathrm{ppm}$.

Debromohamigeran J (62). Pale yellow film; $[\alpha]_{D}^{25}-104.4^{\circ}\left(c 0.58, \mathrm{CH}_{2} \mathrm{Cl}_{2}\right)$; UV (MeOH) $\lambda_{\max }$

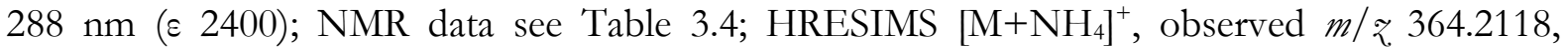
calculated 346.179 for $\mathrm{C}_{20} \mathrm{H}_{26} \mathrm{O}_{5} \mathrm{NH}_{4}, \Delta=+2.8 \mathrm{ppm}$.

Hamigeran L-11-O-methyl ester (50). Colourless film; IR $\nu_{\max } 2956$ (C-H aromatic), 2870 (C$\mathrm{H}), 1721$ ( $\mathrm{C}=\mathrm{O}$ ester), 16710 ( $\mathrm{C}=\mathrm{O}$ acid), 1241 and 1192 (C-O ester stretch); All other data previously described.

Hamigeran L-12-O-methyl ester (63). Colourless film; $[\alpha]_{D}^{25}+89.4^{\circ}\left(c 0.89, \mathrm{CH}_{2} \mathrm{Cl}_{2}\right)$; UV $(\mathrm{MeOH}) \lambda_{\max } 286 \mathrm{~nm}(\varepsilon 2400), 485 \mathrm{~nm}$ ( $\varepsilon$ 570); NMR data see Table 3.5; HRESIMS $[\mathrm{M}+\mathrm{H}]^{+}$, observed $m / ₹ 427.1114$, calculated 426.1039 for $\mathrm{C}_{20} \mathrm{H}_{27} \mathrm{O}_{5}{ }^{79} \mathrm{BrH}, \Delta=-0.77 \mathrm{ppm}$. 
4-Bromohamigeran A (64). Pale yellow film; $[\alpha]_{D}^{25}-65^{\circ}\left(c 0.88, \mathrm{CH}_{2} \mathrm{Cl}_{2}\right)$; UV $(\mathrm{MeOH}) \lambda_{\max } 229$ nm (ع 18000), $281 \mathrm{~nm}$ ( ع 9700), $356 \mathrm{~nm}(\varepsilon 4800)$; NMR data see Table 3.7; HRESIMS $[\mathrm{M}+\mathrm{H}]^{+}$, observed $m / z 503.0063$, calculated 501.9987 for $\mathrm{C}_{20} \mathrm{H}_{24} \mathrm{O}_{5}{ }^{79} \mathrm{Br}_{2} \mathrm{H}, \Delta=-0.62 \mathrm{ppm}$.

Hamigeran R (61). pale yellow film; $[\alpha]_{D}^{25}-45.6^{\circ}\left(c 1.205, \mathrm{CH}_{2} \mathrm{Cl}_{2}\right)$; UV $(\mathrm{MeOH}) \lambda_{\max } 219 \mathrm{~nm}(\varepsilon$ 32000), $309 \mathrm{~nm}$ ( $\varepsilon 2300), 339 \mathrm{~nm}$ ( 2 2900); NMR data see Table 4.2; HRESIMS $\left[\mathrm{M}+\mathrm{NH}_{4}\right]^{+}$, observed $m / z$ 411.128, calculated 393.0942 for $\mathrm{C}_{19} \mathrm{H}_{24} \mathrm{NO}_{3}{ }^{79} \mathrm{BrNH}_{4}, \Delta=+0.52 \mathrm{ppm}$; Negative ion mode HRESIMS $[\mathrm{M}-\mathrm{H}]^{-}$, observed $m / z 392.0867$, calculated 393.0942 for $\mathrm{C}_{19} \mathrm{H}_{23} \mathrm{NO}_{3}{ }^{79} \mathrm{Br}$, $\Delta=-1.83$ ppm: IR $\nu_{\max } 3222(\mathrm{O}-\mathrm{H}), 2956(\mathrm{C}-\mathrm{H}), 2223(\mathrm{C} \equiv \mathrm{N}), 1704(\mathrm{C}=\mathrm{O}) \mathrm{cm}^{-1}$.

Hamigeran S (65). colourless film; $[\alpha]_{D}^{25}+33.4^{\circ}\left(c 6.385, \mathrm{CH}_{2} \mathrm{Cl}_{2}\right)$; UV $(\mathrm{MeOH}) \lambda_{\max } 291 \mathrm{~nm}(\varepsilon$ 4200), $485 \mathrm{~nm}$ ( $\varepsilon$ 1900); NMR data see Table 4.3; HRESIMS $[\mathrm{M}+\mathrm{H}]^{+}$, observed $m / z .738 .1788$, calculated 737.1703 for $\mathrm{C}_{38} \mathrm{H}_{45} \mathrm{NO}_{4}{ }^{79} \mathrm{Br}_{2} \mathrm{H}, \Delta=-1.64 \mathrm{ppm},\left[\mathrm{M}+2 \mathrm{H}_{2} \mathrm{O}+\mathrm{Na}\right]^{+}$, observed $\mathrm{m} /$ z 798.1812, calculated 737.1703 for $\mathrm{C}_{38} \mathrm{H}_{45} \mathrm{NO}_{4}{ }^{79} \mathrm{Br}_{2} 2 \mathrm{H}_{2} \mathrm{ONa}, \Delta=+1.22 \mathrm{ppm}$ : IR $\nu_{\max } 3300(\mathrm{~N}-\mathrm{H})$, $2956(\mathrm{C}-\mathrm{H}), 1728(\mathrm{C}=\mathrm{O}) \mathrm{cm}^{-1}$.

Imine Hamigeran (66). Bright red film; NMR data see Table 5.1.

Glycine Hamigeran (68). Pale yellow film; NMR data see Table 5.2; HRESIMS $[\mathrm{M}+\mathrm{H}]^{+}$, observed $m /$ ₹ 390.1061, calculated 389.0987 for $\mathrm{C}_{20} \mathrm{H}_{24} \mathrm{O}_{5}{ }^{79} \mathrm{BrNO}_{2} \mathrm{H}, \Delta=-0.77 \mathrm{ppm}$.

Hamigeran D epimer (69). Pale yellow film; 1H NMR (600MHz, $\left.\mathrm{CDCl}_{3}\right) \delta \mathrm{CH}-186.32$ $(1 \mathrm{H}, \mathrm{d}), 5.07(1 \mathrm{H}, \mathrm{d})$, other peaks not identified; HRESIMS $[\mathrm{M}+\mathrm{H}]^{+}$, observed $m / z$ 406.1154, calculated 403.1151 for $\mathrm{C}_{21} \mathrm{H}_{26} \mathrm{O}_{5}{ }^{79} \mathrm{BrNO}_{2} \mathrm{H}, \Delta=1.12 \mathrm{ppm}$. 


\section{A Debromohamigeran B NMR Spectra}

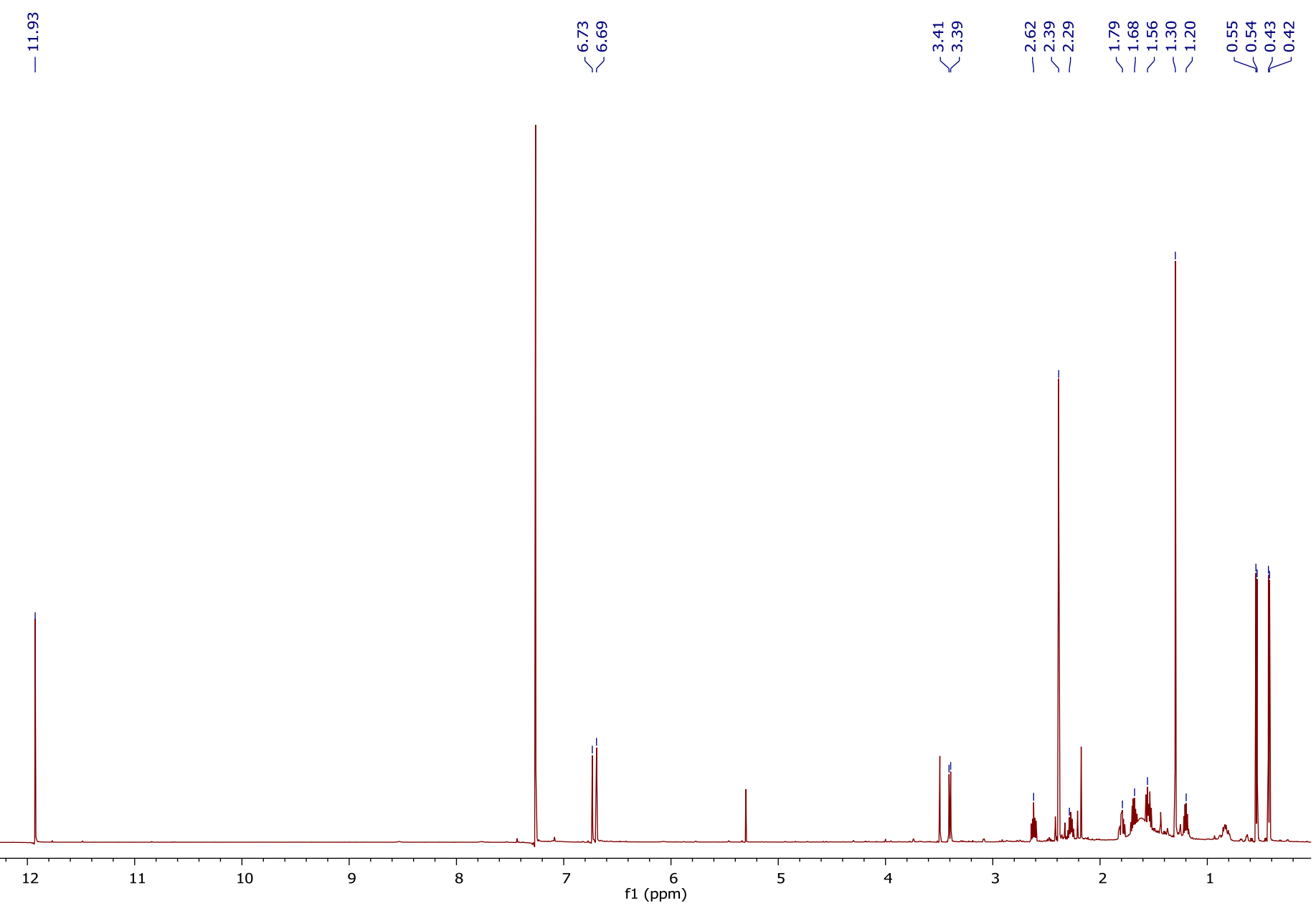

${ }^{1} \mathrm{H}$ NMR spectrum of debromohamigeran $\mathrm{B}(\mathbf{3 7})$ in $\mathrm{CDCl}_{3}(600 \mathrm{MHz})$. 


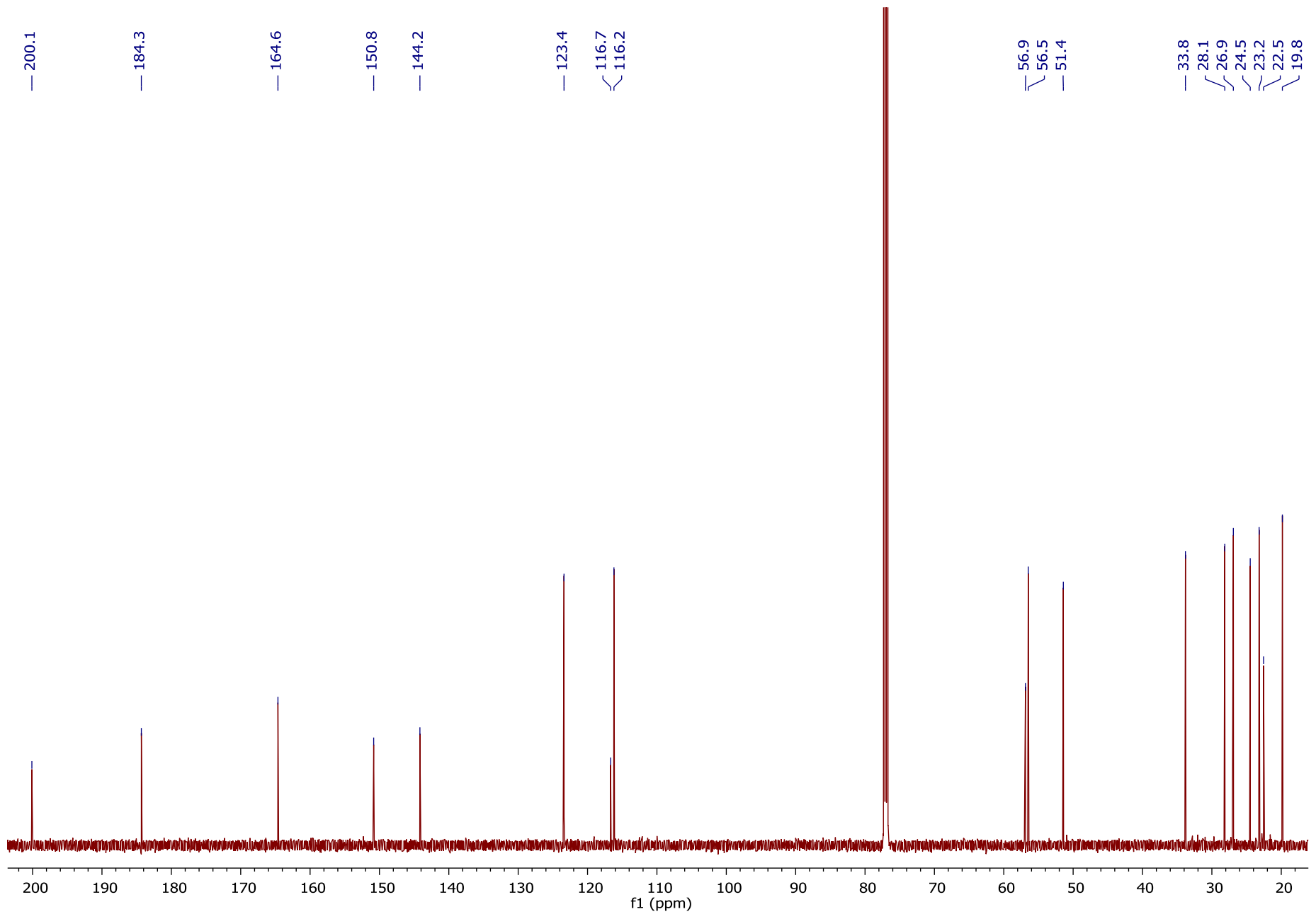

${ }^{13} \mathrm{C}$ NMR spectrum of debromohamigeran $\mathrm{B}(37)$ in $\mathrm{CDCl}_{3}(150 \mathrm{MHz})$. 


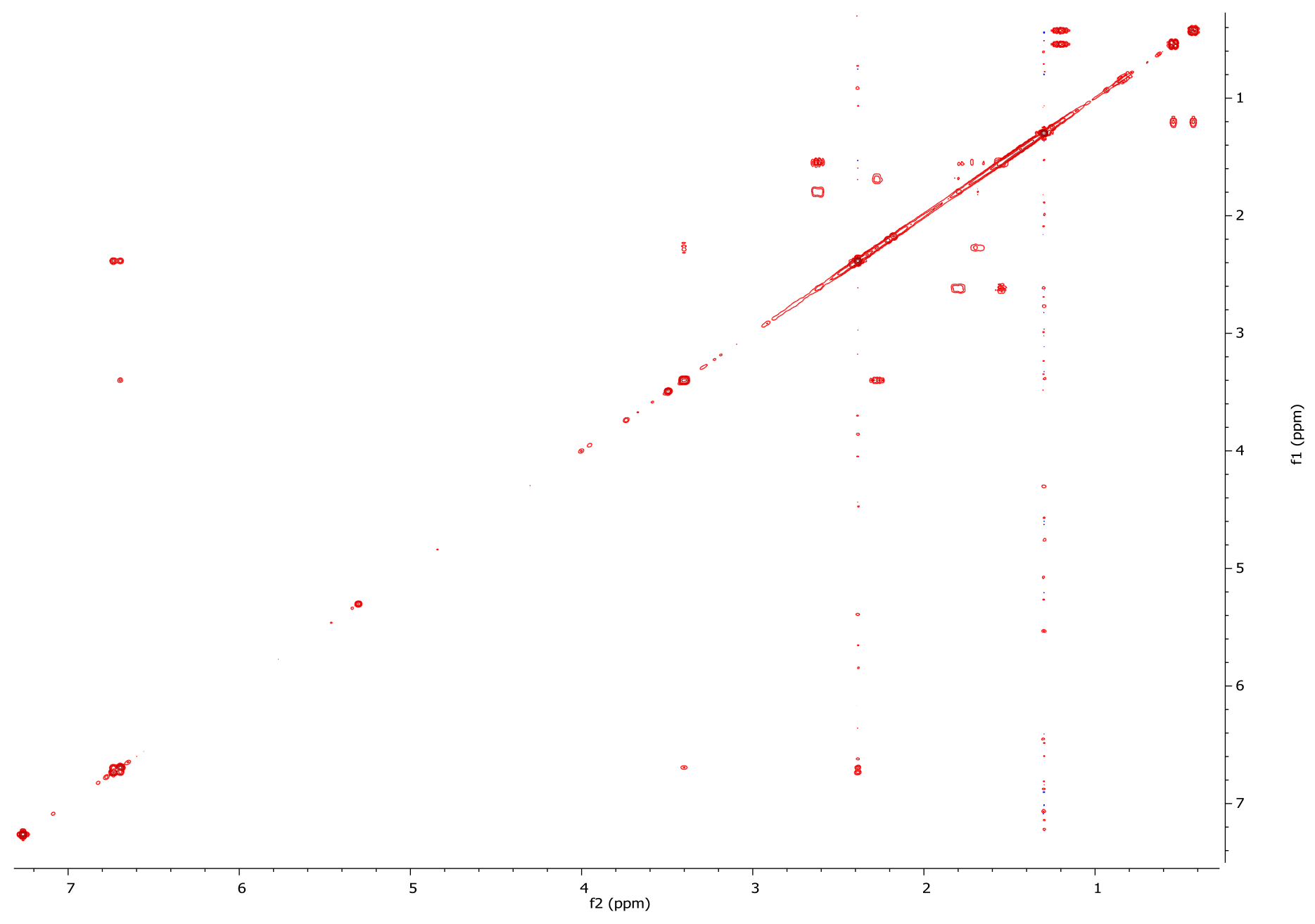

COSY NMR spectrum of debromohamigeran B (37) in $\mathrm{CDCl}_{3}(600 \mathrm{MHz})$. 


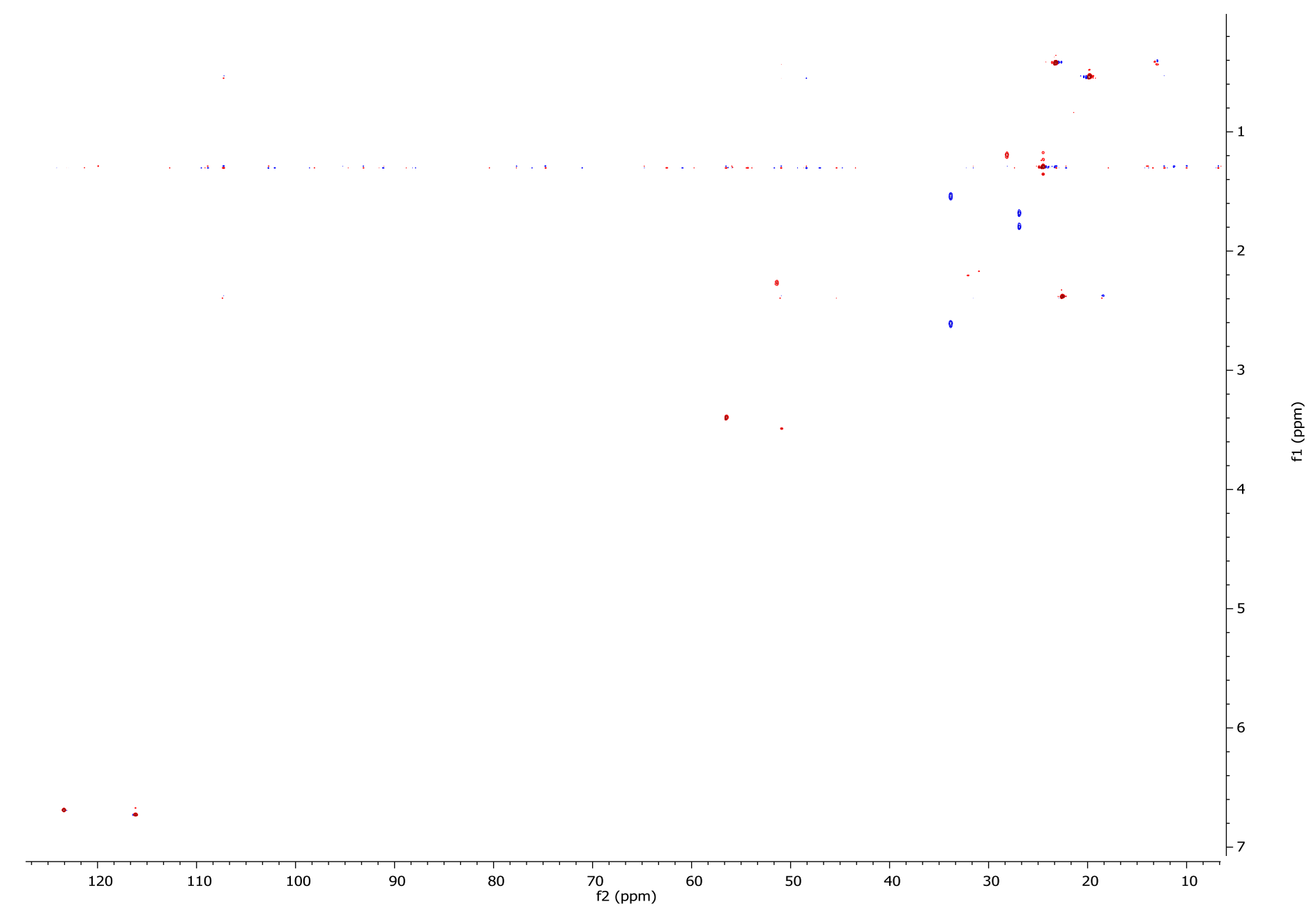

HSQC NMR spectrum of debromohamigeran B (37) in $\mathrm{CDCl}_{3}(600 \mathrm{MHz})$. 


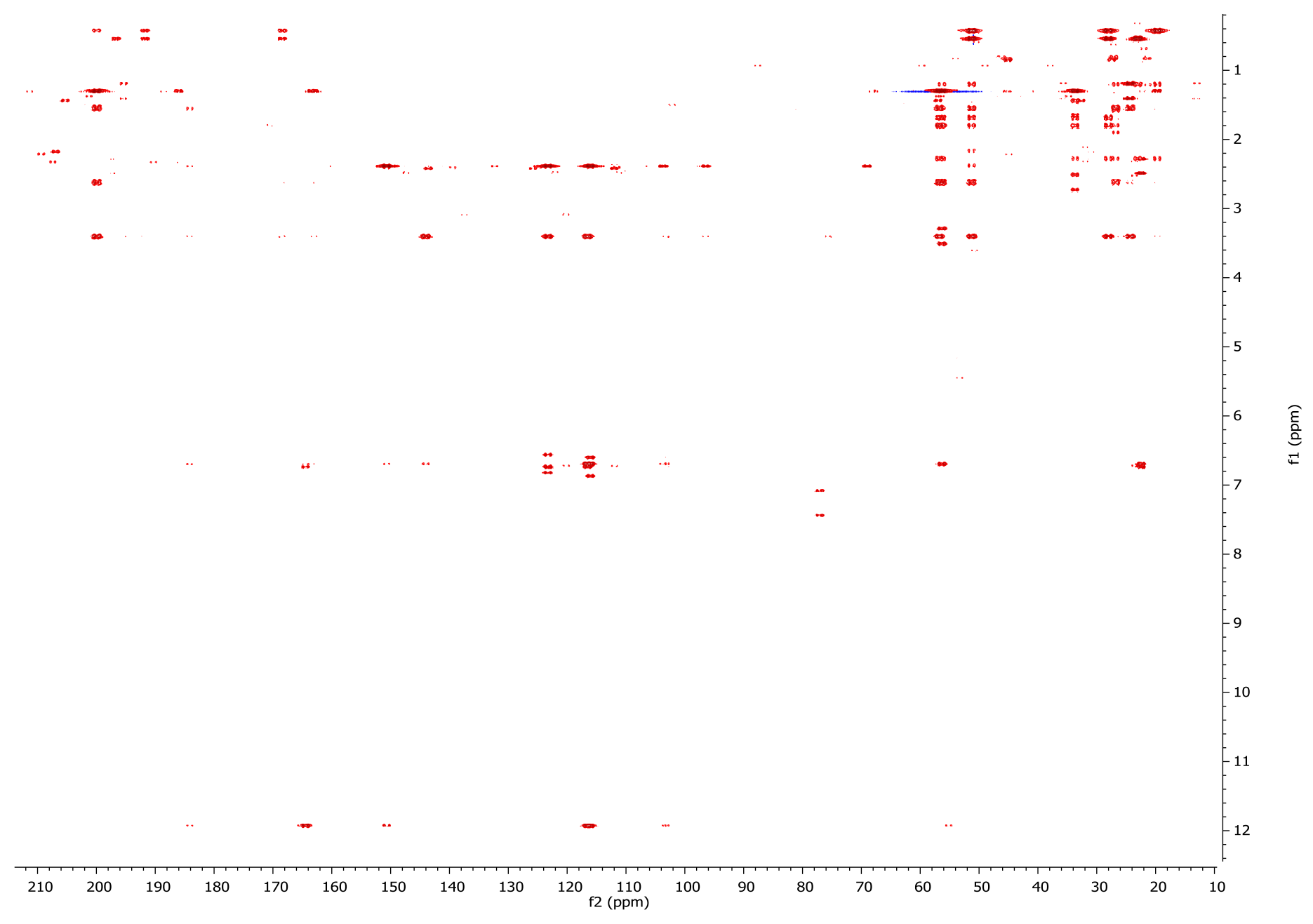

HMBC NMR spectrum of debromohamigeran B (37) in $\mathrm{CDCl}_{3}(600 \mathrm{MHz})$. 


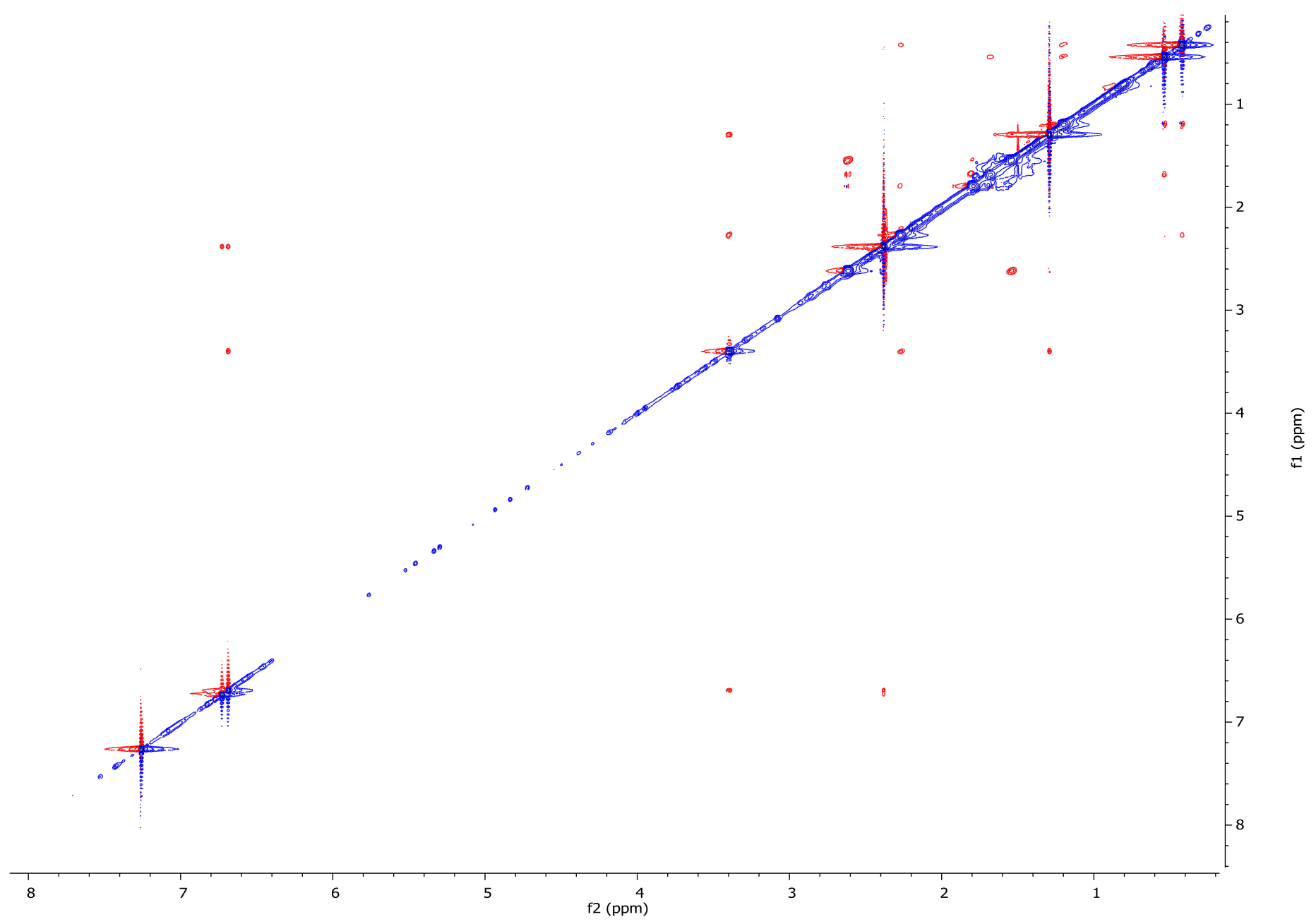

2D NOESY NMR spectrum of debromohamigeran B (37) in $\mathrm{CDCl}_{3}(600 \mathrm{MHz})$. 
Debromohamigeran I NMR Spectra

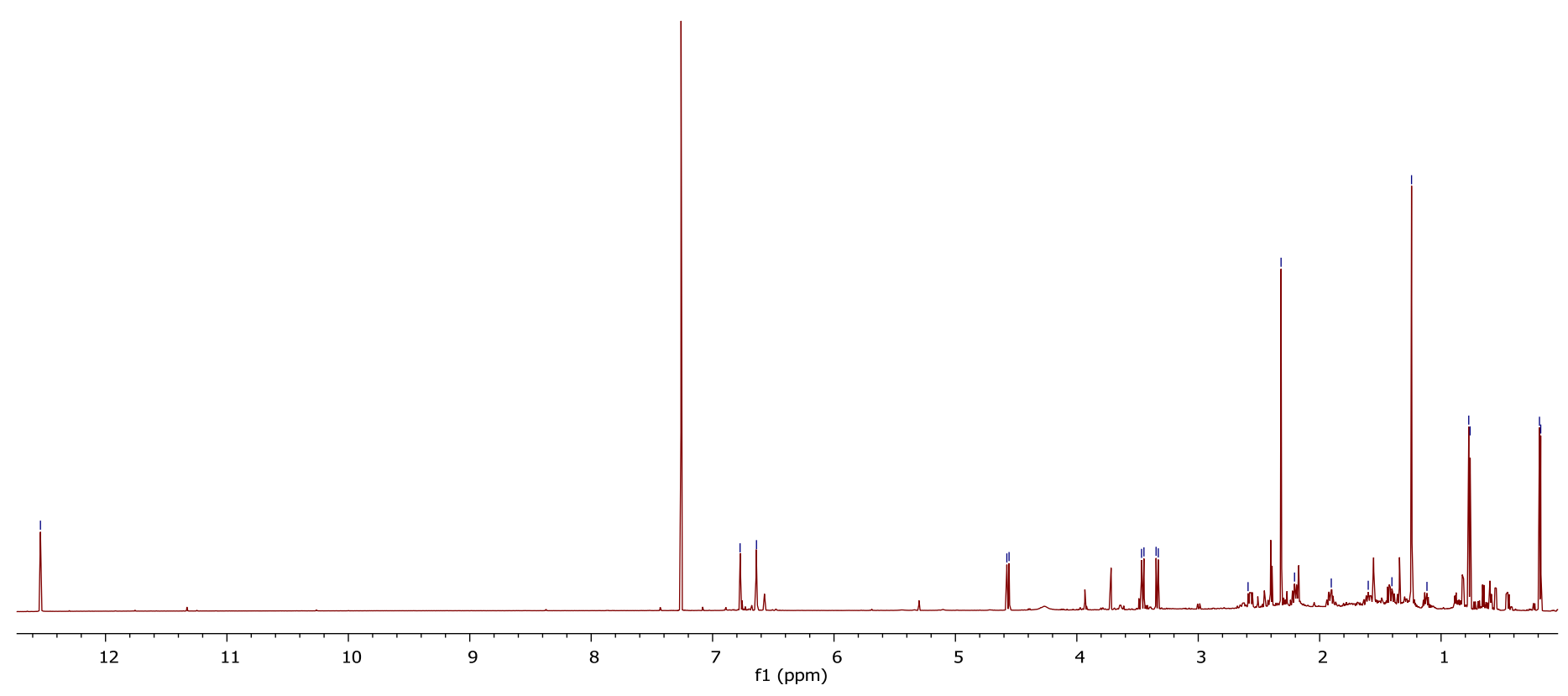

${ }^{1} \mathrm{H}$ NMR spectrum of debromohamigeran I (60) in $\mathrm{CDCl}_{3}(600 \mathrm{MHz})$. 


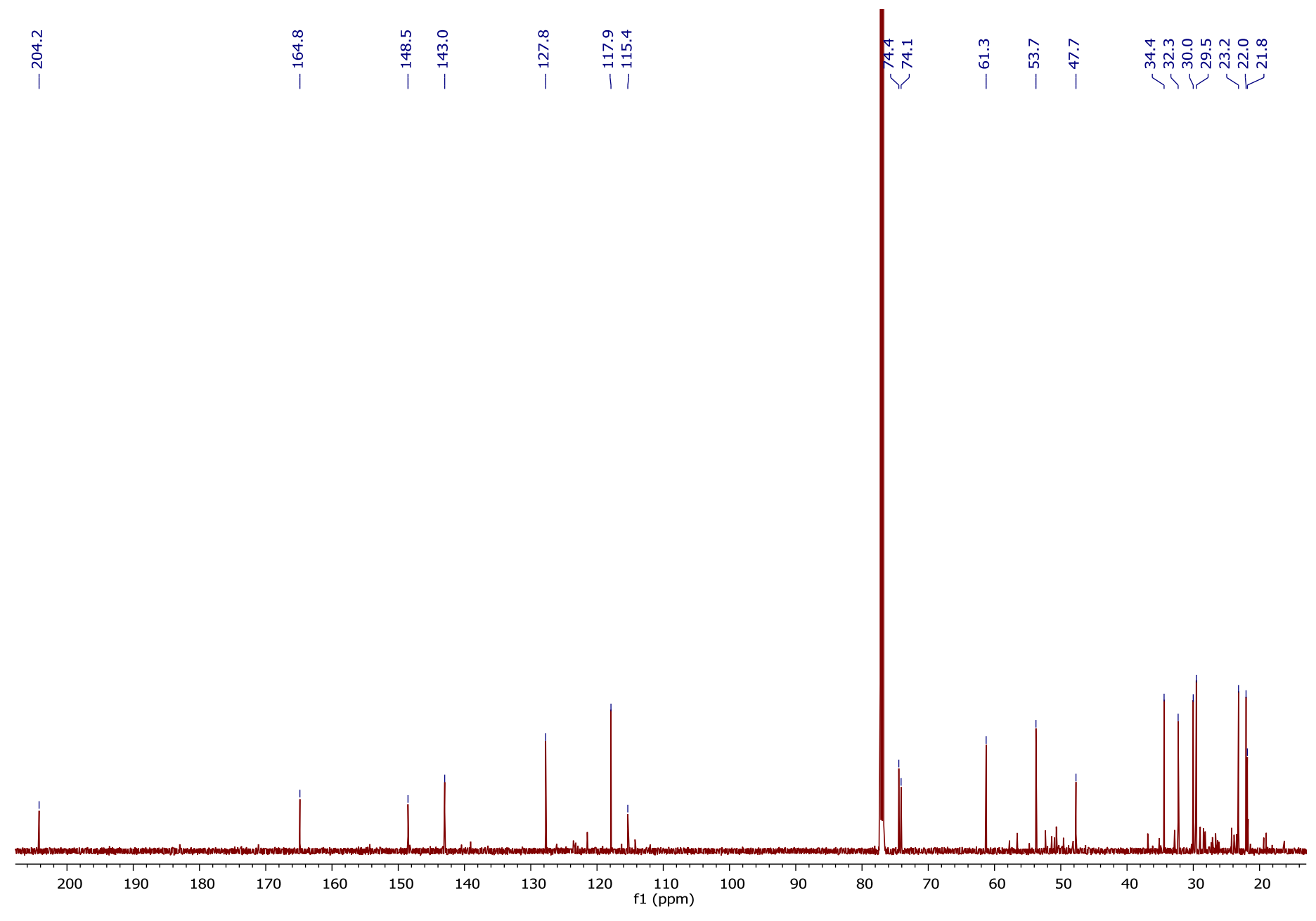

${ }^{13} \mathrm{C}$ NMR spectrum of debromohamigeran I (60) in $\mathrm{CDCl}_{3}(150 \mathrm{MHz})$. 


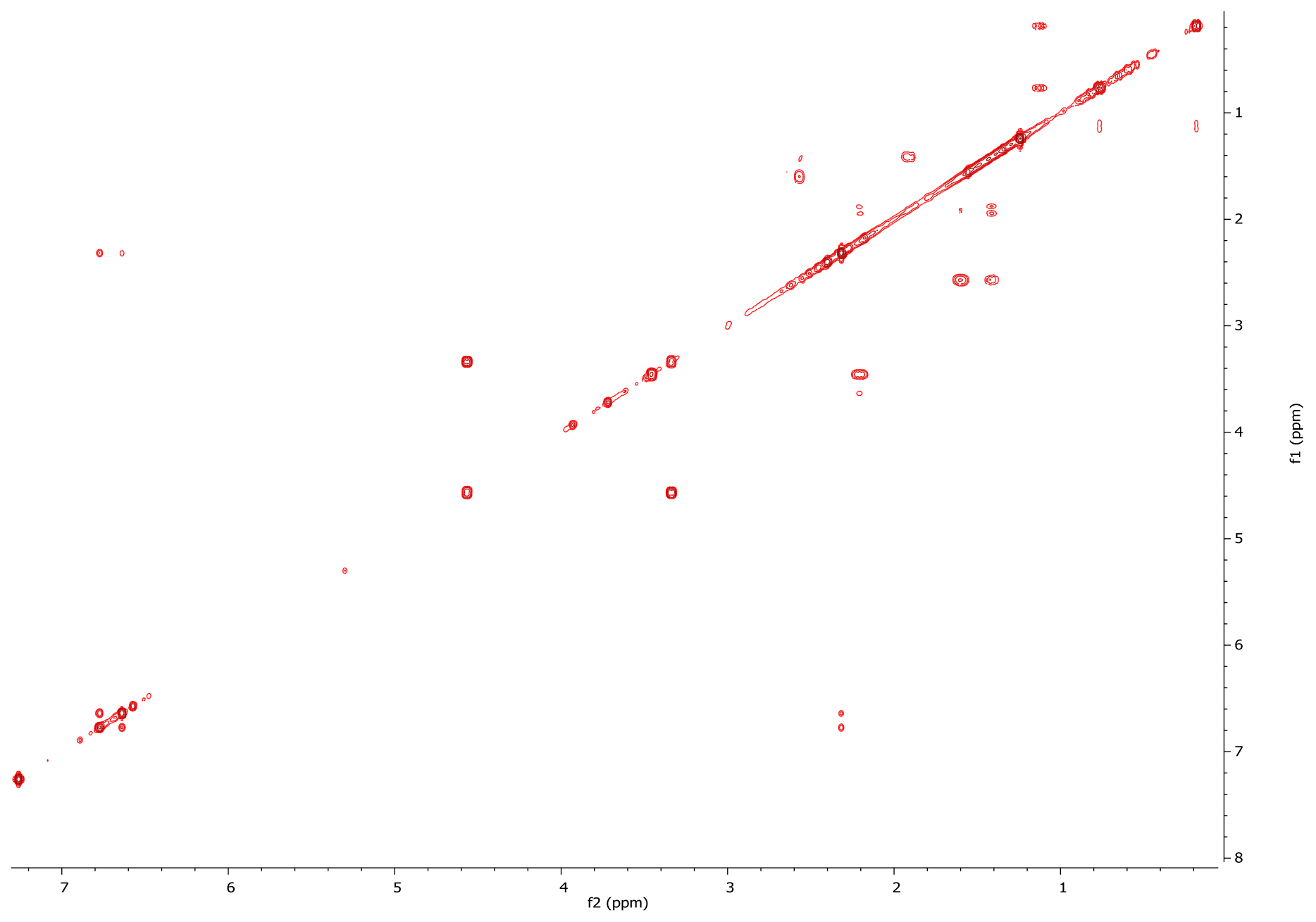

COSY NMR spectrum of debromohamigeran I (60) in $\mathrm{CDCl}_{3}(600 \mathrm{MHz})$. 


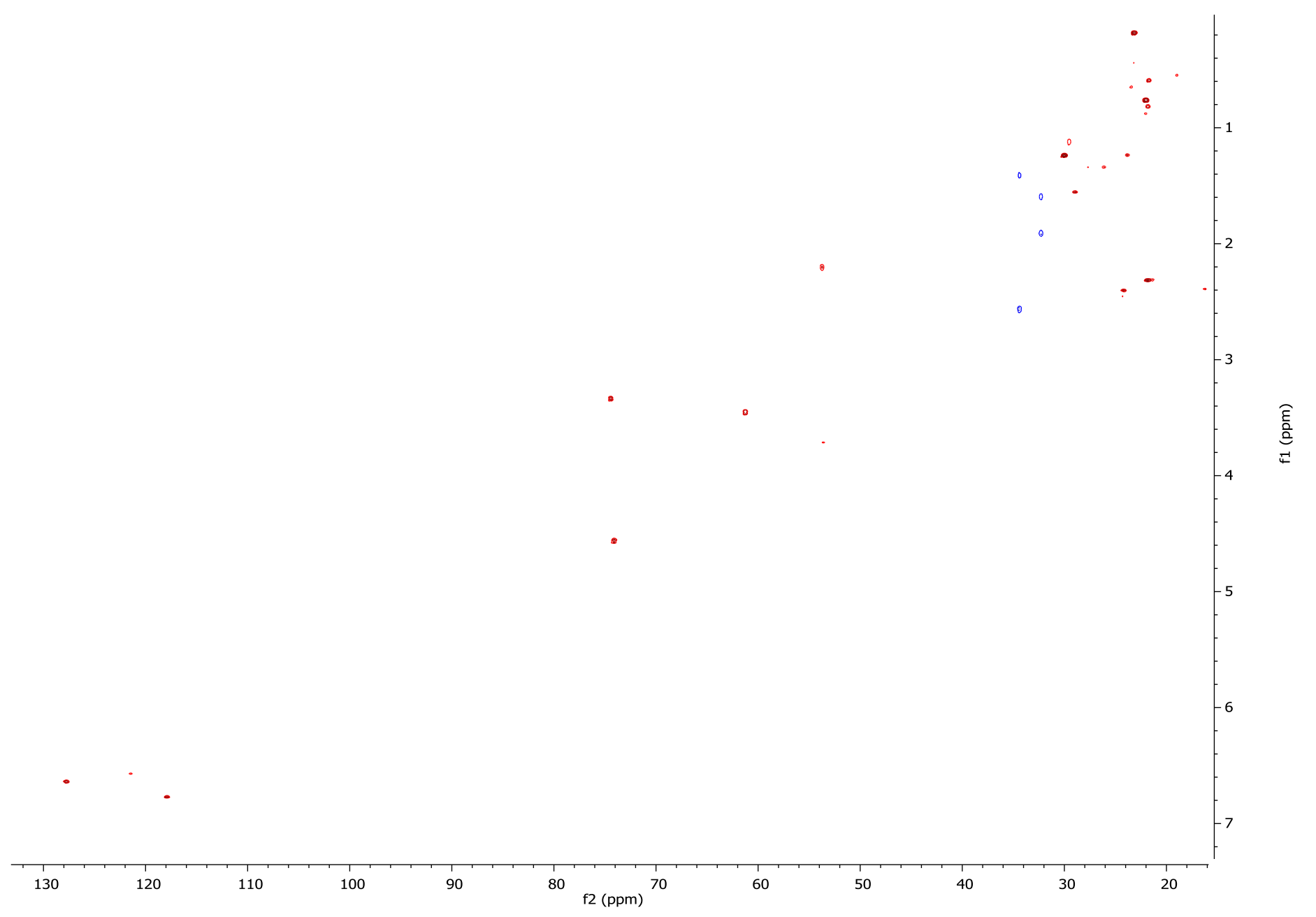

HSQC NMR spectrum of debromohamigeran I (60) in $\mathrm{CDCl}_{3}(600 \mathrm{MHz})$. 


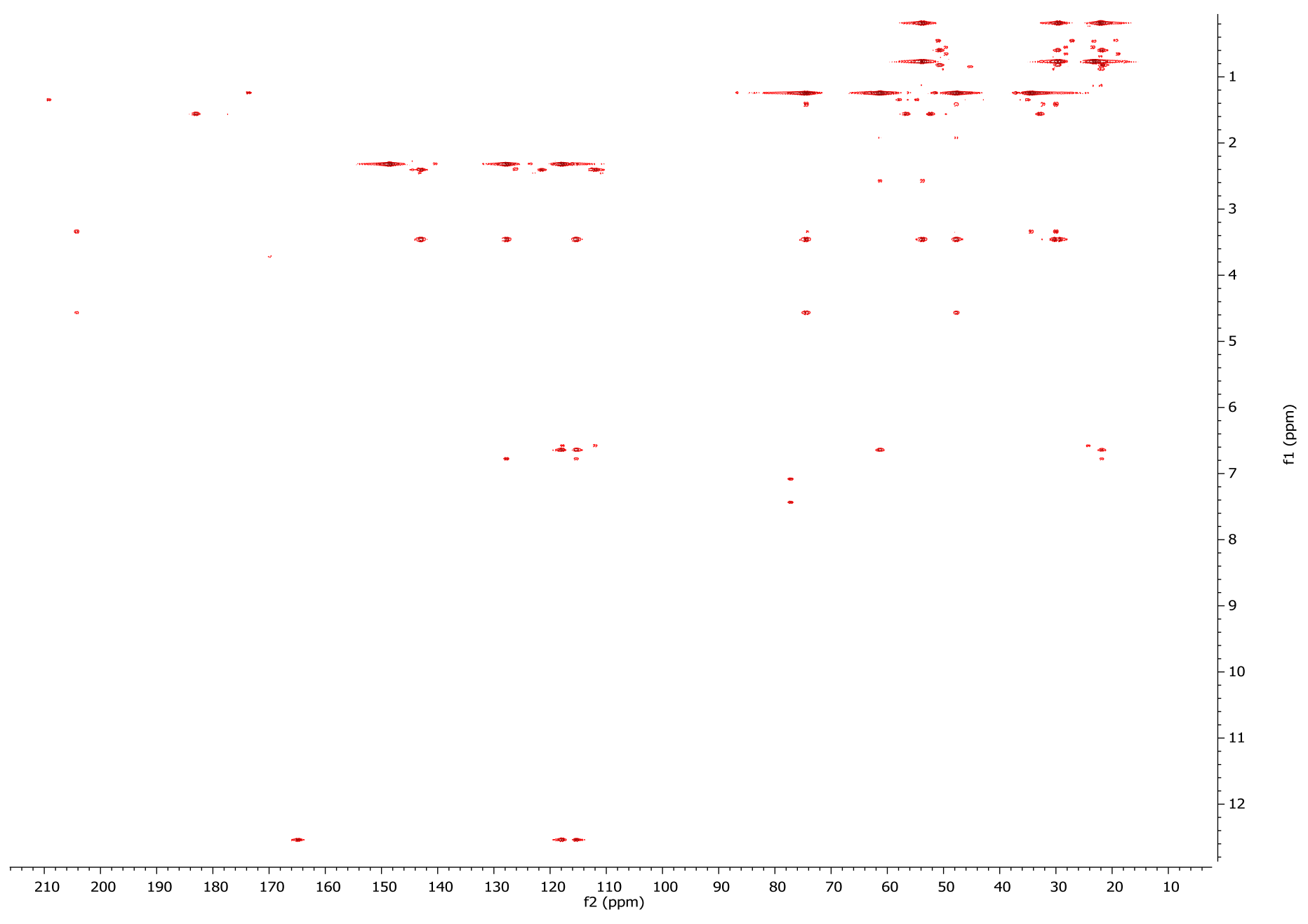

HMBC NMR spectrum of debromohamigeran I (60) in $\mathrm{CDCl}_{3}(600 \mathrm{MHz})$. 


$$
1
$$


C Debromohamigeran J NMR Spectra

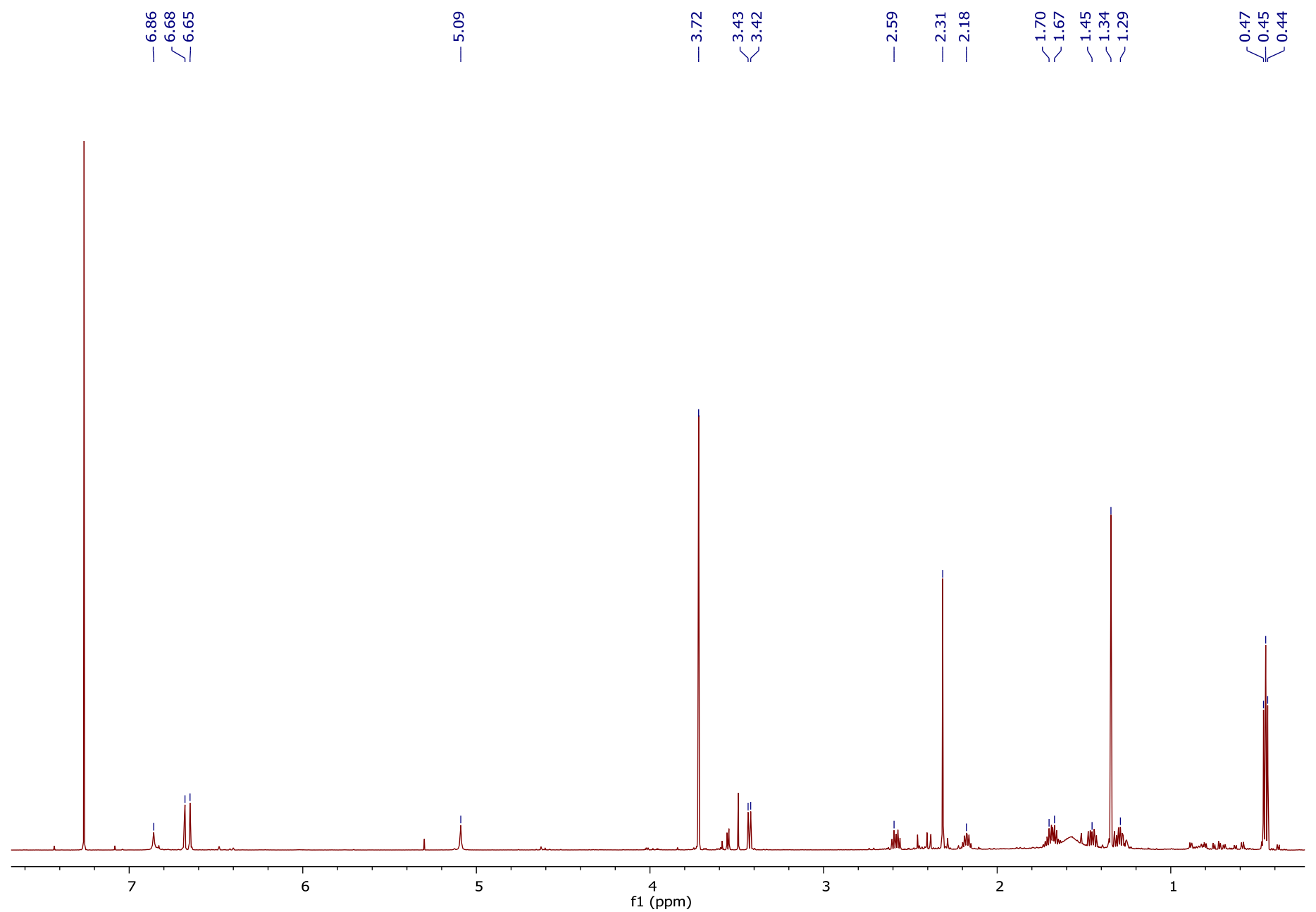

${ }^{1} \mathrm{H}$ NMR spectrum of debromohamigeran J (62) in $\mathrm{CDCl}_{3}(600 \mathrm{MHz})$. 


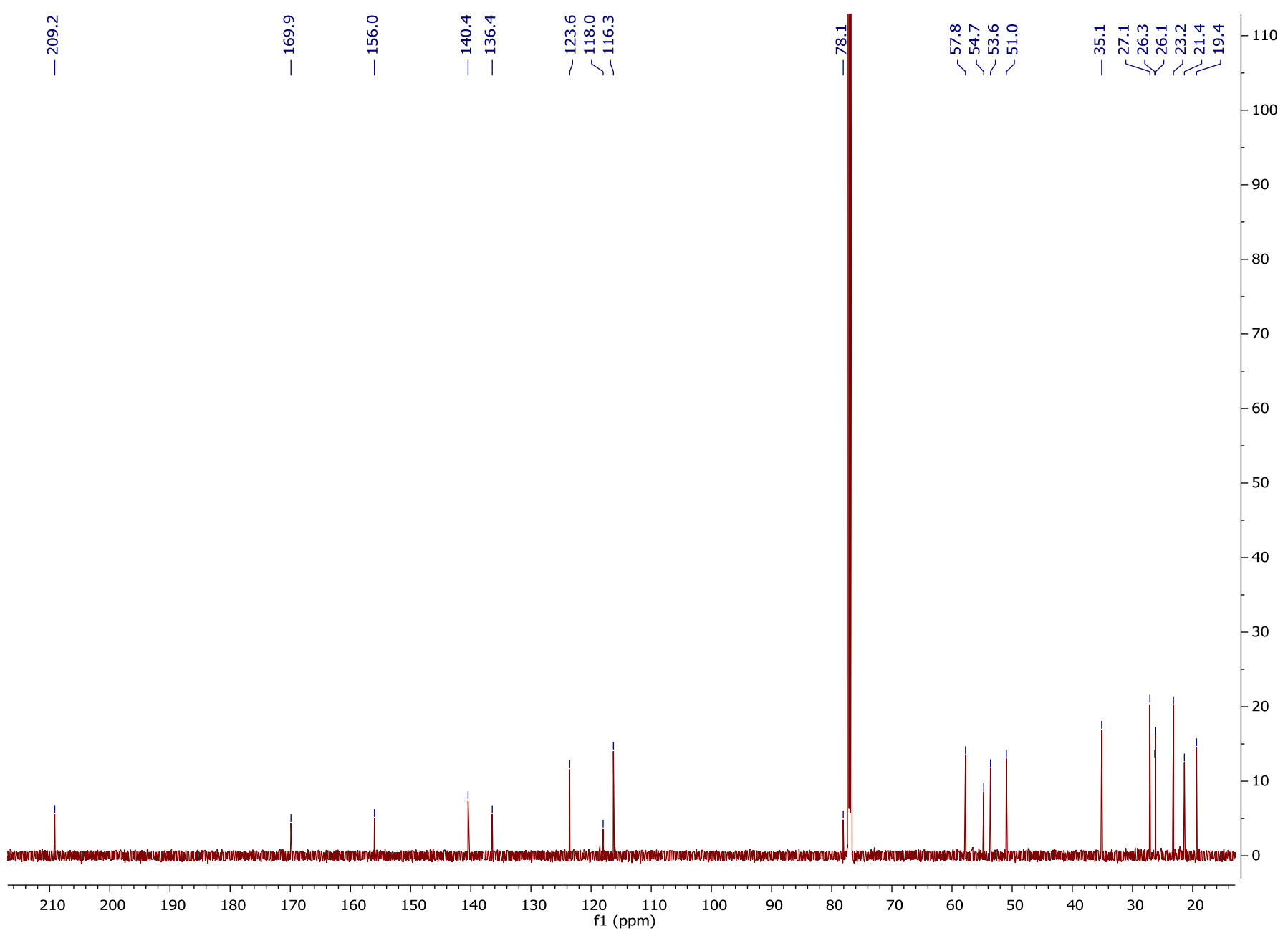

${ }^{13} \mathrm{C}$ NMR spectrum of debromohamigeran J (62) in $\mathrm{CDCl}_{3}(150 \mathrm{MHz})$. 


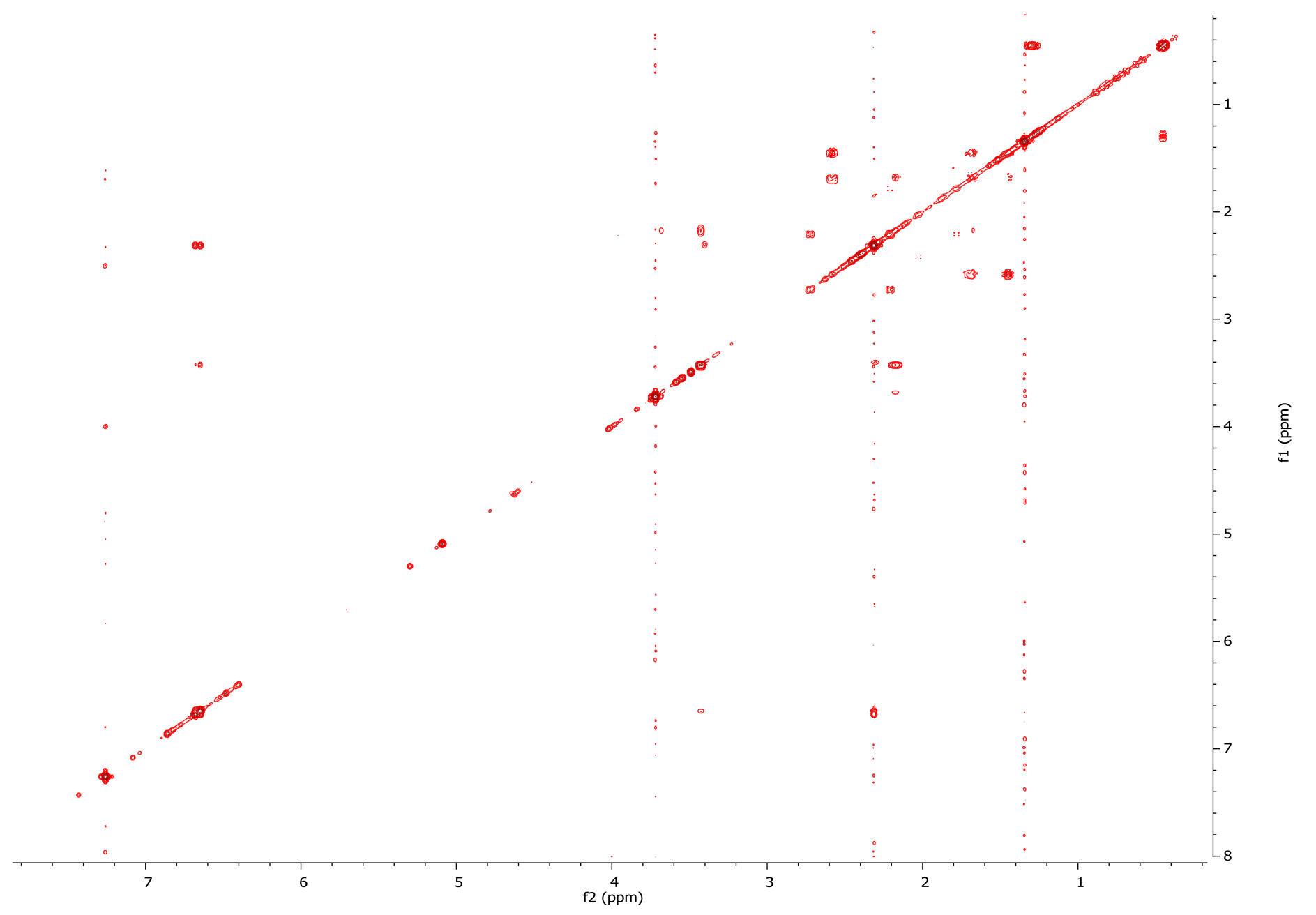

COSY NMR spectrum of debromohamigeran J (62) in $\mathrm{CDCl}_{3}(600 \mathrm{MHz})$. 


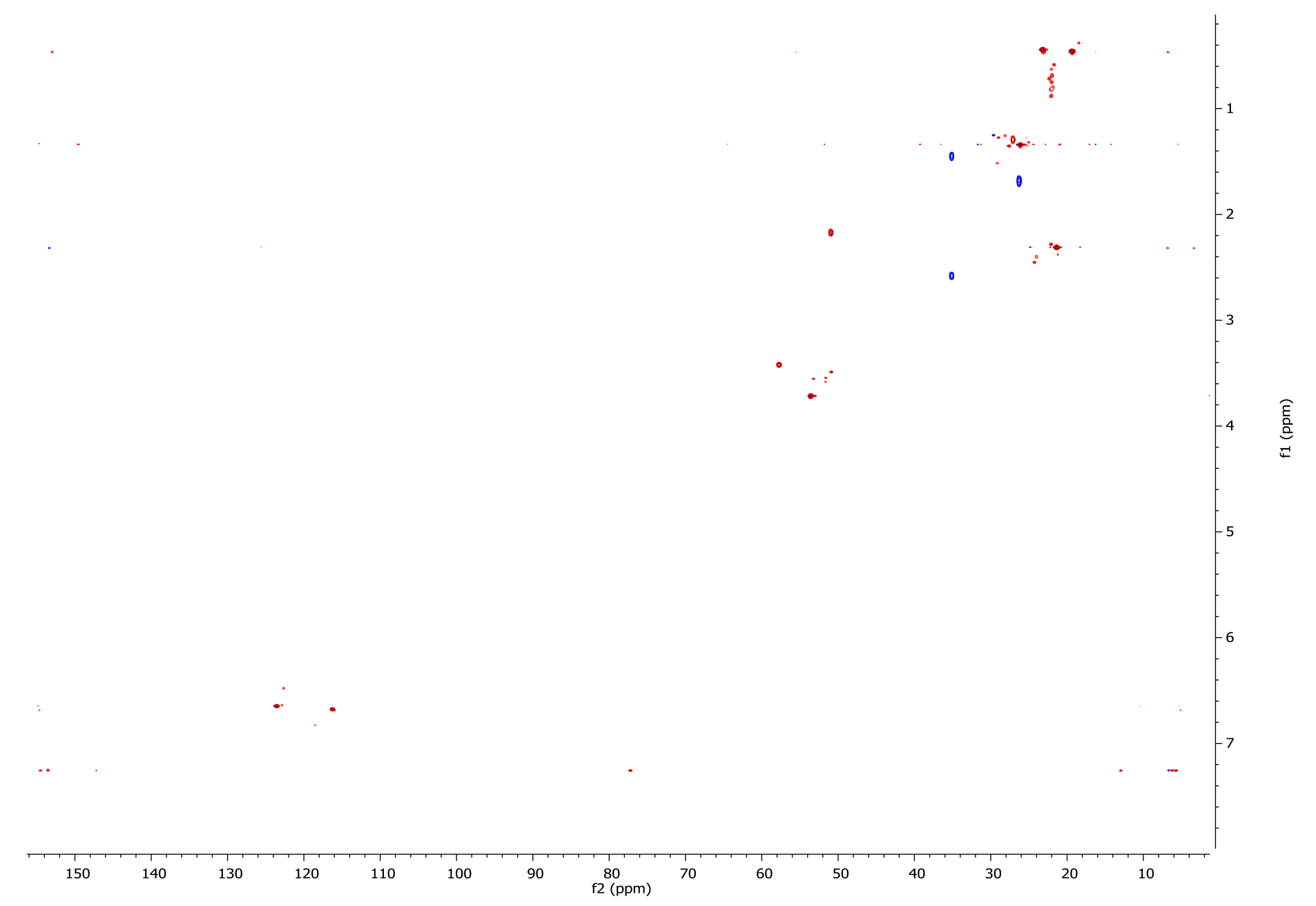

HSQC NMR spectrum of debromohamigeran J (62) in $\mathrm{CDCl}_{3}(600 \mathrm{MHz})$. 


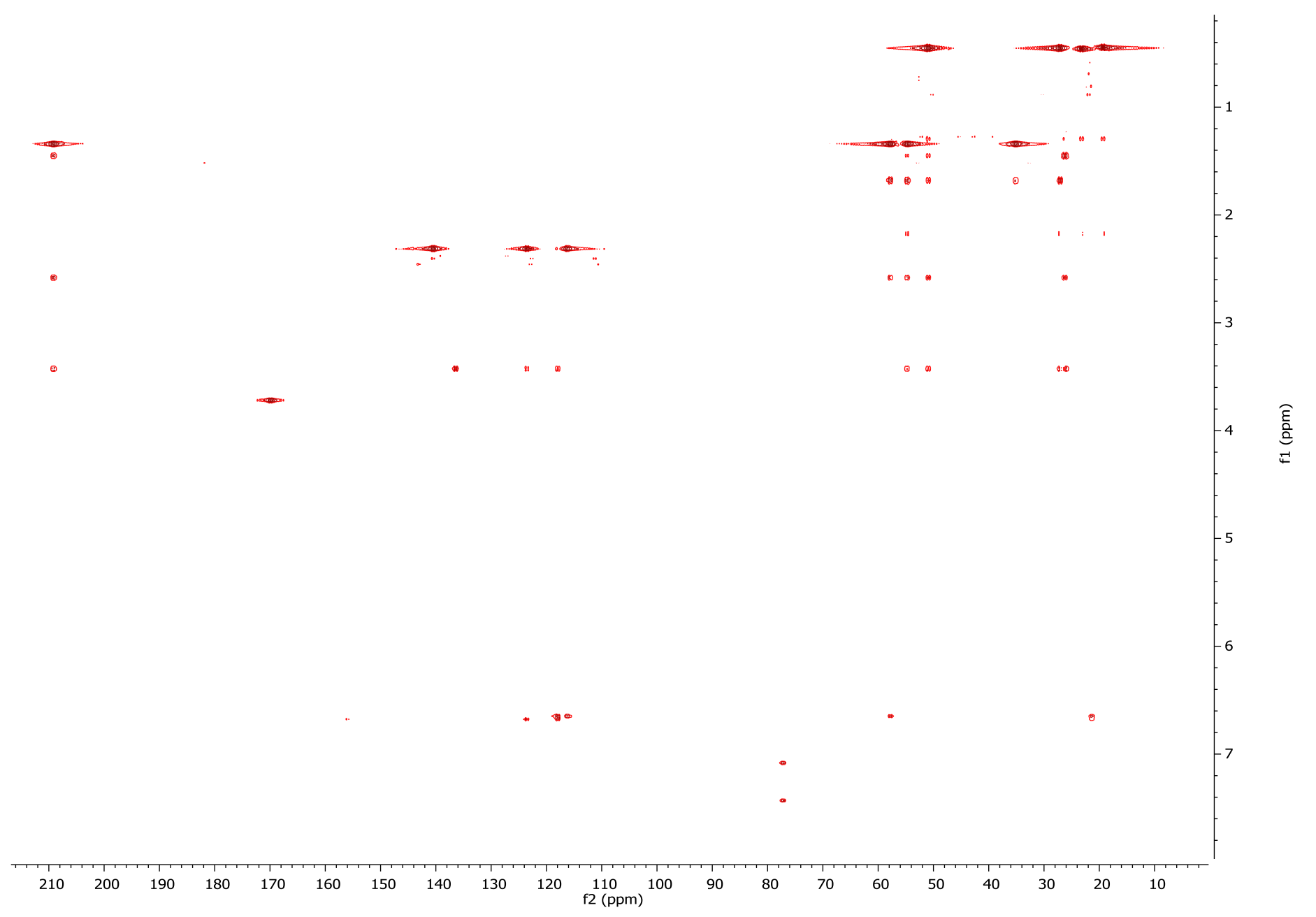

HMBC NMR spectrum of debromohamigeran J (62) in $\mathrm{CDCl}_{3}(600 \mathrm{MHz})$. 


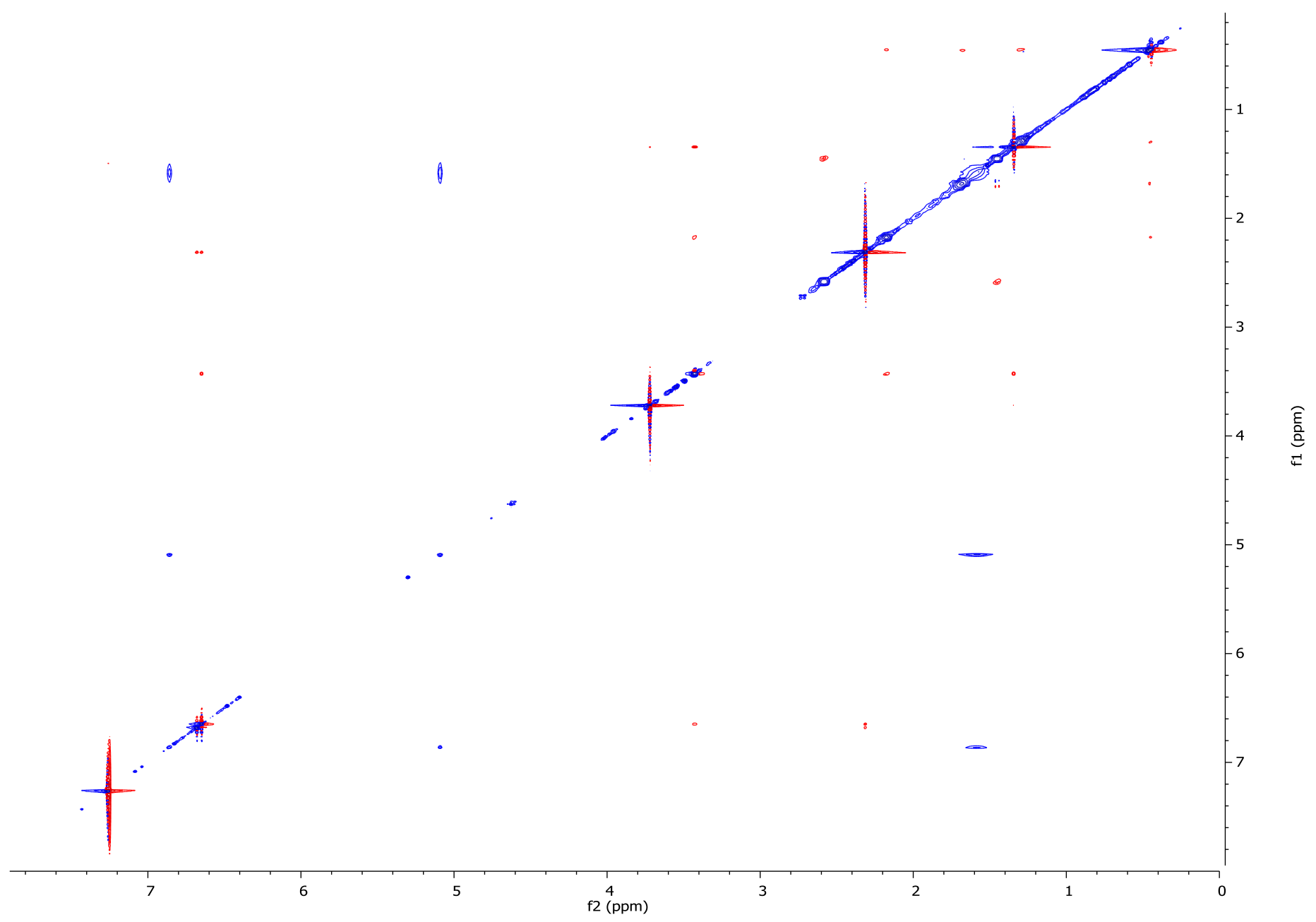

2D NOSEY NMR spectrum of debromohamigeran J (62) in $\mathrm{CDCl}_{3}(600 \mathrm{MHz})$.

118 
D Hamigeran L - $O$ - methyl ester NMR Spectra

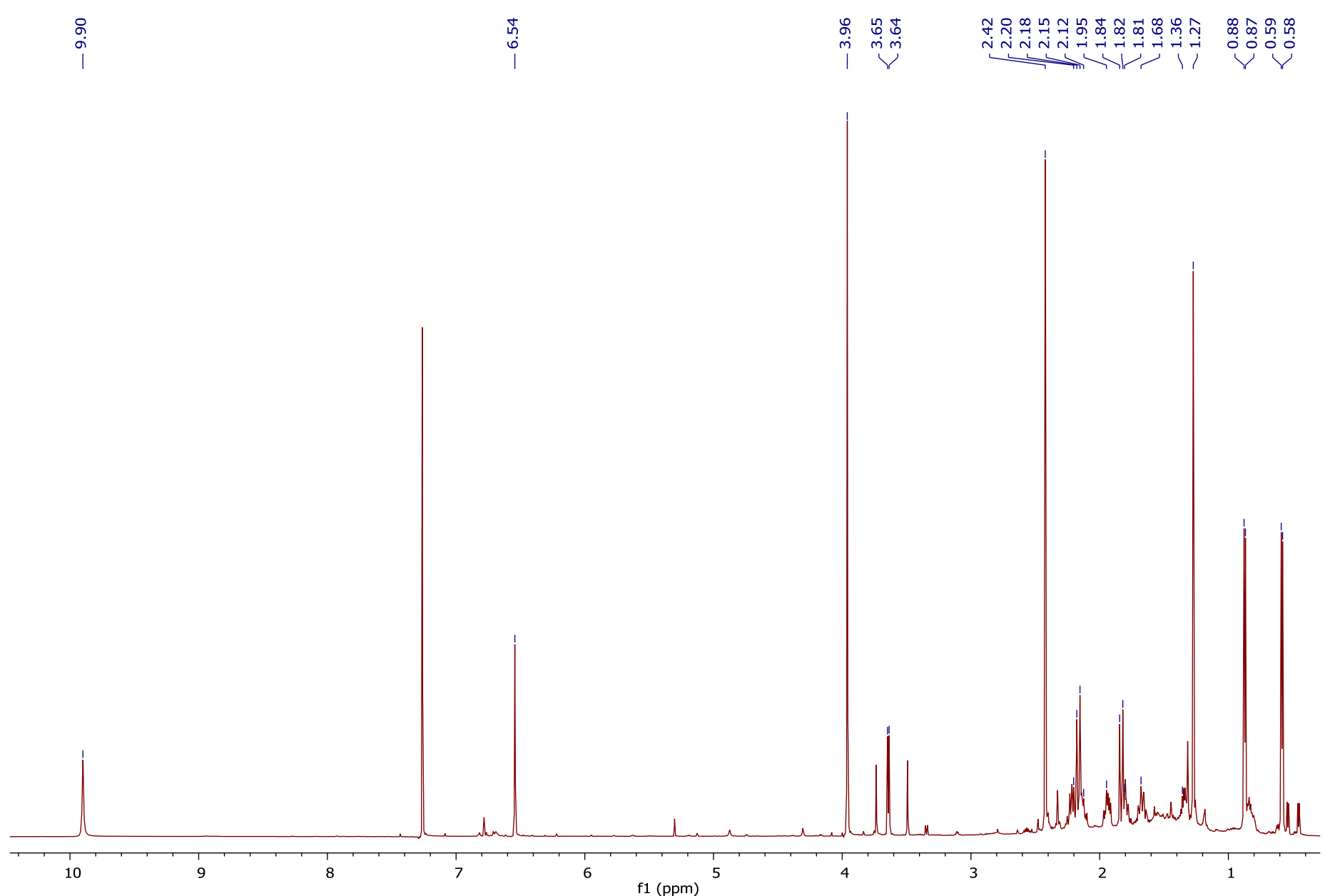

${ }^{1} \mathrm{H}$ NMR spectrum of hamigeran L -O- methyl ester $(\mathbf{6 3})$ in $\mathrm{CDCl}_{3}(600 \mathrm{MHz})$. 


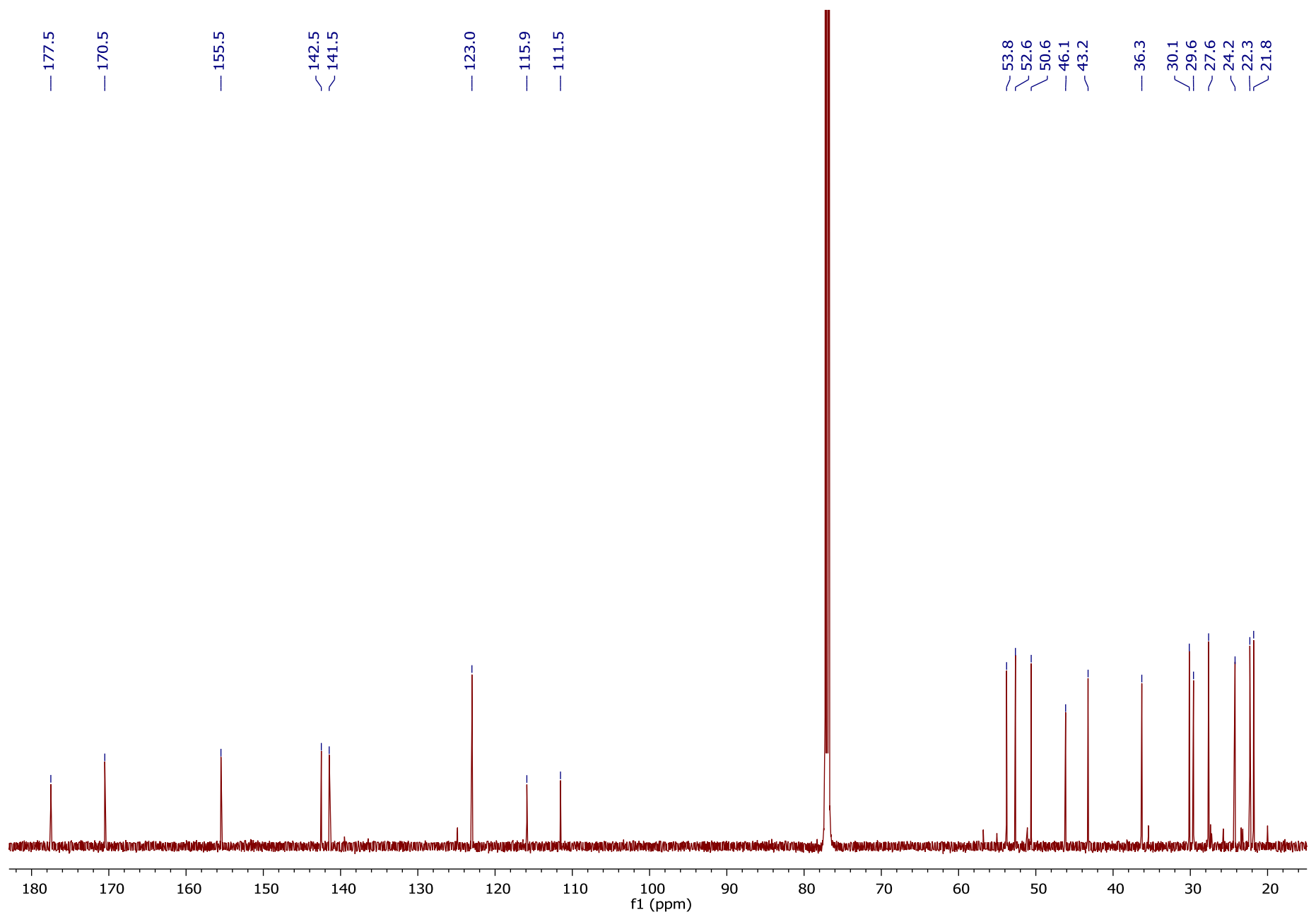

${ }^{13} \mathrm{C}$ NMR spectrum of hamigeran $\mathrm{L}-\mathrm{O}$ - methyl ester $(\mathbf{6 3})$ in $\mathrm{CDCl}_{3}(150 \mathrm{MHz})$. 


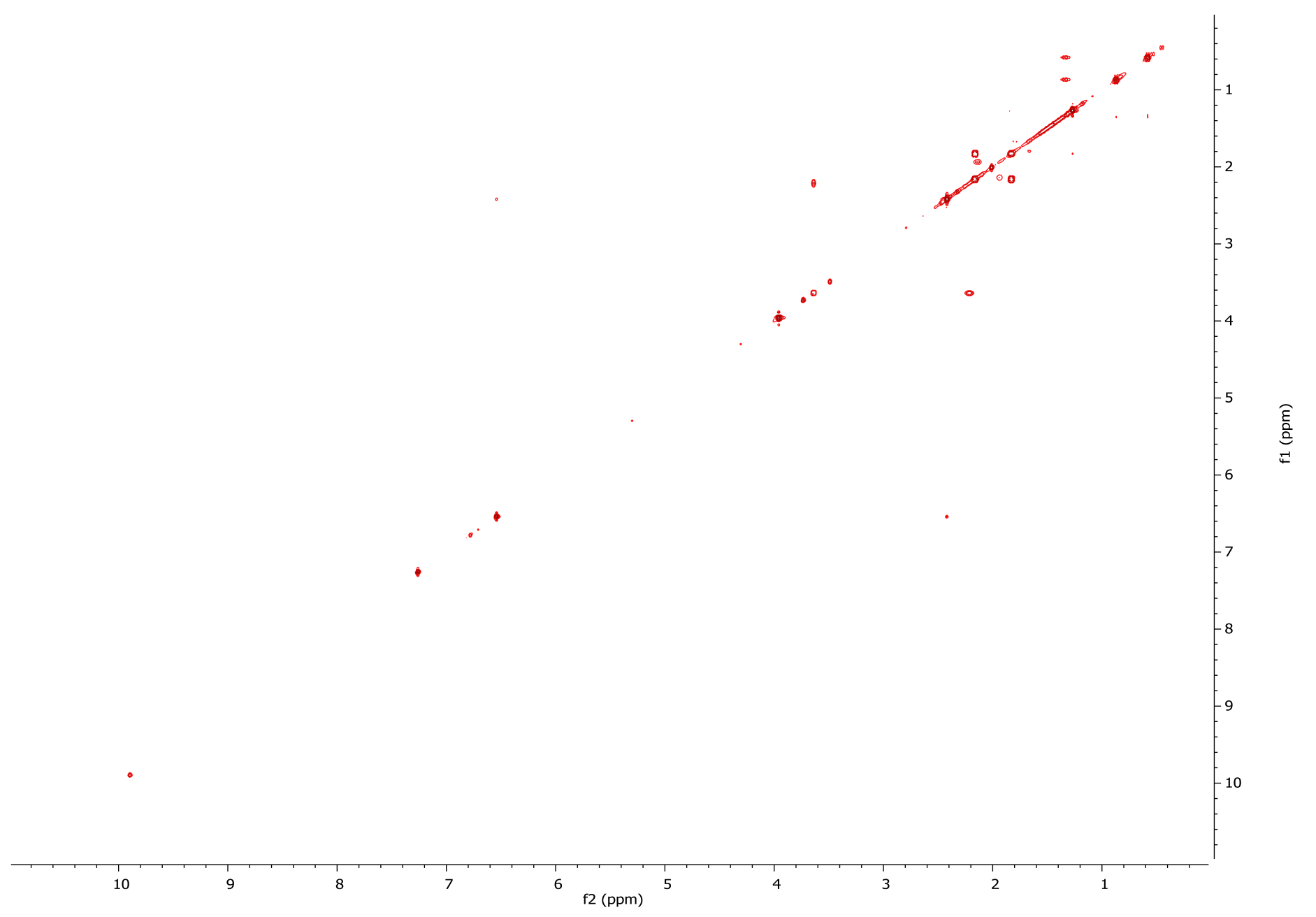

COSY NMR spectrum of hamigeran L - O- methyl ester (63) in $\mathrm{CDCl}_{3}(600 \mathrm{MHz})$. 


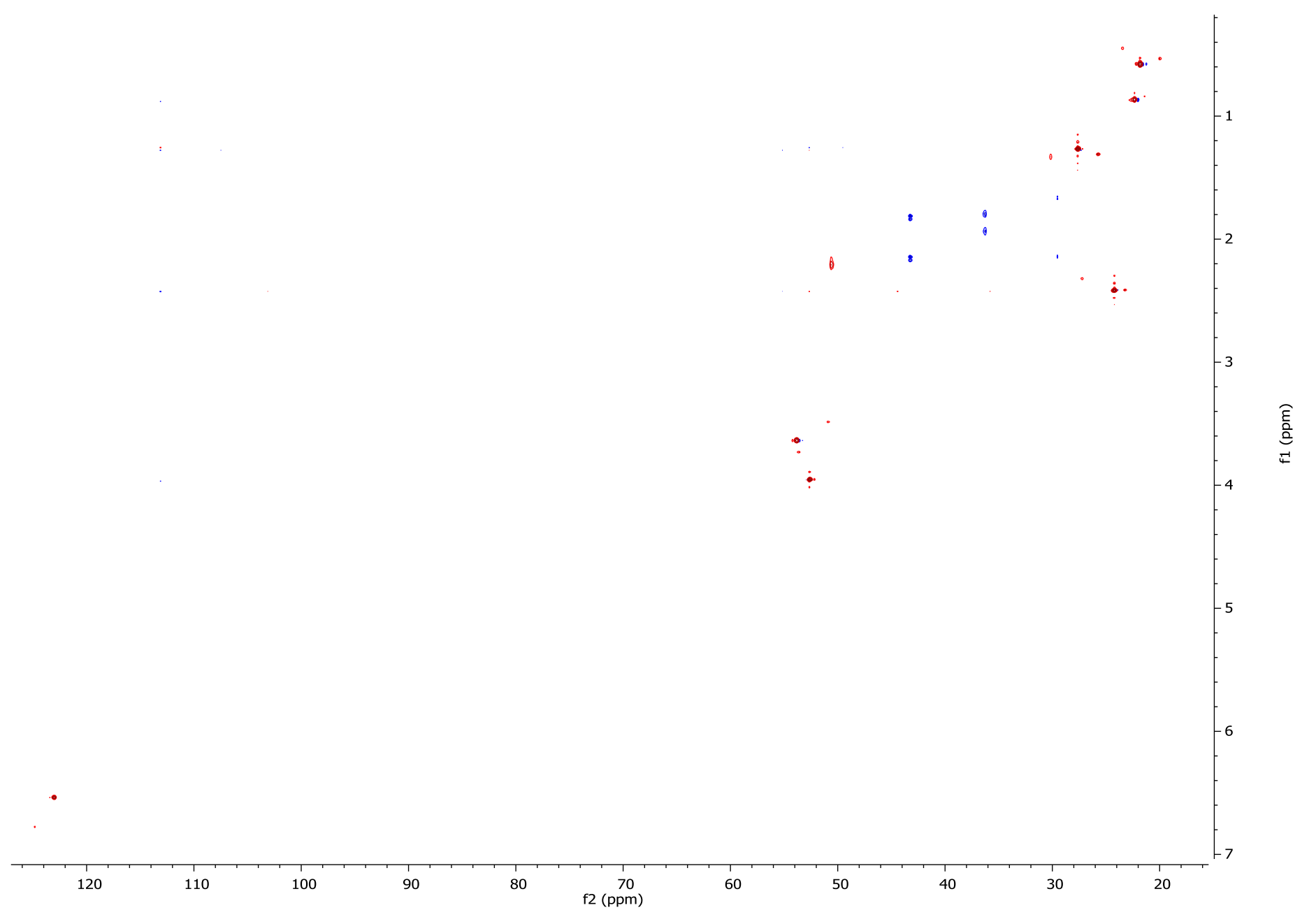

HSQC NMR spectrum of hamigeran L - O- methyl ester (63) in $\mathrm{CDCl}_{3}(600 \mathrm{MHz})$. 


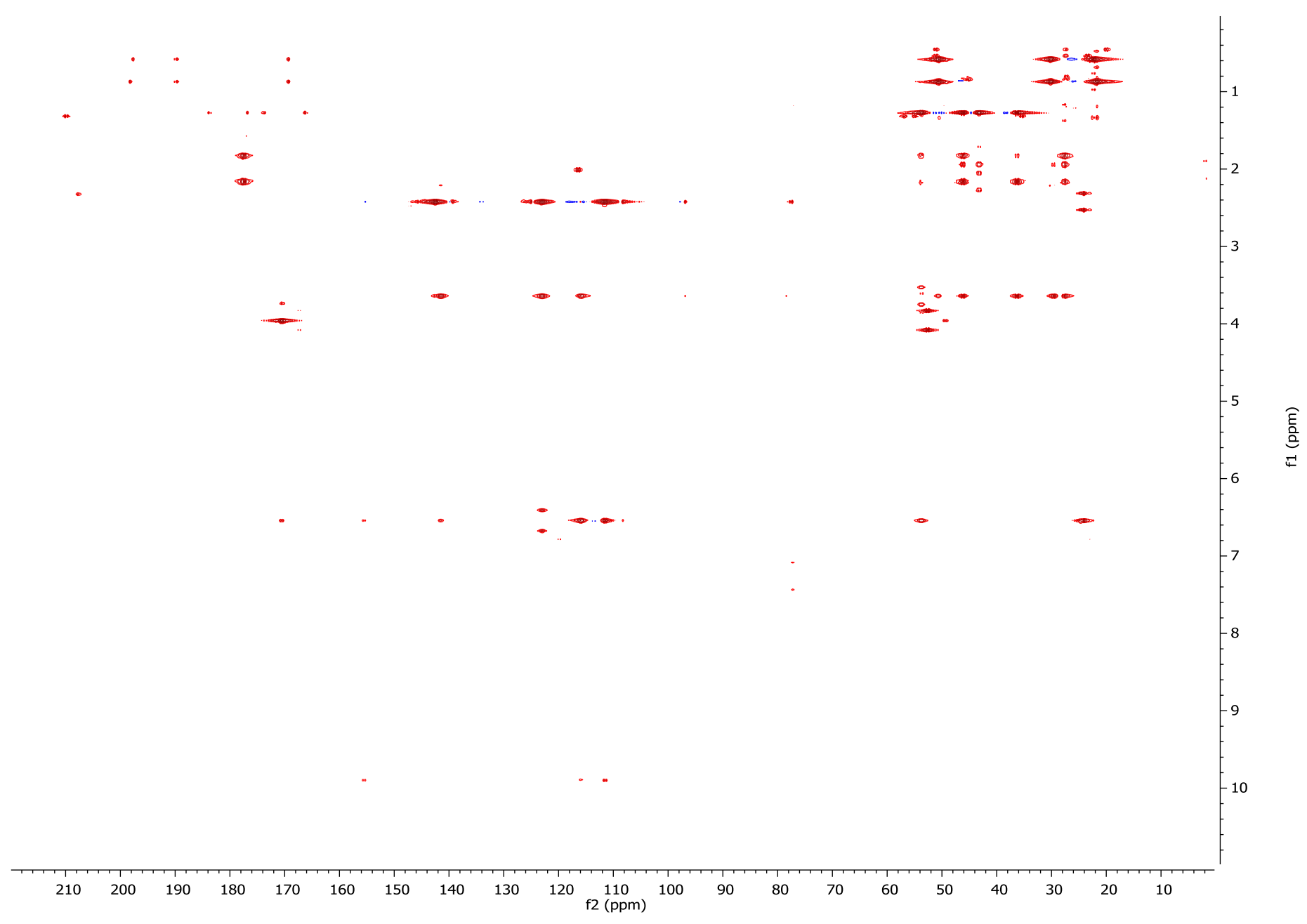

HMBC NMR spectrum of hamigeran L - O- methyl ester (63) in $\mathrm{CDCl}_{3}(600 \mathrm{MHz})$. 


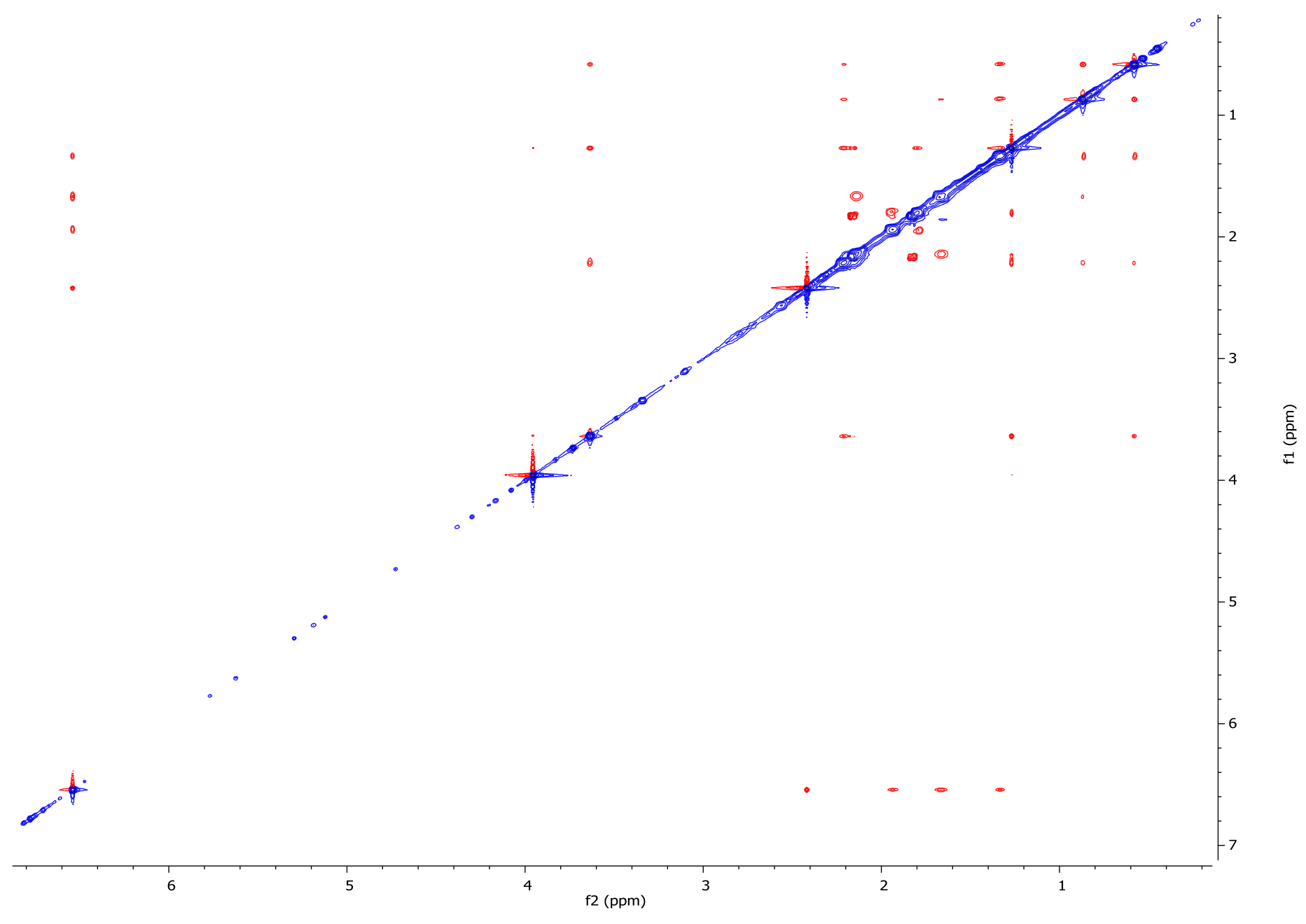

2D NOESY NMR spectrum of hamigeran L -O- methyl ester (63) in $\mathrm{CDCl}_{3}(600 \mathrm{MHz})$. 
4-Bromohamigeran A NMR Spectra

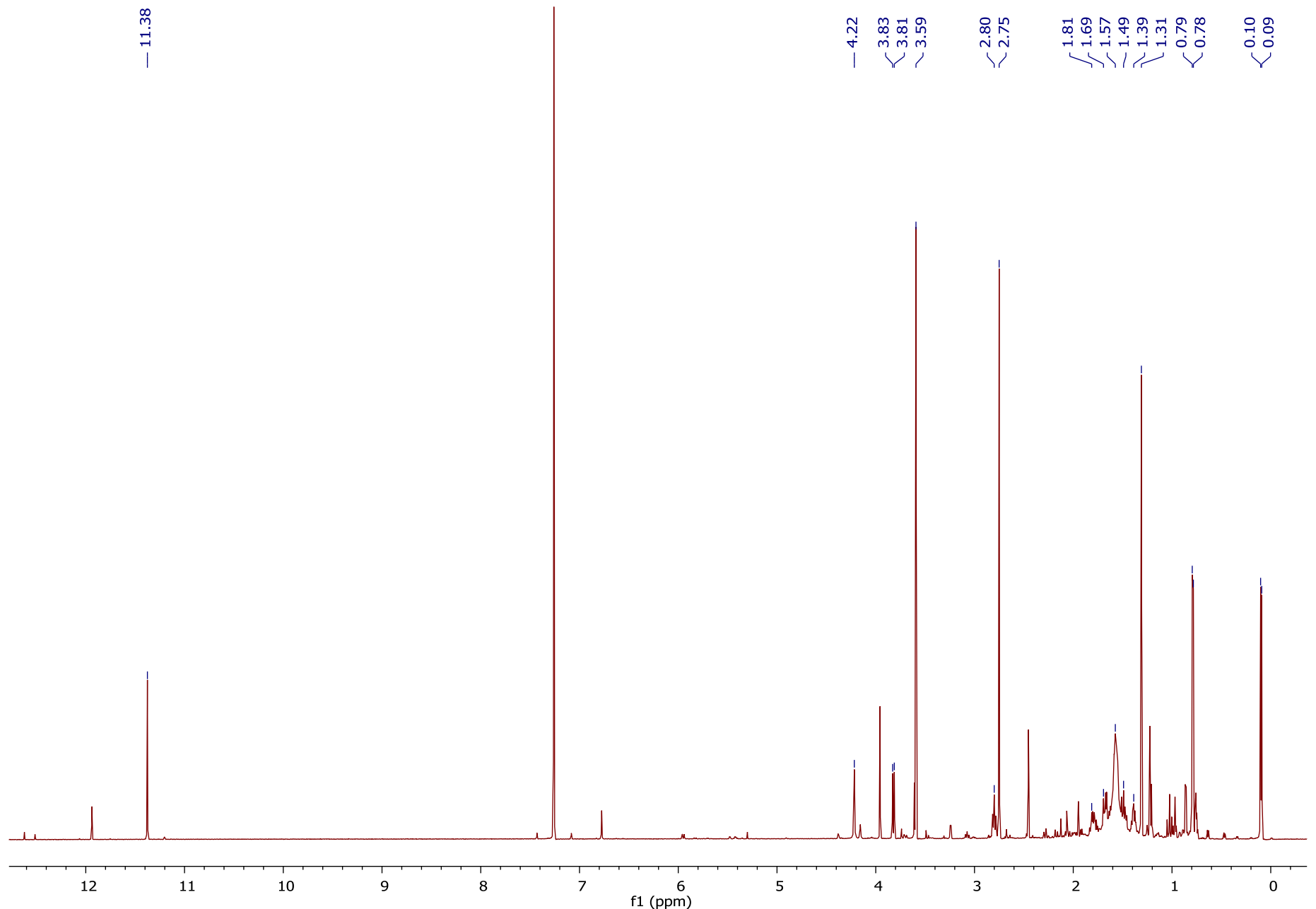

${ }^{1} \mathrm{H}$ NMR spectrum of 4-bromohamigeran A (64) in $\mathrm{CDCl}_{3}(600 \mathrm{MHz})$. 


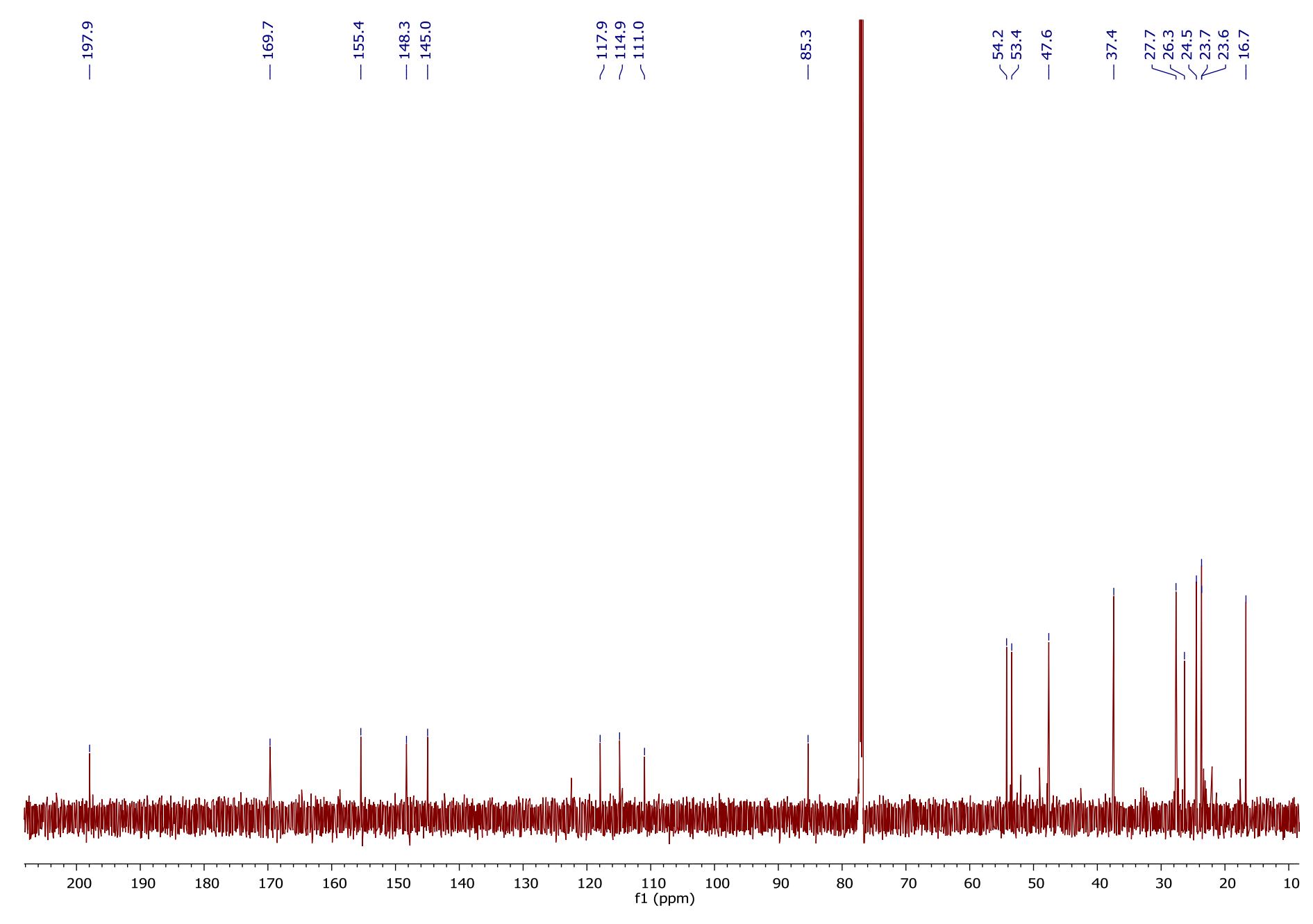

${ }^{13} \mathrm{C}$ NMR spectrum of 4-bromohamigeran A (64) in $\mathrm{CDCl}_{3}(150 \mathrm{MHz})$. 


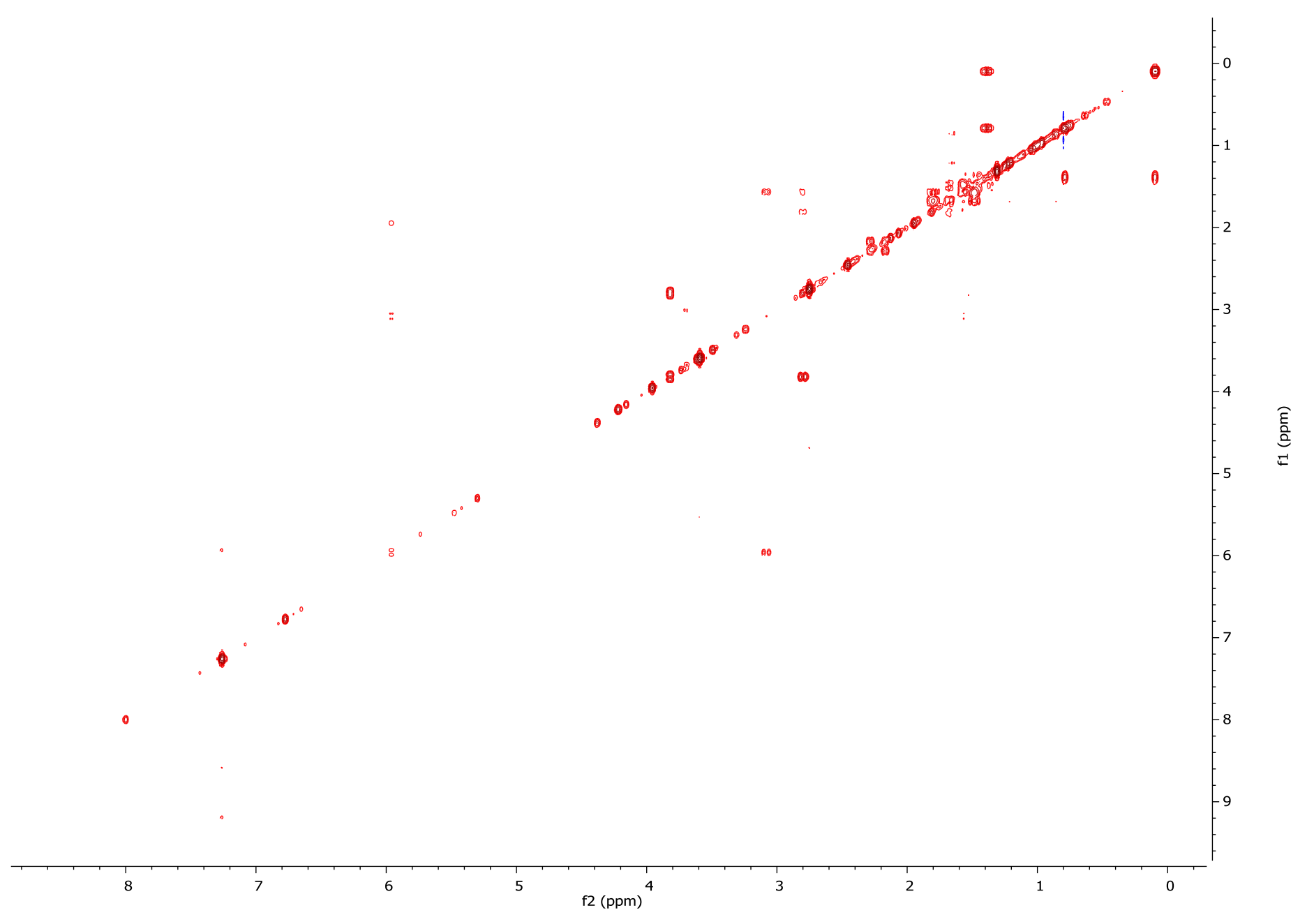

COSY NMR spectrum of 4-bromohamigeran A (64) in $\mathrm{CDCl}_{3}(600 \mathrm{MHz})$. 


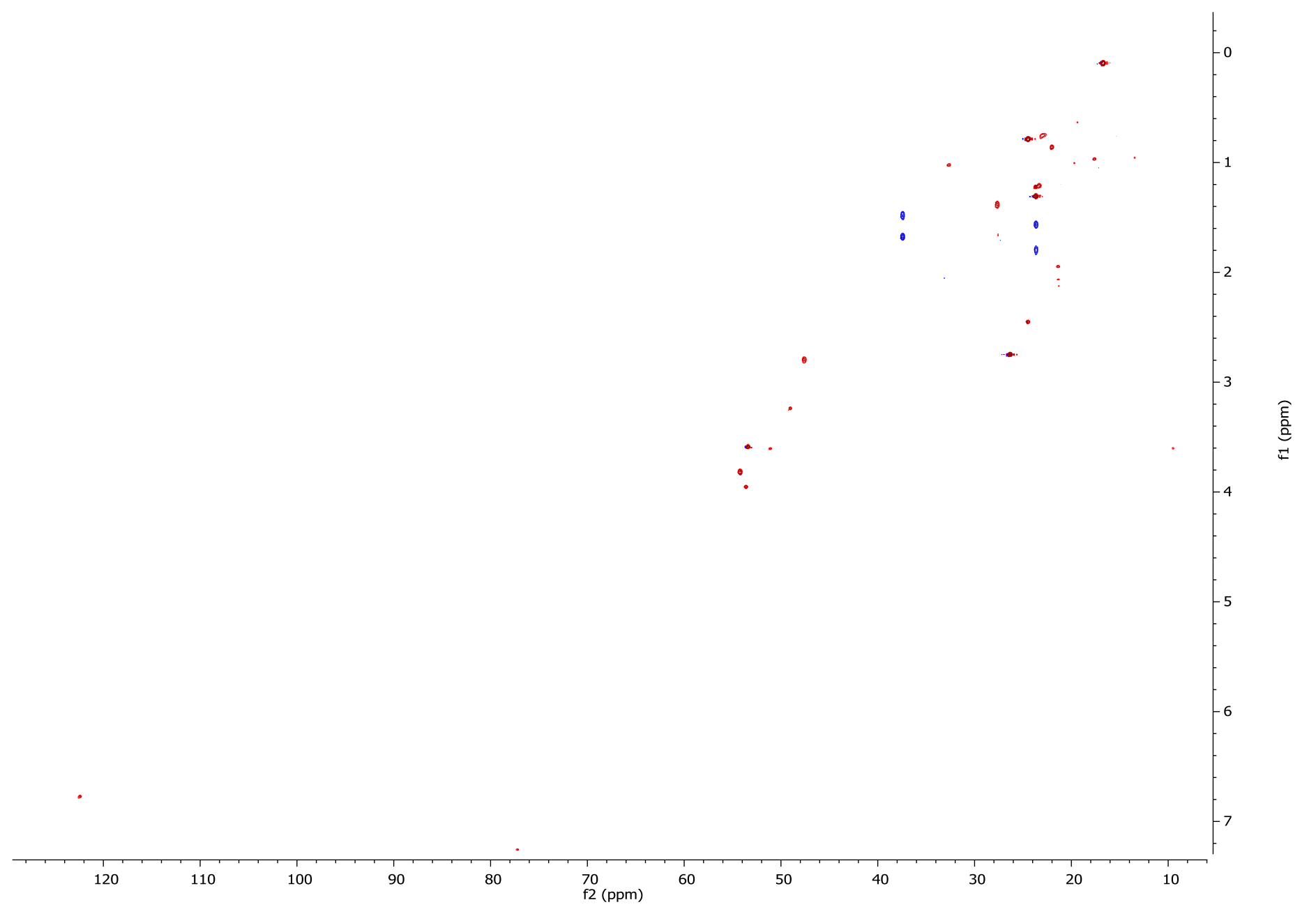

HSQC NMR spectrum of 4-bromohamigeran A (64) in $\mathrm{CDCl}_{3}(600 \mathrm{MHz})$. 


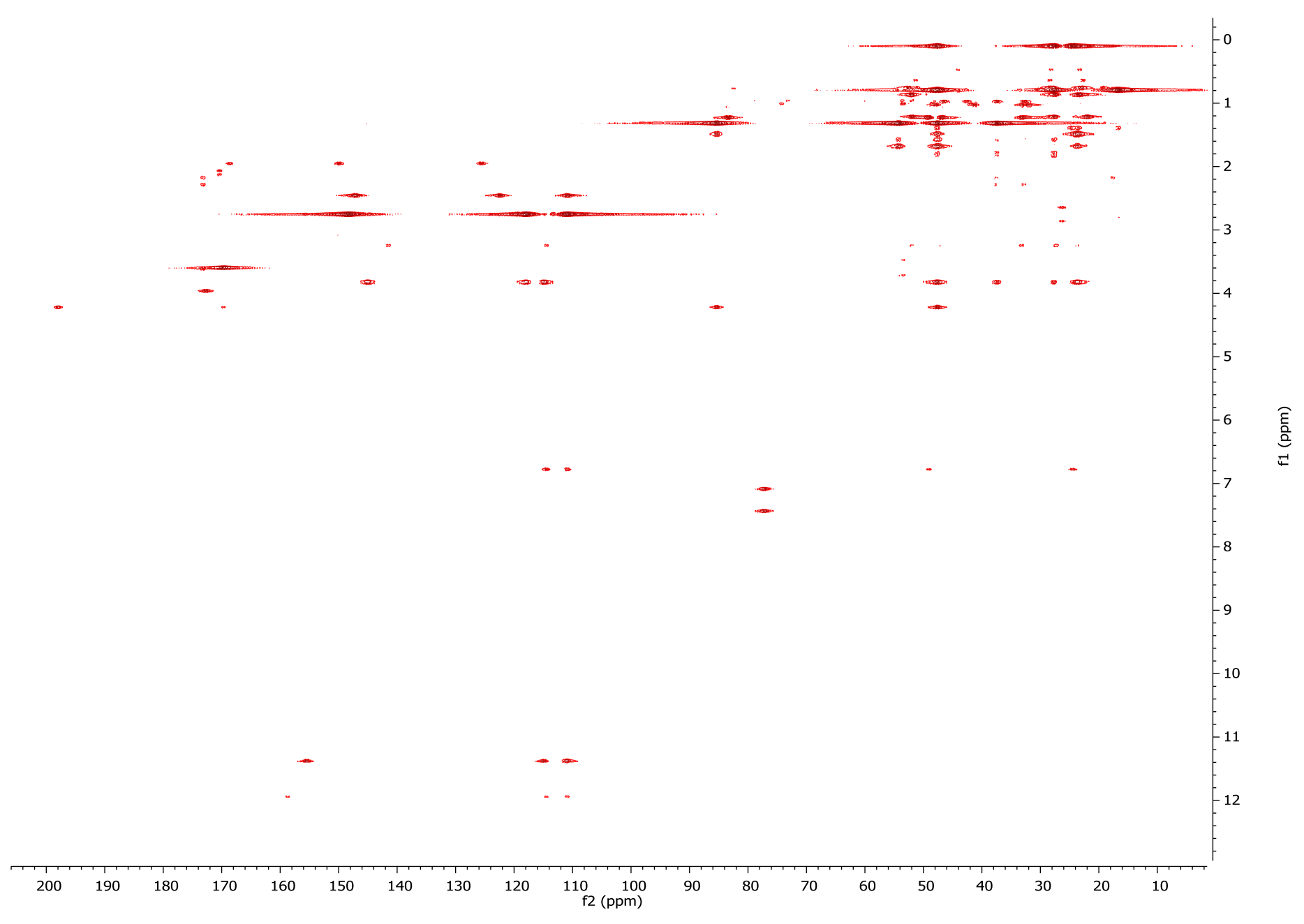

HMBC NMR spectrum of 4-bromohamigeran A (64) in $\mathrm{CDCl}_{3}(600 \mathrm{MHz})$. 


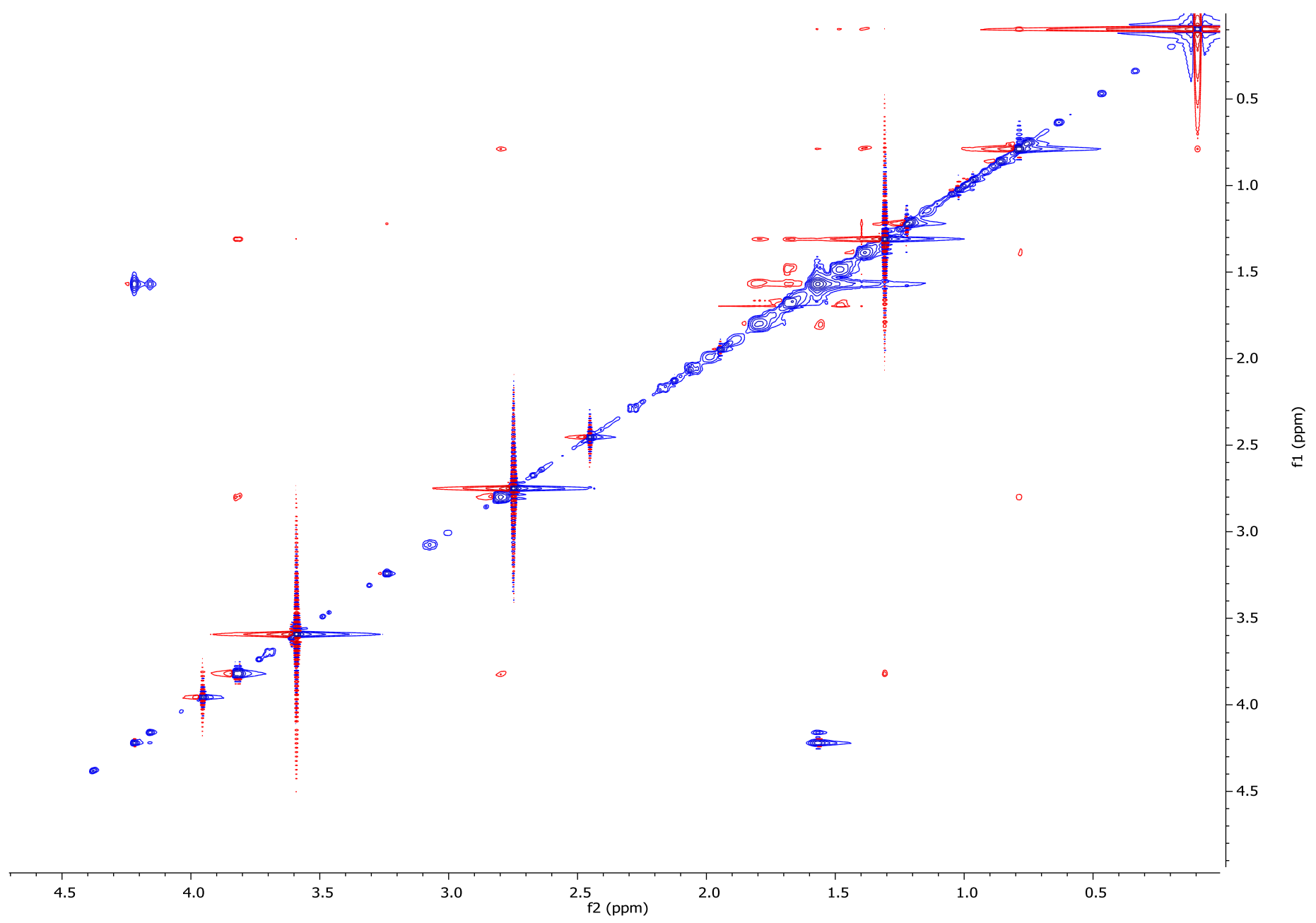

2D NOESY NMR spectrum of 4-bromohamigeran A (64) in $\mathrm{CDCl}_{3}(600 \mathrm{MHz})$. 


\section{F Hamigeran R NMR Spectra}

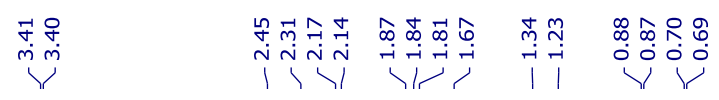

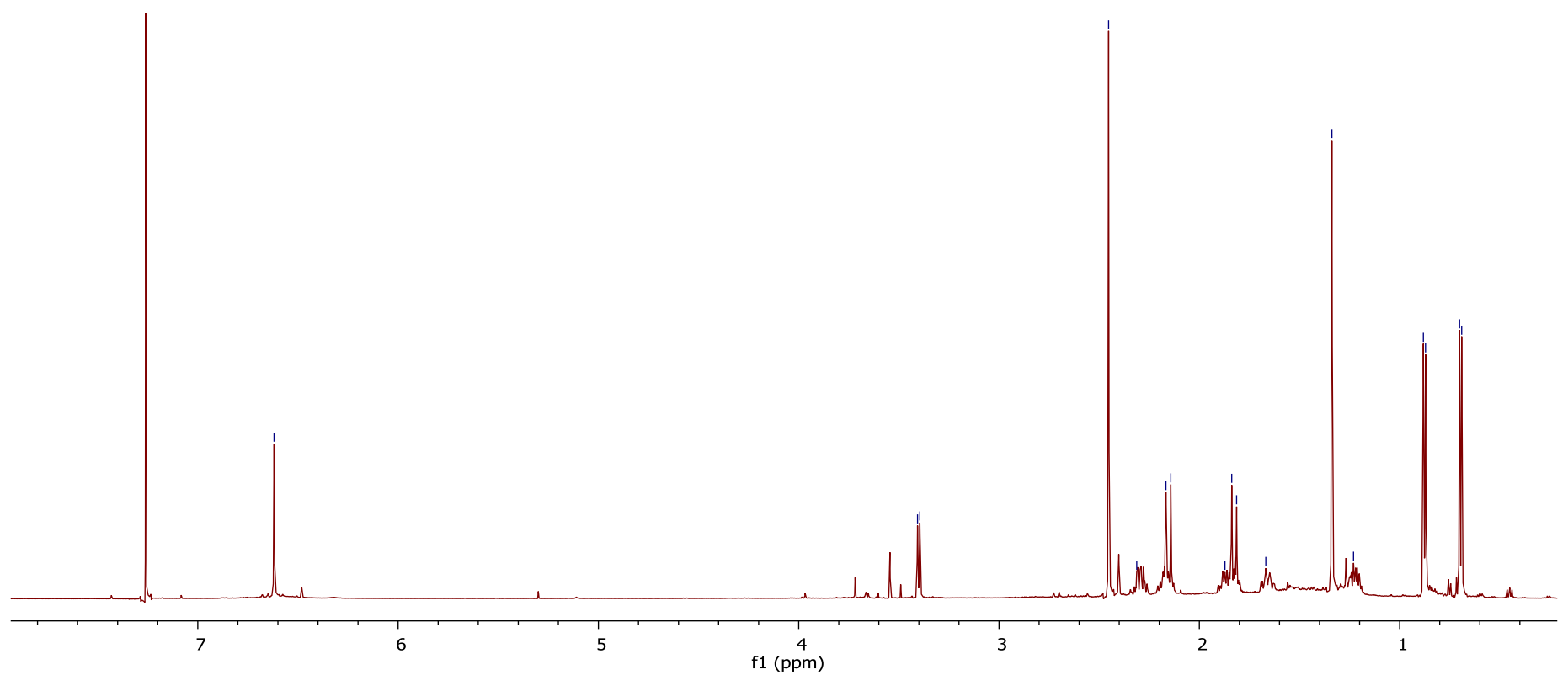

${ }^{1} \mathrm{H}$ NMR spectrum of hamigeran $\mathrm{R}(\mathbf{6 1})$ in $\mathrm{CDCl}_{3}(600 \mathrm{MHz})$. 


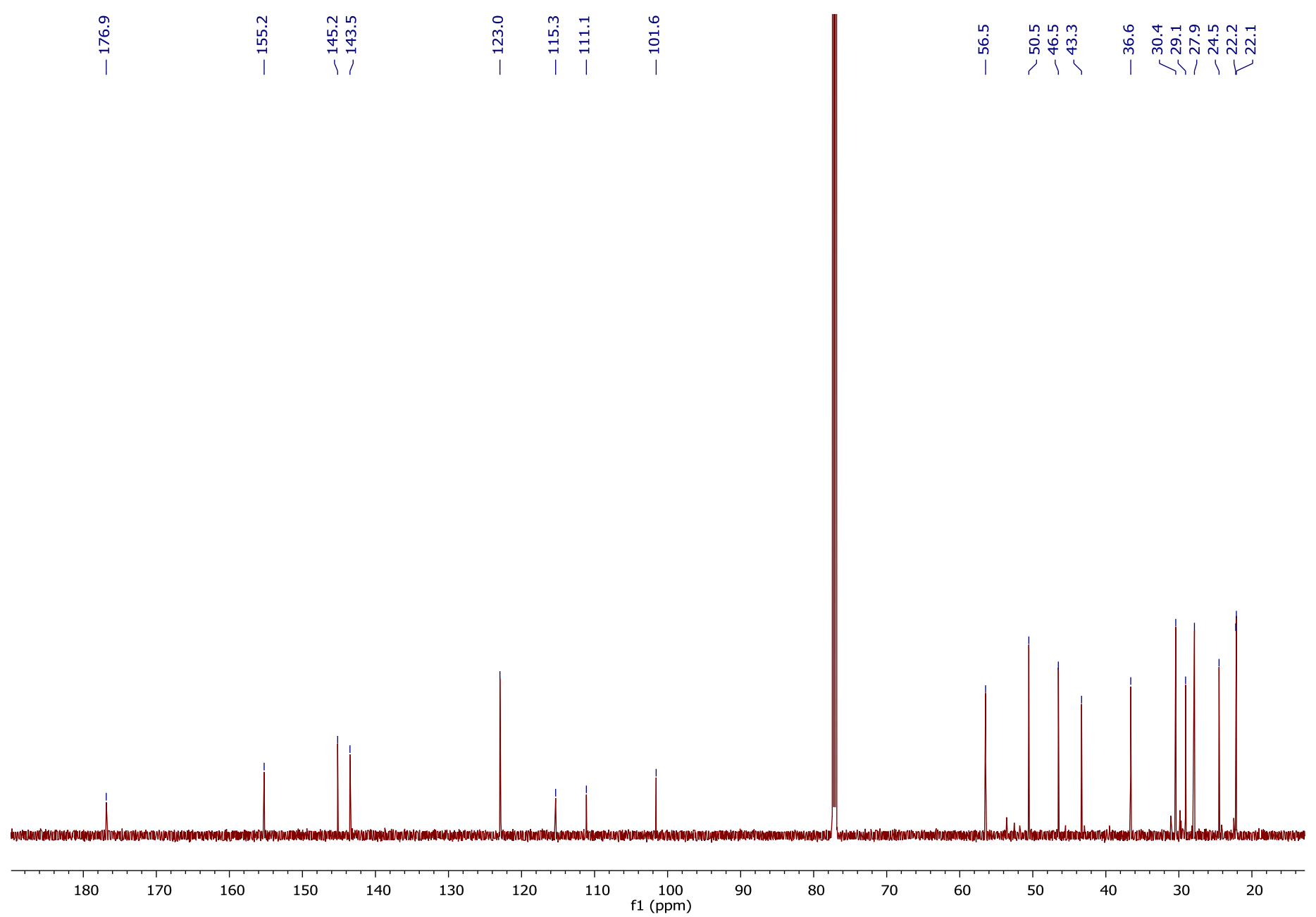

${ }^{13} \mathrm{C}$ NMR spectrum of hamigeran $\mathrm{R}(\mathbf{6 1})$ in $\mathrm{CDCl}_{3}(150 \mathrm{MHz})$. 


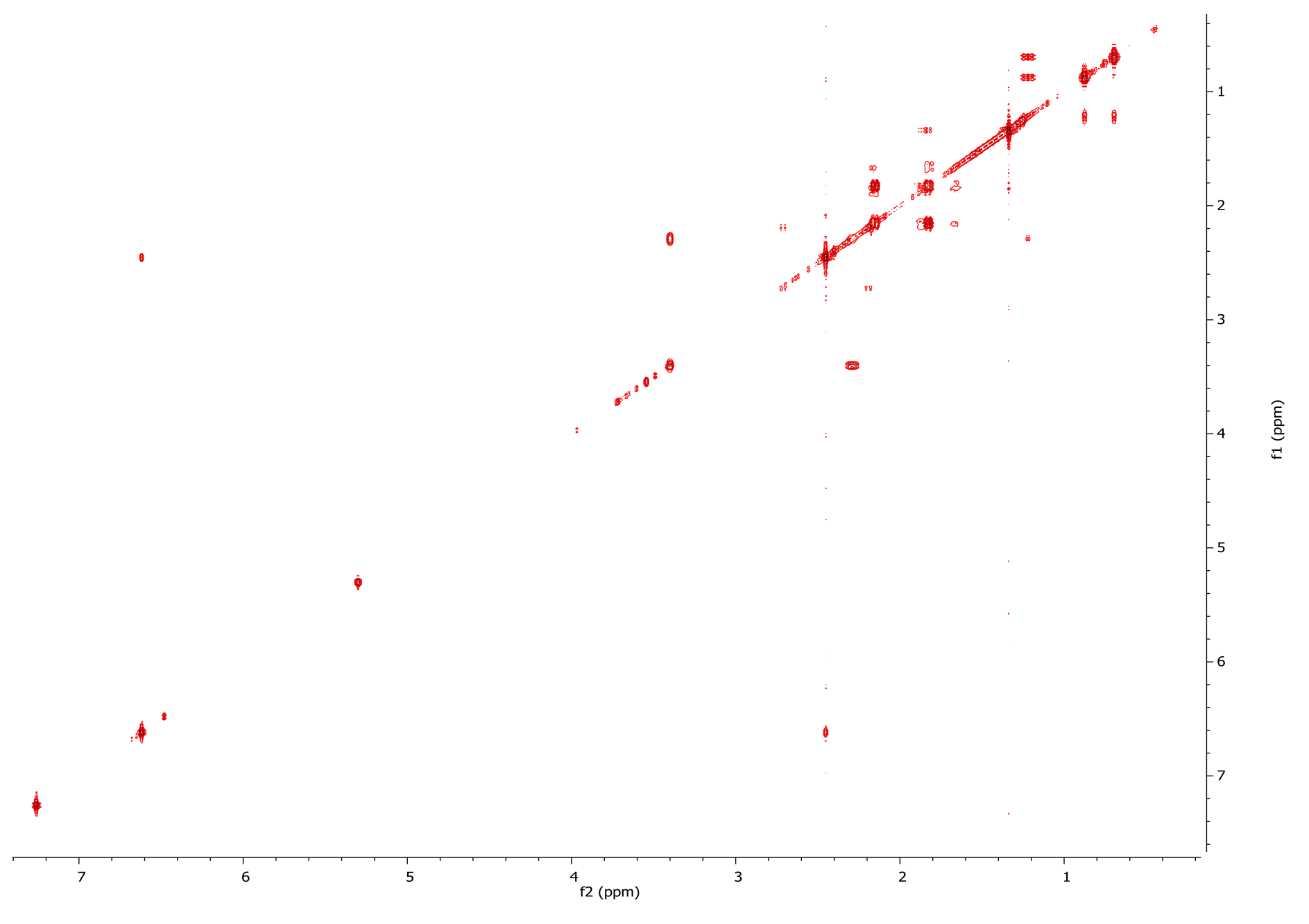

COSY NMR spectrum of hamigeran R (61) in $\mathrm{CDCl}_{3}(600 \mathrm{MHz})$. 


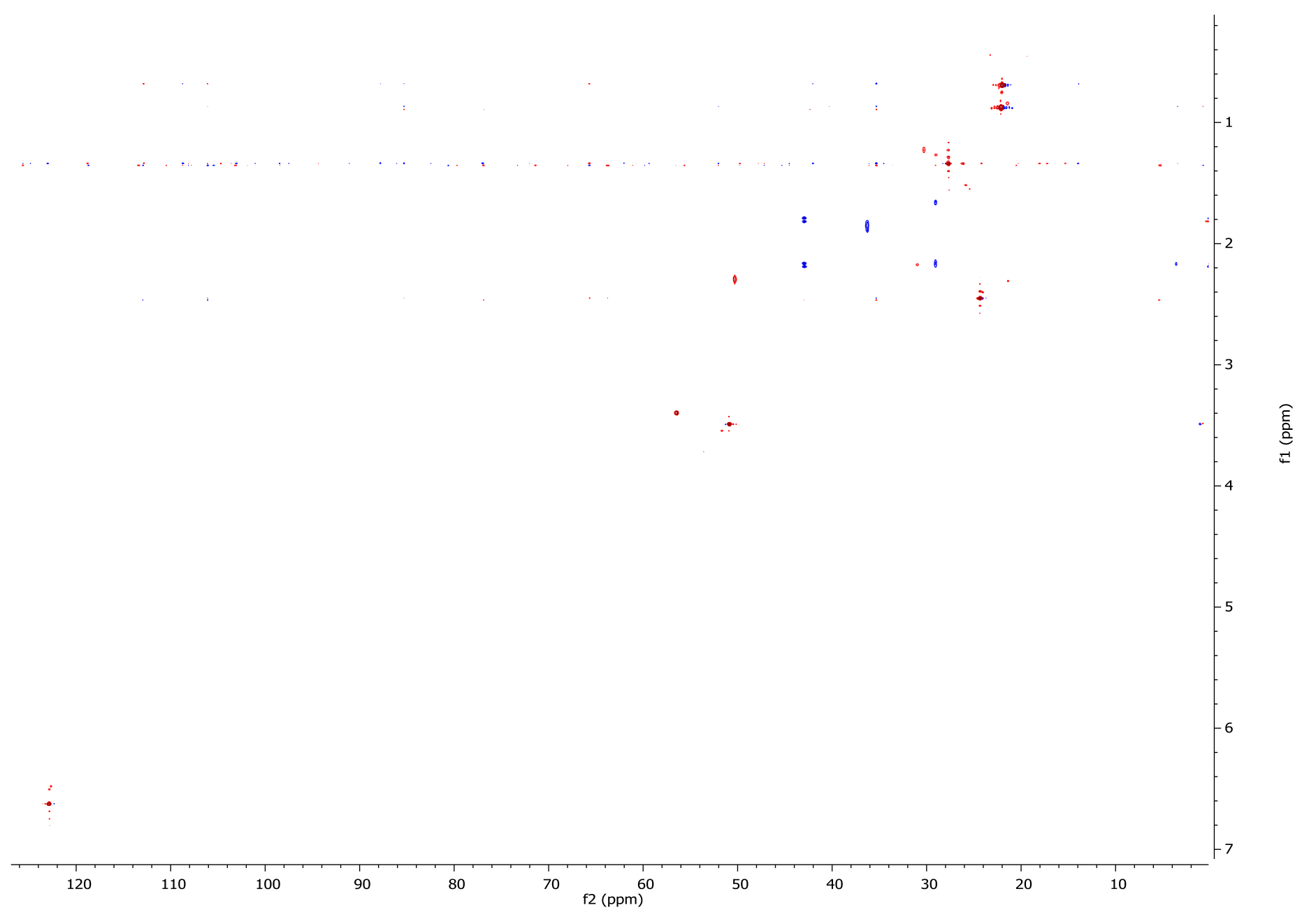

HMBC NMR spectrum of hamigeran $\mathrm{R}(\mathbf{6 1})$ in $\mathrm{CDCl}_{3}(600 \mathrm{MHz})$. 


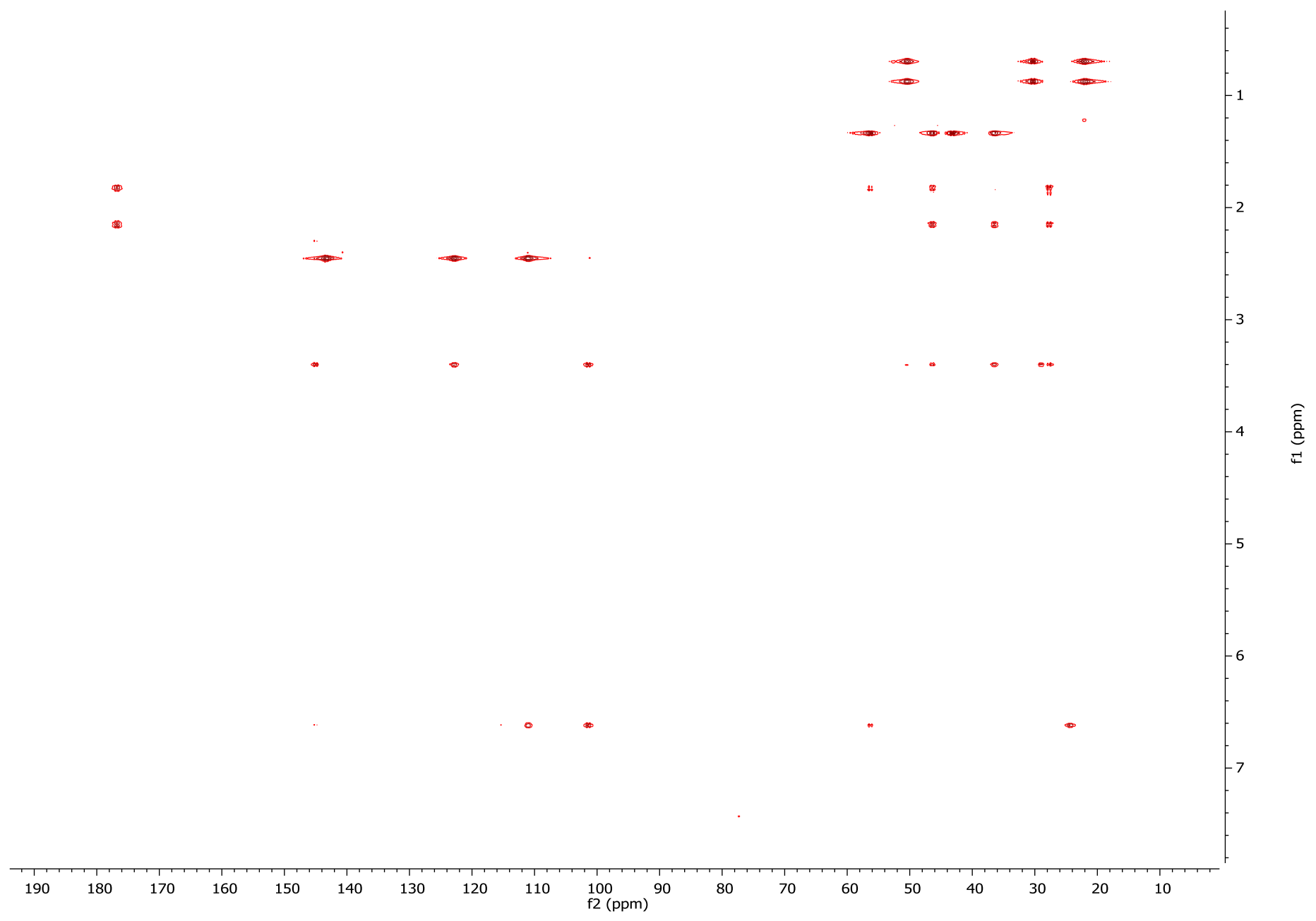

HMBC NMR spectrum of hamigeran $\mathrm{R}(\mathbf{6 1})$ in $\mathrm{CDCl}_{3}(600 \mathrm{MHz})$.

135 


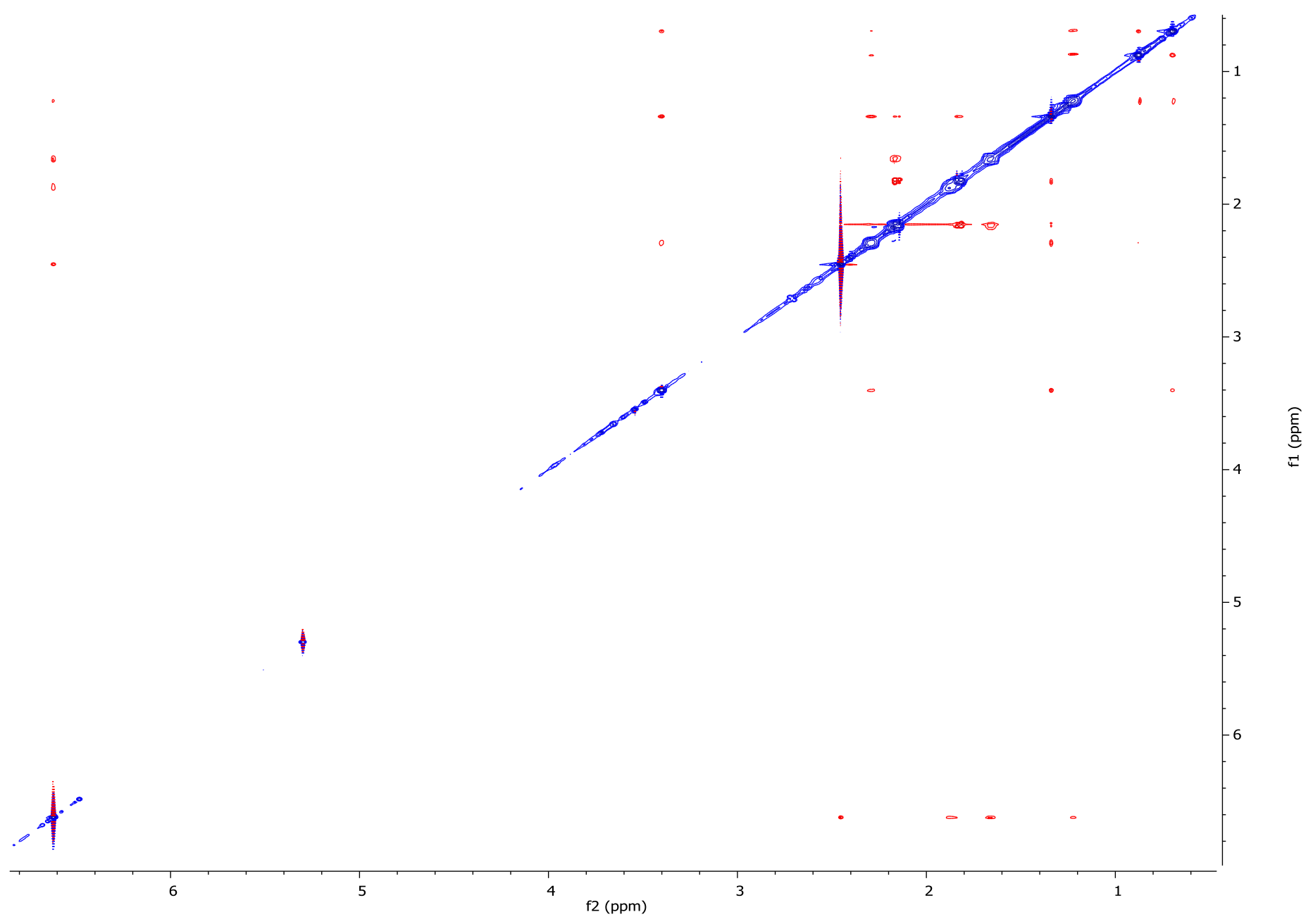

2D NOESY NMR spectrum of hamigeran $\mathrm{R}(\mathbf{6 1})$ in $\mathrm{CDCl}_{3}(600 \mathrm{MHz})$. 
G Hamigeran S NMR Spectra

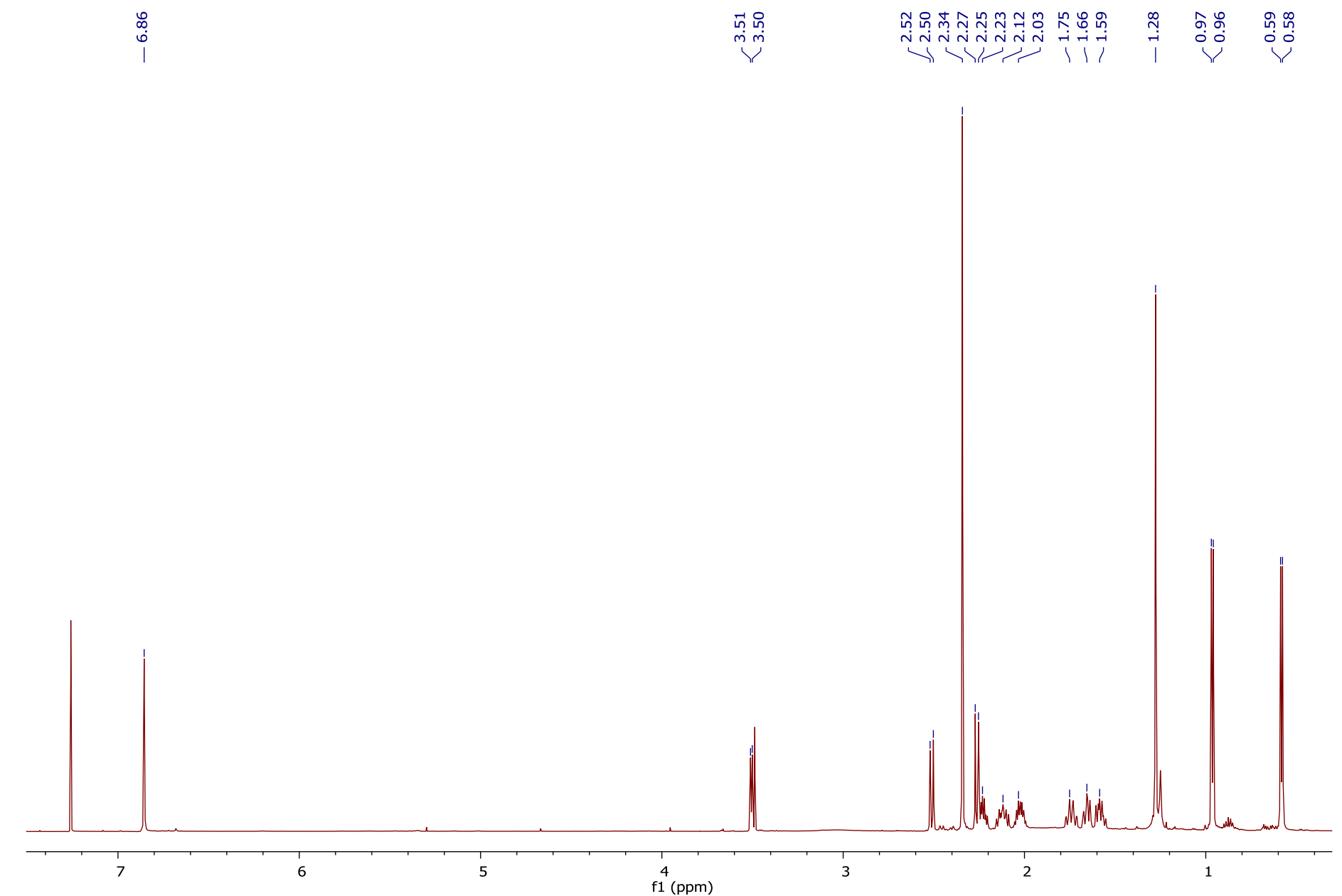

${ }^{1} \mathrm{H}$ NMR spectrum of hamigeran $\mathrm{S}(\mathbf{6 5})$ in $\mathrm{CDCl}_{3}(600 \mathrm{MHz})$. 


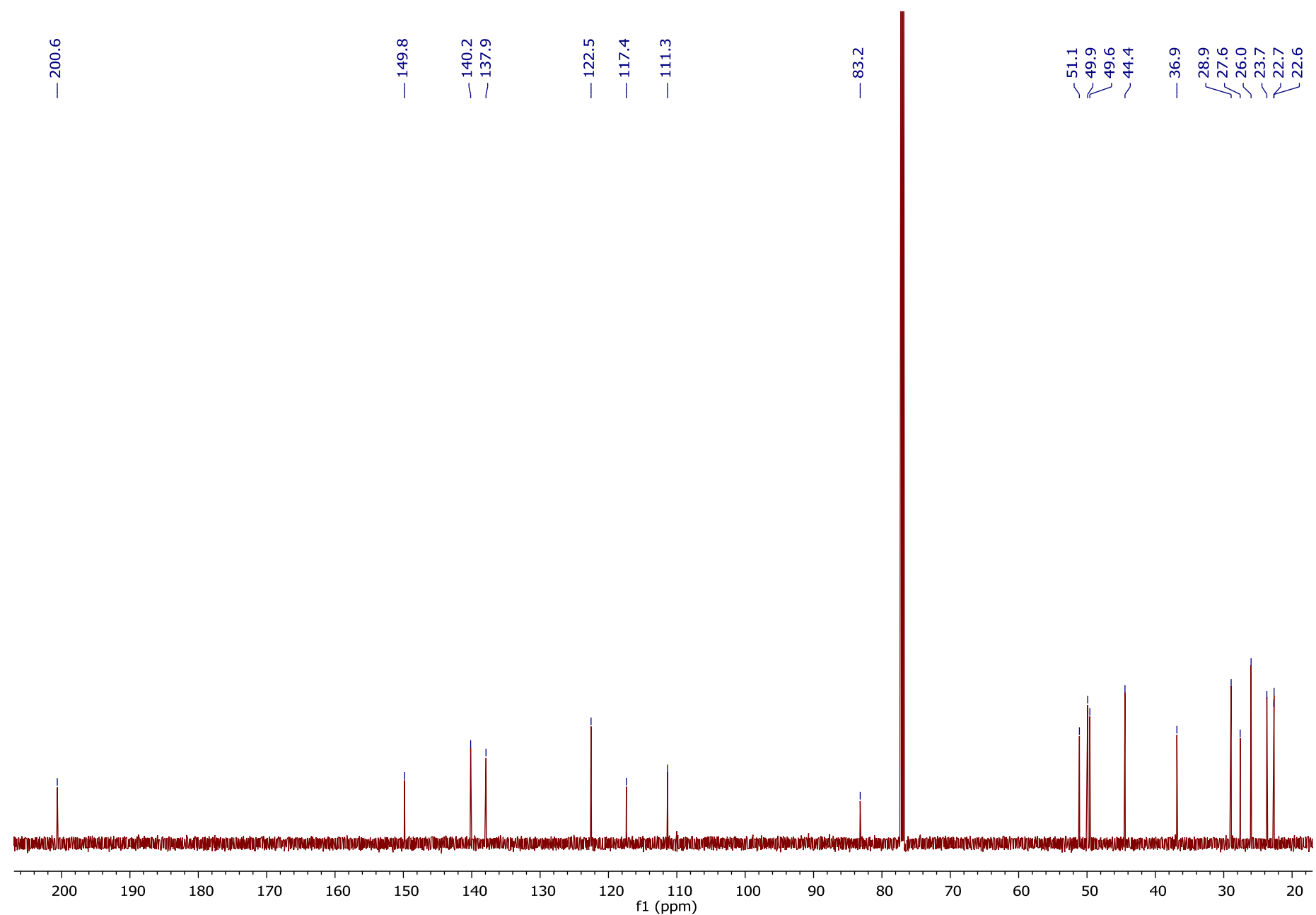

${ }^{13} \mathrm{C}$ NMR spectrum of hamigeran $\mathrm{S}(\mathbf{6 5})$ in $\mathrm{CDCl}_{3}(150 \mathrm{MHz})$. 


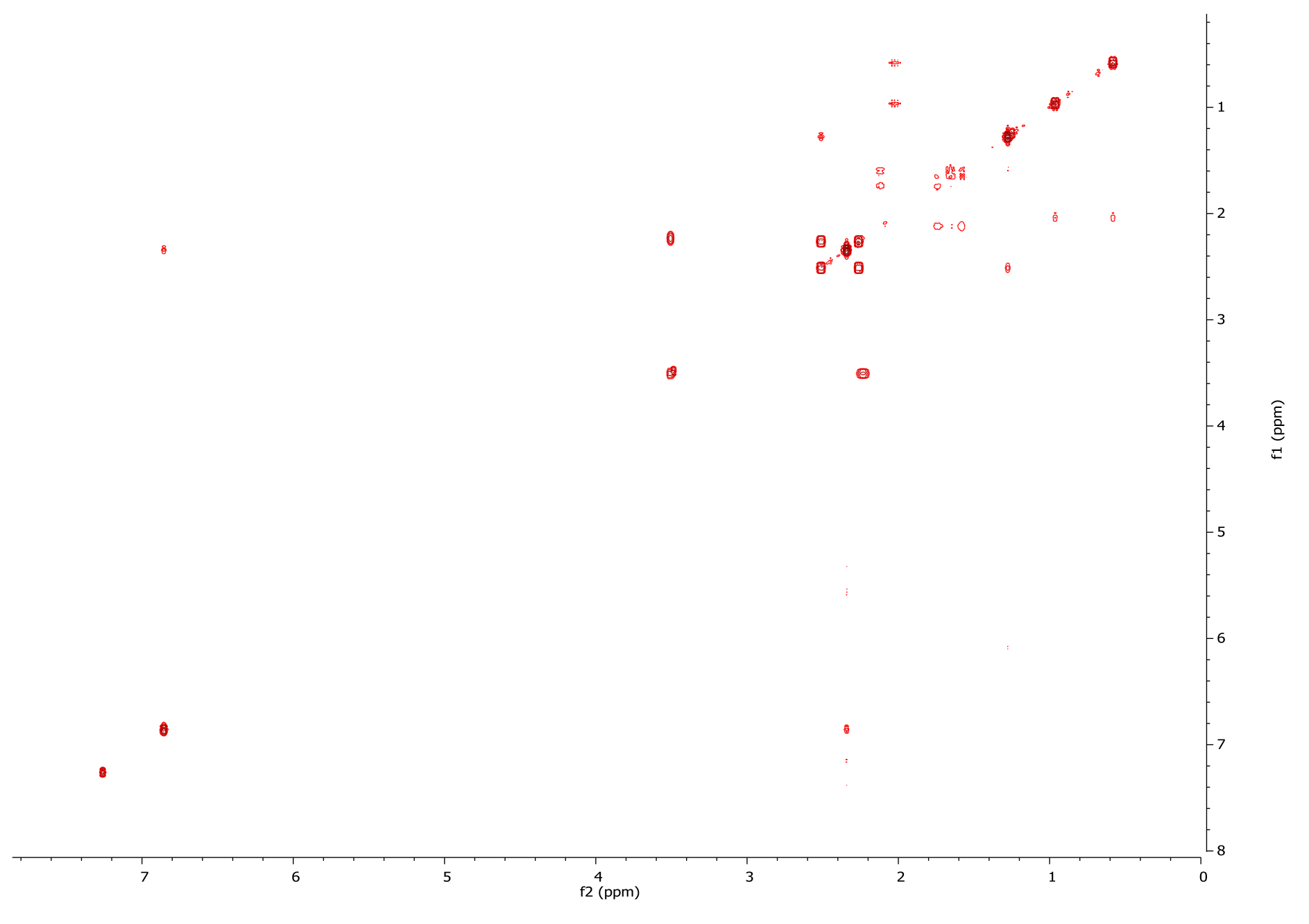

COSY NMR spectrum of hamigeran S (65) in $\mathrm{CDCl}_{3}(600 \mathrm{MHz})$. 


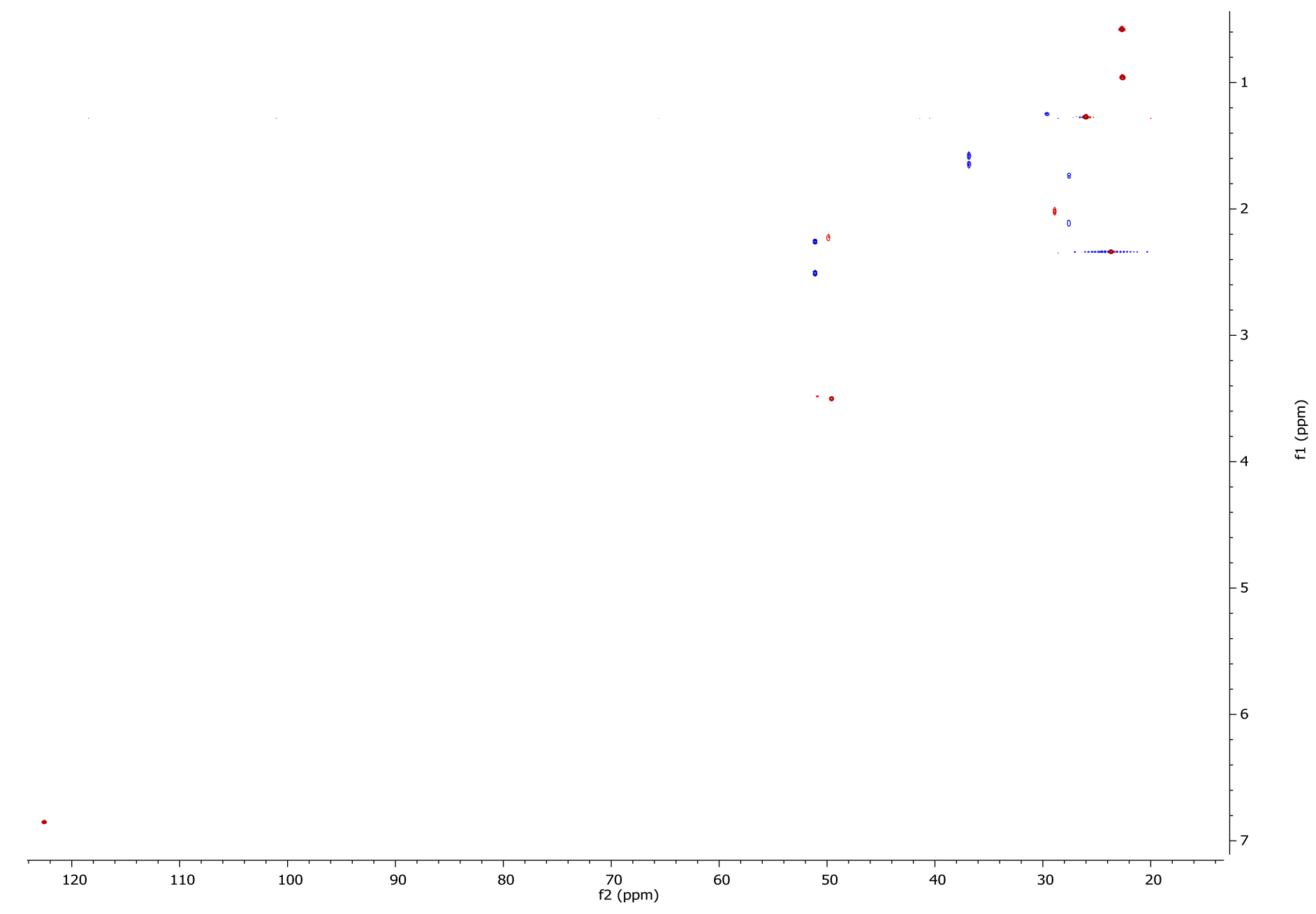

HSQC NMR spectrum of hamigeran S (65) in $\mathrm{CDCl}_{3}(600 \mathrm{MHz})$. 


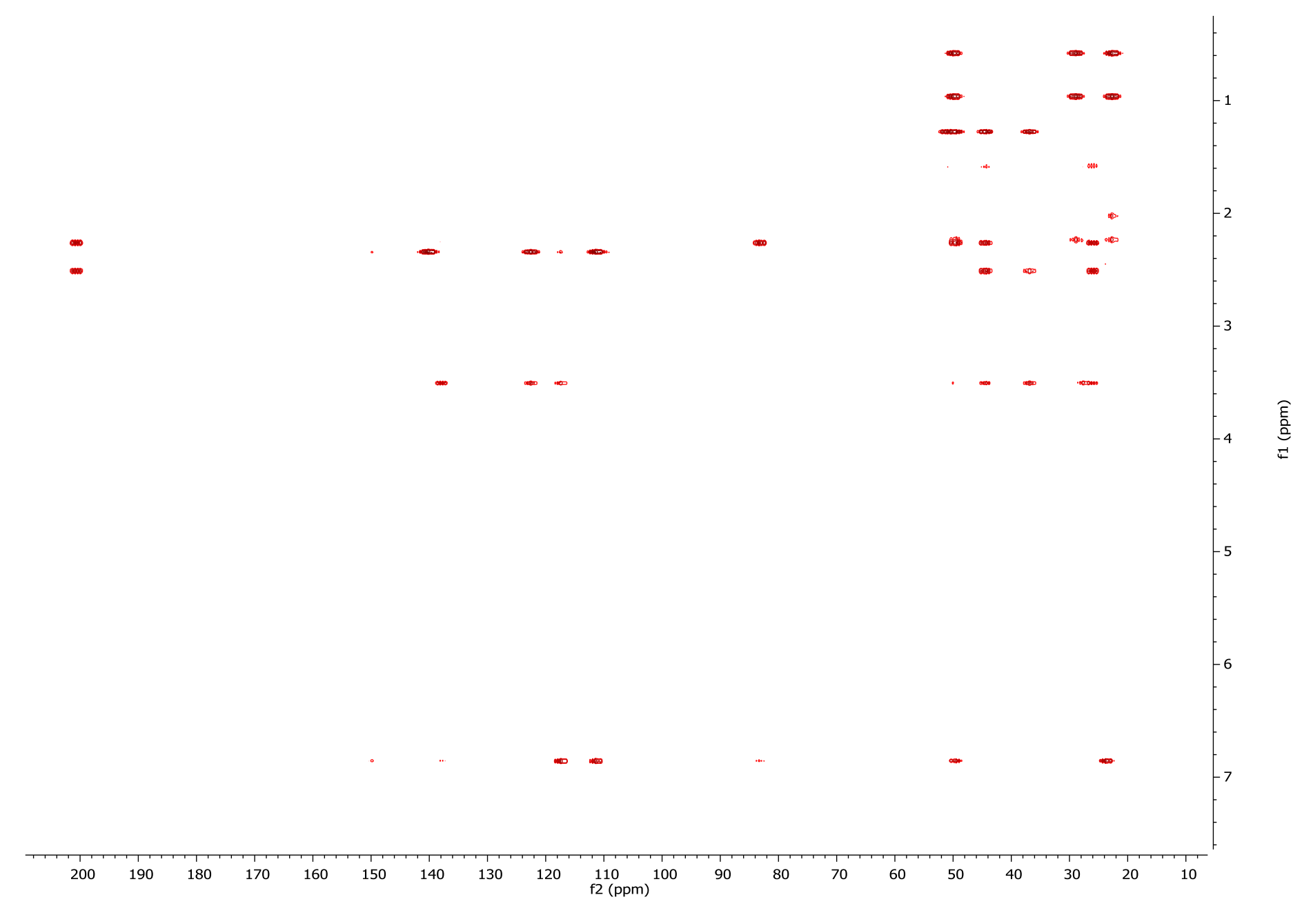

HMBC NMR spectrum of hamigeran S (65) in $\mathrm{CDCl}_{3}(600 \mathrm{MHz})$. 


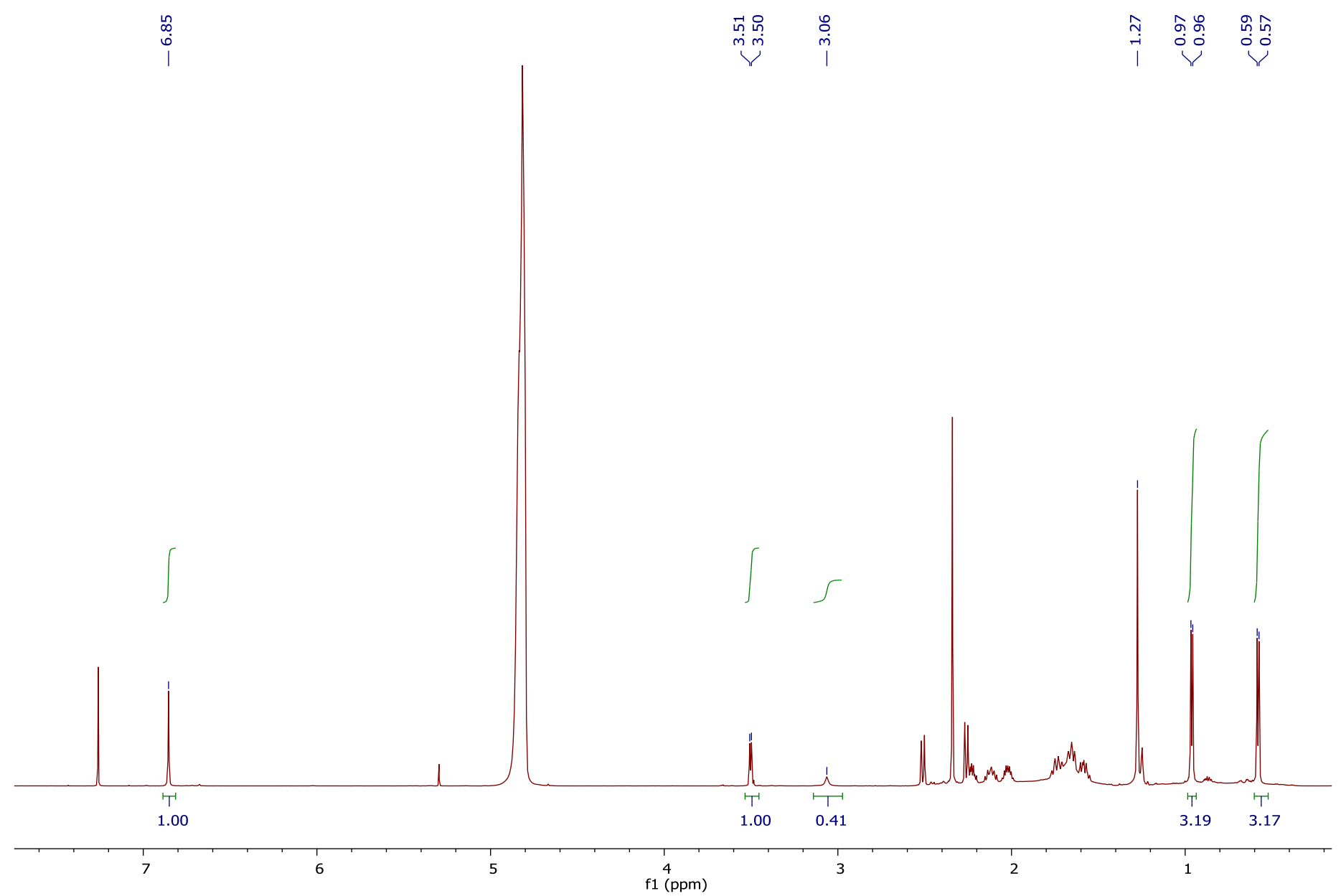

${ }^{1} \mathrm{H} \mathrm{H}_{2} \mathrm{O}$ experiment NMR spectrum of hamigeran $\mathrm{S}(\mathbf{6 5})$ in $\mathrm{CDCl}_{3}(600 \mathrm{MHz})$. 

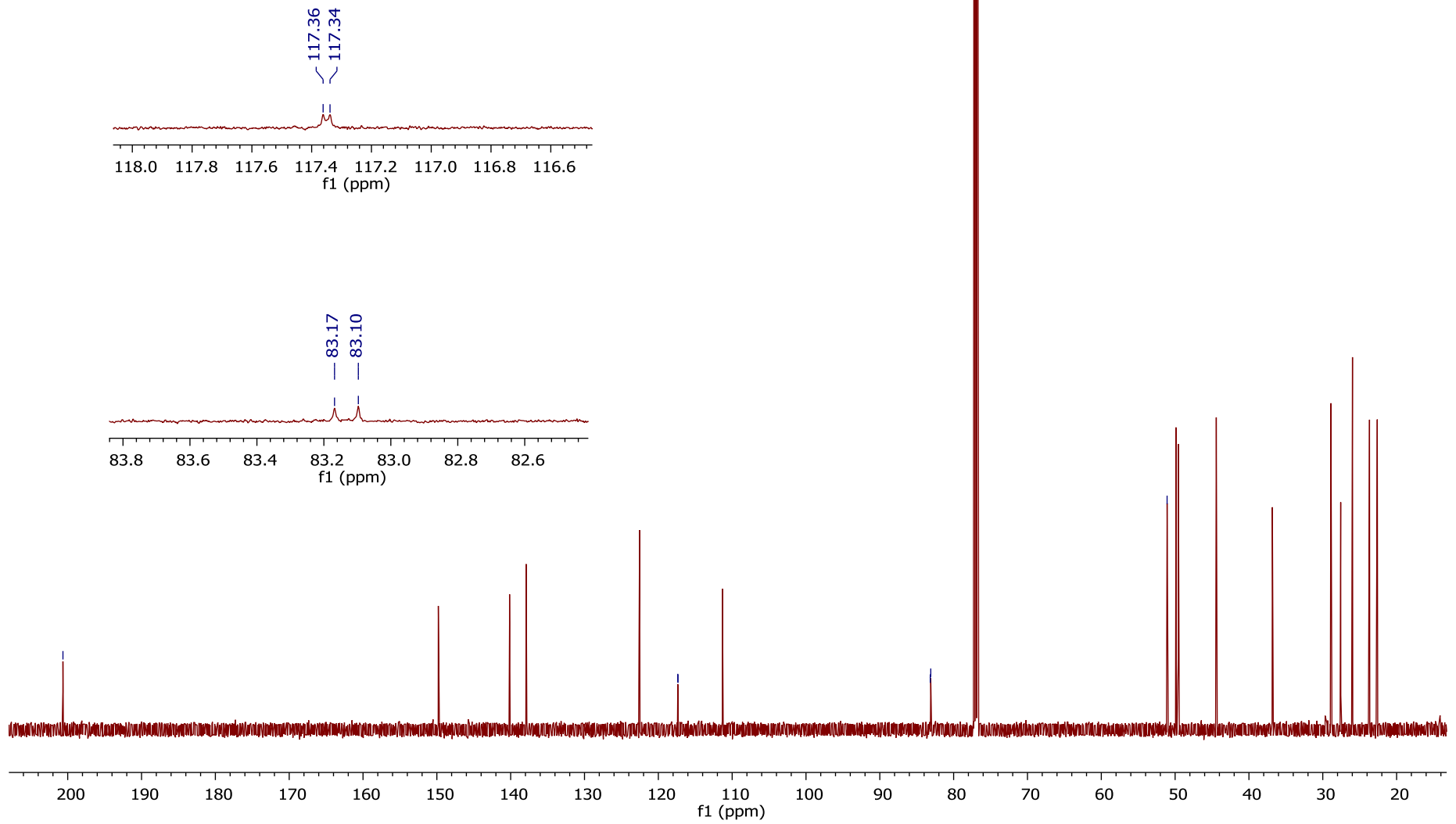

${ }^{13} \mathrm{C} \mathrm{H}_{2} \mathrm{O} / \mathrm{D}_{2} \mathrm{O}$ NMR spectrum of hamigeran $\mathrm{S}(\mathbf{6 5})$ in $\mathrm{CDCl}_{3}(150 \mathrm{MHz})$. 


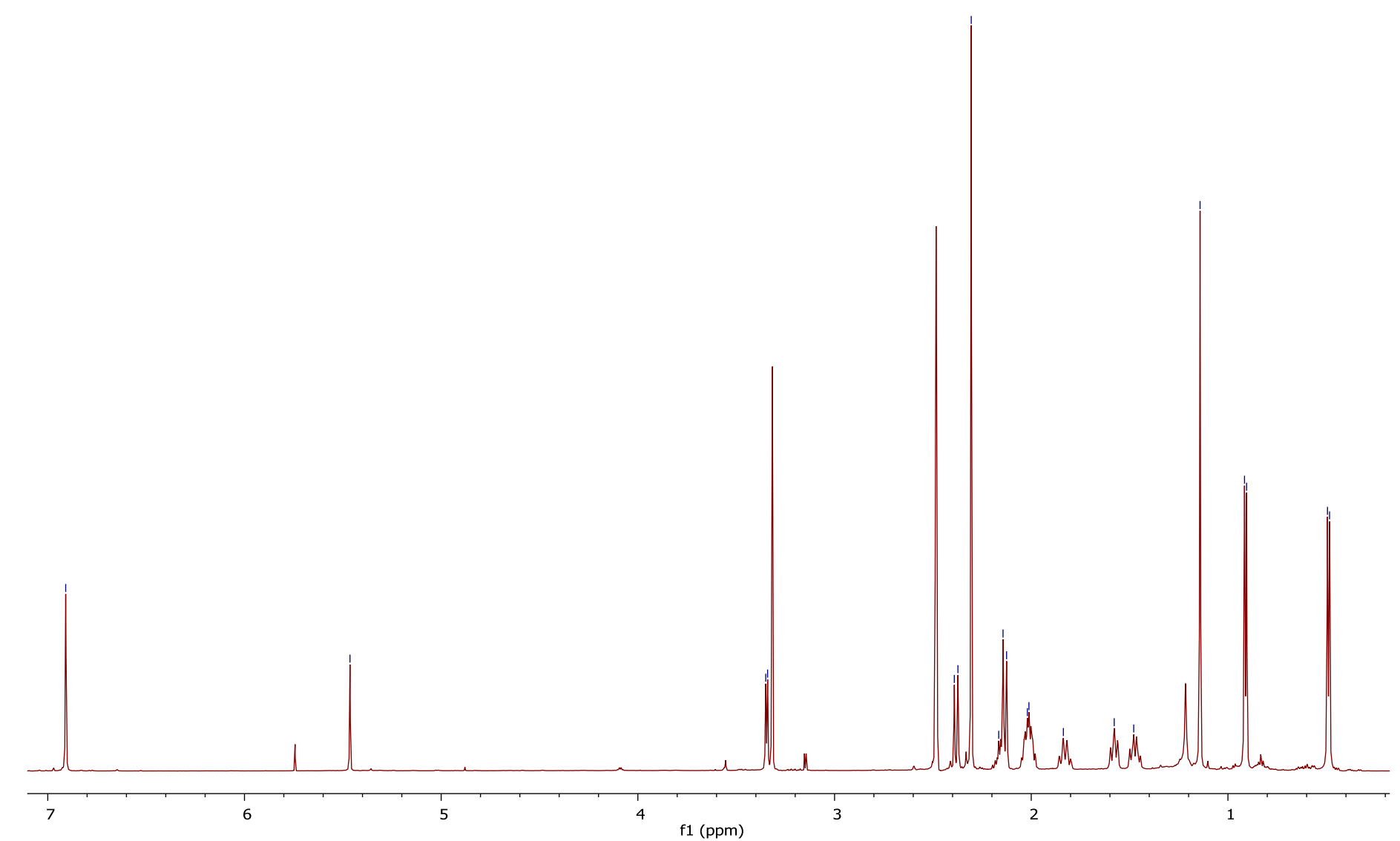

${ }^{1} \mathrm{H}$ NMR spectrum of hamigeran S (65) in DMSO (600 MHz). 


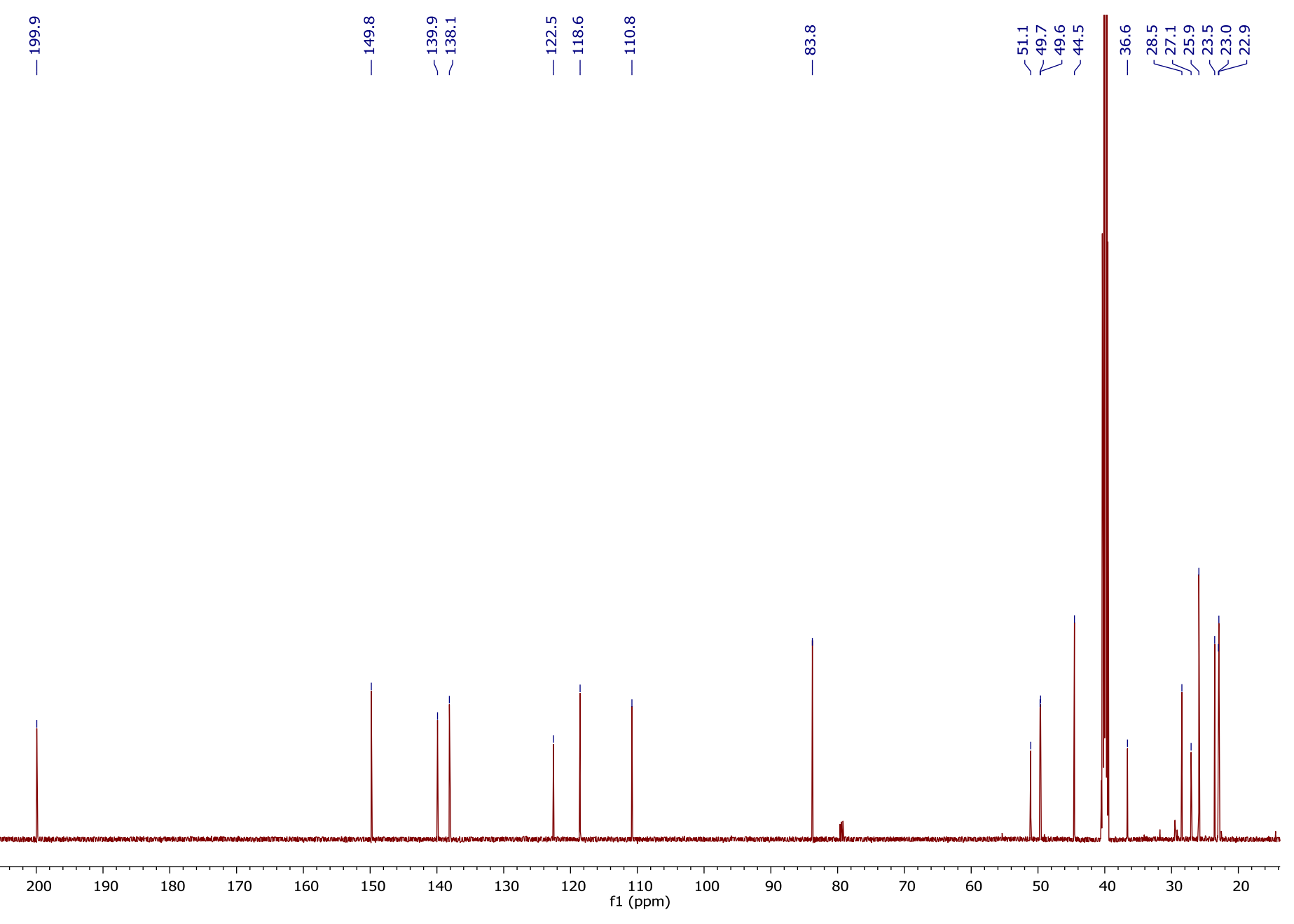

${ }^{13} \mathrm{C}$ NMR spectrum of hamigeran S (65) in DMSO (150 MHz). 


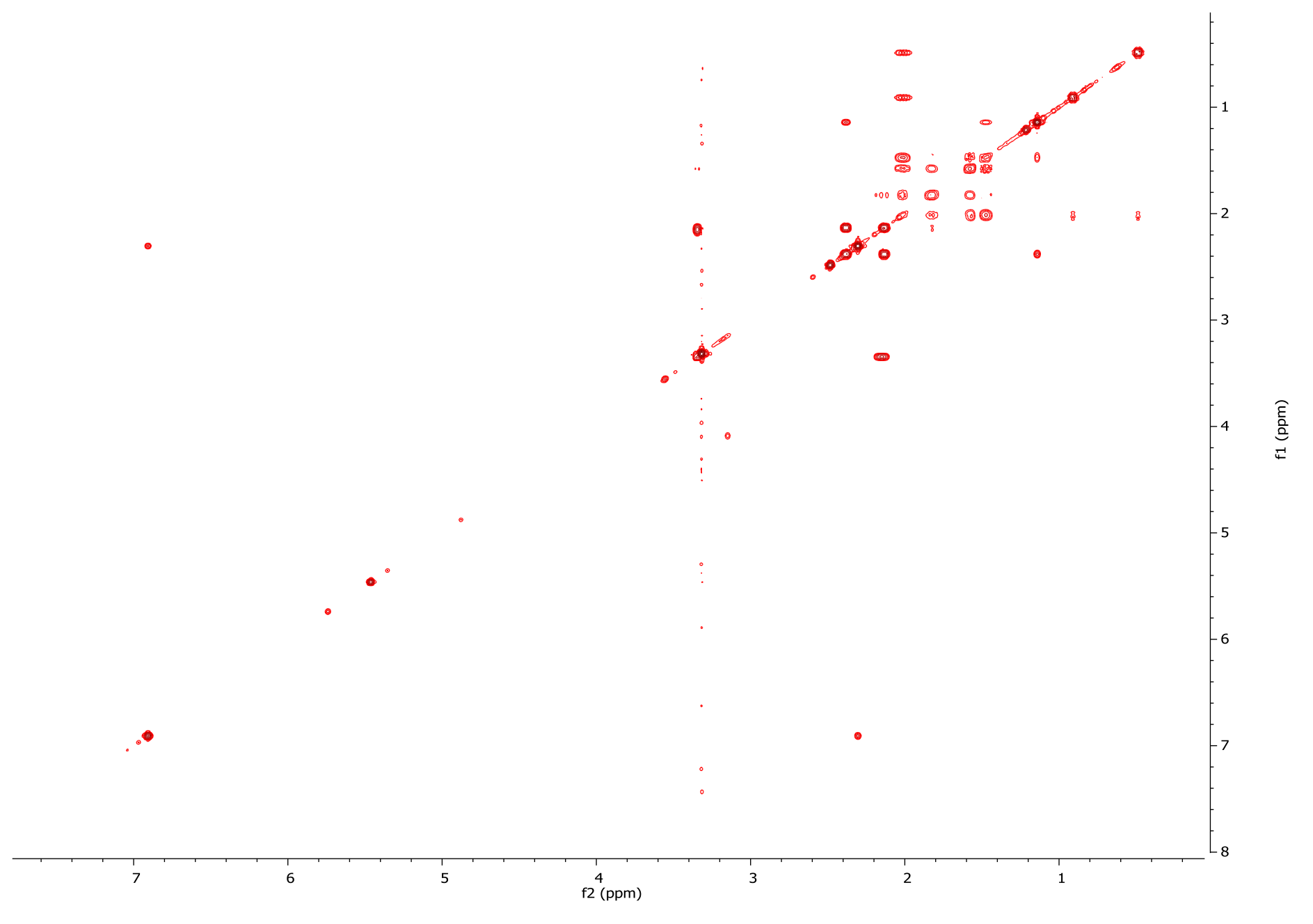

COSY NMR spectrum of hamigeran S (65) in DMSO (600 MHz). 


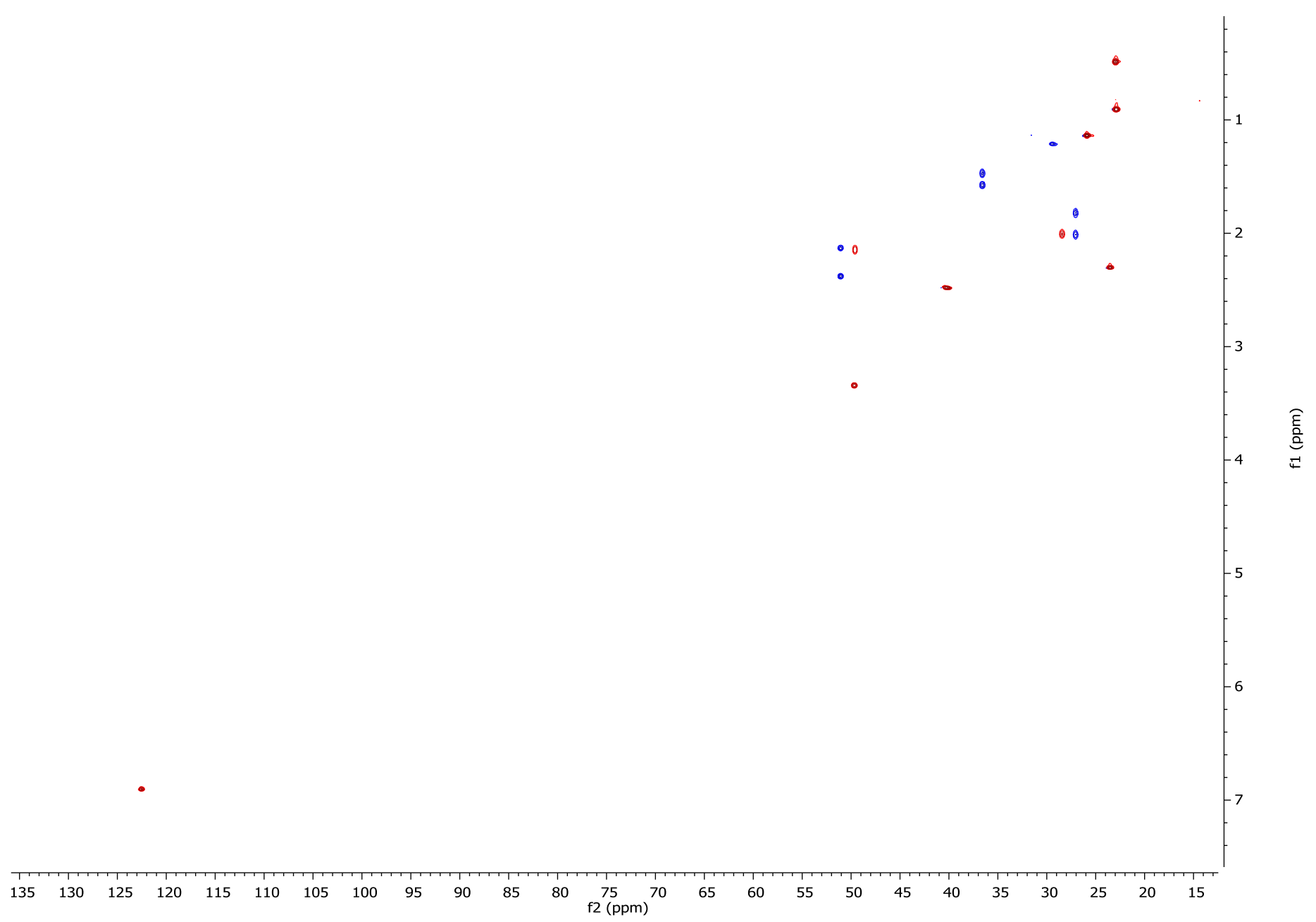

HSQC NMR spectrum of hamigeran S (65) in DMSO (600 MHz). 


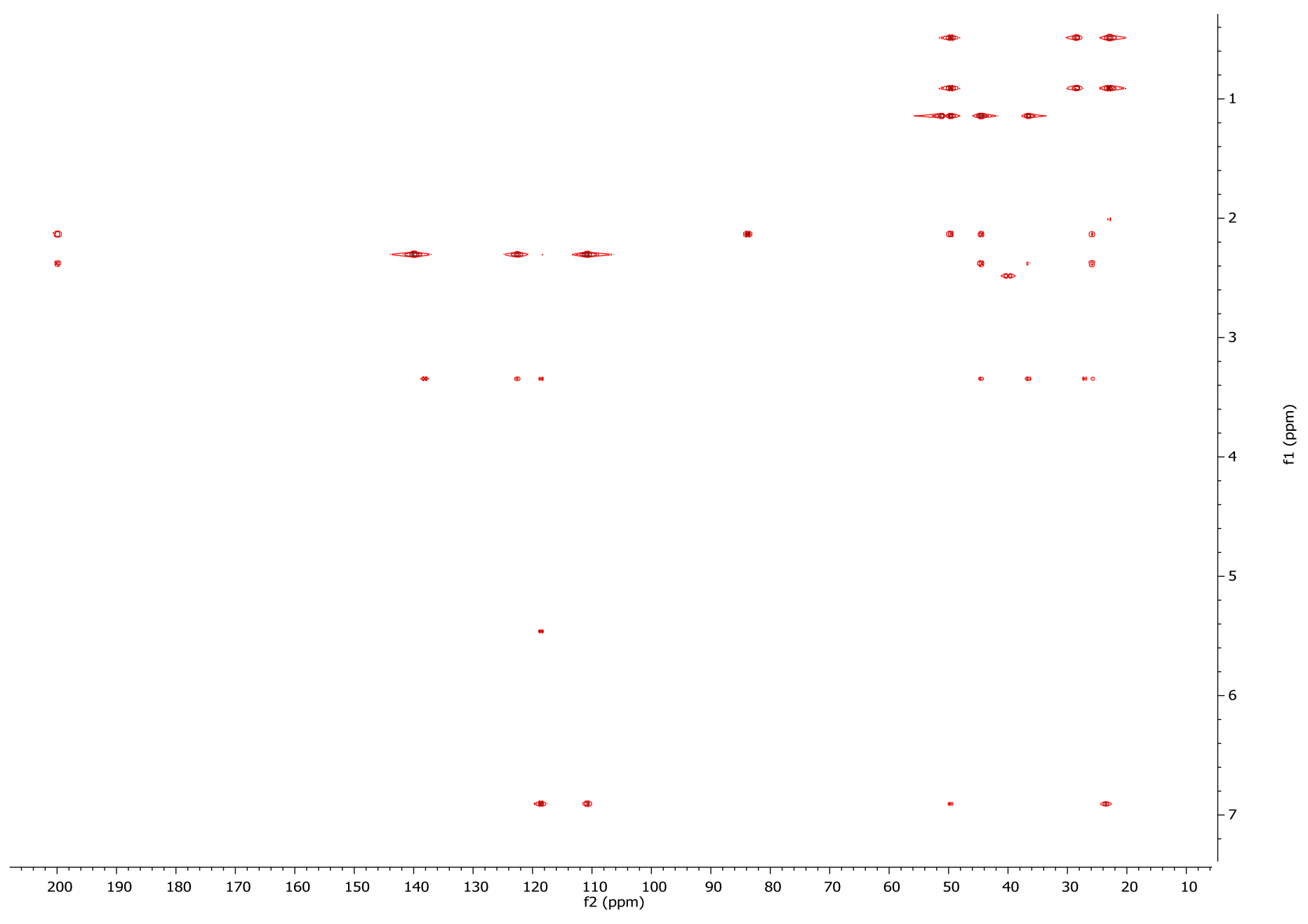

HMBC NMR spectrum of hamigeran S (65) in DMSO (600 MHz). 


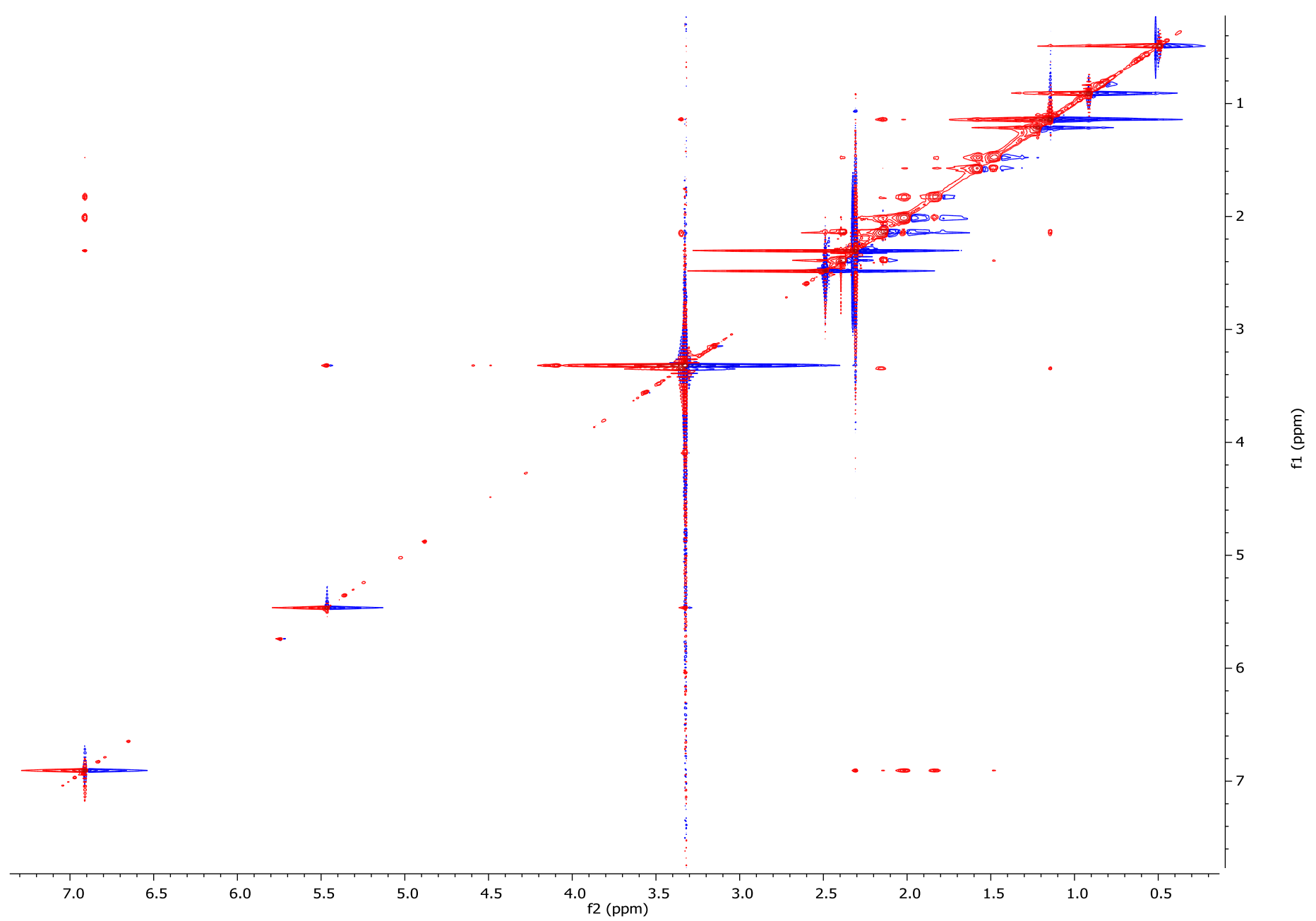

2D NOESY NMR spectrum of hamigeran S (65) in DMSO (600 MHz). 


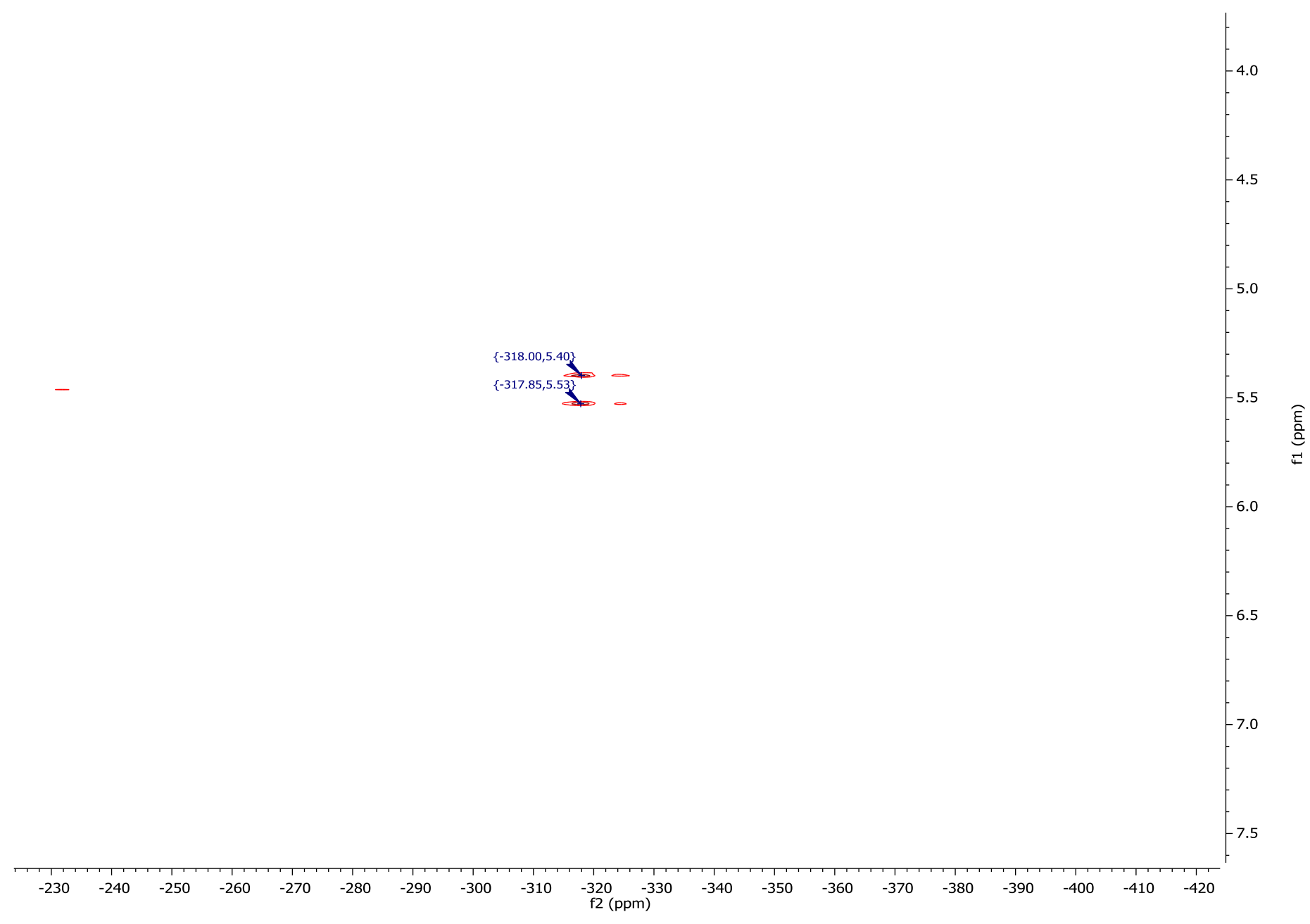

${ }^{15} \mathrm{~N}$ decoupled HMBC NMR spectrum of hamigeran S (65) in DMSO (600 MHz). 


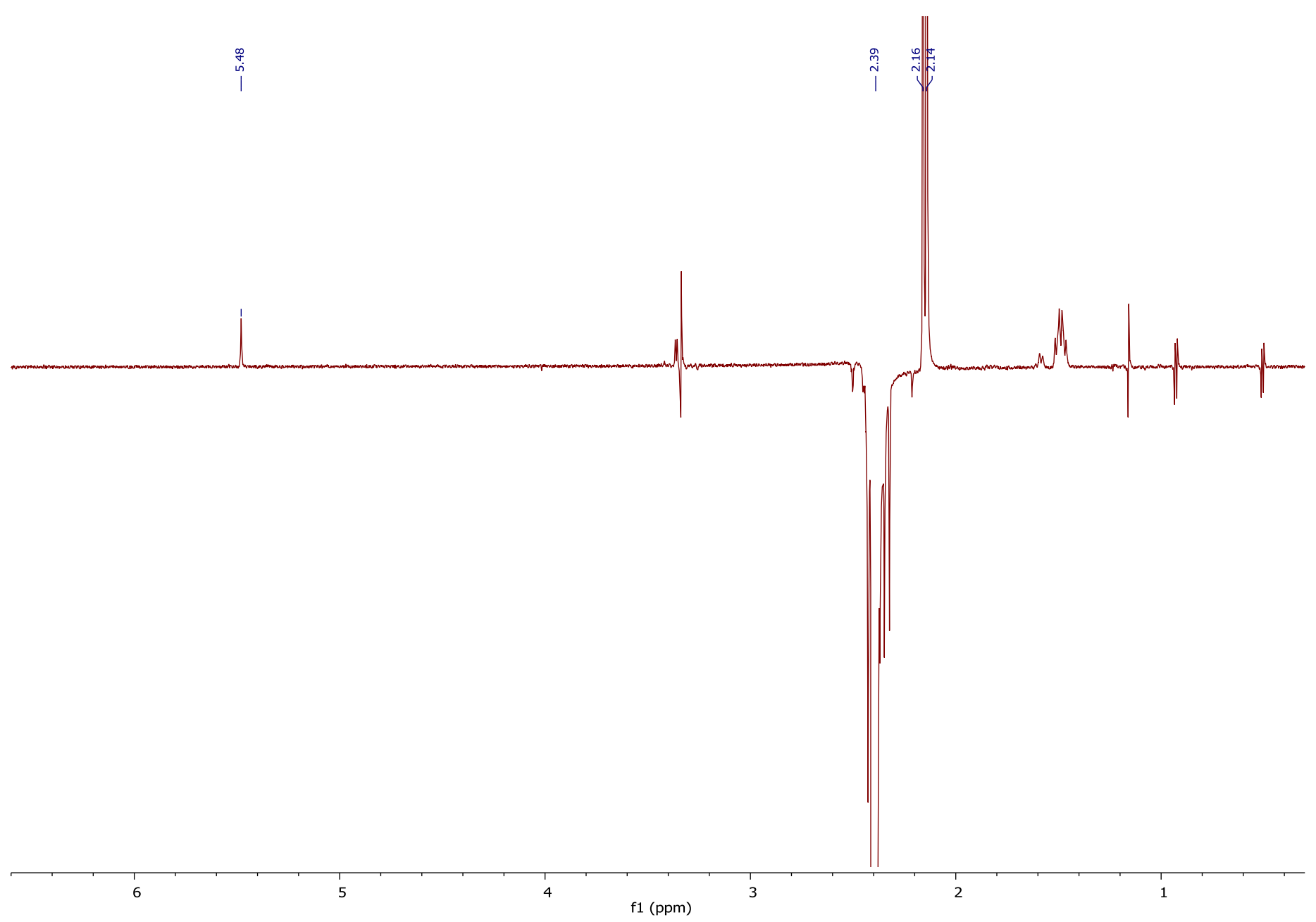

1D ROSY irradiating 2.39 ppm NMR spectrum of hamigeran S (65) in DMSO (600 MHz). 


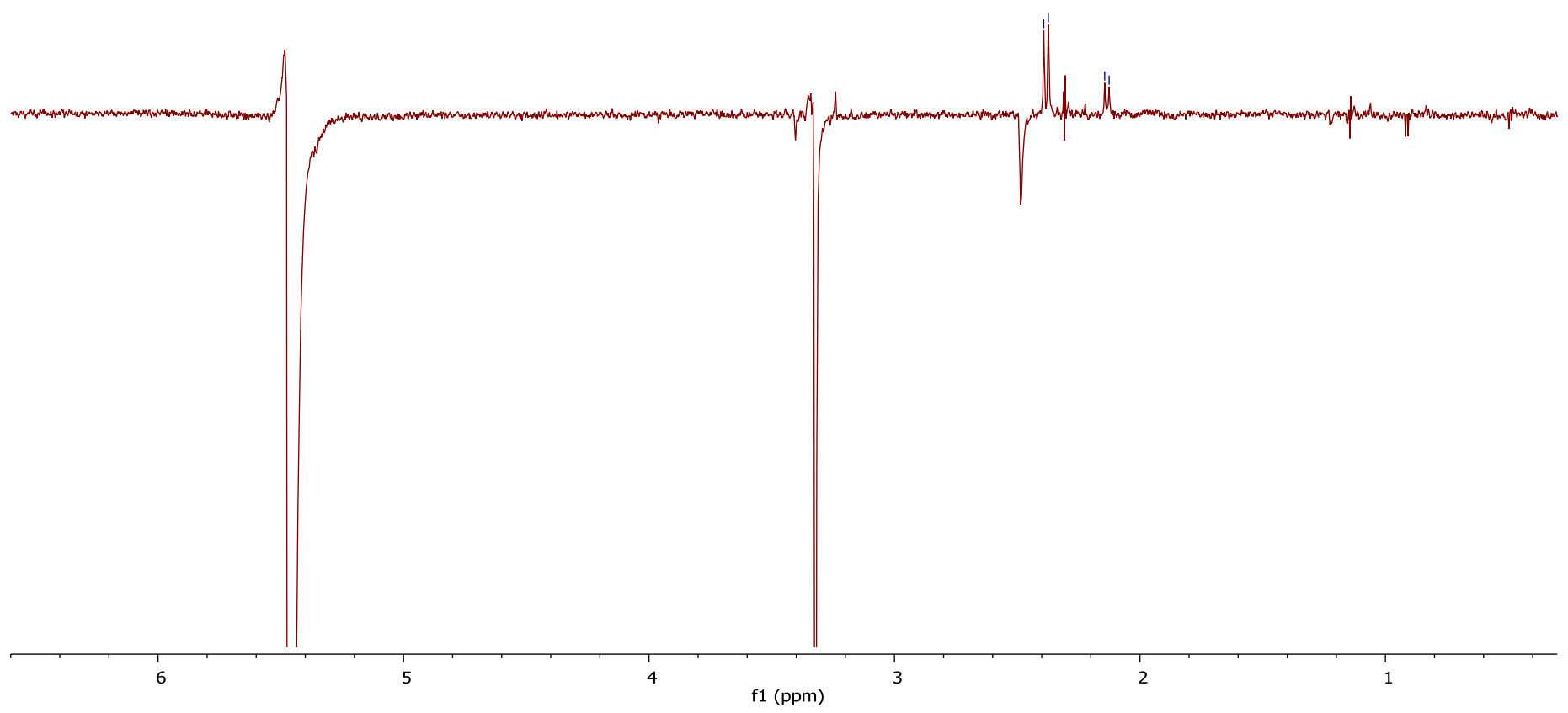

1D ROSY irradiating 5.46 ppm NMR spectrum of hamigeran S (65) in DMSO (600 MHz). 
H Imine from Hamigeran G reaction NMR Spectra

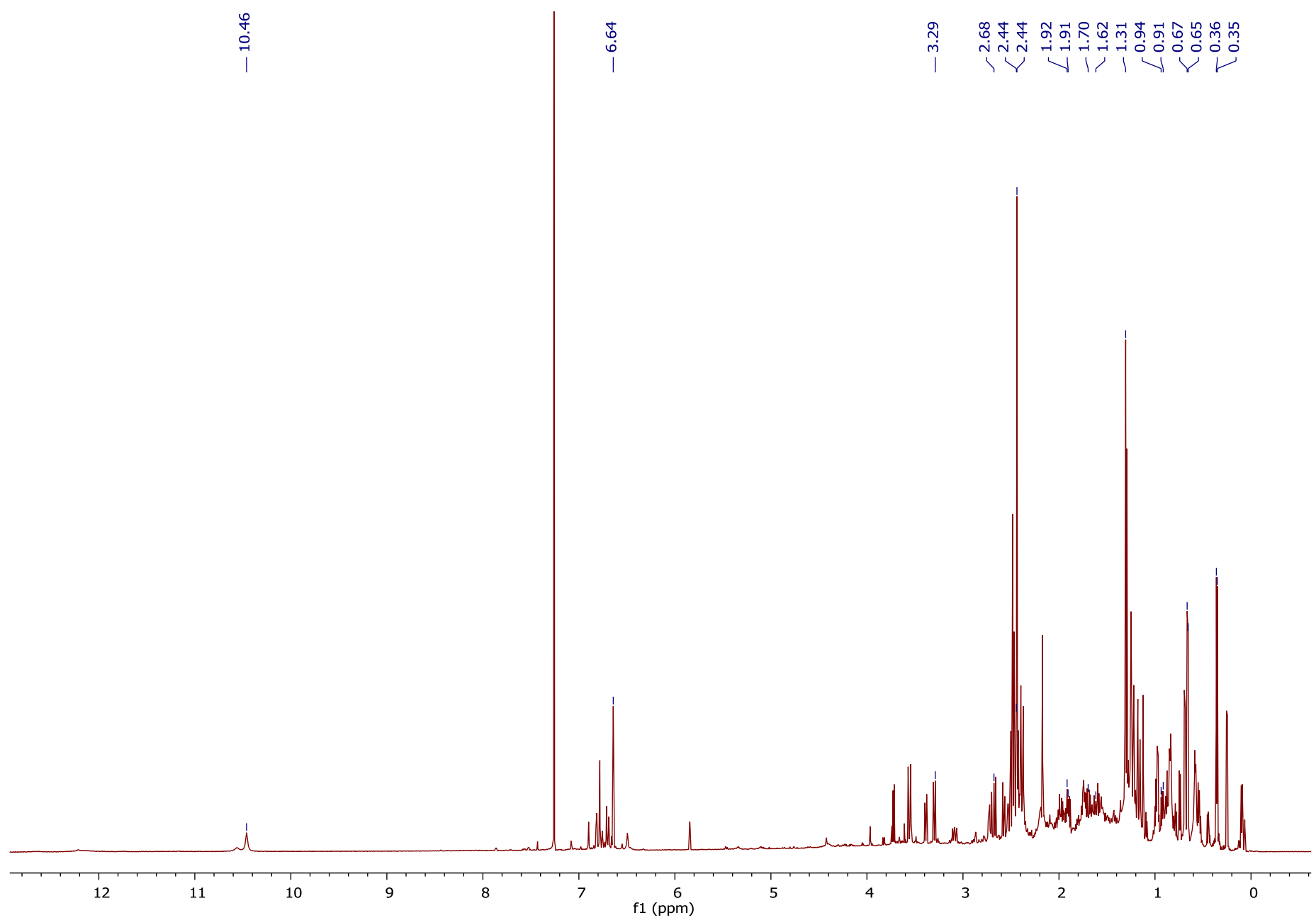

${ }^{1} \mathrm{H}$ NMR spectrum of imine (66) from hamigeran $\mathrm{G}$ reaction in $\mathrm{CDCl}_{3}(600 \mathrm{MHz})$. 


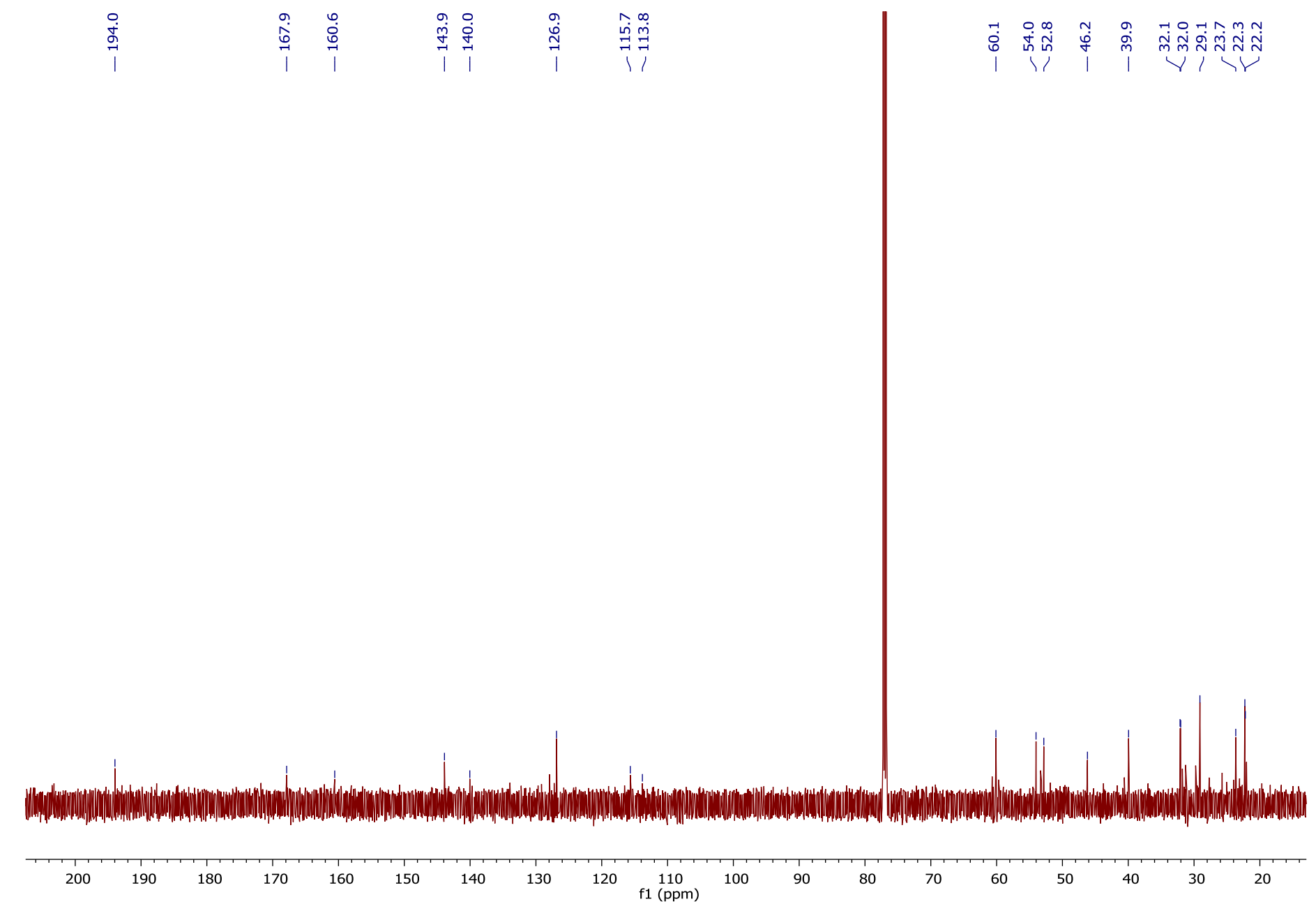

${ }^{13} \mathrm{C}$ NMR spectrum of imine (66) from hamigeran $\mathrm{G}$ reaction in $\mathrm{CDCl}_{3}(600 \mathrm{MHz})$. 


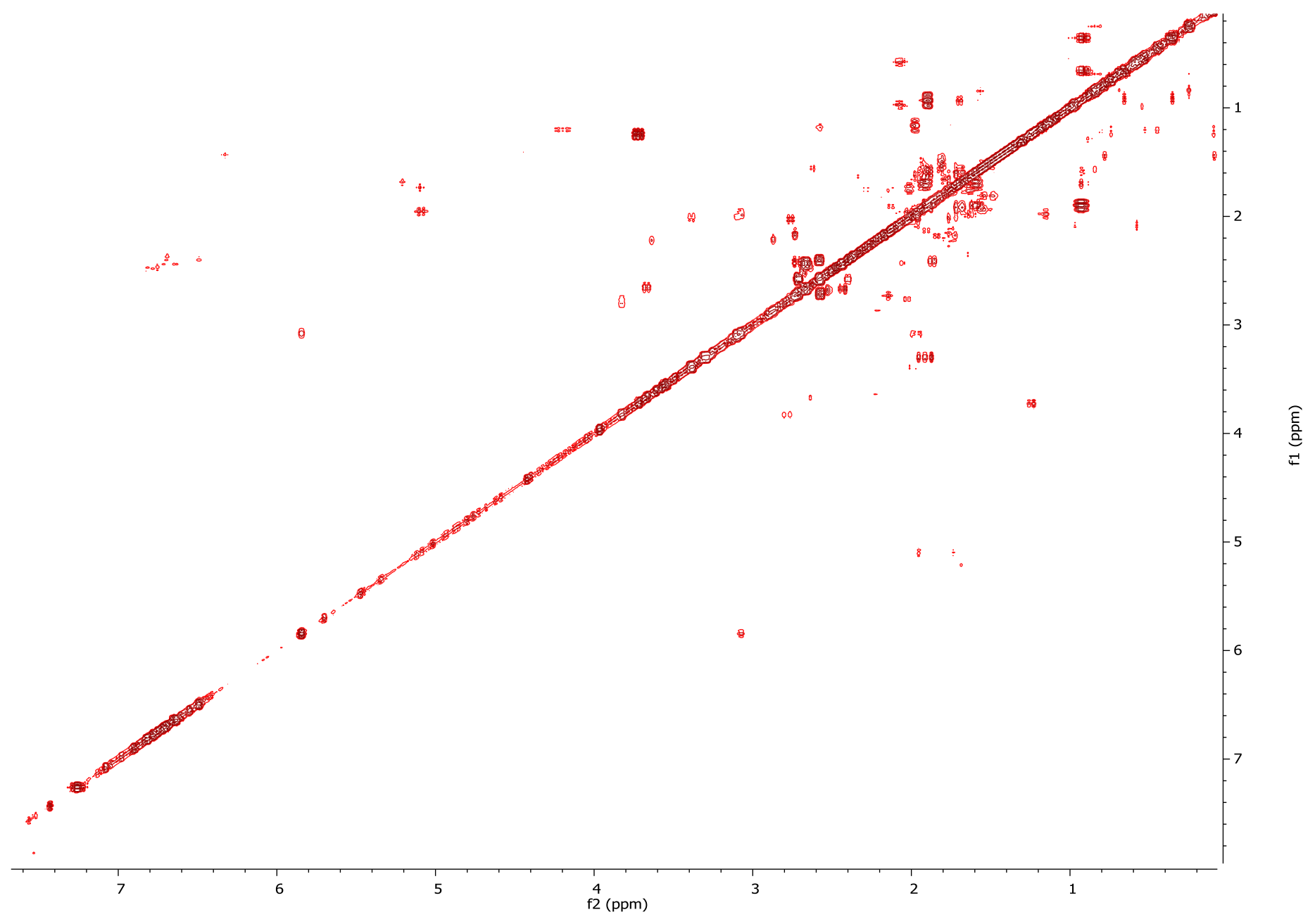

COSY NMR spectrum of imine (66) from hamigeran $\mathrm{G}$ reaction in $\mathrm{CDCl}_{3}(600 \mathrm{MHz})$. 


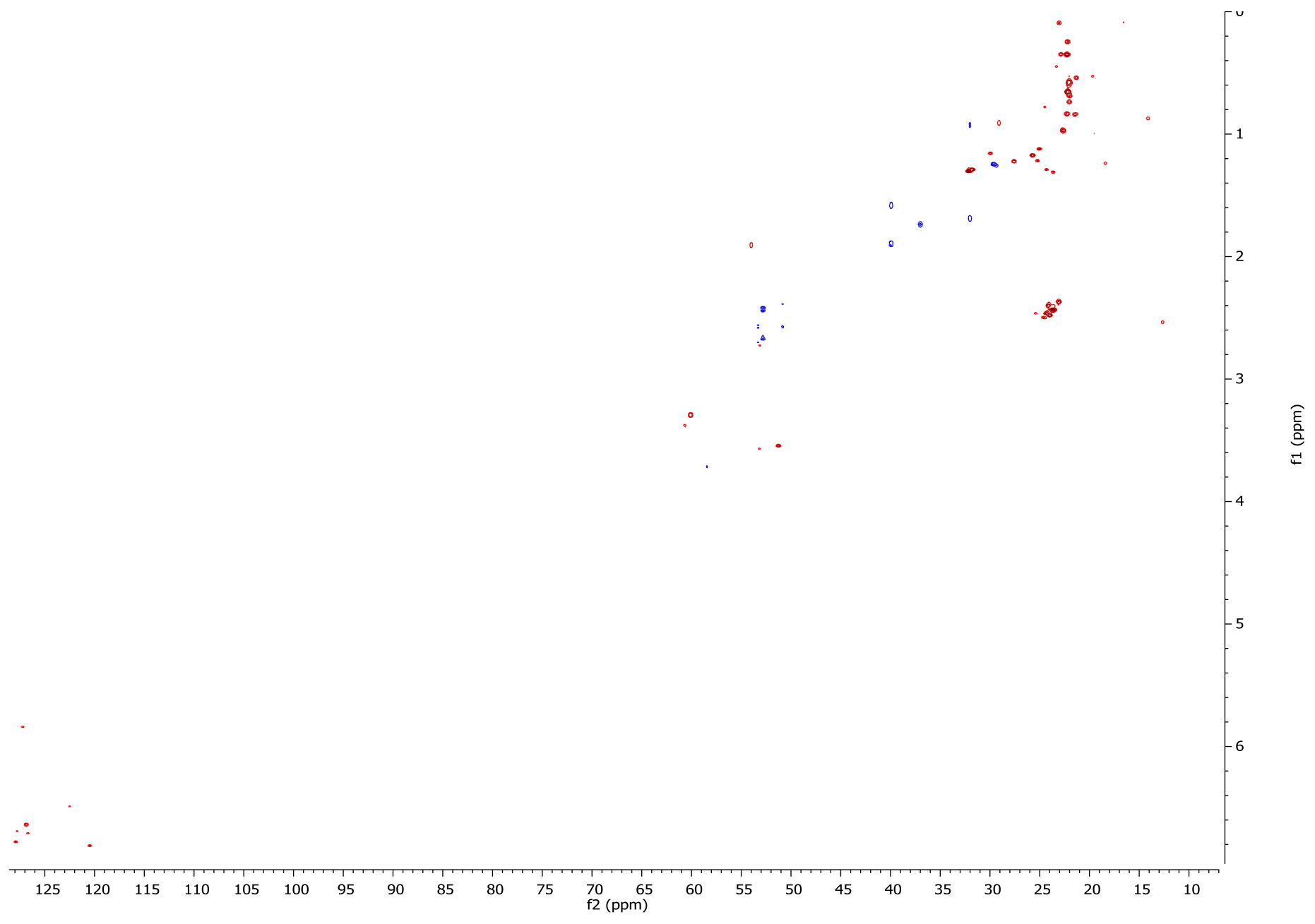

HSQC NMR spectrum of imine (66) from hamigeran $\mathrm{G}$ reaction in $\mathrm{CDCl}_{3}(600 \mathrm{MHz})$. 


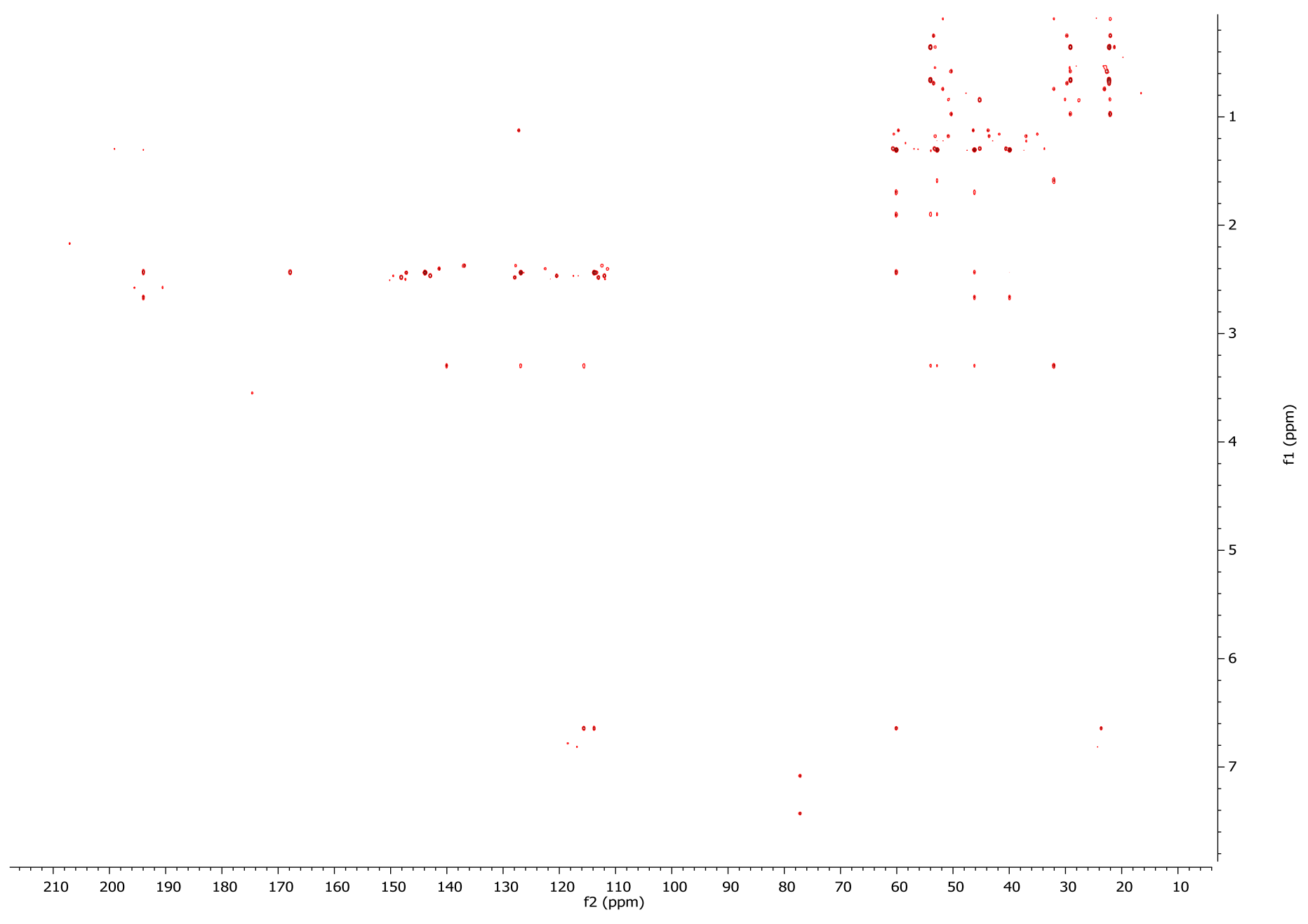

HMBC NMR spectrum of imine (66) from hamigeran $\mathrm{G}$ reaction in $\mathrm{CDCl}_{3}(600 \mathrm{MHz})$. 
I Hamigeran D and Epimer from L-alanine Reaction NMR Spectra

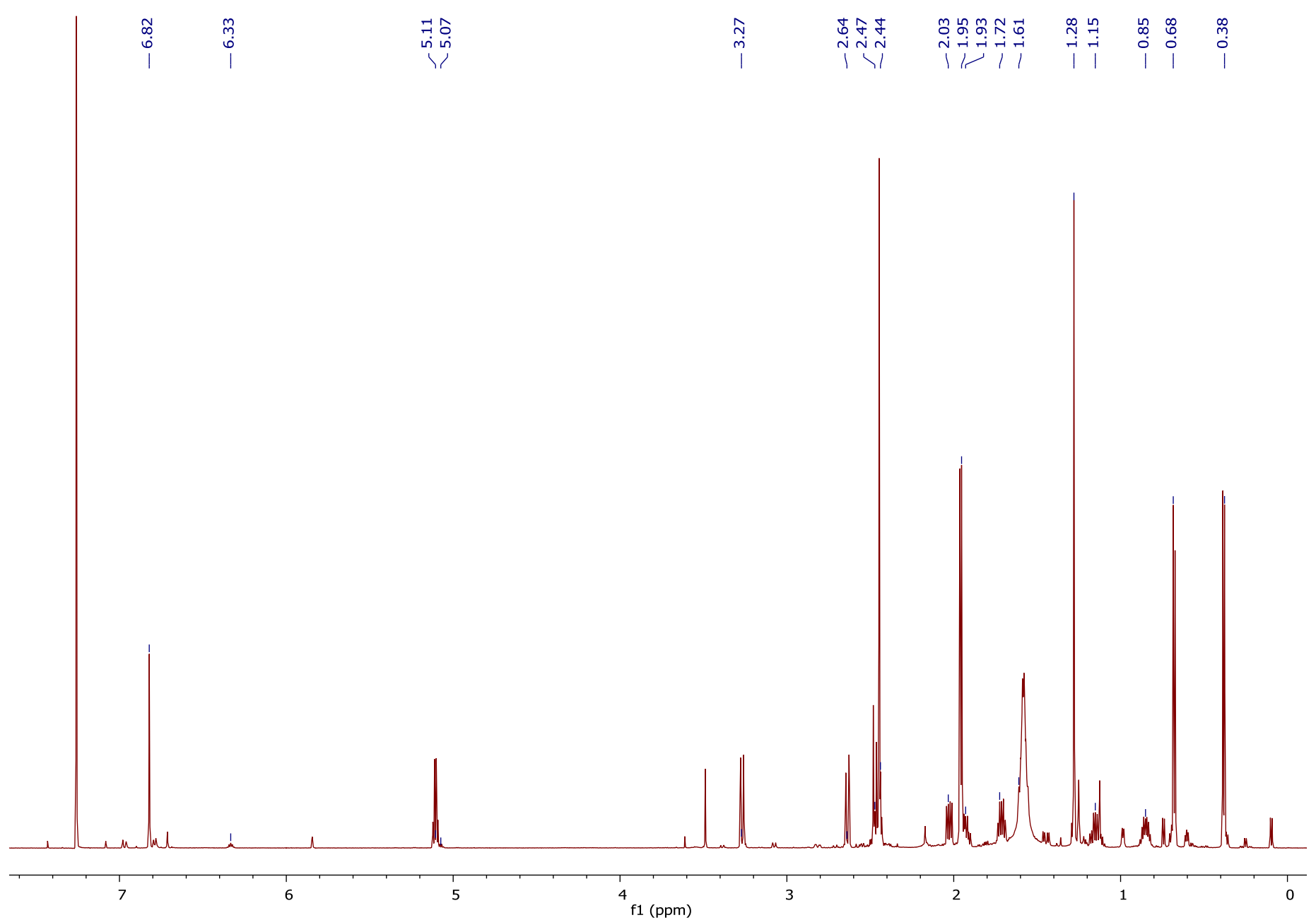

${ }^{1} \mathrm{H}$ NMR spectrum of hamigeran D (33) and epimer (69) in $\mathrm{CDCl}_{3}(600 \mathrm{MHz})$. 


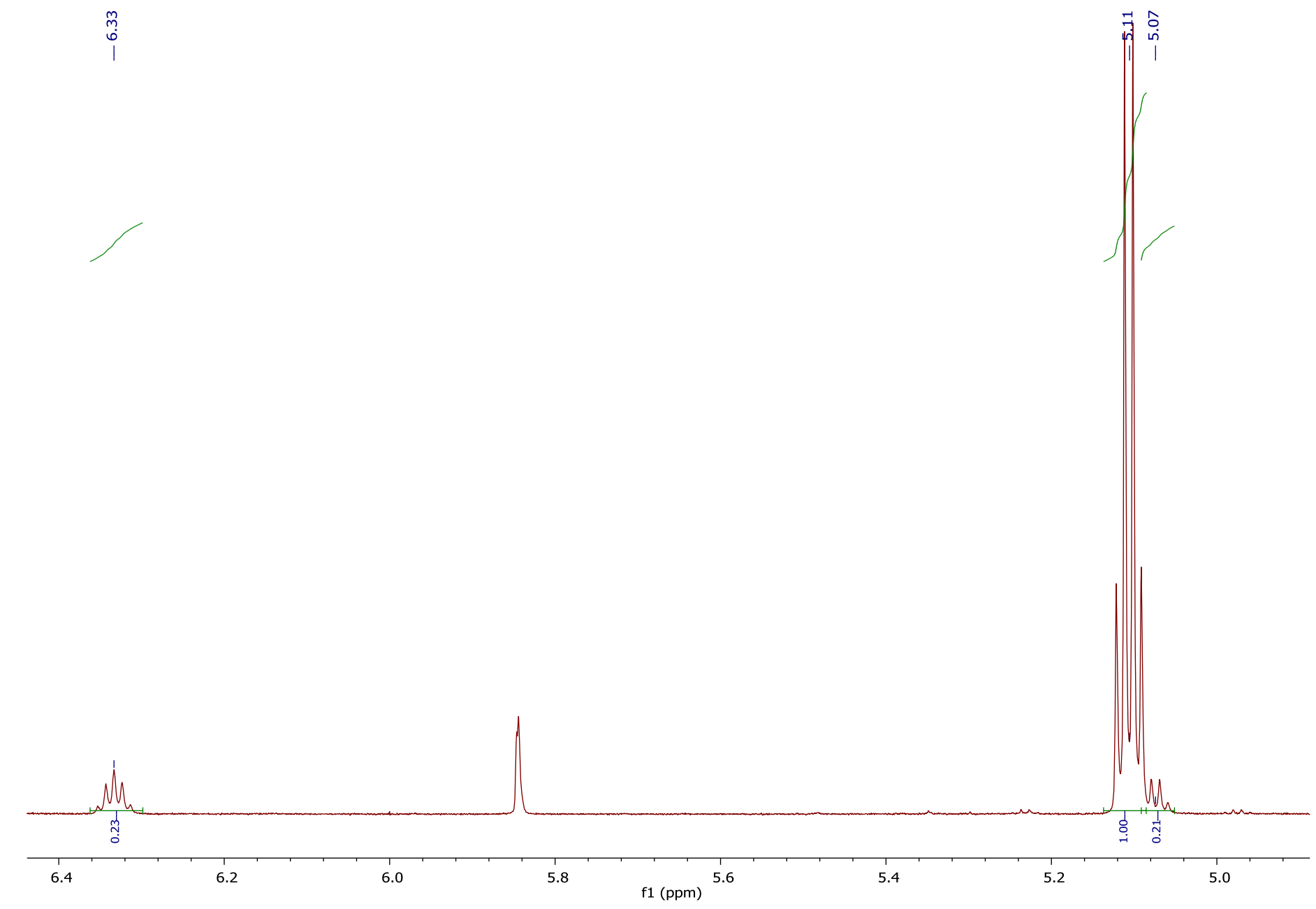

${ }^{1} \mathrm{H}$ NMR spectrum of Close up of C-18 protons hamigeran D (33) and epimer (69) in $\mathrm{CDCl}_{3}(600 \mathrm{MHz})$. 
J Hamigeran D and Epimer from D-alanine Reaction NMR Spectra

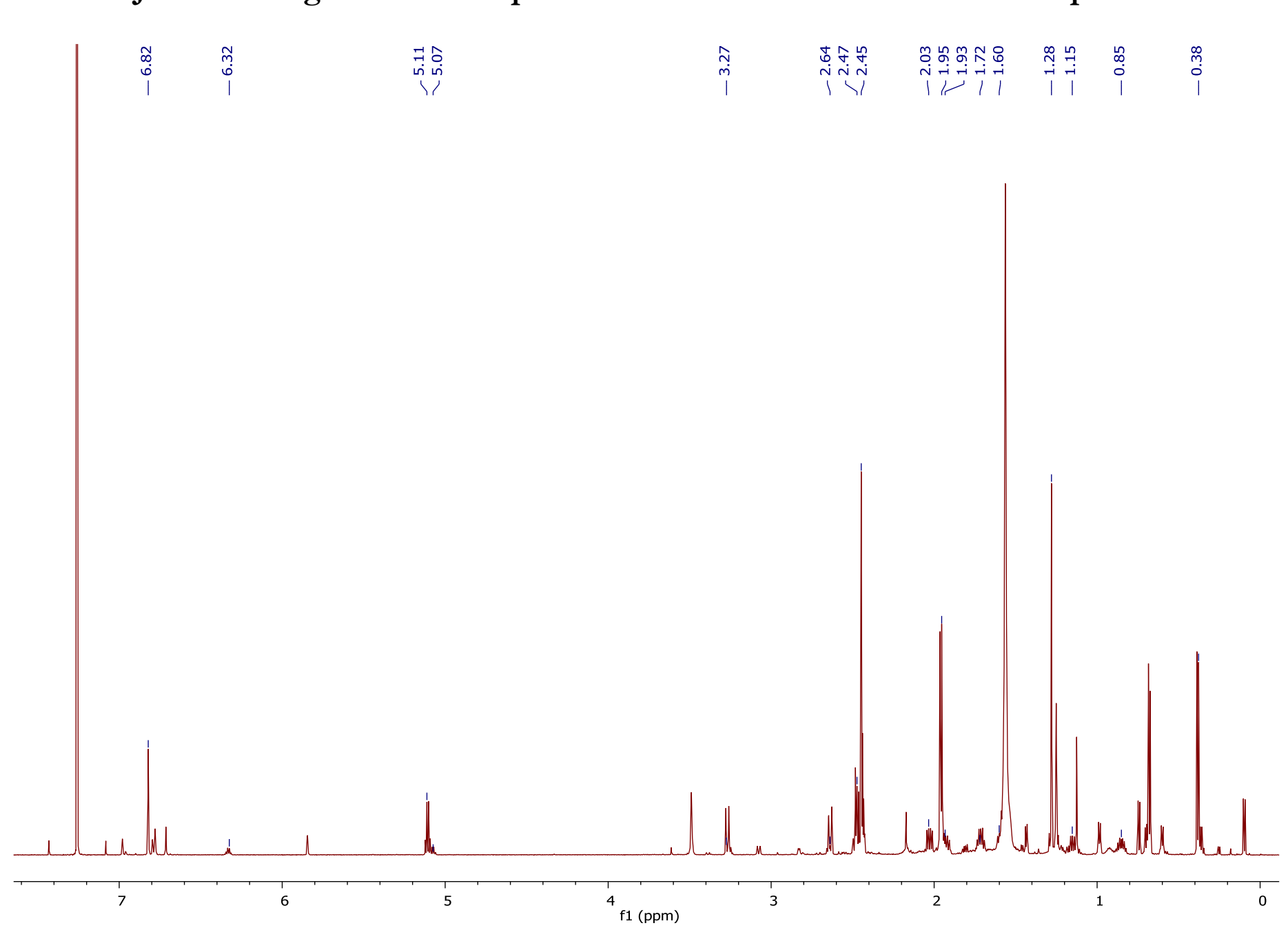

${ }^{1} \mathrm{H}$ NMR spectrum of hamigeran D (33) and epimer (69) in $\mathrm{CDCl}_{3}(600 \mathrm{MHz})$. 


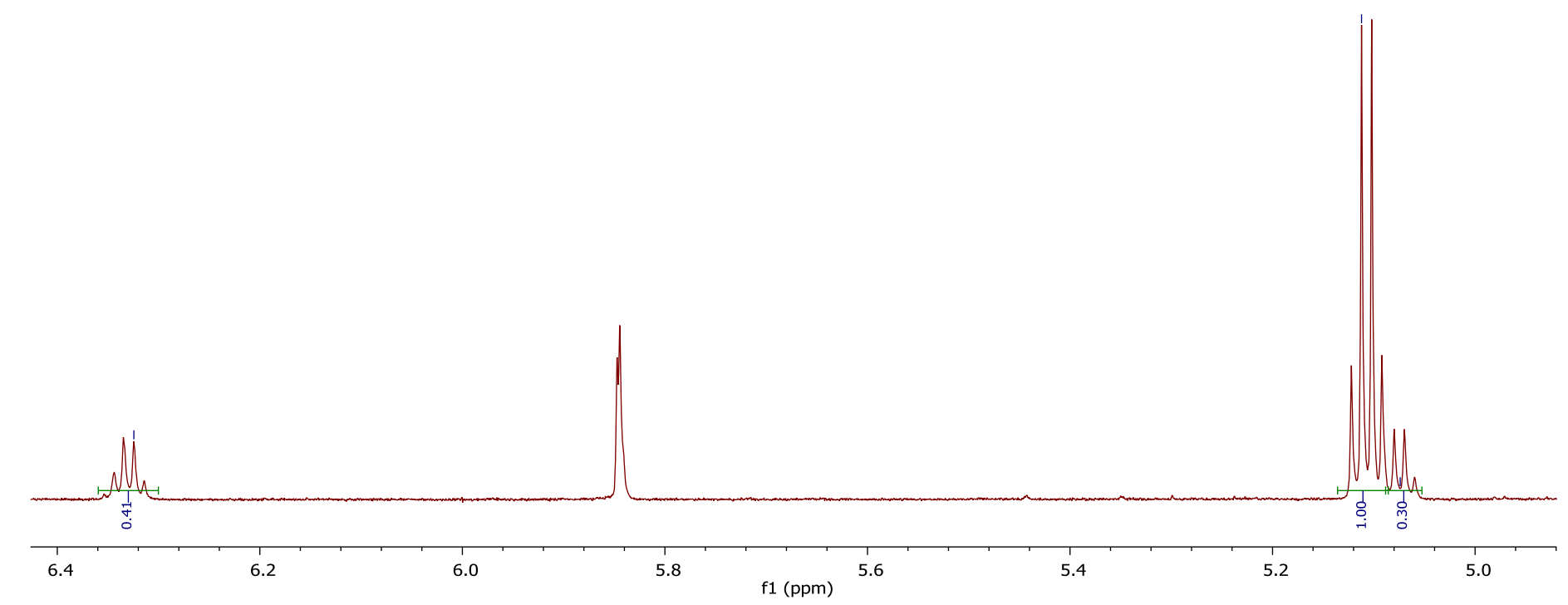

${ }^{1} \mathrm{H}$ NMR spectrum of Close up of C-18 protons hamigeran D (33) and epimer (69) in $\mathrm{CDCl}_{3}(600 \mathrm{MHz})$. 
K Glycine Hamigeran NMR Spectra

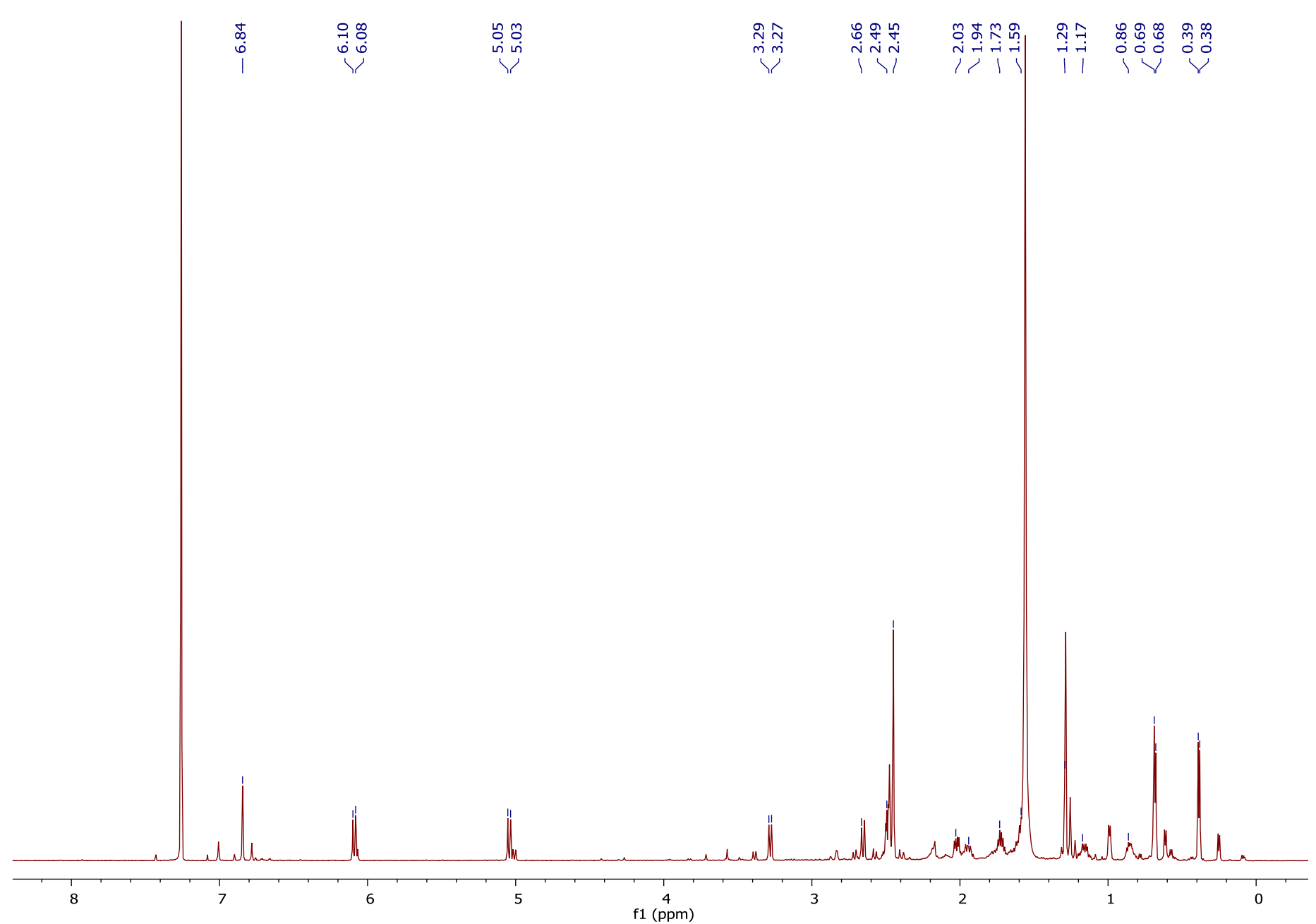

${ }^{1} \mathrm{H}$ NMR spectrum of Glycine hamigeran (68) in $\mathrm{CDCl}_{3}(600 \mathrm{MHz})$. 


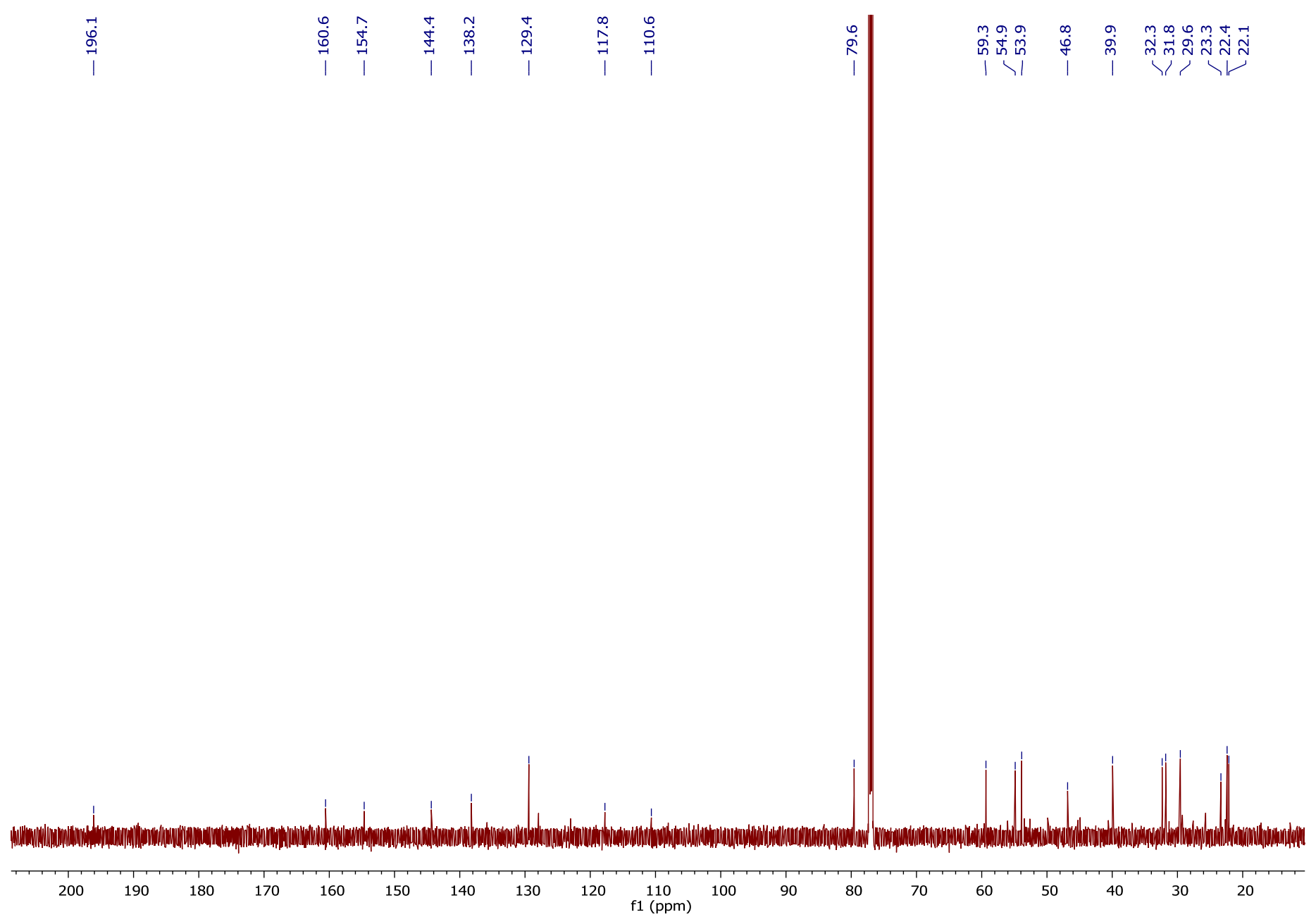

${ }^{13} \mathrm{C}$ NMR spectrum of Glycine hamigeran $(\mathbf{6 8})$ in $\mathrm{CDCl}_{3}(600 \mathrm{MHz})$. 


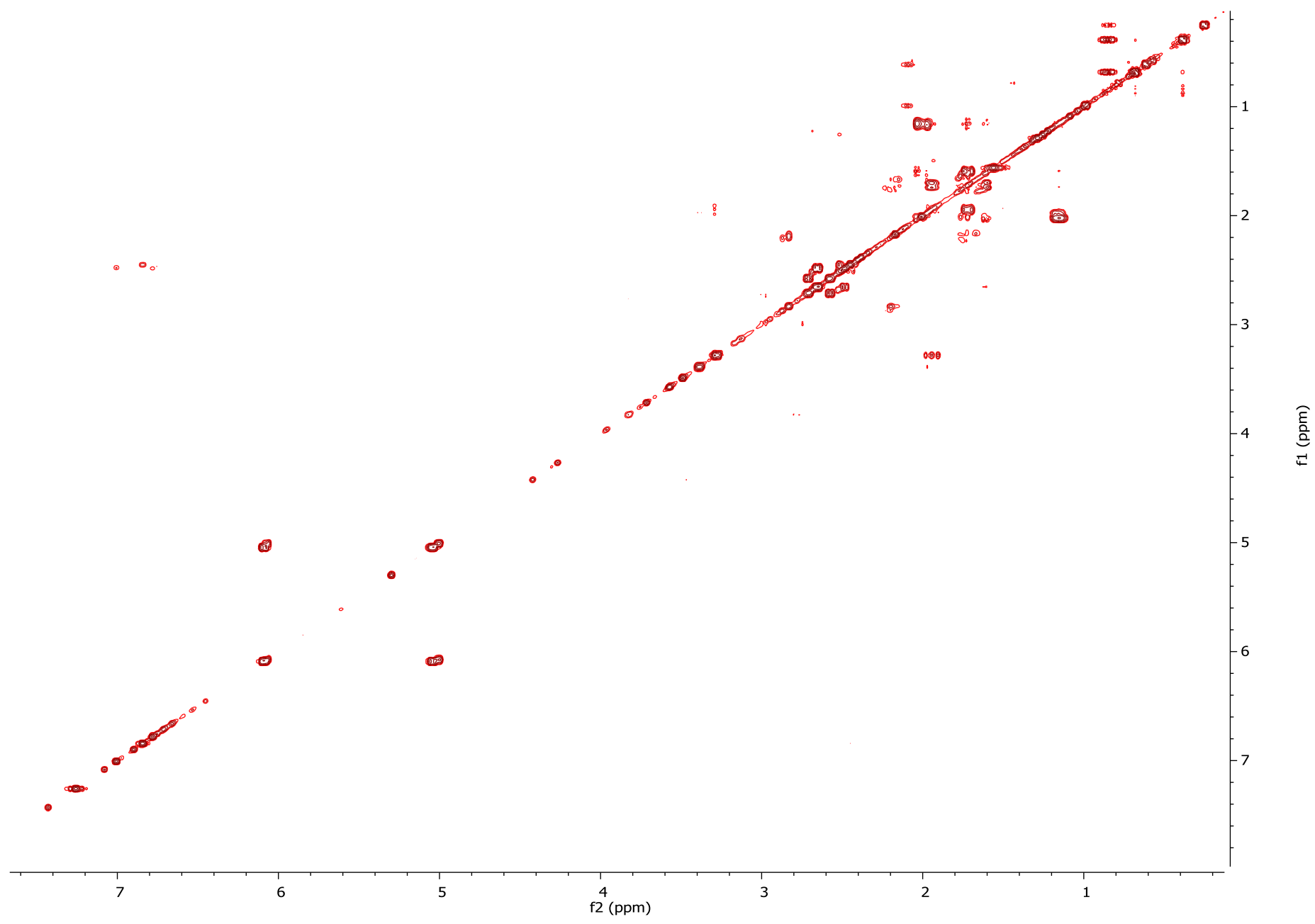

COSY NMR spectrum of Glycine hamigeran (68) in $\mathrm{CDCl}_{3}(600 \mathrm{MHz})$.

164 


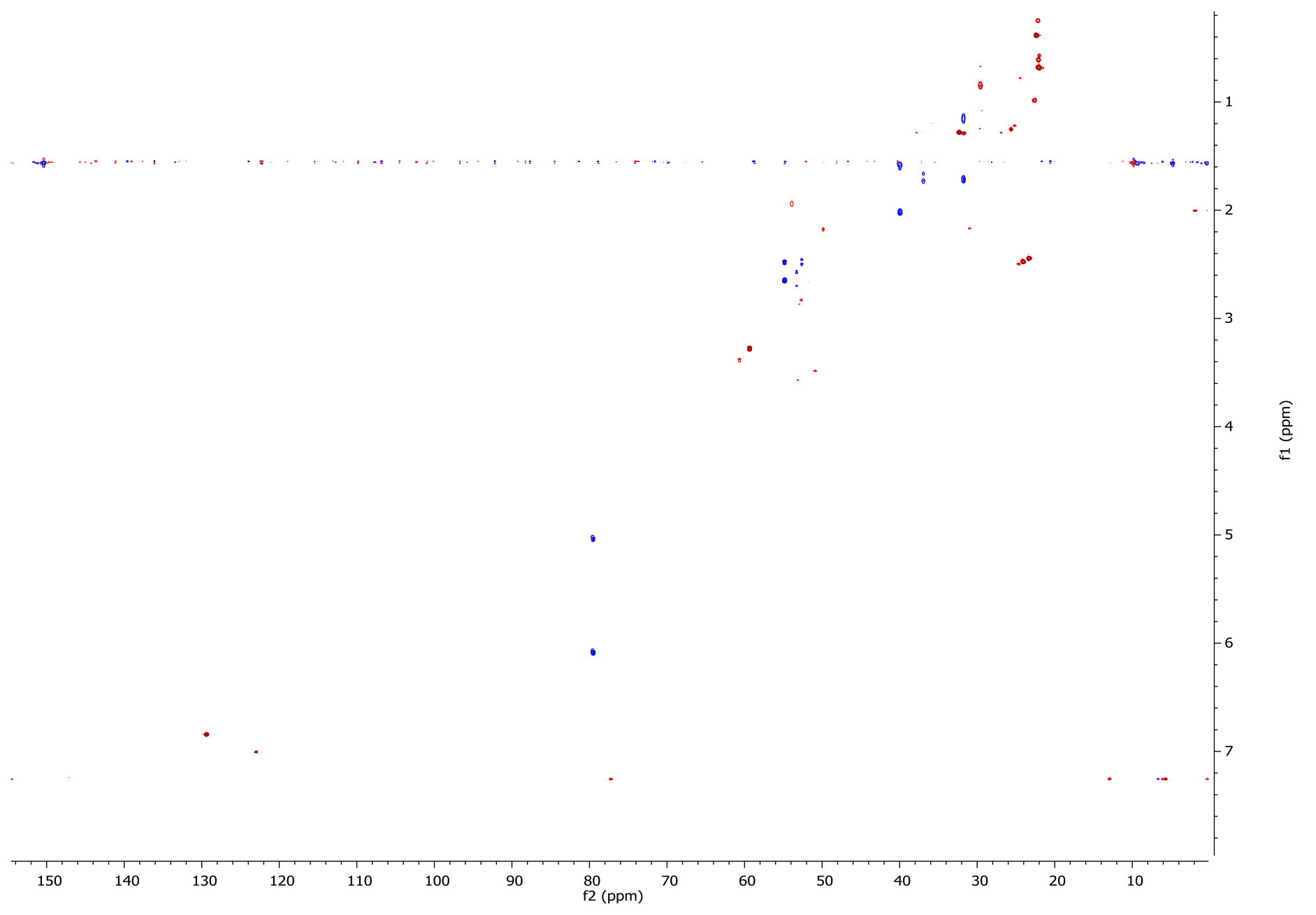

HSQC NMR spectrum of Glycine hamigeran (68) in $\mathrm{CDCl}_{3}(600 \mathrm{MHz})$. 


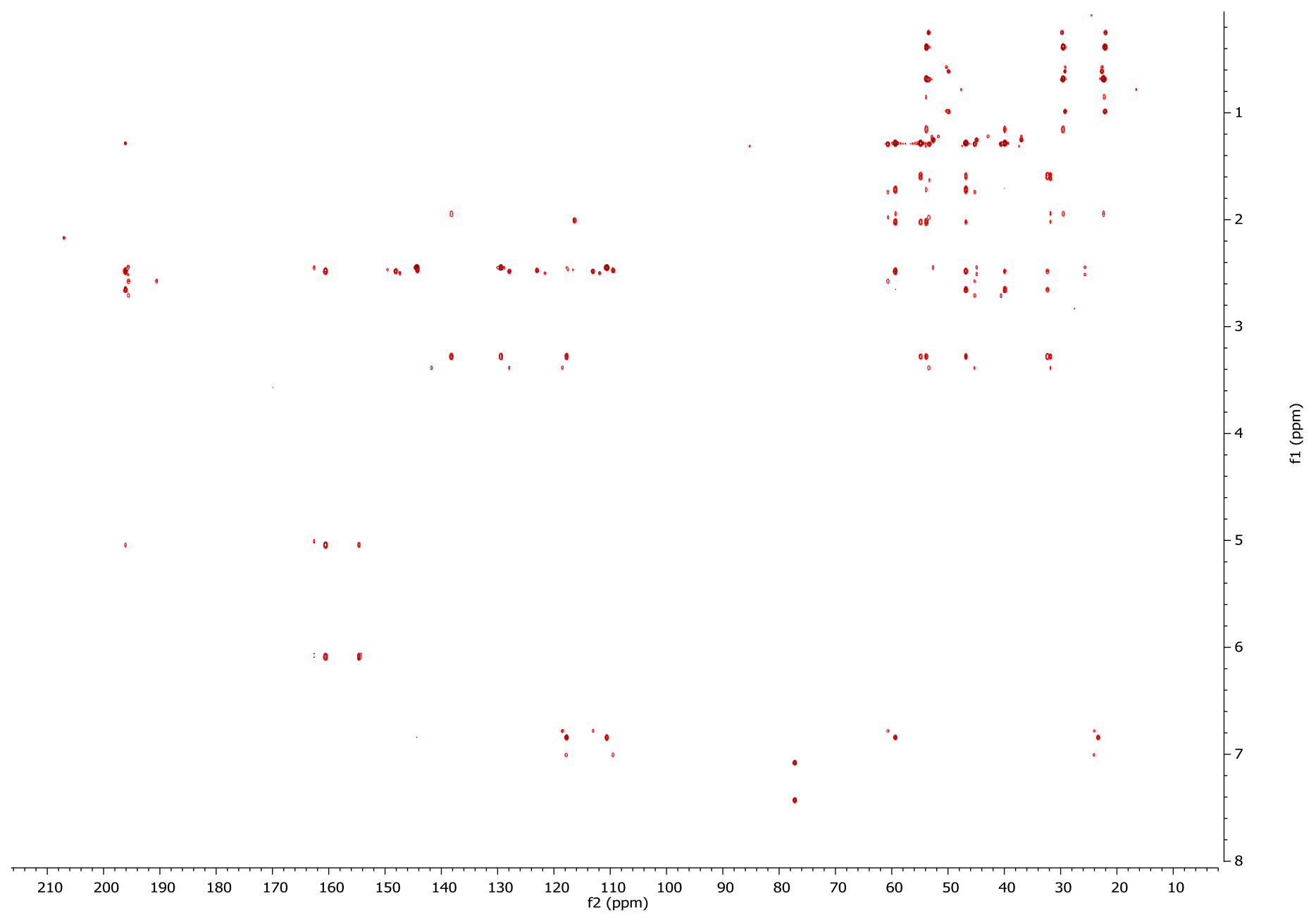

HMBC NMR spectrum of Glycine hamigeran (68) in $\mathrm{CDCl}_{3}(600 \mathrm{MHz})$. 


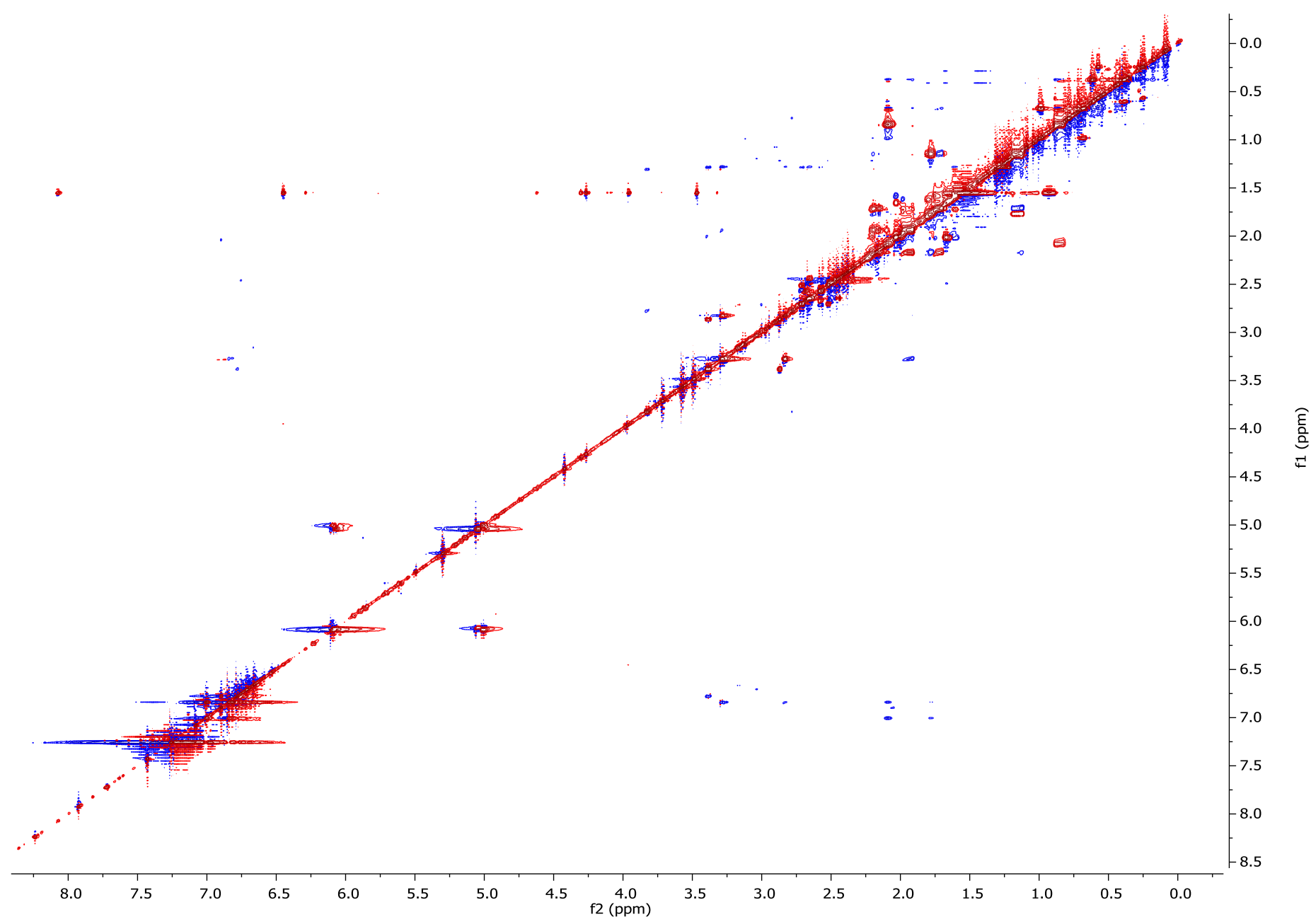

2D NOESY NMR spectrum of Glycine hamigeran (68) in $\mathrm{CDCl}_{3}(600 \mathrm{MHz})$. 
L Imine from hamigeran B reaction NMR Spectra

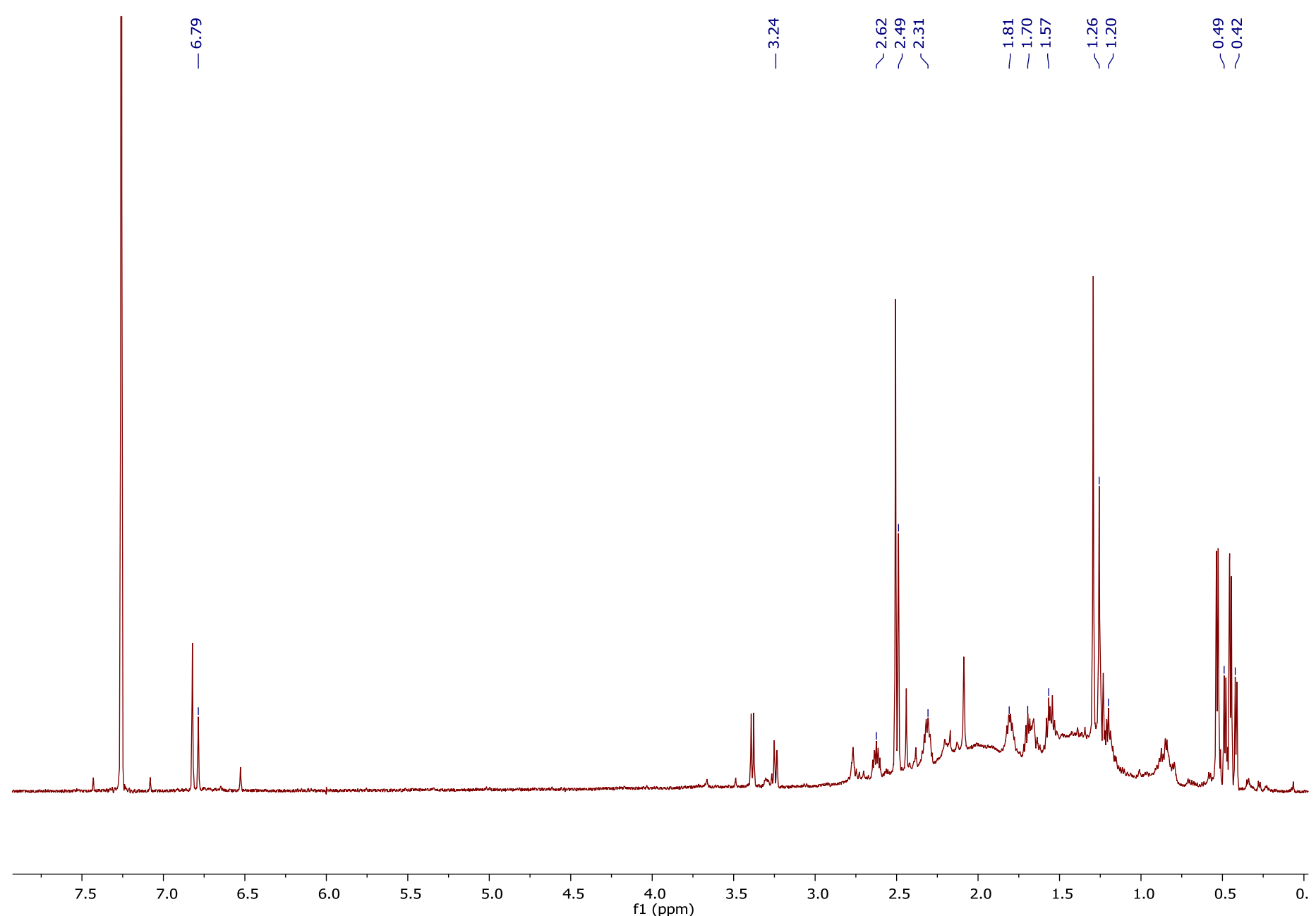

${ }^{1} \mathrm{H}$ NMR spectrum of imine (70) from hamigeran $\mathrm{B}$ reaction in $\mathrm{CDCl}_{3}(600 \mathrm{MHz})$. 
M Hamigeran N and Epimer NMR Spectra

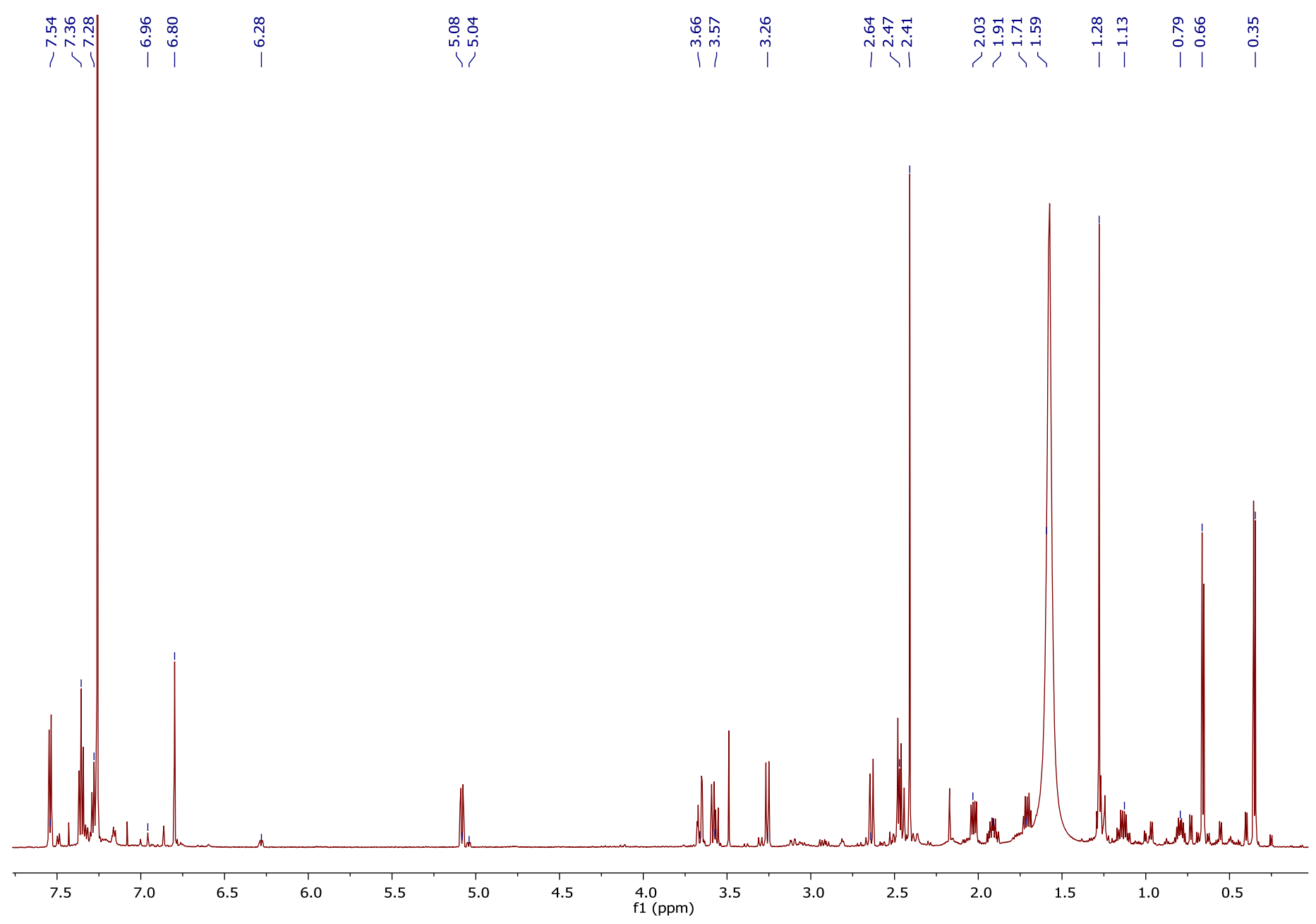

${ }^{1} \mathrm{H}$ NMR spectrum of hamigeran $\mathrm{N}(\mathbf{5 2})$ and epimer (53) in $\mathrm{CDCl}_{3}(600 \mathrm{MHz})$. 


\section{References}

(1) Rogers, K. The Components of Life, From Nucleic Acids to Carbohydrates; Britannica Educational Publishing, 2011; Vol. 1st Volume.

(2) Demain, A.; Fang, A. In History of Modern Biotechnology I; Fiechter, A., Ed.; Springer Berlin Heidelberg: 2000; Vol. 69, p 1.

(3) Williams, D. R.; Myers, B. J.; Mi, L. Org. Lett. 2000, 2, 945.

(4) Stephen, J. C. In Pest Management with Natural Products; American Chemical Society: 2013; Vol. 1141, p 5.

(5) Dobson, C. M. Nature 2004, 432, 824.

(6) Hanson, J. R. Natural Products: The Secondary Metabolites; Royal Society of Chemistry, 2003.

(7) Strobel, G.; Daisy, B. Microbiology and Molecular Biology Reviews 2003, 67, 491.

(8) Patrick, G. L. An Introduction to Medicinal Chemistry; 5th ed., 2013.

(9) Busse, G. Morphine, 2006.

(10) Gueritte-Voegelein, F.; Guenard, D.; Lavelle, F.; Le Goff, M. T.; Mangatal, L.; Potier, P. Journal of Medicinal Chemistry 1991, 34, 992.

(11) Cousteau, J. Y. Le Monde du Silence, translated as The Silent World LONDON, 1953.

Leal, M. C.; Puga, J.; Serôdio, J.; Gomes, N. C. M.; Calado, R. PLoS ONE 2012, 7, e30580.

(13) Database, M.; Department of Chemistry, U. o. C., Ed. Department of Chemistry, University of Canterbury, 2015.

(14) Hirata, Y.; Uemura, D. pure \& appl. Chem 1986, 58, 701.

(15) Miljanich, G. P. Current Medicinal Chemistry 2004, 11, 3029.

(16) Kijjoa, A.; Sawangwong, P. Marine Drugs 2004, 2, 73.

(17) Koehn, F. E.; Carter, G. T. Nat Rev Drug Discov 2005, 4, 206.

(18) Gray, S. D. S. Z. L. A. I. Natural Product Isolation; 2nd ed., 2006.

(19) Presiado, I.; Erez, Y.; Gepshtein, R.; Huppert, D. The Journal of Physical Chemistry C 2010, 114, 3634.

(20) Gert Wörheide(1*), D. E., 2), Christian Menke Porifera Research: Biodiversity, Innovation and Sustainability 2007.

(21) Dumas, j. B.; Peligot, E. Ann. Chim. Phys 1835, 58, 5.

(22) Blunt, J.; Lake, R.; Munro, M.; Yorke, S. Aust. J. Chem. 1981, 34, 2393. 
(23) Blunt, J. W.; Lake, R. J.; Munro, M. H. G. Phytochemistry 1984, 23, 1951.

(24) Perry, N. B.; Blunt, J. W.; Munro, M. H. G. Tetrahedron 1988, 44, 1727.

(25) Litaudon, M.; Hart, J. B.; Blunt, J. W.; Lake, R. J.; Munro, M. h. Tetrahedron lett. 1994, $35,9435$.

(26) Perry, N. B.; Ettouati, L.; Litaudon, M.; Blunt, J. W.; Munro, M. H. G.; Parkin, S.; Hope, H. Tetrahedron 1994, 50, 3987.

(27) Perry, N. B.; Blunt, J. W.; Munro, M. H. G.; Pannell, L. K. J. Am. Chem. Soc. 1988, 110, 4850.

(28) West, L. M.; Northcote, P. T.; Hood, K. A.; Miller, J. H.; Page, M. J. J. Nat. Prod. 2000, 63, 707.

(29) Perry, N. B.; Blunt, J. W.; Munro, M. H. G.; Thompson, A. M. J. Org. Chem. 1990, 55, 223.

(30) Simpson, J. S.; Garson, M. J.; Blunt, J. W.; Munro, M. H. G.; Hooper, J. N. A. J. Nat. Prod. 2000, 63, 704.

(31) Northcote, P. T.; Blunt, J. W.; Munro, M. H. G. Tetrahedron lett. 1991, 32, 6411.

(32) West, L. M.; Northcote, P. T.; Battershill, C. N. J. Org. Chem. 2000, 65, 445.

(33) Hood, K. A.; West, L. M.; Rouwé, B.; Northcote, P. T.; Berridge, M. V.; Wakefield, S. J.; Miller, J. H. Cancer Research 2002, 62, 3356.

(34) Hamel, E.; Day, B. W.; Miller, J. H.; Jung, M. K.; Northcote, P. T.; Ghosh, A. K.; Curran, D. P.; Cushman, M.; Nicolaou, K. C.; Paterson, I.; Sorensen, E. J. Molecular Pharmacology 2006, 70, 1555.

(35) Gaitanos, T. N.; Buey, R. M.; Díaz, J. F.; Northcote, P. T.; Teesdale-Spittle, P.; Andreu, J. M.; Miller, J. H. Cancer Research 2004, 64, 5063.

(36) Prota, A. E.; Bargsten, K.; Northcote, P. T.; Marsh, M.; Altmann, K.-H.; Miller, J. H.; Díaz, J. F.; Steinmetz, M. O. Angew. Chem., Int. Ed. 2014, 53, 1621.

(37) Hassan, W.; Edrada, R.; Ebel, R.; Wray, V.; Proksch, P. Marine Drugs 2004, 2, 88.

(38) Cheng, J.-F.; Lee, J.-S.; Sun, F.; Jares-Erijman, E. A.; Cross, S.; Rinehart, K. L. J. Nat. Prod. 2007, 70, 1195.

(39) Forestieri, R.; Merchant, C. E.; de Voogd, N. J.; Matainaho, T.; Kieffer, T. J.; Andersen, R. J. Org. Lett. 2009, 11, 5166.

(40) Cambie, R. C.; Lal, A. R.; Kernan, M. R.; Bergquist, P. R. J. Nat. Prod. 1995, 58, 940.

(41) Wellington, K. D.; Cambie, R. C.; Rutledge, P. S.; Bergquist, P. R. J. Nat. Prod. 2000, $63,79$.

(42) Nicolaou, K. C.; Gray, D. L. F.; Tae, J. J. Am. Chem. Soc. 2004, 126, 613.

(43) Trost, B. M.; Pissot-Soldermann, C.; Chen, I.; Schroeder, G. M. J. Am. Chem. Soc. 2004, 126, 4480. 
(44) Taber, D. F.; Tian, W. J. Org. Chem. 2008, 73, 7560.

(45) Lau, S. Y. W. Org. Lett. 2010, 13, 347.

(46) Mukherjee, H.; McDougal, N. T.; Virgil, S. C.; Stoltz, B. M. Org. Lett. 2011, 13, 825.

(47) Jiang, B.; Li, M.-m.; Xing, P.; Huang, Z.-g. Org. Lett. 2013, 15, 871.

(48) Singh, A. J.; Dattelbaum, J. D.; Field, J. J.; Smart, Z.; Woolly, E. F.; Barber, J. M.; Heathcott, R.; Miller, J. H.; Northcote, P. T. Org. Biomol. Chem 2013.

(49) Phuwapraisirisan, P.; Matsunaga, S.; van Soest, R. W. M.; Fusetani, N. J. Nat. Prod. 2002, 65, 942.

(50) Dattelbaum, J. D.; Singh, A. J.; Field, J. J.; Miller, J. H.; Northcote, P. T. J. Org. Chem. 2014, 80, 304.

(51) Natividad, R., University of Toronto, 1997.

(52) Kamerbeek, N. M.; Janssen, D. B.; van Berkel, W. J. H.; Fraaije, M. W. Advanced Synthesis \& Catalysis 2003, 345, 667.

(53) Hala M. Refat, A. A. F., Yingchun Lu, and Edward R. Biehl* The Japan Institute of Heterocyclic Chemistry 1996, 43, 977.

(54) Gottlieb, H. E.; Kotlyar, V.; Nudelman, A. J. Org. Chem. 1997, 62, 7512.

(55) West, L. M., Victoria University of Wellington, 2001. 